\title{
II. Der programmierte Konflikt? Gründung und Entwicklung der CSU 1945/1946
}

\section{Konfliktpotentiale und Gemeinsamkeiten}

\author{
a) „An der Wiege der CSU“1. Die Gründung der Union in Würzburg, \\ Bamberg, Nürnberg und Regensburg
}

Mit der Besetzung durch amerikanische Truppen ging im April 1945 auch in Bayern der Zweite Weltkrieg zu Ende. Die Militärmaschinerie des Dritten Reiches war unter den alliierten Offensiven ebenso zusammengebrochen wie die Strukturen der staatlichen Bürokratie oder die noch vor kurzem so mächtig erscheinende NSDAP, deren Würdenträger ihr Heil zumeist in der feigen Flucht gesucht hatten ${ }^{2}$. Die ersten Nachkriegswochen boten auch denjenigen nur wenig Raum für politische Betätigung, die das nationalsozialistische Regime bekämpft oder ihm zumindest ablehnend gegenübergestanden hatten. Das lag nicht nur daran, daß die Militärregierung alle politischen Aktivitäten zunächst verbot, sondern auch und vor allem an dem unüberschaubaren Chaos, das sechs Jahre Krieg und zwölf Jahre Diktatur hinterlassen hatten. Doch aller Apathie und allen Hindernissen zum Trotz fanden sich schon bald wieder informelle Gesprächszirkel und lokale Initiativen zusammen, die zum Teil in Anknüpfung an Traditionen der Weimarer Republik, aber auch in Erinnerung an vor 1933 gescheiterte Konzepte oder an Überlegungen, die während der NS-Zeit in Oppositionskreisen angestellt worden waren, über die politische Neuordnung diskutierten ${ }^{3}$.

Der Gedanke, katholische und evangelische Christen in einer Partei zusammenzuführen, stand dabei vielfach im Vordergrund. Er ging auf Vorstellungen aus der Zeit des Kaiserreiches und der ersten deutschen Demokratie zurück, war aber in dem stark milieugebundenen und hochgradig fragmentierten Parteiensystem der Weimarer Republik nicht zu realisieren gewesen. Versuche, das Zentrum und die neu gegründete BVP nach dem Ersten Weltkrieg aus dem Korsett konfessioneller Zwänge zu befreien und zu christlichen Volksparteien umzubauen, waren bereits in den Ansätzen gescheitert ${ }^{4}$.

1 Franz Josef Strauß, An der Wiege der CSU. Der Gewerkschaftsführer und Politiker Adam Stegerwald, in: Politische Studien Sonderheft 3/1981, S. 41-45.

2 Vgl. dazu die ausgezeichnete Darstellung von Klaus-Dietmar Henke, Die amerikanische Besetzung Deutschlands, München 1995, S. 802-844; zu Kriegsende und Neubeginn in Bayern vgl. auch Thomas Schlemmer, Die Amerikaner in Bayern. Militärregierung und Demokratisierung nach 1945, in: Heinrich Oberreuter, Jürgen Weber (Hrsg.), Freundliche Feinde? Die Alliierten und die Demokratiegründung in Deutschland, München 1996, S. 67-99.

${ }^{3}$ Vgl. Benz, Parteigründungen und erste Wahlen, in: ders. (Hrsg.), Neuanfang in Bayern, S. 9-35.

${ }^{4}$ Vgl. Winfried Becker, Historische Grundlagen der christlich-demokratischen Parteibildung nach 1945, in: Günter Buchstab, Klaus Gotto (Hrsg.), Die Gründung der Union. Traditionen, Entstehung und Repräsentanten, München, Wien 1981, S. 7-33, und Winfried Becker, Die CDU im demokratischen Neubeginn 1945/1946 - Motive der Gründung und parteipolitischer Standort, in: Günther Rüther (Hrsg.), Geschichte der Christlich-Demokratischen und Christlich-Sozialen Bewegungen in 
Die NS-Herrschaft und die Folgen des totalen Kriegs hatten die deutsche Gesellschaft aber bis in ihre Fundamente erschüttert; Grenzen konfessioneller oder sozialer Art, die sich vor 1933 als unüberwindlich erwiesen hatten, begannen durchlässig zu werden, ohne aber gänzlich zu verschwinden und ihre Prägekraft zu verlieren ${ }^{5}$. Außerdem hatte die gemeinsame Erfahrung von Verfolgung und Widerstand auch Frauen und Männer zusammengeführt, die in der Vergangenheit in unterschiedlichen politischen Lagern gestanden hatten; diese Erfahrung wirkte auf die Gründung der Unionsparteien geradezu katalytisch. Nicht zu Unrecht hat der Kölner CDU-Politiker Leo Schwering von einem „Katakombengeist“ gesprochen, der sich zu „Kreisen des Widerstands geformt ", alles überspannt und alle zusammengeklammert habe ${ }^{6}$.

So fanden sich nach dem Ende des Dritten Reiches konservative, nationale, liberale und soziale Kräfte in der Union zusammen, die von dem gemeinsamen Willen getragen waren, eine Volkspartei auf breiter Basis aufzubauen und die christlichen Grundwerte zum Leitfaden ihrer Politik zu machen' ${ }^{7}$. Bei aller Übereinstimmung im Grundsätzlichen waren diese Integrationsprozesse jedoch alles andere als unkompliziert. Sie waren von teilweise heftigen Konflikten um den Parteiaufbau und die konkreten programmatischen Zielsetzungen begleitet, die durch persönliche Animositäten, regionale Disparitäten oder konfessionelle Querelen zusätzlich verstärkt wurden ${ }^{8}$. Hans-Otto Kleinmann hat zu Recht darauf hingewiesen, daß die Frage, von wo nun die Initialzündung für die Gründung der Union ausgegangen sei, zu keiner befriedigenden Antwort führe. Entscheidender sei vielmehr die Tatsache,

"daß die christlich-demokratische Idee sich noch im Chaos des Zusammenbruchs, von einigen Kristallisationskernen ausstrahlend, durch freundschaftliche und verwandtschaftliche Beziehungen, Bekanntschaften aus dem kirchlichen Raum sowie wiederbelebte Verbindungen aus einstiger Partei-, Gewerkschafts- oder Verbandsmitgliedschaft weitergetragen, wie eine Kettenreaktion ausbreitete“".

Auch in Bayern fiel die Unionsidee auf fruchtbaren Boden. Städte wie Würzburg, Bamberg, Nürnberg, Regensburg oder München entwickelten sich in den Sommermonaten des Jahres 1945 zu Zentren programmatischer Diskussion und organisatorischer Aktivitä $t^{10}$. In dieser frühen Phase gingen vor allem von Würzburg wichtige Impulse aus. Als spiritus rector wirkte dort Adam Stegerwald, der frühere Reichsminister und preußische Ministerpräsident, den die amerikanischen Militärbehörden zum Regierungspräsidenten von Unterfranken ernannt hatten ${ }^{11}$. Der führende Repräsentant der

Deutschland. Grundlagen, Unterrichtsmodelle, Quellen und Arbeitshilfen für die politische Bildung, Bonn ${ }^{2} 1987$, S. 333-360.

5 Mit dem Blick auf Bayern vgl. Mintzel, Regionale politische Traditionen, in: Oberndörfer/Schmitt (Hrsg.), Parteien und regionale Traditionen, S. 141.

${ }^{6}$ Leo Schwering, Vorgeschichte und Entstehung der CDU, Köln ${ }^{2} 1952$, S. 25.

7 Vgl. Brigitte Kaff, Eine Volkspartei entsteht. Zirkel und Zentren der Unionsgründung, in: Buchstab/ Gotto (Hrsg.), Gründung der Union, S. 70-101, hier S. 99.

${ }^{8}$ Bei Hans-Otto Kleinmann, Geschichte der CDU 1945-1982, Stuttgart 1993, S. 23-49, werden diese Konflikte allenfalls am Rande thematisiert; Kleinmanns Darstellung neigt generell zur Harmonisierung.

9 Ebenda, S. 22.

10 Vgl. Winfried Becker, Gründung und Wurzeln der Christlich-Sozialen Union, in: Geschichte einer Volkspartei, S. 69-107.

11 Zur Biographie vgl. Helmut J. Schorr, Adam Stegerwald. Gewerkschaftler und Politiker der ersten deutschen Republik. Ein Beitrag zur Geschichte der christlich-sozialen Bewegung in Deutschland, Recklinghausen 1966, insbesondere S. 286-298, sowie Helmut J. Schorr, Adam Stegerwald. Skizze 
interkonfessionellen Christlichen Gewerkschaften zählte seit langem zu den Wortführern einer Neuordnung des deutschen Parteiensystems und hatte im November 1920 mit einer großen Rede vor dem zehnten Kongreß der Christlichen Gewerkschaften Deutschlands Aufsehen erregt ${ }^{12}$. Stegerwald hatte schon damals das Konzept einer christlichen Volkspartei entworfen, die - eine fortschrittliche Sozialpolitik praktizierend - als „politische Zusammenfassung der positiven christlichen Kräfte" zu einer "möglichst geschlossenen politischen Einheitsfront“ führen sollte. Er charakterisierte sein Programm, das teilweise durchaus konservative und autoritäre Züge trug, mit den Worten: „Deutsch, christlich, demokratisch, sozial“"13. Zwar erwiesen sich diese Pläne unter den bestehenden Verhältnissen als nicht praktikabel, der Gewerkschafter hatte durch seine richtungweisende Rede aber einen Orientierungspunkt für diejenigen gesetzt, die nach 1945 den politischen Neubeginn wagten, und auch er selbst knüpfte direkt an diese Vorstellungen an.

Obwohl der Regierungspräsident eigentlich parteipolitische Zurückhaltung zu üben hatte, nahm Stegerwald die Gründung der Union im Raum Würzburg in die Hand ${ }^{14}$. Wie er sich ein zukünftiges Parteiensystem vorstellte, erläuterte er mehreren Offizieren der amerikanischen Militärregierung im Juni 1945. Stegerwald ging davon aus, daß sich in einer neuen Demokratie die Parteienzersplitterung nicht wiederholen würde, die die Weimarer Republik schwer belastet hatte ${ }^{15}$. Er rechnete wegen der gegebenen Not- und Umbruchsituation mit einer Neigung vieler Menschen zum politischen Radikalismus, die zu einer starken kommunistischen Partei und - wenn die Besatzungsmächte dies überhaupt gestatteten - zu einer „schwachen Rechtspartei“ führen würde. Als „Auffangpartei gegen links“ sollte eine starke sozialdemokratische Partei

eines mutigen Lebens, in: Christliche Demokraten der ersten Stunde, hrsg. von der Konrad-Adenauer-Stiftung, Bonn 1966, S. 363-382, hier S. 377 f. Zu Ernennung und Tätigkeit Stegerwalds als Regierungspräsident von Unterfranken vgl. auch Herbert Schott, Die Amerikaner als Besatzungsmacht in Würzburg 1945-1949, Würzburg 1985, S. $27 \mathrm{ff}$.

${ }^{12}$ Vgl. dazu Larry Eugene Jones, Adam Stegerwald und die Krise des deutschen Parteiensystems, in: VfZ 27 (1979), S. 1-29.

13 Rede Adam Stegerwalds vor dem zehnten Kongreß der Christlichen Gewerkschaften Deutschlands am 21. 11. 1920 in Essen (Auszug), abgedruckt in: Rüther (Hrsg.), Geschichte der Christlich-Demokratischen und Christlich-Sozialen Bewegungen in Deutschland, S. $669 \mathrm{f}$.; die vorstehenden Zitate ebenda.

14 Vgl. dazu ausführlich Peter Herde, Unionsparteien zwischen Tradition und Neubeginn: Adam Stegerwald, in: Winfried Becker (Hrsg.), Die Kapitulation von 1945 und der Neubeginn in Deutschland, Köln, Wien 1987, S. 245-295. Stegerwald hatte die Gründung der Würzburger CSU mit zwei großen programmatischen Reden am 21. und 25. 8. 1945 eingeleitet, die eigentliche Gründungsversammlung der Partei fand jedoch erst am 13. 10. 1945 statt. Im September und noch einmal im November 1945 hatte der Regierungspräsident zwei Konferenzen auf regionaler und überregionaler Ebene einberufen, um eine bessere Kooperation der verschiedenen Gründungszirkel zu gewährleisten und um seinen eigenen Führungsanspruch anzumelden. Interventionen der Militärregierung verhinderten jedoch, daß die Tagungen in der geplanten Form stattfinden konnten. Vgl. ebenda, S. $271 \mathrm{f}$. und S. 277 f., sowie Winfried Becker, CDU und CSU 1945-1950. Vorläufer, Gründung und regionale Entwicklung bis zum Entstehen der CDU-Bundespartei, Mainz 1987, S. 78. Interessant sind in diesem Zusammenhang Adam Stegerwalds "Staatspolitische Leitgedanken" vom 15. 9. 1945; ACSP, NL Müller 1.

15 BAK, NL Schäffer 19, Bl. 127-129, Adam Stegerwald an Fritz Schäffer vom 23. 6. 1945; die folgenden Zitate ebenda. Ähnlich auch IfZ-Archiv, Smlg. Henke, Aufzeichnung über ein Gespräch von Angehörigen des OSS mit Adam Stegerwald vom 20. 7. 1945. Mit dieser Einschätzung, die beispielsweise auch Schäffer teilte, stand Stegerwald nicht allein; vgl. Christoph Henzler, Fritz Schäffer 1945-1967. Eine biographische Studie zum ersten bayerischen Nachkriegs-Ministerpräsidenten und ersten Finanzminister der Bundesrepublik Deutschland, München 1994, S. 166. 
dienen, der im gemäßigten Teil des politischen Spektrums eine ebenbürtige „Mittelpartei" gegenüberstehen sollte; Stegerwald räumte dieser "Mittelpartei“ allerdings nur dann Chancen ein, wenn Zentrum und BVP ihren konfessionellen Charakter ablegten, um so "wertvolle Kräfte von rechts anziehen" zu können. Hand in Hand damit ging eine scharfe Distanzierung vom politischen Katholizismus der Zwischenkriegszeit, die in dem Verdikt endete: „Demokratischer Staat und konfessionelle Minderheitspartei sind letzten Endes einander ausschließende Begriffe. ${ }^{\text {"16 }}$

Stegerwald brachte jedoch nicht nur die Konzeption einer interkonfessionellen Sammlungspartei in den Gründungsprozeß der CSU ein. Er stellte durch Kontakte nach Berlin, Frankfurt und Köln zumindest eine lose Verbindung zwischen den verschiedenen Gründungszirkeln der Unionsparteien her. Dabei versuchte Stegerwald, „seine Bemühungen in Würzburg in den gesamtdeutschen Rahmen des Neubeginns einer christlichen Partei zu integrieren " ${ }^{\text {17 }}$. Stegerwald war jedoch von Anfang an ein Außenseiter unter den führenden Mitbegründern der CSU. Die Distanz des ehemaligen Reichsministers zu bayerischen Problemen, seine nationale und unitarische Orientierung lassen vermuten, daß der im Dezember 1945 überraschend verstorbene Stegerwald im Zuge der wachsenden Spannungen innerhalb der neu gegründeten CSU noch schneller aus den Führungsgremien der bayerischen Unionspartei verdrängt worden wäre als der erste Parteivorsitzende Josef Müller.

In Verbindung mit Adam Stegerwald stand auch Gerhard Kroll ${ }^{18}$, einer der Gründerväter der CSU in Bamberg und Oberfranken. Der aus Breslau stammende Nationalökonom hatte zwischen 1929 und 1938 auch Philosophie und Religionsphilosophie studiert, auf eine Habilitation aber aus politischen Gründen verzichtet ${ }^{19}$. Nach 1933 war Kroll wegen weltanschaulicher Differenzen wiederholt mit dem nationalsozialistischen Regime in Konflikt geraten und beruflich benachteiligt worden. In der Weimarer Republik Mitglied der SPD, entwickelte sich der Katholik nach der totalitären Erfahrung des Dritten Reiches zu einem der wichtigsten Programmatiker der Union in Bayern. Im August 1945 trat Kroll mit einer „Denkschrift zur Schaffung einer politischen Einheitsfront aller Christen Deutschlands" an die Öffentlichkeit, deren eigentlicher Adressat die Konferenz der katholischen Bischöfe Deutschlands war ${ }^{20}$. Wie manche Vertreter der christlich-demokratischen Idee in den Westzonen, mit denen er Kontakt aufgenommen hatte, machte er den Abfall des deutschen Volkes vom christlichen Glauben für die gegenwärtige Katastrophe verantwortlich. Daraus zog Kroll die Konsequenz, daß eine Erneuerung von Staat und Gesellschaft allein auf der Grundlage ei-

\footnotetext{
${ }^{16}$ Adam Stegerwald, Wohin gehen wir?, Würzburg 1946, S. 49. Die Ausführungen in dieser 70-seitigen Broschüre bauen auf Stegerwalds Rede anläßlich der Gründungsversammlung der Würzburger CSU am 13. 10. 1945 auf.

17 Herde, Unionsparteien, in: Becker (Hrsg.), Kapitulation, S. 270. Stegerwald hatte bereits im August und September Kontakte zu den wichtigsten Gründungszirkeln der Union außerhalb Bayerns hergestellt und reiste am 20. und 21. 10. 1945 selbst nach Köln, um Vorträge vor ehemaligen Zentrumspolitikern und christlichen Gewerkschaftern zu halten. Vgl. auch Schorr, Adam Stegerwald, S. 287-290.

${ }_{18}$ IfZ-Archiv, Fh 56, Gerhard Kroll an Josef Müller vom 5. 11. 1945.

${ }^{19}$ StA Bamberg, K3/1981-55, OMGUS-Fragebogen Gerhard Krolls vom 17. 2. 1946, und IfZ-Archiv, Fh 56, Lebenslauf Gerhard Krolls vom 26. 1. 1959.

${ }^{20}$ IfZ-Archiv, ED 720 Smlg. Mintzel 1, „Christliche Union. Bamberger Denkschrift zur Schaffung einer politischen Einheitsfront aller Christen Deutschlands"; vgl. dazu auch Arcadius R. Gurland, Die CDU/CSU. Ursprünge und Entwicklung bis 1953, Frankfurt am Main 1980, S. $58 \mathrm{f}$.
} 
nes aktiven Christentums möglich sei und daß dies nur dann gelingen könne, wenn sich die Gräben zwischen den Konfessionen zumindest auf dem Feld der Politik überwinden ließen ${ }^{21}$. Im Bereich der Wirtschaftspolitik forderte er einen radikalen Bruch mit liberalen Prinzipien und entwarf dagegen das Bild einer Wirtschaftsordnung, die auf ständischer Selbstverwaltung unter staatlicher Kontrolle basieren sollte. Orientiert am Primat der Stabilität zeichnete Kroll diesen Staat - und damit wußte er sich mit vielen Zeitgenossen einig, die das Scheitern der Weimarer Republik erlebt hatten - zwar als demokratischen Staat, der jedoch durchaus autoritäre Züge trug. Krolls Vorstellungen waren sichtlich stärker von christlich-religiösen Idealen geprägt als die Adam Stegerwalds, der zuweilen geradezu antiklerikale Töne anschlug ${ }^{22}$. Stegerwald und Kroll trafen sich jedoch in der gesamtdeutschen Ausrichtung ihrer Programme, in denen föderalistische Gedanken nur eine untergeordnete Rolle spielten.

In Bamberg diskutierten im Sommer 1945 mehrere Gruppen über die Gründung politischer Parteien ${ }^{23}$. Neben den Verfechtern der Unionsidee, zu denen außer Kroll beispielsweise auch der aus der katholischen Jugendbewegung kommende spätere Bundestagsabgeordnete Emil Kemmer zählte, bildeten prominente Repräsentanten der ehemaligen BVP wie der Domkapitular Georg Meixner oder der Jurist Lorenz Krapp die einflußreichste Gruppierung im konservativen Lager. Unter dem Eindruck der Schrecken von Krieg und Diktatur und aus Furcht vor einem Erstarken von SPD und KPD fanden sich diese heterogenen Kreise, zu denen noch einige Vertreter monarchistischen respektive liberalen Gedankenguts stießen, zur CSU zusammen ${ }^{24}$, die am 16. November 1945 ihre Gründungsversammlung abhielt.

Würzburg und Bamberg hatten vor $1933 \mathrm{zu}$ den Hochburgen des politischen Katholizismus in Bayern gezählt. In Nürnberg, wo sich circa zwei Drittel der Bevölkerung zum evangelischen Glauben bekannten, hatten prononciert katholische Parteien dagegen stets einen schweren Stand, vor allem dann, wenn sie wie die BVP bayerisch-patriotische Züge trugen ${ }^{25}$. Darüber hinaus war Nürnberg einer der wenigen industriellen Kerne Bayerns mit einer zahlenmäßig starken Arbeiterschaft, die überwiegend zur Sozialdemokratie - in geringerem Maße auch zur KPD - tendierte. Die Initiatoren einer interkonfessionellen Volkspartei standen angesichts dieser Gegebenheiten vor einem doppelten strategischen Problem: Sollte der Durchbruch zur Mehrheitsfähigkeit gelingen, mußten die tief verwurzelten Gegensätze zwischen den Konfessionen überbrückt und zugleich zumindest Teile der sozialdemokratisch orientierten Arbeiterschaft gewonnen werden. Das war nicht gerade einfach, da zwar auf katholischer Seite traditio-

21 Als überzeugter Anhänger des interkonfessionellen Gedankens gehörte Kroll seit 1938 der UnaSancta-Bewegung an; StA Bamberg, K3/1981-55, OMGUS-Fragebogen Gerhard Krolls vom 17. 2. 1946.

22 Vgl. Stegerwald, Wohin gehen wir, S. 55-59.

23 Stadtarchiv Bamberg, Bamberg-Sammlung 2838, Bericht über die Gründung der CSU in Bamberg, ungezeichnet, undatiert; vgl. auch Josef Ludwig Lypp, Die Entstehungsgeschichte der Christlich-Sozialen Union in Bamberg, unveröffentlichte Diplomarbeit, Bamberg 1983, und Georg Güttler, Die Entwicklung des CSU-Kreisverbands Bamberg-Stadt (1945-1975), unveröffentlichte Zulassungsarbeit, Bamberg 1976.

${ }^{24}$ IfZ-Archiv, Fh 56, undatierter Aufruf der CSU für Bamberg-Stadt und -Land.

25 Zur politischen Entwicklung in Nürnberg vor 1933 und nach 1945 vgl. Wolfgang Eckart, Amerikanische Reformpolitik und deutsche Tradition. Nürnberg 1945-1949. Nachkriegspolitik im Spannungsfeld zwischen Neuordnungsvorstellungen, Notlage und pragmatischer Krisenbewältigung, Nürnberg 1988, S. 30-60 und S. 324-384. 
nelle Verbindungen zur Arbeiterschaft bestanden, die protestantische Stadtbevölkerung aber ausgesprochen bürgerlich-konservativ geprägt $\mathrm{war}^{26}$. Eine Vermittlung in diesem Zielkonflikt war überaus schwierig, und die CSU in Nürnberg drohte lange Jahre davon zerrieben zu werden.

Vielleicht wäre die Partei überhaupt nie so recht auf die Beine gekommen, hätten nicht die Kirchen eine führende Rolle im Gründungsprozeß der Nürnberger CSU übernommen ${ }^{27}$. Unterstützt von Geistlichen fanden erste Besprechungen zur Gründung einer neuen Partei in katholischen Männervereinen statt, die sich mit Duldung der Militärregierung bereits wenige Wochen nach Kriegsende gebildet hatten. Auf protestantischer Seite gab es zunächst keine organisierten Gruppierungen. Die Initiative lag damit ebenso wie in der Folgezeit die organisatorische Hauptlast der Parteigründung bei den Katholiken. Der Idee einer konservativen Sammlungspartei auf interkonfessioneller Grundlage begegnete man allerdings auch bei den Protestanten nicht ohne Sympathie. Das Erbe von Krieg und Diktatur ließ eine Verständigung zwischen katholischen und evangelischen Christen denkbar und notwendig erscheinen. Die im bürgerlichen Lager weit verbreitete Furcht vor einem Linksrutsch der notleidenden Bevölkerung ${ }^{28}$ trug ebenfalls dazu bei, daß man sich entschloß, den zunächst diskutierten Plan, mit dem Christlichen Volksdienst eine dezidiert protestantische Partei zu gründen, fallenzulassen.

Vorbehalte gegen den interkonfessionellen Gedanken waren damit jedoch ebensowenig ausgeräumt wie die Befürchtung, die CSU sei nichts anderes als die Fortsetzung der Bayerischen Volkspartei mit anderen Mitteln. Derartige Ängste wurden auch durch die Tatsache geschürt, daß die prominentesten Mitbegründer der CSU vor 1933 der BVP angehört hatten ${ }^{29}$. Auf protestantischer Seite tat man sich dagegen schwer, profilierte Persönlichkeiten oder gar erfahrene Politiker zu finden, die bereit waren, sich aktiv am Aufbau der Union zu beteiligen. Als Träger nationalkonservativer Traditionen waren sie entweder politisch belastet oder so verunsichert, daß sie die weitere Entwicklung erst einmal abwarten wollten ${ }^{30}$. Damit stand die CSU in Nürnberg wie in allen Teilen Bayerns, die primär protestantisch geprägt waren, vor einem existenzgefährdenden Dilemma: Wie konnte die evangelische Bevölkerung für eine Partei gewonnen werden, deren öffentliche Bekenntnisse zur Interkonfessionalität schon wegen des hohen Anteils an Katholiken in Führungspositionen zweifelhaft erscheinen mußten, auch wenn der Rückgriff auf den organisatorischen und politi-

${ }^{26}$ Zur Gründung der CSU in Nürnberg vgl. ebenda, S. 355-372, und die nützliche, aber wissenschaftlich ungenügende Darstellung von Heinz-Werner Stuiber, Die CSU in Nürnberg-Fürth. Zur Geschichte des Bezirksverbandes 1945-1983, Nürnberg 1983, S. 41-48.

27 Zur Rolle der Kirchen bei der Gründung der CSU in Franken vgl. Franz Kühnel, Die CSU und der fränkische Protestantismus 1945-1953, unveröffentlichte Magisterarbeit, Erlangen 1983, S. 16-24; Hans Woller, Gesellschaft und Politik in der amerikanischen Besatzungszone. Die Region Ansbach und Fürth, München 1986, S. 187-194; Jutta Beyer, Demokratie als Lernprozeß. Politische Kultur und lokale Politik nach 1945 am Beispiel der Städte Forchheim und Schwabach, Nürnberg 1989, S. 226-240.

28 IfZ-Archiv, Smlg. Henke, Field Intelligence Study 29: „The political Parties of Nürnberg“.

29 Zu nennen wären an erster Stelle der im oberbayerischen Moorenweis geborene Emanuel Deggendorfer, vor 1933 für die BVP im Nürnberger Stadtrat, der spätere Landtagsabgeordnete Josef Donsberger und Adolf Konrad, der vor 1933 als Vorsitzender der Christlichen Gewerkschaften in Nürnberg fungiert und die BVP seit 1919 im Landtag vertreten hatte.

30 Vgl. dazu Clemens Vollnhals, Die Hypothek des Nationalprotestantismus. Entnazifizierung und Strafverfolgung von NS-Verbrechen nach 1945, in: GuG 18 (1992), S. 51-69. 
schen Sachverstand ehemaliger BVP-Mitglieder zumindest in der Gründungsphase mehr auf strukturelle $Z$ wänge als auf planvolles Handeln zurückzuführen war? Auf der Gründungsversammlung der Nürnberger CSU am 13. Oktober 1945 war man sich noch darüber einig, daß die Protestanten mehr Ämter und Mandate erhalten sollten, als es ihrer Mitgliederzahl entsprach, um die Union glaubwürdig und für evangelische Christen attraktiv zu machen ${ }^{31}$. In der Folgezeit standen Fragen der konfessionellen Parität und des konfessionellen Proporzes im Mittelpunkt der parteiinternen Diskussion. Diesbezügliche Konflikte, die oft genug in erbitterte persönliche Auseinandersetzungen mündeten, überlagerten alle anderen Probleme und trugen viel dazu bei, daß die Nürnberger CSU kaum ein eigenes politisches und programmatisches Profil entwickeln konnte 32 .

In Niederbayern und in der Oberpfalz wurde Regensburg zum wichtigsten Ausgangspunkt für die Gründung der Union. Der dortige Gründungszirkel fungierte nicht nur als Kommunikationszentrum, sondern unterstützte die lokalen Initiativen in den umliegenden Landkreisen auch organisatorisch und programmatisch ${ }^{33}$. Die amerikanische Militärregierung hatte die Union in Regensburg unter dem Namen Partei der Christlich-Sozialen Einigung in Bayern zwar erst am 15. November 1945 lizenziert, die Vorgeschichte der neu gegründeten Partei reichte jedoch weiter zurück als es das Datum der Lizenzierung vermuten läßt. Schon während des Krieges kam eine Gruppe von NS-Gegnern - ehemalige BVP-Politiker und Liberale, christliche Gewerkschafter und Vertreter katholischer Organisationen - zu Gesprächen über die politische Neuordnung nach der zu erwartenden Niederlage Deutschlands zusammen. Im Herbst 1944 wurden Leitsätze für eine christliche Partei erarbeitet, die dann im Januar 1945 in das Programm für einen Christlich-Demokratischen Volksbund bzw. für einen Christlichen Volksbund Bayerns eingingen. Die Verfasser dieses Programms verurteilten die nationalsozialistische Diktatur und forderten eine christlich-demokratische Erneuerungsbewegung in der Tradition der tausendjährigen Kultur des christlichen Abendlandes, „um den drohenden Zusammenbruch und Untergang unseres Volkes und unserer Kultur abzuwenden und Frieden, Arbeit und Brot zu sichern “34. Die Zehn Gebote als Fundament und Ausdruck des christlichen Sittengesetzes sollten die Grundlage des politischen und gesellschaftlichen Lebens bilden.

Als die Mitbegründer der Christlich-Sozialen Einigung im Sommer 1945 ein erstes Parteiprogramm entwarfen, griffen sie diese Vorarbeiten auf, wie die kurze Präambel des Grundsatz- und Aktionsprogramms zeigt, das den Unterlagen für die Militärregie-

31 Vgl. Eckart, Amerikanische Reformpolitik, S. 366.

32 ACSP, NL Müller 107, enhält eine Vielzahl von Dokumenten zu diesem Problemkomplex. Zur programmatischen Entwicklung der CSU in Nürnberg vgl. Eckart, Amerikanische Reformpolitik, S. 367-370, auf der Basis der bisher kaum ausgewerteten Artikel in der Fränkischen Volksstimme, die in den ersten Monaten des Jahres 1946 als Mitteilungsblatt der CSU in Franken eine wichtige Funktion erfüllte. Ein Programm der Nürnberger CSU in deutscher und englischer Sprache findet sich im IfZ-Archiv, Fh 56.

${ }^{33}$ Zur Gründung der CSU in Regensburg vgl. Michaela Riebel, CSU im Werden. Gründung und Entwicklung der Christlich-Sozialen Union in Regensburg von 1945 bis zu den Wahlen zum Ersten Deutschen Bundestag, Regensburg 1985, S. 30-49, und Thomas Schlemmer, Auf dem Weg zur Demokratie. Parteigründungen und erste Wahlen in Regensburg 1945/46, in: Regensburger Almanach 29 (1996), S. 59-72.

34 Zit. nach Josef Kirchmann, Die Bedeutung christlicher Werte in Programm und Praxis der CSU, Diss., St. Ottilien 1985, S. 27. 
rung beigefügt war ${ }^{35}$. Erstaunlicherweise enthielt dieses Programm kein Bekenntnis zum eigentlichen Kernpunkt des Unionsgedankens, dem Prinzip der Interkonfessionalität. Dabei stand es von Anfang an außer Zweifel, daß die neue Partei nur auf der Basis der gleichberechtigten Zusammenarbeit von katholischen und evangelischen Christen aufgebaut werden konnte. Wie sehr die Erinnerung an das Scheitern der Weimarer Republik und die Schrecken der vergangenen Jahre die Mitbegründer der Union beeinflußten, zeigt eine Rede Karl Staudingers, der vor 1933 im Regensburger Stadtrat die Deutsche Demokratische Partei vertreten hatte und nun zu den führenden Repräsentanten der Christlich-Sozialen Einigung gehörte: Staudinger erklärte am Neujahrstag des Jahres 1946 vor einer dichtgedrängten Zuhörerschaft in Wenzenbach:

„Die ehemaligen Gruppen der Bayerischen Volkspartei, der demokratischen Fraktion, des Bauernbundes, der liberalen Wirtschaftsvereinigung, der christlich orientierten Landwirte, Handwerker, Mittelständler und Arbeiter der Stirn und der Faust hatten das Gefühl: Gott sei Dank, daß einmal das Trennende zurückgerückt und das Einigende in den Vordergrund gestellt wird. Hätten vor 12 Jahren die Mehrheitssozialisten, die kath[olischen] Parteien, die Demokraten und der Bauernbund den Mut und die Selbstüberwindung zu einer geschlossenen Abwehrfront gegen die NSDAP aufgebracht, es wäre uns ein Meer von Blut, ein Berg von Not, eine Flut von Tränen, eine Milliardenlast von [...] Innenschulden und Wiedergutmachungsforderungen [...] erspart geblieben! “36

Staudingers Rede machte auch klar, daß die Partei der Christlich-Sozialen Einigung nicht nur eine Partei gläubiger evangelischer und katholischer Christen sein sollte, sondern eine große Sammlungspartei, die allen Bevölkerungsschichten und politischen Strömungen Platz bot, sofern sie sich auf den Boden des Dekalogs und des christlichen Sittengesetzes stellten.

Anders als in Würzburg, Bamberg und Nürnberg hielt man in Regensburg zunächst am Namen Partei der Christlich-Sozialen Einigung fest. „Von dem Namen ,Union“ will man hier nichts wissen“, schrieb Josef Held, ein Sohn des ehemaligen bayerischen Ministerpräsidenten Heinrich Held, Anfang Dezember 1945 an Josef Müller. Dieser Begriff sei erstmals in Berlin gebraucht worden und überdies ,ein wirtschaftlicher Begriff“"37. Noch im Vorfeld der Lizenzierung der CSU auf Landesebene teilte Geschäftsführer Otto Schedl im Namen der Christlich-Sozialen Einigung dem vorläufigen Landesvorsitzenden Josef Müller mit:

„Unsere Regensburger Gründungsmitglieder tragen durch die Übersendung ihrer Unterschriften der Forderung zur Gründung einer Landespartei Rechnung. Sie bekennen sich jedoch mit der Unterschrift nicht automatisch zum Münchner Programm und Münchner Namen, sie halten vielmehr zur endgültigen Festlegung des Namens und zur Aufstellung eines endgültigen Programms und Satzungen eine Sitzung der Landespartei für nötig. “38

Diese Skepsis gegenüber dem Münchner Gründerkreis, von dessen Aktivitäten noch ausführlich die Rede sein wird, richtete sich vor allem gegen die Vorstellungen von Föderalismus und Reichspolitik, die Josef Müller und seine Anhänger vertraten. War man im Kreis um den Ochsensepp reichsfreundlich und gemäßigt föderalistisch einge-

${ }^{35}$ Grundsatz- und Aktionsprogramm der Partei der Christlich-Sozialen Einigung in Bayern, abgedruckt in: Geschichte einer Volkspartei, S. 433-436.

36 Mittelbayerische Zeitung vom 8. 1. 1946: „Politische Versammlungen“.

37 ACSP, NL Müller 163, Josef Held an Josef Müller vom 4. 12. 1945.

38 ACSP, NL Müller 161, Otto Schedl an Josef Müller vom 28. 12. 1945. 
stellt, so lautete die erste Forderung im Programm der Partei der Christlich-Sozialen Einigung in Regensburg: „Der bayerische Staat, dessen eigene Staatshoheit durch Unrecht und nationalsozialistische Gewaltherrschaft zerstört wurde, ist wieder herzustellen. “ 39

\section{b) Chance und Hypothek: Die "bayerische Frage“}

Der Unionsgedanke als Konzept zur Überwindung der nach Kriegsende herrschenden materiellen und geistig-ideellen Not zielte im Kern auf eine Überbrückung aller „Grabenbrüche der neueren deutschen Geschichte ${ }^{“ 40}$ und beinhaltete damit nicht nur ein Ende der konfessionellen Spaltung auf dem Feld der Politik, sondern schloß auch landsmannschaftliche Gegensätze oder gar die Revitalisierung des alten bayerischen Reichsvorbehalts aus ${ }^{41}$. Die Gründung der CSU zeigte jedoch bald, daß die Praxis erheblich anders aussah. Seit den Herbstmonaten des Jahres 1945 prallten vor allem im Münchner Gründerkreis divergierende und nur schwer zu vereinbarende Vorstellungen von der Lösung der „bayerischen Frage“ aufeinander. Die diesbezüglichen Konflikte drohten alle anderen Probleme zu überlagern und waren mitverantwortlich für die Schärfe und Erbitterung, mit der die Führungs- und Flügelkämpfe in der jungen Partei ausgefochten wurden. Die „bayerische Frage“, das heißt die Frage nach der Stellung Bayerns in einem übergeordneten deutschen Staatswesen und nach seinen Einflußmöglichkeiten im nationalen Rahmen, war immer dann besonders aktuell, wenn die staatliche Neuordnung Deutschlands auf der Tagesordnung stand ${ }^{42}$.

$\mathrm{Da}$ der neu gegründeten Christlich-Sozialen Union Protagonisten der bayerischen Eigenstaatlichkeit ebenso angehörten wie gemäßigte Befürworter eines deutschen Bundesstaates und Politiker, für die der Begriff Föderalismus mehr oder weniger ein Fremdwort war, litt die bayerische Unionspartei unter den desintegrierenden Auswirkungen der Debatten über die künftige Stellung Bayerns besonders. Die „bayerische Frage“ war der Brennpunkt der Flügelkämpfe und bestimmte nicht nur den Rhythmus der innerparteilichen Auseinandersetzungen, sondern belastete auch die Beziehungen der CSU zu den Unionsparteien in den anderen Teilen Deutschlands schwer ${ }^{43}$.

Um dieses Problem in seiner ganzen Tragweite erfassen zu können, muß man sich einige Stationen der neueren bayerischen Geschichte in Erinnerung rufen. Anders als es eine weitverbreitete staatsbayerische Ideologie suggeriert ${ }^{44}$, die auch von den kon-

${ }^{34}$ Grundsatz- und Aktionsprogramm der Partei der Christlich-Sozialen Einigung in Bayern, abgedruckt in: Geschichte einer Volkspartei, S. 433-436.

${ }^{40}$ Gerhard Schulz, Die CDU - Merkmale ihres Aufbaus, in: Max Gustav Lange u. a., Parteien in der Bundesrepublik. Studien zur Entwicklung der deutschen Parteien bis zur Bundestagswahl 1953, Stuttgart, Düsseldorf 1955, S. 3-153, hier S. 31.

${ }^{41}$ Vgl. Günter Müchler, Zum frühen Verhältnis von CDU und CSU, in: Politische Studien 23 (1972), S. 595-613, hier S. 596.

${ }^{42}$ Vgl. Ilse Unger, Die Bayerische Bewegung. Politische Strömungen in Bayern nach 1945, unveröffentlichte Magisterarbeit, Erlangen 1969, S. 1-33.

${ }^{43}$ Für Barbara Fait, Die Anfänge der CSU 1945-1948. Der holprige Weg zur Erfolgspartei, München 1995, S. $264 \mathrm{ff}$., spielen die Auseinandersetzungen um die "bayerische Frage" dagegen nur eine vergleichsweise untergeordnete Rolle.

${ }^{44}$ Unterstützt von einem großen Teil der katholischen Bevölkerung in den altbayerischen und schwäbischen Regionen legitimierten verantwortliche Politiker ihr Streben nach der möglichst weitgehenden Selbständigkeit Bayerns immer wieder mit einer mehr als 1000 jährigen Stammes-, Kultur- und Staatstradition, die die Basis eines Souveränitätsanspruchs bildete, der sich „unmittelbar auf die 
servativ-patriotischen Kräften in der CSU vertreten wurde ${ }^{45}$, ist Bayern in seiner heutigen Gestalt ein Produkt der napoleonischen Ära und der Neuordnung Europas im Zuge des Wiener Kongresses. Das junge Königreich vereinigte neben den altbayerischen Kernlanden viele vormals selbständige Territorien des Heiligen Römischen Reiches $^{46}$, Regionen, die aus einer „Mehrzahl heterogener und verwaltungsmäßig abgegrenzter ,politischer Kulturen“" bestanden und die „ihrerseits in eine Vielzahl soziokultureller Milieus gegliedert waren “47. Die Bemühungen der königlichen Regierung, Bayern zu einem einheitlichen Staat zu formen, riefen in den neu erworbenen Territorien meist Widerstände hervor und führten vor allem dort, wo eine erfolgreiche Integrationspolitik durch besondere Blockaden, beispielsweise durch konfessionelle Gegensätze, beeinträchtigt wurde, zur Ausbildung eines dauerhaften regionalen Sonderbewußtseins ${ }^{48}$. Noch heute lassen sich in Bayern drei sogenannte Traditionszonen ausmachen, die auf diese Entwicklung zurückgehen und ihre Prägekraft zum Teil erst in der jüngsten Vergangenheit verloren haben ${ }^{49}$. An erster Stelle ist die altbayerische Traditionszone zu nennen, die den Kern des katholischen Kurfürstentums Bayern umfaßt, dann die schwäbische Traditionszone und schließlich die fränkische, die wiederum in katholische und protestantische Regionen zerfällt. Der Erwerb der markgräflich-brandenburgischen Gebiete Ansbach und Bayreuth sowie verschiedener reichsstädtischer Territorien im fränkischen Raum schuf gleichsam eine Schneise, in der eine bewußt protestantisch-reformatorische Tradition dominierte und so das Königreich in das überwiegend katholische Mainfranken und das ebenfalls hauptsächlich katholische Süd- und Südostbayern teilte. Die Eingliederung der markgräflich-brandenburgischen und der reichsstädtischen Territorien zählte dort noch lange Zeit zu den einschneidendsten kollektiven Erfahrungen, die Ressentiments und Mißtrauen gegen den bayerischen Staat schürten.

Die Beharrungskraft der heterogenen politisch-kulturellen Traditionen zeigte sich auch in einem regional fragmentierten Parteiensystem. Die fränkisch-protestantischen Landesteile bildeten für eine bayerisch orientierte, katholische Partei lange Zeit eine Art Tabubezirk; sie entwickelten sich ebenso wie die Industrieinseln im agrarisch ge-

staatsbildende Funktion der Stämme und die darauf gegründete unabgeleitete Herrschergewalt" bezog. Zugleich wurde der „immerwährende Bund zwischen Stamm und Staat “ betont, ohne den Bayern nicht alle Herausforderungen und Katastrophen der Geschichte überstanden hätte und der auch die Voraussetzung für den Erhalt der bayerischen Stammeseigenart sei. Vgl. Peter Jakob Kock, Bayerns Weg in die Bundesrepublik, München ${ }^{2} 1988$, S. 31, bzw. Max Spindler, Die Grundlagen der Kulturentwicklung in Bayern. Vortrag im Herbst 1946, gehalten vor dem Bayerischen Landesverein für Heimatpflege, in: ders., Erbe und Verpflichtung. Aufsätze und Vorträge zur bayerischen Geschichte, hrsg. von Andreas Kraus, München 1966, S. 4-23, hier S. 13 (Zitat) und S. 22 f.

${ }^{45}$ IfZ-Archiv, Fh 56, Aktennotiz über eine Rede Alois Hundhammers am 10. 8. 1947 in Waldsassen.

46 Vgl. dazu Peter Claus Hartmann, Bayerns Weg in die Gegenwart. Vom Stammesherzogtum zum Freistaat heute, Regensburg 1989, S. 351-357.

47 Mintzel, Regionale politische Traditionen, in: Oberndörfer/Schmitt (Hrsg.), Parteien und regionale Traditionen, S. 132.

$48 \mathrm{Vgl}$. Helmut Berding, Staatliche Identität, nationale Integration und politischer Regionalismus, in: ders., Aufklären durch Geschichte. Ausgewählte Aufsätze, Göttingen 1990, S. 284-309, hier S. $287 \mathrm{ff}$. und S. 293-300. Zur staatlichen Integrationspolitik in der zweiten Hälfte des 19. Jahrhunderts vgl. auch Manfred Hanisch, Für Fürst und Vaterland. Legitimitätsstiftung in Bayern zwischen Revolution 1848 und deutscher Einheit, München 1991.

t9 Vgl. hierzu und zum folgenden Mintzel, Regionale politische Traditionen, in: Oberndörfer/Schmitt (Hrsg.), Parteien und regionale Traditionen, S. 131-138, und Alf Mintzel, Geschichte der CSU. Ein Überblick, Opladen 1977, S. 29-34. 
prägten Flächenstaat tendenziell zu Hochburgen nationalliberaler Parteien oder der Sozialdemokratie. Die katholische Bevölkerung Bayerns war in zwei Lager gespalten, wobei das bäuerlich-kleinbürgerliche, prononciert katholisch-konservative im altbayerischen Raum dominierte, während sich eine mehr reichsorientierte Strömung in Schwaben und Mainfranken behaupten konnte.

Die betont bayerischen Kräfte in Altbayern und den katholischen Teilen Schwabens hatten sich aus Protest gegen Liberalismus, Preußentum und eine Lösung der deutschen Frage ohne Österreich erstmals nach dem Krieg von 1866 in patriotischen Bauernvereinen und katholischen Kasinos formiert. Aus diesen Wurzeln entstand 1869 die Bayerische Patriotenpartei, die bei den Landtagswahlen zwar auf Anhieb die Mehrheit der Mandate eroberte, nach der Reichsgründung jedoch in vorsichtige Befürworter und radikale Gegner des Kaiserreichs zerfiel ${ }^{50} .1877$ benannte sich die Patriotenpartei in bayerisches Zentrum um, ohne aber ihre bayerisch-föderalistische Orientierung und ihre organisatorische Eigenständigkeit aufzugeben. Mit der Gründung der antisozialistischen und radikal föderalistischen Bayerischen Volkspartei wurde 1918 erneut eine autonome bayerische Landespartei ins Leben gerufen, die bis 1933 die Geschicke Bayerns wesentlich bestimmte ${ }^{51}$. Aber auch der BVP gelang es nicht, die innerbayerischen Spannungslinien und Regionalismen außer Kraft zu setzen, obwohl sie die stärkste politische Kraft war. Die BVP blieb eine überwiegend „altbayerische Partei mit relativ starken subregionalen Verankerungen im katholischen Mainfranken " 52 , die sich überdies mit dem liberaleren und teilweise antiklerikalen Bayerischen Bauernbund (BBB) starker landespolitischer Konkurrenz ausgesetzt sah ${ }^{53}$.

Der Erfolg konservativer, katholisch-konfessioneller und föderalistischer Parteien wie der Patriotenpartei oder der BVP ist nicht nur auf die Verwurzelung der Staatsund Stammestradition in breiten Schichten der bayerischen Bevölkerung und deren bewußte politische Instrumentalisierung zurückzuführen, sondern verweist auch auf ein sozial- und mentalitätsgeschichtlich interessantes Phänomen, dessen Ursprünge in die zweite Hälfte des 19. Jahrhunderts zurückreichen. Als Folge der Industrialisierung griff damals eine von Teilen des Landvolks und der katholischen Geistlichkeit getragene Fortschrittskritik ausgesprochen destruktiven Charakters um sich, der es nicht darum ging, die als bedrohlich empfundenen Veränderungsprozesse gleichsam im Sinne wertkonservativer Normen zu gestalten ${ }^{54}$. Die Konsequenzen des ökonomischen und sozialen Wandels, wie man sie insbesondere in den rasch wachsenden Städten beobachten konnte, wurden vielmehr rundheraus abgelehnt. Altbayerische Stammestradition, Katholizismus und das Beharrungsvermögen einer von den Folgen der Industrialisierung lange Zeit nur mittelbar betroffenen Agrargesellschaft „verbanden sich zumal in

50 Vgl. Dieter Albrecht, Von der Reichsgründung bis zum Ende des Ersten Weltkrieges (1871-1918), in: Max Spindler (Hrsg.), Handbuch der bayerischen Geschichte, Bd. IV/1: Das Neue Bayern 1800-1970, München 1974, S. 283-386, hier S. 298-307.

51 Vgl. Klaus Schönhoven, Die Bayerische Volkspartei 1924-1932, Düsseldorf 1972, S. 17-50.

52 Mintzel, Regionale politische Traditionen, in: Oberndörfer/Schmitt (Hrsg.), Parteien und regionale Traditionen, S. 138.

${ }^{53}$ Zum BBB vgl. Hannsjörg Bergmann, Der Bayerische Bauernbund und der Bayerische Christliche Bauernverein 1919-1928, München 1986.

$54 \mathrm{Vgl}$. Klaus Tenfelde, Bayerische Wirtschaft und Gesellschaft im 19. und frühen 20. Jahrhundert, in: Hartmut Mehringer (Hrsg.), Von der Klassenbewegung zur Volkspartei. Wegmarken der bayerischen Sozialdemokratie 1892-1992, München u. a. 1992, S. 9-19, hier S. $12 \mathrm{ff}$.; das folgende Zitat ebenda, S. 13. 
Krisenzeiten zu einem bayerischen Syndrom, das ganze Generationen von Bauern, ländlichen Unterschichten und Kleinbürgern prägte“. In den unsicheren Jahren der Weimarer Republik, vor allem aber während der nationalsozialistischen Diktatur und des Zweiten Weltkriegs erhielt dieses Phänomen noch einmal neue Nahrung.

Aufmerksamen Zeitgenossen wie dem 1944 hingerichteten Ulrich von Hassell war die Vertiefung der bestehenden Kluft zwischen dem Norden und dem Süden Deutschlands nicht entgangen ${ }^{55}$. Die althergebrachten antipreußischen Ressentiments, aufgeladen durch die egalisierenden Zumutungen eines immer gewaltbereiteren Regimes, durch die zermürbenden Erfahrungen des Bombenkrieges und insbesondere durch den wachsenden Zustrom von Flüchtlingen, Vertriebenen und Evakuierten, kamen aber erst nach dem Ende der Kampfhandlungen voll zum Ausbruch. Dabei waren diese traditionellen Stereotypen nicht nur Ausdruck des skizzierten „bayerischen Syndroms“ und des Strebens nach staatlicher Eigenständigkeit. Die Gleichsetzung von Preußentum und Nationalsozialismus ${ }^{56}$ und das Werben für die Wiederherstellung der vollen bayerischen Souveränität waren auch ein Versuch, von der eigenen Verantwortung für die deutsche Katastrophe abzulenken, und damit eine „partikularistische Ausflucht aus der gemeinsamen Erblast“57 mit dem Ziel, ähnlich wie Österreich eine mildere Behandlung durch die Siegermächte zu erreichen $^{58}$.

Als Reaktion auf die totale Niederlage war nach Kriegsende in vielen Teilen Deutschlands eine Renaissance föderalistischer Ideen zu beobachten, „und zwar als Allheilmittel gegen Diktatur und Totalitarismus“59. Antizentralistische und partikularistische Tendenzen, gepaart mit antipreußischen Ressentiments, waren nicht nur in Bayern weit verbreitet, sondern auch im Rheinland, in Schleswig-Holstein oder in Niedersachsen ${ }^{60}$, wenn sie dort auch wesentlich weniger Sprengkraft zu entfalten ver-

55 Vgl. Ulrich von Hassell, Vom andern Deutschland. Aus den nachgelassenen Tagebüchern 1938-1944, Zürich, Freiburg 1946, S. 59. Als „Preußen“ wurden im Prinzip alle mißliebigen Personen diffamiert, die nicht aus Süddeutschland oder Österreich, sondern aus anderen Regionen Deutschlands stammten.

56 Die Gleichsetzung von Preußentum und Nationalsozialismus war in bayerisch-konservativen Kreisen nicht erst seit 1945 ein feststehender Topos. So hieß es in einem Memorandum der Bayerischen Heimatbewegung: „Deutschland ist zugrunde gegangen, weil es preußisch war. Deutschland ist so hemmungslos dem Nationalsozialismus verfallen, weil Preußentum und Nationalsozialismus wesensähnlich sind. [...] Für die Bayern bedeutet die Ausrottung des Nationalsozialismus auch die Ausmerzung alles Preußischen aus Bayern. 1400 Jahre selbständig, schütteln wir die kurzlebige unselige preußisch-deutsche Herrschaft ab und verkünden aufs neue den souveränen Staat Bayern." Zit. nach Kock, Bayerns Weg, S. 95. Zum ambivalenten Verhältnis von preußischen Traditionen, nationalsozialistischer Weltanschauung und nationalsozialistischer Herrschaftspraxis vgl. Hans Mommsen, Preußentum und Nationalsozialismus, in: Wolfgang Benz, Hans Buchheim, Hans Mommsen (Hrsg.), Der Nationalsozialismus. Studien zur Ideologie und Herrschaft, Frankfurt am Main 1993, S. 29-41.

57 Lutz Niethammer, Problematik der Entnazifizierung in der BRD, in: Sebastian Meissl, Klaus-Dieter Mulley, Oliver Rathkolb (Hrsg.), Verdrängte Schuld, verfehlte Sühne. Entnazifizierung in Österreich 1945-1955, München 1986, S. 15-27, hier S. 20.

58 Zur besonderen Situation Österreichs, das in der alliierten Nachkriegsplanung seit der Moskauer Konferenz vom Oktober/November 1943 als erstes Opfer des Nationalsozialismus bezeichnet wurde, vgl. Günter Bischof, Die Instrumentalisierung der Moskauer Erklärung nach dem 2. Weltkrieg, in: Zeitgeschichte 20 (1993), S. 345-366.

59 Kock, Bayerns Weg, S. 17; eine instruktive Zusammenfassung der Föderalismusdebatte in den ersten Nachkriegsjahren ebenda, S. 17-27.

60 Vgl. Unger, Bayerische Bewegung, S. 1. In Niedersachsen kam es wie in Bayern zur Gründung einer autonomen Landespartei, der Niedersächsischen Landespartei, seit 1947 Deutsche Partei, die sich al- 
mochten. Der demokratische Neubeginn und der Aufbau politischer Parteien im Sommer 1945 reflektierten diese Entwicklung. In Ober- und Niederbayern sowie in der Oberpfalz trugen die enstehenden nichtsozialistischen Gruppierungen betont, zum Teil sogar radikal staatsbayerische und monarchistische Züge; in München versuchte Anton von Aretin mit einigen Mitgliedern der 1939 zerschlagenen Widerstandsgruppe um Josef Zott und Adolf Freiherr von Harnier eine Bayerische Arbeiter- und Bauernpartei als Kristallisationpunkt für alle bayerischen, föderalistischen und königstreuen Kräfte ins Leben zu rufen ${ }^{61}$. Auch in den Gründungszirkeln der altbayerischen Sozialdemokratie sah man, unter dem Einfluß Wilhelm Hoegners stehend, keinen Gegensatz zwischen sozialistischer Politik und bayerischer Eigenständigkeit ${ }^{62}$. Selbst der KPDLandesverband Bayern forderte gegen jede marxistische Tradition die „volle Entfaltung der Bundesländer auf föderativer Grundlage “63. Es entstand so etwas wie eine „bayerische Bewegung“, die sich die Wiederherstellung und später die Verteidigung der Staatlichkeit Bayerns auf ihre Fahnen geschrieben hatte ${ }^{64}$. Auf der Basis des bayerischen Staats- und Stammesbewußtseins fand die „bayerische Bewegung“ Anhänger bei allen politischen Richtungen und umfaßte - jeweils stark bayerisch-traditionalistisch eingefärbt - Sozialdemokraten, Monarchisten und Vertreter bürgerlich-demokratischen oder christlich-konservativen Gedankenguts. Wenn die Zielvorstellungen der „bayerischen Bewegung“ auch ähnlich heterogen waren wie ihre Trägerschichten, so war sie doch ein politischer Faktor, mit dem bis in die Anfangsjahre der Bundesrepublik gerechnet werden mußte.

Wie groß das in der „bayerischen Frage“ enthaltene Konfliktpotential war und wie schwer die CSU daran zu tragen haben würde, deutete sich bereits in den ersten programmatischen Texten an, die 1945 in den verschiedenen Gründungszirkeln der CSU verfaßt wurden. Dabei zeigte sich, daß die entscheidende Bruchlinie entlang der historisch gewachsenen Grenze zwischen der altbayerischen und der fränkischen Traditionszone verlief. Während man in den Landkreisen Oberbayerns, Niederbayerns und der Oberpfalz mehrheitlich den staatlichen Rechten Bayerns erste Priorität einräum$\mathrm{te}^{65}$, wiesen die nördlich der Donau erarbeiteten Parteiprogramme zumeist über die bayerischen Grenzen hinaus und stellten Fragen des gesamtstaatlichen Aufbaus oder der Sozial- und Wirtschaftspolitik in den Mittelpunkt ${ }^{66}$. Wohlgemerkt: daß ein künftiger deutscher Staat nur auf föderativer Basis aufgebaut sein könnte, war unter den Mitbegründern der CSU weithin unumstritten. Die entscheidende Frage war vielmehr,

lerdings nur bis zum Ende der fünfziger Jahre behaupten konnte; vgl. Horst W. Schmollinger, Die Deutsche Partei, in: Richard Stöss (Hrsg.), Parteien-Handbuch. Die Parteien der Bundesrepublik Deutschland 1945-1980, Bd. 2: CSU bis DSU, Opladen 1986, S. 1025-1111.

61 BayHStA, NL Pfeiffer 52, Aktennotiz für Fritz Schäffer vom 18. 9. 1945.

62 Vgl. Peter Kritzer, Wilhelm Hoegner. Politische Biographie eines bayerischen Sozialdemokraten, München 1979, S. 248-277.

${ }^{63} \mathrm{SZ}$ vom 22. 1. 1946: Programm der KPD, Landesbezirk Bayern.

${ }_{64} \mathrm{Vgl}$. hierzu und zum folgenden Unger, Bayerische Bewegung, S. I-V.

${ }^{65}$ Für Oberbayern beispielsweise das „Politische Glaubensbekenntnis und Arbeitsprogramm der christlich-sozialen Union bayerischer Demokraten“ aus Altötting (IfZ-Archiv, Fh 56), für die Oberpfalz das Programm der Partei der Christlich-Sozialen Einigung in Regensburg (abgedruckt in: Geschichte einer Volkspartei, S. 433-436), für Niederbayern den Aufruf und die Satzung der Christlich-Sozialen Volkspartei in Rottenburg an der Laaber (BayHStA, NL Pfeiffer 144).

${ }^{66}$ Dies blieb auch der amerikanischen Militärregierung nicht verborgen; IfZ-Archiv, RG 260, 12/ 147-2/16, OMGBY - Historical Report, 13. 11. 1945-14.12. 1945. 
wie ein solches Staatswesen konkret ausgestaltet sein sollte und welche Stellung für Bayern darin vorgesehen war. Die Programme und Aufrufe der CSU in Hof, Bamberg oder Nürnberg forderten zwar ebenfalls den bundesstaatlichen Aufbau des neuen Deutschlands, aber ihre deutsche, ja reichsfreundliche Orientierung war doch unverkennbar $^{67}$. Daher verwundert es nicht, daß diese Aussagen in Südbayern auf Mißtrauen oder gar offene Ablehnung stießen. Dort teilte man vielfach extrem föderalistische und radikal bayerische Vorstellungen, wie sie beispielsweise der spätere Bundesminister und langjährige Vizepräsident des Deutschen Bundestages Richard Jaeger im Herbst 1945 in seinen "Gedanken zur bayerischen Selbstbesinnung" niedergelegt hat$t^{68}$ : Für den jungen Juristen, der Krieg und Gefangenschaft erst seit wenigen Wochen hinter sich gelassen hatte, war die ökonomische, kulturelle und politische Hegemonie Preußens ebenso für die deutsche Katastrophe verantwortlich wie der Nationalsozialismus, für den das Preußentum als stärkster „Gegensatz zu den wahren Werten deutscher Kultur" und als „antihumane, im tiefsten antichristliche Weltanschauung" der ideale Nährboden gewesen sei. Der Eintritt Bayerns in das Bismarckreich erschien Jaeger als „die Tat eines geisteskranken Königs und einer geistig verwirrten Landtagsmehrheit" und damit als „eine der folgenschwersten Fehlentscheidungen der bayerischen Geschichte". Die Abkehr Deutschlands von einem seit den Kriegen Friedrichs des Großen beschrittenen Irrweg, so Jaeger weiter, sei nur dann möglich, wenn neben dem Nationalsozialismus ,auch das Preußentum mit Stumpf und Stil ausgerottet und vernichtet" und der preußische Staat zerschlagen würde. Erst die Ausschaltung des Faktors Preußen garantiere den Frieden und die Sicherheit der Welt, erst dadurch werde der Neuaufbau Deutschlands und Mitteleuropas auf der Grundlage eines echten Föderalismus möglich.

Der Föderalismusbegriff Jaegers war dabei weniger an den Leitbildern der deutschen Verfassungsgeschichte orientiert als an den Verfassungen der Schweiz oder der USA. Was ihm vorschwebte, war ein lockerer Bund deutscher Staaten, eingebettet in eine europäische Konföderation auf der Basis einer mittelalterlich anmutenden Universalreichsidee. Aber auch monarchistische und partikularistische Gedankengänge waren dem jungen Mitbegründer der CSU nicht fremd. So schrieb er mit Blick auf den südöstlichen Nachbarn Bayerns: „Ist es für Österreich recht, ein selbständiger und unabhängiger Staat zu werden, so ist es für Bayern billig." Als ersten Schritt zur Verwirklichung seines Programms forderte Jaeger die Übernahme der vollen Souveränität durch den bayerischen Staat, der zugleich nicht nur von aktiven Nationalsozialisten und Exponenten von Preußentum und Militarismus gesäubert werden sollte, sondern überhaupt "von allen landfremden Elementen“. Die Erneuerung der bayerischen Staatsbürgerschaft, die beschleunigte Rückführung der Evakuierten und die dauerhafte politische Entrechtung der Flüchtlinge sollten ebenfalls

67 IfZ-Archiv, Fh 56, Programm des CSU-Ortsverbands Hof, Aufruf des CSU-Kreisverbands Bamberg-Stadt und -Land, undatiert, sowie Programm der Nürnberger CSU.

68 Vgl. Richard Jaeger, Auf dem Weg zur Demokratie. Gedanken zur bayerischen Selbsțbesinnung vom Herbst 1945, in: Lehrjahre der CSU. Eine Nachkriegspartei im Spiegel vertraulicher Berichte an die amerikanische Militärregierung, hrsg. von Klaus-Dietmar Henke und Hans Woller, Stuttgart 1984, S. 145-196; die folgenden Zitate ebenda, S. $152 \mathrm{ff} .$, S. 157 und S. 159. Während Jaeger Preußentum und Nationalsozialismus in einem Atemzug nannte, schrieb er dem bayerischen Volk "seit germanischen Zeiten“ eine stark demokratische Gesinnung zu. Ebenda, S. 171. 
dazu dienen, „Bayern den Bayern“"69 zurückzugeben und seine Souveränität dauerhaft zu sichern.

Für die protestantische Bevölkerung Mittel- und Oberfrankens, die im mehrheitlich evangelischen Reich stets ein Gegengewicht zum katholisch dominierten bayerischen Staat gesehen hatte, stammten derartige Vorstellungen aus dem separatistischen Gruselkabinett. Aber auch viele fränkische und schwäbische Mitbegründer der CSU, die sich zwar als Bayern fühlten, aber stets dem nationalen Gedanken verbunden gewesen waren, konnten damit nur wenig anfangen, selbst dann, wenn sie föderalistische Ideen nicht grundsätzlich ablehnten. Der evangelische Vorsitzende des Bezirksverbands Oberfranken, Georg Barth, in dem bereits das Mißtrauen erwachte, wenn in Stellungnahmen zur staatlichen Neuordnung Deutschlands der Terminus Reich durch den Begriff Bund ersetzt wurde, stellte angesichts der radikal föderalistischen Forderungen aus dem Süden Bayerns gar den Grundkonsens in Frage, auf dem die CSU ruhte:

„Die Union in Bayern gewann in den Wahlen zur verfassunggebenden Landesversammlung - gewisse Persönlichkeiten sagen gern dafür Nationalversammlung! - über 1.600.000 Stimmen. Rund 400.000 Wähler haben sich also mit den Anhängern der einstigen BVP zusammengefunden. Es ist der christliche Grundgedanke, der bewußt oder gefühlt einigend wirkt; es ist darüber hinaus die immer wieder gegebene ehrliche Versicherung, daß die BVP tot ist, daß deren Gedankengut 1933 überrollt und damit endgültig versunken ist. Eine Reihe von Beobachtungen aber drängt die Frage auf, die nicht mehr unterdrückt werden kann: Ist die BVP wirklich tot? Ist es für viele nicht nur eine Änderung des Firmenschildes, wenn man heute unter dem guten Namen der Union die alten hausbackenen politischen Ziele der BVP verfolgt?" ${ }^{70}$

Die frühen Programmentwürfe und öffentlichen Aufrufe des Münchner Gründerkreises, die als Orientierungspunkte für eine künftige Partei auf Landesebene gedacht waren, verraten nur wenig von der stark bayerisch-föderalistischen, antipreußischen Gesinnung vieler Gründungsmitglieder. Diesen programmatischen Texten, die all denen entgegenkamen, die vor 1933 den Reichsvorbehalt der BVP abgelehnt hatten und die nun für die neue Sammlungspartei gewonnen werden sollten, ist ihr Kompromißcharakter deutlich anzumerken. Das „Grundsatz-Programm einer Christlich-Demokratischen Volkspartei in Bayern“ aus den ersten Septembertagen des Jahres 1945 gab sich beispielsweise mit der Forderung zufrieden, ein neuer deutscher Staat müsse von unten nach oben aufgebaut werden, auf einer „gebietsmässig und kräftemässig ausgeglichenen föderativen Grundlage" beruhen und Bayern als geschlossenem staatlichen Gebilde die freie „Entfaltung seiner kulturellen Kräfte“ ermöglichen. Zugleich sah man in der "Aufrechterhaltung aller bei Deutschland verbleibenden Gebiete“ eine entscheidende Voraussetzung für den Neuanfang ${ }^{71}$. Auch die staatspolitischen Leitsät-

69 So lautete eine der wichtigsten Forderungen des allgemeinen Programms der BVP, in: Im Zeichen des Föderalismus. Programme und Programmatisches der Bayerischen Volkspartei, München 1924, S. 3-7, hier S. 6.

70 ACSP, NL Müller 5, Memorandum Georg Barths „Ist die Bayerische Volkspartei tot?“ vom 17. 7. 1946.

71 BayHStA, NL Pfeiffer 41, „Grundsatz-Programm einer Christlich-Demokratischen Volkspartei in Bayern" vom September 1945; auch abgedruckt in: Andreas Kraus (Hrsg.), Land und Reich, Stamm und Nation. Probleme und Perspektiven bayerischer Geschichte. Festgabe für Max Spindler zum 90. Geburtstag, Bd. 3: Vom Vormärz bis zur Gegenwart, München 1984, S. 469 ff. Eine ähnliche Formulierung findet sich in dem Aufruf „Bayerische Christlich-Soziale Union“, dessen erster Entwurf (BayHStA, NL Pfeiffer 41) vom 10.9. 1945 datiert; Entwurf und publizierte Fassung abgedruckt in: Christiane Reuter, „Graue Eminenz der bayerischen Politik“. Eine politische Biographie Anton Pfeiffers (1888-1957), München 1987, S. 322-329. 
ze des ersten offiziellen Programms der CSU, der „Zehn Punkte der Christlich-Sozialen Union" vom 31. Dezember 1945, klangen moderat. An wenig exponierter Stelle fanden sich dort die Forderungen nach der föderativen „Neugestaltung des Reiches, Stärkung der Verantwortlichkeit der Länder und Selbstverwaltungskörper, Pflege der besonderen Belange unserer bayerischen Heimat ${ }^{\text {"72 }}$. Solche eher unverbindlichen Formulierungen spiegeln aber weniger die tatsächliche Kompromißbereitschaft im heterogenen Münchner Gründerkreis wider als das Kräfteverhältnis zwischen den Verfechtern der Unionsidee um den gemäßigt föderalistischen, aber stets über Bayern hinaus denkenden Josef Müller und den Anhängern der ehemaligen BVP. Wie die BVP-Traditionalisten wirklich dachten, zeigt ein Programmentwurf, der wohl Ende September 1945 von Anton Pfeiffer als Alternative zu den Überlegungen des Müller-Kreises verfaßt wurde und in vielem an die Forderungen Richard Jaegers erinnerte ${ }^{73}$.

Wie die weitere Entwicklung zeigte, waren die unterschiedlichen Positionen kaum miteinander zu vereinbaren. $\mathrm{Zu}$ groß war das gegenseitige Mißtrauen, zu schwer wogen die tiefgreifenden Differenzen, die die historisch gewachsenen Spannungslinien offen zutage treten ließen. In der „bayerischen Frage“ waren die verschiedenen Gruppierungen in der CSU lange Zeit nur zu Formelkompromissen fähig, über deren Ausgestaltung immer wieder erbittert gerungen wurde. Zumindest für Teile der CSU „bedeutete der Föderalismus das Kernstück aller Politik“, und nahezu ,alle innerparteilichen Schlachten wurden im Zeichen der Alternative Föderalismus - Zentralismus geschlagen"74.

Die Auseinandersetzungen über die "bayerische Frage“ erschöpften sich jedoch nicht in Debatten über die Stellung Bayerns in einem künftigen deutschen Staat. Sie waren vielmehr untrennbar verknüpft mit dem Konflikt, der sich an der Streitfrage entzündete, wie das Verhältnis der CSU zu den Unionsparteien in den anderen Teilen Deutschlands gestaltet werden sollte ${ }^{75}$. Josef Müller stellte seiner im Vergleich zu den Vertretern der innerparteilichen Opposition geradezu deutschen und europäischen Orientierung eine entsprechende organisationspolitische Konzeption zur Seite. Eine „Reichspartei im früheren Sinne“ lehnte Müller ab. Er forderte dagegen einen organisatorischen Rahmen auf der Basis starker Landesverbände mit einem Parteivorstand, in dem die einzelnen Landesvorsitzenden eine dominierende Rolle spielen sollten ${ }^{76}$. Auf längere Sicht sah Müller die CSU als Landesverband in einer künftigen - wenn auch stark dezentralisierten - gesamtdeutschen Unionspartei.

Im April 1946 forcierte Müller den Versuch, die Unionsparteien der US-Zone ähnlich wie in der britischen Besatzungszone zu einem Zonenverband zusammenzufas-

72 Abgedruckt in: Protokolle und Materialien, S. 1713f. Vgl. dazu Mintzel, Geschichte der CSU, S. $205 \mathrm{ff}$,, und dic anderslautende, aber plausiblere Interpretation von Konrad Repgen, Über die Anfänge des CSU-Programms von 1945, in: Kraus (Hrsg.), Land und Reich, Bd. 3, S. 459-471, hier S. 461.

73 BayHStA, NL Pfeiffer 41, ungezeichneter, undatierter Programmentwurf; eine ähnliche Stoßrichtung weist auch das vorläufige Programm der Münchner CSU auf (NL Pfeiffer 41, im Entwurf NL Pfeiffer 142), das im November 1945 dem Lizenzierungsantrag beigelegt wurde.

${ }_{75}^{7+}$ Günter Müchler, CDU/CSU. Das schwierige Bündnis, München 1976, S. 24.

75 Vgl. Mintzel, CSU, in: ders./Oberreuter (Hrsg.), Parteien in der BRD, S. 201.

76 Vgl. Josef Müller, Maximen der Unionspolitik, in: Unsere soziale Revolution, München 1948, S. 3-7, hier S. 5 f., und das Protokoll der Sitzung des Landesarbeitsausschusses der CSU am 1. 5. 1946 in München, in: Protokolle und Materialien, S. 201. 
$\operatorname{sen}^{77}$. Obwohl zunächst Einigung über eine Zonenpartei mit der Bezeichnung Christliche Union erzielt werden konnte, kam das Projekt, die CSU in eine umfassendere organisatorische Konstruktion einzubinden, nicht zustande. Bald auftretende Bedenken gegen die mühsam austarierte Kompromißformel und persönliche Rivalitäten dürften dafür verantwortlich gewesen sein, daß diese Initiative zunächst im Sande verlief ${ }^{78}$. Als die Vorsitzenden der süddeutschen Unionsparteien im September einen weiteren Versuch unternahmen, scheiterte der Plan erneut. Diesmal sprach sich auch Josef Müller dagegen aus ${ }^{79}$, da sich in der Zwischenzeit Veränderungen im Kräfteverhältnis innerhalb der CSU ergeben hatten, die den Landesvorsitzenden dazu zwangen, der stärker werdenden innerparteilichen Opposition Tribut zu zollen ${ }^{80}$.

Waren die Außenbeziehungen der Partei in den ersten Monaten des Jahres 1946 noch weitgehend Monopol des vorläufigen Landesvorsitzenden, so versuchten die Gegenspieler Müllers im Vorfeld der ersten ordentlichen Landesversammlung im Mai 1946, sein diesbezügliches Engagement stärker als bisher zu kontrollieren und an die vorläufigen Führungsgremien der Partei zu binden ${ }^{81}$. In dieser Frage kam es zu einer für die Parteiführung um Josef Müller unbequemen Koalition zwischen den Exponenten des katholisch-konservativen Parteiflügels und prominenten bäuerlichen Interessenvertretern, die jede potentielle Einschränkung der Selbständigkeit der CSU ebenso mit Mißtrauen betrachteten wie Aktivitäten, die ihrer Meinung nach zu einer Gefahr für die bayerische Eigenstaatlichkeit werden konnten. Es war Michael Horlacher, der diesen Bedenken vor dem Landesarbeitsausschuß der CSU Ausdruck gab:

„Ich habe Verständnis, wenn die Berliner Unterstützung brauchen, aber uns dürfen sie nicht mehr überspielen. Diesen Zustand mache ich nicht mehr mit, ich bin kein Preußenfeind, ich bin ein Freund aller Demokraten Deutschlands. Aber nach dem Zerfall Preußens muß die Geschichte von 1860 bis 1945 zurückrevidiert werden. Es muß der Süden des Reiches eine beherrschende Rolle im ganzen Reich gewinnen. ${ }^{* 82}$

Die Konsequenz, die Horlacher daraus für das Verhältnis der einzelnen Unionsparteien zog, war eindeutig: „Darum die Frage der Verhandlungen mit anderen Zonen nur in der Form von Arbeitsgemeinschaften".

77 Vgl. hierzu Müchler, Zum frühen Verhältnis, S. 602, und Henning Köhler, Adenauer. Eine politische Biographie, Frankfurt am Main, Berlin 1994, S. $418 \mathrm{ff}$.

${ }^{78}$ Vgl. dazu auch das Schreiben Adenauers „An die Teilnehmer eines bizonalen CDU/CSU-Treffens in Stuttgart" vom 8. 4. 1946 und die Aktennotiz Konrad Adenauers vom 6. 4. 1946, in: Adenauer. Briefe 1945-1947, bearb. von Hans Peter Mensing, Berlin 1983, S. 202-205 bzw. S. 208 f.

79 Im Entwurf eines Schreibens an Konrad Adenauer (ACSP, NL Müller 410/6) betonte Müller im August 1946: „Ich sprach mich gegen eine Gründung der Partei auf U. S. Zonenbasis aus. Ich bin der Auffassung, dass die Entwicklung schon darüber hinweggegangen ist. Wir müssen der Lösung auf gesamtdeutscher Basis nähertreten."

${ }^{80}$ Unterstützt von Müller führte August Haußleiter am 28. 2. 1947 vor den Mitgliedern des Landesvorstands der CSU aus (ACSP, NL Müller 9): „In der amerikanischen Zone allein sind die Länder die Träger der politischen Entwicklung. Nur in der amerikanischen Zone spielen die Landtage eine große Rolle. Da wir ein föderalistisch gegliedertes Deutschland haben, wollen wir auch eine föderalistische Gliederung der Organe der Union Deutschlands. Eine zentralistisch organisierte Partei wird unvermeidlich den zentralistischen Staat ansteuern. Daher ist eine föderalistische Gliederung der Union wichtig. Bayern will die Zonenorganisation, die unnatürlich ist, ausschalten und [die] Länder herausarbeiten."

81 Vgl. Mintzel, Anatomie, S. 251-270.

82 Protokoll der Sitzung des Landesarbeitsausschusses der CSU am 1.5. 1946 in München, in: Protokolle und Materialien, S. 200; das folgende Zitat ebenda. 
Das organisatorische Prinzip einer Arbeitsgemeinschaft der Unionsparteien war auch das Kernstück der Resolution, die Joseph Baumgartner am 17. Mai 1946 den Delegierten der Landesversammlung vorlegte. Die Initiatoren forderten die Landesversammlung auf, „eine Christlich-Soziale Union als Einheitspartei der Christlich-Sozialen Unionen für ganz Deutschland“ abzulehnen und lediglich der Bildung einer Arbeitsgemeinschaft zuzustimmen, die die „Selbständigkeit der einzelnen Christlich-Sozialen Unionen [. . . ] auf jeden Fall [...] unberührt“ ließe ${ }^{83}$. Zwar gelang es Müller, diesen Antrag von der Tagesordnung abzusetzen ${ }^{84}$, aber die innerparteiliche Opposition hatte aufgezeigt, wo für sie die Grenze der Kooperation mit den Schwesterparteien in den anderen Teilen Deutschlands $\mathrm{lag}^{85}$. Solchen Bedenken und Warnungen mußte Josef Müller um so mehr Rechnung tragen, als sich in der zweiten Hälfte des Jahres 1946 mit den Fraktionen in der Verfassunggebenden Landesversammlung und dann vor allem im Landtag alternative Entscheidungszentren innerhalb der CSU herausbildeten, die den Handlungsspielraum der Parteiführung mehr und mehr einschränkten ${ }^{86}$. Nachdem der Parteivorsitzende bei der Regierungsbildung im Dezember 1946 von seinen innerparteilichen Gegnern im Verein mit Teilen der SPD überspielt worden war, wurde es für die CSU-Führung zunehmend schwieriger, ihren Einfluß auf politische Grundsatzentscheidungen geltend zu machen. Auch die Tatsache, daß mit Hans Ehard ein CSUPolitiker das Amt des Ministerpräsidenten bekleidete, der die Förderung und Verteidigung föderalistischer Prinzipien auf seine Fahnen geschrieben hatte, trug nicht dazu bei, die Position Müllers zu stärken. Die Prärogative des bayerischen Ministerpräsidenten und seines wichtigsten politischen Koordinierungsinstruments, der Staatskanzlei, auf dem Feld der bayerischen Außenbeziehungen blieb auch nach dem Eintritt Josef Müllers in das zweite Kabinett Ehard im September 1947 erhalten $^{87}$.

Die Entwicklung der CSU zur autonomen Landespartei, so könnte man bilanzieren, begann bereits 1946 und war weitgehend zementiert, als die Bayernpartei im Frühjahr 1948 landesweit lizenziert wurde. Dabei ging die Verfestigung dieser Sonderrolle Hand in Hand mit der Erosion der innerparteilichen Machtstellung Josef Müllers ${ }^{88}$. Hans Ehard, längst schon zu einem der Meinungsführer in der CSU avanciert, defi-

${ }^{83}$ IfZ-Archiv, ED 132 NL Baumgartner 2, Resolution für die Landesversammlung der CSU am 17.5. 1946 in München. Zu den 15 Unterzeichnern gehörten neben Landwirtschaftsminister Baumgartner u. a. Michael Horlacher, Alois Schlögl und Fridolin Rothermel, drei der einflußreichsten Vertreter des Bayerischen Bauernverbands.

84 Zum Verlauf der Debatte vgl. das Protokoll der Landesversammlung der CSU am 17.5. 1946 in München, in: Protokolle und Materialien, S. 257-263.

85 Zur Arbeitsgemeinschaft der CDU/CSU Deutschlands vgl. Die Unionsparteien 1946-1950. Protokolle der Arbeitsgemeinschaft der CDU/CSU Deutschlands und der Konferenzen der Landesvorsitzenden, bearb. von Brigitte Kaff, Düsseldorf 1991, S. IX-XXIV.

86 Am 6. September versuchte Müller, die mißtrauischen Mitglieder des Landesausschusses zu beruhigen, wobei er seinen Kontrahenten durchaus entgegenkam, ohne allerdings sein Hauptziel aufzugeben: "Ich darf nochmals feststellen: Auch die Union, die eines Tages für Deutschland entstehen wird, die jetzt zunächst durch eine Arbeitsgemeinschaft repräsentiert ist, wird auf föderalistischer Basis aufgebaut sein, als eine Zusammenfassung von gleichberechtigten Unionen. Ich habe klargestellt, daß es ausgeschlossen ist, daß wir in dieser Hinsicht unsere Selbständigkeit aufgeben könnten oder auch nur unseren Namen ändern würden." Protokoll der Sitzung des Landesausschusses der CSU am 6. 9. 1946 in München, in: Protokolle und Materialien, S. 542.

87 Vgl. Karl-Ulrich Gelberg, Hans Ehard. Die föderalistische Politik des bayerischen Ministerpräsidenten 1946-1954, Düsseldorf 1992, S. $48 \mathrm{f}$.

88 Vgl. dagegen die teilweise anderslautenden Ausführungen von Müchler, Zum frühen Verhältnis, S. 595 und S. 606. 
nierte auf der Landesversammlung im Januar 1948 das Verhältnis der CSU zu den anderen Unionsparteien folgendermaßen: Die CSU sei eine „bayerische Partei mit einer bayerischen Zielsetzung". Ihre Politik bedürfe daher

„eigenständiger politischer Organisationen, die in sich selbst ruhen und ihre politischen Impulse aus sich selbst empfangen; das heißt, wir brauchen eine Landespartei, die ihre oberste Instanz in sich selbst hat und die frei ist von irgendwelchen Weisungen, die von außen an sie kommen. (Beifall.) Die Christlich-Soziale Union ist als eine selbständige Landespartei gegründet, und es widerspräche ihrem natürlichen Entwicklungsgesetz, nach dem sie angetreten ist, wollte man sie etwa in ein Teilstück einer Reichspartei umwandeln. (Erneuter Beifall.) Reichsparteien entstehen [. . .] immer unter dem Einfluß zentralistischer Tendenzen. ${ }^{\text {"89 }}$

Damit war klar ausgedrückt, welche Rolle der CSU im föderalistischen Kalkül Hans Ehards zukam: Als autonome Landespartei sollte sie sowohl ein sichtbares Zeichen als auch ein wirksames Instrument bayerischer Eigenstaatlichkeit sein, deren Verwirklichung und Sicherung Persönlichkeiten wie Ehard, Hundhammer oder Pfeiffer auf ihre Fahnen geschrieben hatten.

\section{c) Sammlungskonzept und Sozialismusfurcht}

Angesichts der historischen Hypotheken, mit denen die neu gegründete Partei von Anfang an belastet war, und angesichts der erbitterten Führungs- und Flügelkämpfe, die daraus resultierten, erscheint es auf den ersten Blick erstaunlich, daß die CSU nicht zerbrach, sondern ihre organisatorische Einheit allen Wirren zum Trotz wahren konnte. Unter diesen Auspizien übersieht man jedoch leicht, wie groß auch die Gemeinsamkeiten waren, die die Gründung der CSU als interkonfessionelle Sammlungspartei überhaupt erst ermöglichten und die Partei später zusammenhielten ${ }^{90}$. Die inneren Bindungskräfte waren immerhin stark genug, um die Kontrahenten auch in schier ausweglosen Situationen vor dem offenen Bruch zurückschrecken zu lassen. Aus berechtigter Furcht, ihre Mitstreiter könnten ihnen in letzter Konsequenz die Gefolgschaft verweigern, wagten es weder die Exponenten des Müller-Flügels noch ihre katholisch-konservativen Gegenspieler, die Spaltung der Partei zu riskieren.

Was hielt nun die so zerrissene CSU im Innersten zusammen ${ }^{11}$ ? Da war einmal die Idee, Katholiken und Protestanten, Konservative und Liberale, Bürger, Arbeiter und Bauern in einer Partei der Sammlung auf der Basis des christlichen Sittengesetzes zusammenzuführen, von der die Union getragen wurde ${ }^{92}$. Ob ihnen der Unionsgedanke

${ }^{89}$ Protokoll der Landesversammlung der CSU am 24./25. 1. 1948 in Marktredwitz, in: Protokolle und Materialien, S. $1493 \mathrm{f}$.

90 So erklärte beispielsweise Franz Josef Strauß, nachdem die Delegierten der Landesversammlung seinen Mentor Josef Müller im Mai 1949 als Parteivorsitzenden abgewählt hatten: „Schon oft hat es so ausgesehen, als gehe die Partei auseinander, schon oft ist sie als dem Zusammenbruch nahe erklärt worden. Aber das ist gerade das Erstaunliche und Große an der Union, daß sie trotz aller Risse und Streitigkeiten und Schwierigkeiten immer wieder an der Idee fest- und zusammengehalten hat, daß immer wieder die Idee der Union stärker war als die Kräfte, die sie auseinanderreissen wollten." IfZ-Archiv, ED $720 \mathrm{Smlg}$. Mintzel 46, Protokoll der Sitzung des Vorstands des CSU-Bezirksverbands Schwaben am 11.6. 1949.

$9 t \mathrm{Zu}$ nennen wäre in diesem Zusammenhang auch die Rolle der Militärregierung; vgl. S. $64 \mathrm{f}$.

92 In einem Bericht des amerikanischen Geheimdienstes OSS über ein Gespräch mit einem ungenannten Mitglied der Münchner Stadtverwaltung, das vor 1933 der BVP angehört hatte, heißt es: „He felt that the BVP would be revived to represent the buergerlich Christian bloc of the population, but suggested that its base be broadened to appeal to both Catholics and Protestants. He claimed 
wirklich am Herzen lag oder ob sie ihn aus taktischen Erwägungen befürworteten ${ }^{93}$ : Den Mitbegründern der CSU war in ihrer überwiegenden Mehrheit klar, daß die Neuauflage der 1933 untergegangenen Parteien auch zu einer Neuauflage der als verhängnisvoll erkannten Zersplitterung der Parteienlandschaft führen mußte ${ }^{94}$ und daß eine breit angelegte Sammlungsbewegung naturgemäß die besten Chancen hatte, den politischen Neubeginn nach den eigenen Vorstellungen zu gestalten. Dazu kam ein weiterer wichtiger Punkt: die weit verbreitete Furcht vor einem Linksrutsch und vor einer Radikalisierung der Bevölkerung, die den Zusammenschluß aller nicht- bzw. antisozialistischen Kräfte zu einer verlockenden Vorstellung werden ließ. Josef Müller versuchte, diese Sozialismusängste in seinem Sinne $\mathrm{zu}$ instrumentalisieren. Wenn man die Situation geschickt ausnütze, so vertraute Müller Ende 1945 einem Vertreter der Militärregierung an, sei es möglich, den verschiedenen Zirkeln „die Notwendigkeit einer alle Gruppen umfassenden christlichen Partei soweit“ klarzumachen, „daß sie wenigstens dieses eine Mal zusammengingen“. Er fürchtete jedoch zugleich, die neue Partei könne zerbrechen, „wenn die anfängliche Furcht vor der Linken nachlasse ${ }^{\text {"95. }}$.

Wie die ersten Wahlen im Frühjahr 1946 zeigten, erwies sich die Angst vor einem galoppierenden Linksradikalismus als unbegründet ${ }^{96}$. Die Ereignisse in der SBZ Repressionen gegen die CDU oder die (Zwangs-)Vereinigung von SPD und KPD hielten die antisozialistischen und antikommunistischen Affekte in der bayerischen Unionspartei aber ebenso wach wie die immer schärferen Auseinandersetzungen zwischen den westlichen Alliierten und der Sowjetunion im Zeichen des beginnenden Kalten Krieges ${ }^{97}$. Der Rekurs auf linke Feindbilder diente in der CSU so stets einem doppelten Zweck: zum einen der Mobilisierung von Wählern und Mitgliedern, zum anderen der Stärkung des zeitweise ungenügenden innerparteilichen Zusammenhalts. Prälat Georg Meixner, zu dieser Zeit Vorsitzender der CSU-Landtagsfraktion, ging 1954 sogar so weit, die Notwendigkeit einer interkonfessionellen Partei mit der kommunistischen Bedrohung zu begründen. Meixner erklärte vor dem Landesausschuß:

that [ein Wort unleserlich] strife had been largely overcome during the Nazi regime." IfZ-Archiv, Smlg. Henke, „Interview with BVP Municipal Official (Munich)“, 5. 6. 1946; das Gespräch fand bereits am 30. Mai statt.

93 Daß das Konzept, die alten Parteigrenzen aus der Zeit vor 1933 durch eine breit angelegte Sammlungspartei zu überwinden, bei den meisten Mitbegründern der CSU Anklang fand, heißt nicht, daß man sich darüber einig gewesen wäre, welche politischen Strömungen in der neu zu gründenden Partei zusammengefaßt werden sollten.

94 Vgl. z. B. Stegerwald, Wohin gehen wir, S. 5.

95 Die politischen Parteien in Bayern - Tendenzen im Landesmaßstab (8. 11. 1945), in: Zwischen Befreiung und Besatzung. Analysen des US-Geheimdienstes über Positionen und Strukturen deutscher Politik 1945, hrsg. von Ulrich Borsdorf und Lutz Niethammer, Wuppertal 1976, S. 229-253, hier S. $234 \mathrm{f}$. Zusammenfassend wurde noch einmal festgestellt, die „Ablchnung des Sozialismus sei das einzige Mittel, um die auseinanderstrebenden Elemente der Union zusammenzuhalten.“

96 Bei den Gemeindewahlen am 27. 1. 1946 erreichte die SPD 16,6 Prozent und die KPD nur 2,3 Prozent, bei den Wahlen auf Landkreisebene am 28. 4. 1946 22,9 und 3,9 Prozent und sogar bei den Stadtkreiswahlen am 26. 5. 1946 blieben die SPD (38,0 Prozent) und die KPD (6,9 Prozent) hinter der CSU (45,1 Prozent) zurück. Angaben nach der Tabelle bei Benz, Parteigündungen und erste Wahlen, in: ders. (Hrsg.), Neuanfang in Bayern, S. 35.

97 Eine Vielzahl von Belegen dafür bieten die Protokolle der Führungsgremien der CSU aus den Jahren 1946-1948; vgl. z. B. die Ausführungen August Haußleiters vor dem Landesausschuß am 6. 9. 1946, in: Protokolle und Materialien, S. $531 \mathrm{f}$. 
"Auf politischem Feld aber haben wir uns zu gemeinsamen Tun [und] zu gemeinsamer Abwehr des beide Konfessionen und Kirchen in gleicher Weise bedrohenden atheistischen Kommunismus zusammengefunden. Und daß dies ein Gebot der Stunde und angesichts der derzeitigen Weltlage eine dringende Notwendigkeit ist - ich glaube, das bedarf keines weiteren Beweises. “98

\section{d) Die totalitäre Erfabrung als Voraussetzung der Unionsgründung und ibre Instrumentalisierung in den Fübrungs- und Flügelkämpfen}

Auch wenn die Auseinandersetzung mit den sozialistischen Parteien in den letzten Monaten des Jahres 1945 mehr und mehr an Bedeutung gewann, darf man doch nicht übersehen, daß die CSU nicht nur als Gegengewicht zu SPD und KPD gegründet wurde, sondern auch und vor allem als Antwort auf die totalitäre Erfahrung des Dritten Reiches. Die nationalsozialistische Diktatur und die Folgen des Zweiten Weltkriegs bildeten den Ausgangspunkt aller wichtigen programmatischen Texte aus den Gründungstagen der bayerischen Unionspartei. Die kompromißlose Ablehnung von Ideologie und Herrschaftspraxis des NS-Staates ging Hand in Hand mit einer Absage an jede Form von Militarismus, Expansionismus oder übersteigertem Nationalismus, und auch in den Kristallisationskernen der CSU begriff man den Nationalsozialismus - wie jede Form totalitärer Herrschaft - als „schuldhafte Verirrung in materialistisches und kollektivistisches Denken und Verhalten"99. Freilich gingen die Mitbegründer der CSU nicht überall so weit wie im niederbayerischen Rottenburg, wo die Bevölkerung in einem Aufruf mit deutlichen Worten daran erinnert wurde, wie tief das NS-Regime in der deutschen Gesellschaft verankert gewesen sei:

„Die ganze Welt mußte sich erheben gegen diese abscheulichste Tyrannei, die je die Weltgeschichte geschaut. [...] Wie war das alles möglich? Gestehen wir es ein! Weil eine übergroße Mehrheit unseres Volkes, unpolitisch in jeder Form, gleichgültig und gedankenlos, ohne Ernst und Verantwortungsbewußtsein, ohne inneren sittlichen Halt und ohne bürgerlichen Mut, ohne Gefühl für die Wahrheit, Recht und Gerechtigkeit und staatsbürgerliche Wohlanständigkeit den Hetzern und Maulhelden nachlief, gleichgültig und sogar wohlgefällig einen Teil seiner besten Männer in den Kot ziehen und vergewaltigen ließ, gedanken- und verantwortungslos wirtschaftliche und moralische Bankrotteure auf den Schild erhob und ihre zeitweiligen Erfolge anbetete, dem Radikalismus und der brutalsten Vergewaltigung Andersdenkender laut zujubelte oder wenigstens heimlich zunickte, feige und unentschlossen sich vor jeder Drohung oder Gewaltanwendung niederbückte, um eines scheinbaren oder wirklichen Vorteiles willen Haltung und Gesicht verlor und - ohne Bedenken aus Eigennutz - nicht selten um eines Groschen Gewinnes oder Verlustes willen - die eigene Seele verkaufte."100

Solche Passagen, die sich in abgewandelter und abgeschwächter Form in vielen Programmen der ersten Stunde finden, waren nicht nur leere Worte oder ein Tribut an die amerikanische Besatzungsmacht. Sie waren auch Ausdruck eines ernsthaften Bemühens, die Überreste des Nationalsozialismus zu beseitigen. Daß man die Notwendigkeit einer politischen Säuberung nirgendwo bestritt und der Forderung nach $\mathrm{Be}$ -

98 ACSP, CSU-LL, Protokoll der Sitzung des Landesausschusses der CSU am 3. 7. 1954 in Landshut.

99 Kleinmann, Geschichte der CDU, S. 80; vgl. auch Maria Mitchell, Materialism and Secularism: CDU Politicians and National Socialism 1945-1949, in: JMH 67 (1995), S. 278-308.

100 BayHStA, NL Pfeiffer 144, Aufruf der Christlich-Sozialen Volkspartei in Bayern (Landkreis Rottenburg an der Laaber), undatiert; fast identische Formulierungen finden sich im Aufruf der CSU „An alle wahlfähigen Männer und Frauen des Landkreises Marktheidenfeld“ vom Dezember 1945/ Januar 1946; IfZ-Archiv, Fh 56. 
strafung der Schuldigen wiederholt erste Priorität einräumte ${ }^{101}$, hieß jedoch nicht, daß die führenden Vertreter der CSU den diesbezüglichen Initiativen der Militärregierung kritiklos gegenüberstanden. Im Gegenteil, die Frage der Entnazifizierung, deren Praxis beispielsweise von Josef Müller wiederholt abgelehnt und angeprangert wurde, entwickelte sich 1946 zu einem zentralen Konfliktfeld zwischen den Besatzungsbehörden und der bayerischen Unionspartei ${ }^{102}$.

Dessen ungeachtet gehörten die totalitäre Erfahrung und der daraus resultierende antinationalsozialistische Impuls sicherlich zu den Gegengewichten, die die zentrifugalen Wirkungen der Führungs- und Flügelkämpfe ausbalancierten. Verfolgung, Unterdrückung und Widerstand mußten zwar nicht unbedingt zur Veränderung bestehender politischer Überzeugungen führen; der gemeinsame Erfahrungshorizont erleichterte jedoch 1945 den Dialog zwischen Menschen, die vor 1933 in unterschiedlichen politischen Lagern gestanden hatten und nun in einer Partei zusammenarbeiten wollten, und ermöglichte später manchen Kompromiß.

Die Frage, in welchem Ausmaß die Mitbegründer der CSU mit dem nationalsozialistischen Regime in Konflikt geraten waren, ließ sich bisher nur ansatzweise beantworten $^{103}$. Einer breiteren Öffentlichkeit sind nur wenige prominente Politiker der bayerischen Unionspartei bekannt, die Verfolgungsmaßnahmen ausgesetzt gewesen waren oder der braunen Diktatur aktiven Widerstand entgegengesetzt hatten ${ }^{104}$. Dagegen weiß man kaum etwas darüber, wie die Träger der neuen Partei auf regionaler oder lokaler Ebene die NS-Zeit erlebt hatten, wie viele von ihnen in die Mühlen des Herrschafts- und Unterdrückungsapparats geraten waren oder welche Konzessionen sie den neuen Machthabern gegenüber gemacht hatten. Um etwas Licht in das Dunkel

101 So beispielsweise im ersten Punkt des Aufrufs der Bayerischen Christlich-Sozialen Union vom September oder Oktober 1945 (abgedruckt in: Protokolle und Materialien, S. $1708 \mathrm{ff}$.), der auf eine frühere Fassung im "Grundsatz-Programm einer Christlich-Demokratischen Volkspartei in Bayern" vom September 1945 zurückgeht (BayHStA, NL Pfeiffer 41). Zugleich wurde schon früh der Gedanke der Rehabilitierung und Integration von Mitläufern in die neu zu schaffende demokratische Gesellschaft geäußert. So heißt es in der Denkschrift Richard Jaegers vom Herbst 1945: „Ziel der Säuberung ist die Liquidation des Nationalsozialismus, nicht aber die der Nationalsozialisten. [...] Am Ende aber müssen alle Nationalsozialisten, an deren Händen keine Blutschuld klebt, für die Demokratie gewonnen werden." Lehrjahre, S. 159.

102 Vgl. dazu Lutz Niethammer, Die Mitläuferfabrik. Die Entnazifizierung am Beispiel Bayerns, Berlin, Bonn 1982, insbesondere S. 219-225, und Friedrich Hermann Hettler, Josef Müller („Ochsensepp“). Mann des Widerstandes und erster CSU-Vorsitzender, München 1991, S. 266-269, sowie Reuter, Anton Pfeiffer, S. 104-115. Vgl. auch die Diskussionen in den Führungsgremien der CSU, beispielsweise im Erweiterten Landesausschuß am 6. 7. 1946 oder im Landesausschuß am 4. 10. 1946; in: Protokolle und Materialien, S. 481-488 bzw. S. 648-670, sowie IfZ-Archiv, RG 260, 11/35-2/9, Bericht Erwin Wendts "Josef Mueller's (CSU Bavaria) View on Denazification" vom 18.6. 1946, und ACSP, NL Müller 1, Gedanken Josef Müllers zur Regierungsbildung im September 1945.

103 Becker, Gründung und Wurzeln, in: Geschichte einer Volkspartei, S. 71, kommt nach einer Untersuchung von Einzelfällen zu dem bedenkenswerten Schluß, die „persönlichen Lebensschicksale von Unionsgründern unterschiedlicher Herkunft in Bayern" zeigten "die bewußtseinsbildende Bedeutung der Auseinandersetzung mit dem Nationalsozialismus “. Ob man angesichts der Forschungslage aber so weit gehen kann zu behaupten, daß in den Reihen der Unionsgründer in Bayern „die Verhaltensformen des Widerstands" bzw. "der Verweigerung oder der Nichtanpassung" dominierten, ist fraglich.

104 Vgl. z. B. Hettler, Josef Müller, S. 56-199, oder Bernhard Zittel, Alois Hundhammer (1900-1974), in: Jürgen Aretz, Rudolf Morsey, Anton Rauscher (Hrsg.), Zeitgeschichte in Lebensbildern. Aus dem deutschen Katholizismus des 19. und 20. Jahrhunderts, Bd. 5, Mainz 1982, S. 253-265, hier S. 261 f. Einiges auch bei Klaus Schönhoven, Der politische Katholizismus in Bayern unter der NS-Herrschaft 1933-1945, in: Martin Broszat, Hartmut Mehringer (Hrsg.), Bayern in der NS-Zeit, Bd. 5: Die Parteien KPD, SPD, BVP in Verfolgung und Widerstand, München, Wien 1983, S. 541-646. 
zu bringen, sollen im folgenden die Biographien der Personen, die zwischen Januar und Oktober 1946 dem (Erweiterten) Landesausschuß der CSU angehörten, unter dieser Fragestellung untersucht werden. Der (Erweiterte) Landesausschuß war die erste landesweite Vertretung der bayerischen Unionspartei, noch bevor die Delegierten am 17. Mai 1946 erstmals zu einem ordentlichen Parteitag zusammentraten. Dort wurden alle wichtigen politischen und organisatorischen Probleme beraten, oft kontrovers diskutiert und vielfach auch entschieden. Dem (Erweiterten) Landesausschuß gehörten neben den Vertretern des Münchner Gründerkreises und den CSU-Mitgliedern, die Ministerpräsident Hoegner in sein Kabinett berufen hatte, Delegierte aus allen Bezirksverbänden an. Auch wenn diese auf Landesebene nicht weiter hervortraten, nahmen sie in ihrem Wirkungskreis oftmals wichtige Funktionen wahr; sie prägten das Bild der CSU in den Orts- und Kreisverbänden und agierten immer wieder als Stellvertreter der eigentlichen Kontrahenten in den Auseinandersetzungen, von denen die Frühgeschichte der CSU gekennzeichnet ist ${ }^{105}$.

Von den ca. 220 Delegierten und Gästen, die zwischen Januar und Oktober 1946 an den Tagungen des (Erweiterten) Landesausschusses teilnahmen, konnten 178 mehr oder weniger vollständig erfaßt werden. Davon kamen mindestens 95 Personen, also immerhin mehr als die Hälfte, in der einen oder anderen Weise mit dem nationalsozialistischen Herrschaftssystem in Konflikt ${ }^{106}$; bei weiteren legt die Biographie - politische Betätigung oder Aktivitäten in kirchlichen Organisationen - die Vermutung von Verfolgung oder nicht systemkonformem Verhalten nahe, ohne daß dies explizit nachzuweisen ist. 61 Männer und Frauen wurden zwischen 1933 und 1945 zum Teil wiederholt verhaftet und zumeist für mehrere Wochen in "Schutzhaft" gehalten. Oft genug beglichen die NS-Schergen dabei blutig und gnadenlos die Rechnungen, die aus der Zeit der sich mehr und mehr radikalisierenden politischen Auseinandersetzungen vor der Machtübernahme Hitlers offengeblieben waren. Alois Hundhammer beispielsweise, als Landtagsabgeordneter der BVP den neuen Machthabern besonders verhaßt, wurde im Konzentrationslager Dachau gequält und gedemütigt ${ }^{107}$, sein Fraktionskollege Alois Schlögl entging zwar der Verhaftung, ein Rollkommando der SA aus seinem Stimmkreis Landshut spürte ihn aber im Juni 1933 auf und mißhandelte den Direktor des Niederbayerischen Christlichen Bauernvereins so lange, bis er schwer verletzt und besinnungslos liegen blieb ${ }^{108}$.

Ein Teil der Verhafteten kam jedoch nicht mit einigen Wochen „Schutzhaft“ davon. Franz Fackler, Franz Liedig, Josef Müller, Emil Muhler ${ }^{109}$, Hans Nientimp und Franz Steber saßen für lange Monate, wenn nicht gar Jahre in den Gefängnissen oder Kon-

${ }^{105} \mathrm{Zu}$ Zusammensetzung, Funktion und Stellung des (Erweiterten) Landesausschusses der CSU vgl. S. $69 \mathrm{ff}$. Dort auch Angaben zur Erhebung der biographischen Daten, die - soweit nicht anders angegeben - aus dem Fundus stammen, der für das Dokumentationsprojekt „Protokolle und Materialien zur Frühgeschichte der Christlich-Sozialen Union“ zusammengetragen wurde. Alle Zahlenangaben beruhen auf eigenen Recherchen und Berechnungen.

106 Darunter sind die nationalsozialistischen Verfolgungsmaßnahmen in ihrer ganzen Bandbreite sowie alle nachweisbaren Aktivitäten, die gegen das Regime gerichtet waren, zu verstehen.

107 Vgl. Zittel, Alois Hundhammer, in: Aretz/Morsey/Rauscher (Hrsg.), Zeitgeschichte in Lebensbildern, Bd. 5, S. 261.

108 Vgl. Schönhoven, Politischer Katholizismus in Bayern, in: Broszat/Mehringer (Hrsg.), Bayern in der NS-Zeit, Bd. 5, S. 643.

109 Vgl. Otto Gritschneder, Die Akten des Sondergerichts über Stadtpfarrer Dr. Emil Muhler, in: Beiträge zur altbayerischen Kirchengeschichte 29 (1975), S. 125-149. 
zentrationslagern des Dritten Reiches ein. Steber trug schwere gesundheitliche Schäden davon ${ }^{110}$, Müller wurde wiederholt mit dem Tode bedroht ${ }^{111}$, und es grenzt an ein Wunder, daß er nicht dem Furor der Nationalsozialisten zum Opfer fiel, der noch in den letzten Tagen des Krieges so viele Widerstandskämpfer und Regimegegner das Leben kostete ${ }^{112}$.

Soweit feststellbar, waren darüber hinaus 46 Personen „nur“ oder zusätzlich von beruflicher Benachteiligung betroffen. Die Palette der Diskriminierungen reichte dabei von der Nichtberücksichtigung bei Beförderungen über disziplinarische Maßnahmen und Strafversetzungen bis hin zur Entlassung und zum Verlust der beruflichen Existenz. Besonders hart traf es hauptamtliche Mitarbeiter von politischen Parteien oder gesellschaftlichen Organisationen, die nach 1933 entweder aufgelöst oder in neue Strukturen überführt worden waren. Funktionäre der Christlichen Gewerkschaften wie Hugo Karpf, Lorenz Sedlmayr, Albert Kaifer und Heinrich Krehle hatten ebenso ihren Arbeitsplatz verloren wie führende Repräsentanten der Bayerischen Christlichen Bauernvereine oder die wenigen Angestellten im Generalsekretariat der BVP unter Anton Pfeiffer. Daß dieser Personenkreis oft längere Zeit, ja manchmal mehrere Jahre, arbeitslos war, lag nicht nur an der schwierigen Wirtschaftslage. Mindestens genauso schwer wog die Tatsache, daß viele Arbeitgeber aus Furcht vor Repressalien davor zurückschreckten, ehemalige „Gewerkschafts-Bonzen “113 oder führende Männer und Frauen der „Systemzeit“ einzustellen. Ein Teil der nun stellungslosen Politiker oder Verbandsfunktionäre kam in der katholischen Kirchenverwaltung unter $^{114}$, andere - beispielsweise Anton Pfeiffer, der als Beamter unter besonderem Druck der neuen Machthaber stand, oder Joseph Baumgartner, der sich eine neue Existenz als Versicherungsangestellter aufzubauen versuchte - beugten sich vor dem NSRegime und bekundeten wenigstens äußerlich ihre Loyalität ${ }^{115}$. Wer dazu nicht bereit war, über kein Vermögen verfügte und nicht in seinen angestammten Beruf zurückkehren konnte, mußte demütigende, schlecht bezahlte Hilfsarbeiten übernehmen oder sich in eine ökonomische Nische zurückziehen. So konnten beispielsweise Lorenz Sedlmayr und Alois Hundhammer ein Einzelhandelsgeschäft in München über-

110 Vgl. Franz Heubl, Jugend und Demokratie. Erfahrungen nach dem Zusammenbruch, in: Christoph Böhr (Hrsg.), Jugend bewegt Politik. Die Junge Union Deutschlands 1947 bis 1987, Krefeld 1988, S. 69-80, hier S. 73. Steber war Reichsführer der katholischen Sturmschar gewesen und wurde 1937 vom Volksgerichtshof zu fünf Jahren Zuchthaus verurteilt.

111 ACSP, NL Müller 198, Rede Josef Müllers am 28. 5. 1948 in Würzburg.

$112 \mathrm{Zu}$ den terroristischen Auswüchsen des NS-Regimes in der Endphase des Krieges vgl. Henke, Amerikanische Besetzung, S. 844-861.

113 BayHStA, NL Sedlmayr 1, Lebenserinnerungen Lorenz Sedlmayrs, abgeschlossen 1968.

114 Beispielsweise Heinrich Krehle, 1930-1933 Landessekretär der Christlichen Gewerkschaften Bayerns, der nach mehrmonatiger Arbeitslosigkeit 1934 bei einem katholischen Kirchensteueramt unterkam. Bei Hugo Karpf hinterließ die Erinnerung daran einen bitteren Beigeschmack: „Die Kirche, d. h. das Würzburger Ordinariat, hat mir in diesen zwölf Jahren [1933-1945] keine Tätigkeit, etwa in einem Kirchensteueramt o. ä., verschafft [.. ] und sich auch sonst mir gegenüber doch recht zurückgehalten, so daß manchmal das bittere Gefühl aufkommen konnte: Der Mohr hat seine Schuldigkeit getan, der Mohr kann gehen. "Erinnerungen Hugo Karpfs, in: Abgeordnetete des Deutschen Bundestages. Aufzeichnungen und Erinnerungen, Bd. 3, Boppard am Rhein 1985, S. 88-139, hier S. 105.

115 Vgl. Reuter, Anton Pfeiffer, S. 67 f., bzw. BAK, NL Schäffer 17, Bl. 9 f., Bayerische Versicherungsbank - Allianz - AG an Fritz Schäffer vom 28.3. 1946 und dessen Antwortschreiben vom 29.3. 1946, sowie Bl. $26 \mathrm{ff}$., zusammenfassender und kommentierter Bericht über ein Schreiben Joseph Baumgartners vom November 1933. 
nehmen ${ }^{116}$, während Hugo Karpf zunächst für den katholischen Begräbnisverein Aschaffenburg und später - obwohl gelernter Schneider - nur als Hilfsarbeiter in einer Textilfabrik tätig war ${ }^{117}$.

Doch die Unsicherheit, erneut in die Fänge des Regimes zu geraten, blieb auch nach der Haftentlassung und einer mehr oder weniger gelungenen beruflichen Neuorientierung ein ständiger Begleiter. Rupert Berger, der sich als Vorsitzender der BVP in Traunstein unter den dortigen Nationalsozialisten viele Feinde gemacht hatte, tauchte 1933 zunächst für einige Wochen unter und wurde dann, nachdem er sich den Behörden gestellt hatte, für mehrere Monate im KL Dachau inhaftiert. Da er seine Stellung als Angestellter bei der Allgemeinen Ortskrankenkasse in Traunstein verloren hatte, pachtete er nach seiner Entlassung ein kleines Kolonialwarengeschäft. Doch Berger war den örtlichen NS-Größen nach wie vor ein Dorn im Auge: Im Frühjahr 1934 verübte die SA einen Sprengstoffanschlag auf seinen Laden, der dabei schwer beschädigt wurde. Zudem zwang man den späteren Oberbürgermeister von Traunstein und langjährigen CSU-Landtagsabgeordneten, seine Heimatstadt zu verlassen. Erst als Gastwirt in Regensburg und Landshut blieb Berger von Übergriffen weitgehend verschont ${ }^{118}$.

Neben der Furcht vor immer neuen Verfolgungsmaßnahmen und neben der oft großen materiellen Unsicherheit wogen die soziale Isolation und die Ausgrenzung besonders schwer. Hugo Karpf, Gewerkschaftssekretär und BVP-Reichstagsabgeordneter, dachte noch 1983 mit Bitterkeit an diese Jahre zurück:

„Von vielen in Aschaffenburg wurde ich nun wie ein Aussätziger behandelt, so daß ich mit meiner Familie lange lieber nicht auf öffentlichen Wegen spazierenging. Empörend war nicht so sehr das Verhalten der,Alten Kämpfer'; peinlich war, wie nicht wenige, auch von unserer Seite, zu den Nazis überschwenkten und erklärten, schon immer so gedacht zu haben. Man wurde nun von allen Seiten gemieden und konnte in einer kleinen Stadt, wo jeder jeden kannte, praktisch kaum mehr Kontakte zu Gleichgesinnten halten." ${ }^{119}$

Von den Personen, die 1946 an den Sitzungen des (Erweiterten) Landesausschusses teilnahmen, hatten mindestens zehn der braunen Diktatur aktiven, organisierten Widerstand entgegengesetzt, für den sie zum Teil teuer bezahlen mußten. So zählten Franz Fackler, Georg Gamperl, Albert Kaifer, Josef Messmer und Josef Stürmann zum Kreis der bayerischen Monarchisten um den 1945 hingerichteten Josef Zott und den kurz nach Kriegsende verstorbenen Adolf von Harnier, die sich die Restauration einer konstitutionellen Monarchie auf christlich-sozialer Basis auf ihre Fahnen geschrieben hatten ${ }^{120}$. Im August 1939 zerschlug die Gestapo diese Gruppe und verhaftete 125 Personen, darunter auch Gamperl, Kaifer, Messmer, Stürmann und Fackler; Fackler saß bis 1944 in Untersuchungshaft, bevor er vom Volksgerichtshof zu zwei

116 BayHStA, NL Sedlmayr 1, Lebenserinnerungen, bzw. Zittel, Alois Hundhammer, in: Aretz/Morsey/Rauscher (Hrsg.), Zeitgeschichte in Lebensbildern, Bd. 5, S. 262.

117 Vgl. Karpf, Erinnerungen, in: Abgeordnetete des Deutschen Bundestages, Bd. 3, S. $104 \mathrm{f}$.

118 Traunsteiner Wochenblatt vom 11. 2. 1958: "Rupert Berger war ein Kämpfer für echte Freiheit“.

119 Karpf, Erinnerungen, in: Abgeordnetete des Deutschen Bundestages, Bd. 3, S. 104; ähnliches wußte auch Maria Probst zu berichten; vgl. Ursula Männle, Maria Probst (1902-1967), in: Aretz/Morsey/ Rauscher (Hrsg.), Zeitgeschichte in Lebensbildern, Bd. 7, S. 113-127, hier S. 114.

120 Auch die späteren CSU-Politiker Hans und Heinrich Pflüger gehörten diesem Kreis an; Heinrich Pflüger wurde 1944 vom Volksgerichtshof zu fünf Jahren Zuchthaus verurteilt. Der Harnier-Kreis nahm auch mit Alois Hundhammer Kontakt auf, der sich jedoch aus Vorsicht schnell von dieser Gruppierung distanzierte. Vgl. Christina M. Förster, Der Harnier-Kreis. Widerstand gegen den Nationalsozialismus in Bayern, Paderborn u. a. 1996, S. 156 f., S. 320, S. 517 und S. 549. 
Jahren und drei Monaten Gefängnis verurteilt wurde ${ }^{121}$. Josef Müller dagegen arbeitete nicht in einer der stark bayerisch-etatistisch ausgerichteten Gruppierungen gegen das NS-Regime, sondern führte im Auftrag der national-konservativen Militäropposition, der auch sein späterer Vertrauter und Mitstreiter Franz Liedig zuzurechnen ist, Sondierungsgespräche mit Vertretern der britischen Regierung unter Vermittlung des Vatikans. Müller wurde 1943 verhaftet und - obwohl vom Reichskriegsgericht freigesprochen - bis Kriegsende in verschiedenen Konzentrationslagern und Gefängnissen inhaftiert; im Mai 1945 befreiten ihn amerikanische Truppen zusammen mit Liedig und anderen Sondergefangenen der SS im Pustertal ${ }^{122}$.

Von 15 weiteren Mitgliedern des (Erweiterten) Landesausschusses, die das Glück hatten, nach 1933 einer Verhaftung zu entgehen, ist bekannt, daß sie von anderen Verfolgungsmaßnahmen wie Überwachung und Polizeiaufsicht, Vermögensbeschlagnahme $^{123}$, Haussuchungen und Verhören, Zensur und Redeverbot oder körperlichen Mißhandlungen betroffen waren oder durch kritische Äußerungen, kirchliches Engagement und Hilfe für politisch oder rassisch Verfolgte mit dem Regime in Konflikt gerieten. Mit Maria Deku, Berta Dötsch, Elisabeth Hahn und Maria Probst ${ }^{124}$ mußten vier zum Teil selbst verfolgte Mitbegründerinnen der CSU zudem mit ansehen, wie nahe Angehörige verhaftet oder beruflich benachteiligt wurden. Emigranten sucht man dagegen nahezu vergeblich. Lediglich Georg Gamperl, 1946 bis 1949 Müllers Statthalter im CSU-Bezirksverband Oberpfalz, und der spätere Schwandorfer Landtagsabgeordnete Josef Krempl entzogen sich dem Zugriff des Unterdrückungsapparats vorübergehend durch Flucht ins Ausland.

Erwähnenswert sind überdies zwei weitere Fälle: Friedrich Wilhelm von Prittwitz und Gaffron, ein überzeugter Demokrat, legte 1933 aus Protest gegen die Machtübernahme der Nationalsozialisten sein Amt als Botschafter in den USA nieder ${ }^{125}$; der Journalist Hans Geiselberger, der zeitweilig als Sekretär der BVP-Reichstagsfraktion fungiert hatte, wurde in den Wirren der letzten Kriegstage von einem SS-Standgericht zum Tode verurteilt, konnte sich jedoch der Vollstreckung des Urteils entziehen ${ }^{126}$.

121 Vgl. James Donohoe, Hitler's conservative opponents in Bavaria 1930-1945. A study of Catholic, monarchist and separatist anti-Nazi activities, Leiden 1961, S. 130-146 und S. 268-311, und Hildegard Vieregg, Wächst Gras darüber? München: Hochburg des Nationalsozialismus und Zentrum des Widerstands, München 1993, S. 120-126, sowie Wilhelm Seutter von Lötzen, Bayerns Königstreue im Widerstand. Erinnerungen 1933-1964, Feldafing o. J. (1978). Nach der bei Donohoe, Conservative opponents, S. $279 \mathrm{f}$,, abgedruckten Liste fungierte Kaifer im Zott-Harnier-Kreis als „Hauptkreisleiter" für Schwaben, Franz Fackler als Mitglied der Landesleitung und stellvertretender "Kreisleiter" von München.

122 Vgl. dazu Josef Müller, Bis zur letzten Konsequenz. Ein Leben für Frieden und Freiheit, München 1975, S. 80-281; die Befreiung der „Sonderhäftlinge“ in Südtirol schildert Henke, Amerikanische Besetzung, S. 875-881.

123 Eine Liste mit den Namen führender BVP-Politiker, deren Konten Ende Juni 1933 auf Anordnung der Bayerischen Politischen Polizei gesperrt wurden, findet sich im BAK, NL Lex 16, Schreiben der Direktion der Bayerischen Hypotheken- und Wechselbank vom 26. 6. 1933.

124 BAK, NL Probst 599, mehrere Versionen des Lebenslaufs von Maria Probst, die mit dem 1945 gefallenen ehemaligen BVP-Landtagsabgeordneten Alfred Probst verheiratet gewesen war.

125 Telegramm Friedrich Wilhelm von Prittwitz und Gaffrons an Reichsaußenminister Konstantin Freiherr von Neurath vom 11.3. 1933, abgedruckt in: Günter Buchstab, Brigitte Kaff, Hans-Otto Kleinmann (Hrsg.), Verfolgung und Widerstand 1933-1945. Christliche Demokraten gegen Hitler, Düsseldorf 1986, S. 123.

${ }^{126} \mathrm{Zu}$ Hans Geiselberger vgl. auch Norbert Frei, Nationalsozialistische Eroberung der Provinzpresse. Gleichschaltung, Selbstanpassung und Resistenz in Bayern, Stuttgart 1980, S. $231 \mathrm{ff}$. 
Betrachtet man den untersuchten Personenkreis genauer, ergibt sich folgendes Bild: Von den 95 Mitgliedern des (Erweiterten) Landesausschusses der CSU, die in die Mühlen des nationalsozialistischen Verfolgungsapparats geraten waren, bekannten sich 79 zum katholischen und zwölf zum evangelischen Glauben ${ }^{127}$. Mindestens 53 Personen hatten vor 1933 der BVP und sechs dem Zentrum angehört; davon hatten 43 ein Amt in diesen Parteien bekleidet oder ein Mandat auf kommunaler, Landes- oder Reichsebene ausgeübt ${ }^{128}$. Diese Zahlen verweisen nicht nur auf das Gewicht der ehemaligen BVP-Mitglieder in der Formierungsphase der CSU. Sie verdeutlichen auch, in welchem Ausmaß deren von einer spezifisch bayerischen Variante des politischen Katholizismus geprägte Orientierung durch die Erfahrung von Resistenz, Haft und Verfolgung überformt wurde, zumal ein erheblicher Teil des hier untersuchten Personenkreises 1933 entweder noch zum politischen Nachwuchs gehörte oder erst dabei war, in hohe Ämter aufzusteigen. Hunderte Funktions- und Mandatsträger der BVP wurden im März 1933 in „Schutzhaft“ genommen oder im Juni 1933 vorübergehend verhaftet, weil die NS-Machthaber die Auflösung der BVP erzwingen wollten ${ }^{129}$. Die Mitglieder und Anhänger der BVP blieben jedoch trotz allem zumeist den weltanschaulichen Grundlagen und Zielen ihrer Partei verpflichtet und wurden von den Nationalsozialisten stets mit Argwohn betrachtet. Sie reagierten „auf die Zerschlagung ihrer Organisation in der Regel mit Rückzug und Distanzierung“, verschanzten „sich meist hinter den Barrikaden des kirchenkatholischen Verbands- bzw. Pfarreilebens“ und nahmen „vielfach von dort in Form individueller und kollektiver Gesinnungsopposition den weltanschaulichen Kleinkrieg gegen das Regime auf"130. So war es keine Überraschung, daß sich viele ehemalige BVP-Politiker erneut in Gefängnissen und Konzentrationslagern wiederfanden, als nach dem gescheiterten Attentat auf Hitler am 20. Juli 1944 mit den Aktionen "Gitter“ und „Gewitter“ eine große Verhaftungswelle ausgelöst wurde ${ }^{131}$.

Zwar gingen die Nationalsozialisten gegen Sozialdemokraten oder Kommunisten noch wesentlich brutaler vor als gegen die Parteien des bürgerlichen Lagers - von den Reichstagsabgeordneten der KPD starben zwischen 1933 und 194542 an den Konse-

127 Bei vier Personen ließ sich die Konfession nicht ermitteln. 15 Laien hatten vor 1933 nachweislich aktiv in katholischen Organisationen mitgearbeitet, bei mindestens vier Personen ist eine enge Bindung an die evangelische Kirche feststellbar. Unter den sonstigen Verbandsmitgliedschaften fällt der hohe Anteil an Mitgliedern der Christlichen Gewerkschaften auf, denen wenigstens 15 Personen angehört hatten.

128 Lediglich elf Personen waren vor 1933 Mitglieder anderer Parteien gewesen. Vier hatten - soweit feststellbar - dem Bayerischen Bauernbund, einer dem Bayerischen Landbund, zwei der DVP, zwei der DDP/StP und zwei der SPD angehört.

129 BayHStA, Stk 106523, „Verzeichnis der anläßlich der Aktion gegen die Bayerische Volkspartei in Schutzhaft genommenen Personen“, angefertigt von der Bayerischen Politischen Polizei, vom 1. 8. 1933; diese Liste enthält die Namen von rund 2000 BVP-Politikern.

130 Förster, Harnier-Kreis, S. 128.

131 Vgl. Schönhoven, Politischer Katholizismus in Bayern, in: Broszat/Mehringer (Hrsg.), Bayern in der NS-Zeit, Bd. 5, S. 546 ff. und S. 576-583. Zur politischen Verfolgung der bayerischen Landtagsabgeordneten vgl. Martin Schumacher (Hrsg.), Das Ende der Parlamente 1933 und die Abgeordneten der Landtage und Bürgerschaften der Weimarer Republik in der Zeit des Nationalsozialismus. Politische Verfolgung, Emigration und Ausbürgerung 1933-1945. Ein biographischer Index, Düsseldorf 1995, S. 21*-25\%. Zu den Aktionen "Gitter" und "Gewitter" vgl. Martin Schumacher (Hrsg.), M. d. R. Die Reichstagsabgeordneten der Weimarer Republik in der Zeit des Nationalsozialismus. Politische Verfolgung, Emigration und Ausbürgerung 1933-1945. Eine biographische Dokumentation, Düsseldorf 3., erheblich erweiterte und überarbeitete Auflage 1994, S. $38 \%$ f. 
quenzen der erlittenen Verfolgung, von den Reichstagsabgeordneten der SPD 38, von den Reichstagsabgeordneten von BVP, Zentrum und verwandten Parteien dagegen „nur" sieben ${ }^{132}$. Gleichwohl: Für einen Politiker der BVP, der sich als Mitglied einer staatstragenden Partei gesehen hatte, in seiner engeren Heimat zu den geachteten Honoratioren zählte und den vielleicht sogar punktuelle Sympathien mit der NSDAP verbanden, mußten staatliche Willkür und der Terror von SA und SS als etwas schier Unbegreifliches erscheinen.

Ohne einer fundierten sozialgeschichtlichen Untersuchung der Unionsgründung vorgreifen zu können, lassen sich aus dem vorliegenden Material einige vorläufige Schlüsse ziehen, die für die Interpretation der Frühgeschichte der bayerischen Unionspartei von großer Bedeutung sind. Wie die programmatischen Texte aus der Gründungsphase und die politische Praxis der ersten Nachkriegsjahre zeigen, bewirkte die konkrete Verfolgungserfahrung bei vielen Mitbegründern der CSU eine Abkehr von allzu antidemokratischem, reaktionärem und autoritärem Gedankengut, von dem die BVP zumindest teilweise ebenso geprägt gewesen war wie die nationalliberalen oder protestantisch-konservativen Parteien der Weimarer Republik. Das heißt nicht, daß die Form der pluralistischen, freiheitlich-demokratischen Regierungs- und Gesellschaftssysteme westlicher Prägung nun unbedingt bejaht wurde ${ }^{133}$; die Achtung von unveräußerlichen Grund- und Menschenrechten, Rechtssicherheit und Rechtsstaatlichkeit gewannen jedoch einen bisher nicht gekannten Stellenwert ${ }^{134}$. Dieses Fundament für einen demokratischen Neubeginn wurde bei einigen Mitbegründern der bayerischen Unionspartei durch eine dauerhafte antifaschistische Gesinnung verstärkt, die Politikern wie Josef Müller sogar während des Kalten Krieges das Gespräch mit Vertretern der radikalen Linken ermöglichte ${ }^{135}$. Müller entwickelte sich wie sein großer Gegenspieler Hundhammer mit den Jahren zu einer Art moralischer Instanz in der CSU; beide erhoben immer wieder ihre Stimme und protestierten, wenn politisch kompromittierte Persönlichkeiten mit Ämtern oder Mandaten betraut werden sollten ${ }^{136}$.

132 Vgl. ebenda, S. 44*; unter den Zahlenangaben für Zentrum und BVP sind auch betroffene Reichstagsabgeordnetc des CSVD, des Volksdienstes und der Christlich-Föderalistischen Partei subsumiert.

${ }^{133}$ Vgl. z. B. die am Primat der Stabilität orientierten Vorstellungen in den Denkschriften von Richard Jaeger (in: Lehrjahre, S. 172-177) und Gerhard Kroll (IfZ-Archiv, ED 720 Smlg. Mintzel 1, „Christliche Union. Bamberger Denkschrift zur Schaffung einer politischen Einheitsfront aller Christen Deutschlands").

${ }^{134}$ Vgl. z. B. das Kapitel „Recht und Staat“ in der Denkschrift Richard Jaegers, in: Lehrjahre, S. 166-169.

${ }^{135}$ So berichtete Ernst Nieckisch, der im Rahmen einer Vortragsreihe für die Nationale Front der Blockparteien und Massenorganisationen der DDR im März 1950 auch Josef Müller besuchte, Ministerpräsident Otto Grotewohl: „Die Presse nahm von meinem Erscheinen in Bayern Notiz. Durch einen Mittelsmann erhielt ich eine Einladung zu dem bayerischen Justizminister und stellvertretenden Ministerpräsidenten Dr. Josef Müller. Dr. Müller empfing mich im Justizministerium. Bisher war ich mit ihm nicht bekannt, doch begrüsste er mich wie einen alten Bekannten. Er habe seinerzeit meine Broschüre ,Hitler, ein deutsches Verhängnis' gelesen; es habe ihm sehr imponiert, dass ich trotz dieser Broschüre in Deutschland geblieben sei und mich der Rache der Nazi ausgesetzt habe. Er wisse von meiner Minierarbeit gegen das Hitlerregime bis zu meiner Verhaftung 1937 und von meiner Verurteilung zu lebenslänglichem Zuchthaus. Da er selbst ein Verfolgter war, genoss ich wie selbstverständlich seine Sympathie." Stiftung Archiv der Parteien und Massenorganisationen der DDR im Bundesarchiv, NL Nieckisch 517, Bericht Ernst Nieckischs über ein Gespräch mit Josef Müller im März 1950. Ich danke Birgit Rätsch für eine Kopie dieses Dokuments.

${ }^{136}$ BAK, NL Guttenberg 248, Bl. 219-230, Protokoll der außerordentlichen Sitzung des Vorstands des CSU-Bezirksverbands München am 8. 9. 1958; ACSP, CSU-LL, Protokoll der Sitzung des geschäftsführenden Landesvorstands am 30.11. 1963. 
Dagegen blieb die Kommunikation zwischen den Vertretern der verschiedenen Traditionsstränge des Widerstands gegen den Nationalsozialismus in der CSU schwierig. So betrachteten die ehemaligen Mitglieder prononciert bayerischer Widerstandszirkel, die sich im Juli 1946 zur „Widerstandsgruppe der Christlich-Sozialen Union“ zusammengeschlossen und - ihrem mehrdeutigen Namen gemäß - mit Alois Hundhammer einen erklärten Gegner der Parteiführung um den Ochsensepp zu ihrem Vorsitzenden gewählt hatten ${ }^{137}$, Aktivisten der Militäropposition wie Müller und Liedig mit Skepsis und unterstellten ihnen Sympathien für Preußentum und Zentralismus. Die „bayerische Frage" überlagerte auch in diesem Fall gemeinsame Erfahrungen und ähnliche programmatische Vorstellungen in anderen Bereichen, die mit dem Bekenntnis der „Widerstandsgruppe“ zu einem „Sozialismus aus christlichem Verantwortungsgefühl“ ${ }^{138}$, einem Erbe des Zott-Harnier-Kreises, durchaus gegeben waren ${ }^{139}$.

Verglichen mit der Zahl der NS-Gegner scheint die Zahl der Delegierten, die der NSDAP bzw. anderen NS-Organisationen angehört hatten oder von der amerikanischen Militärregierung als politisch belastet angesehen wurden, gering gewesen zu sein. 17 Mitglieder des (Erweiterten) Landesausschusses waren der NSDAP respektive einer dieser Partei angegliederten, von ihr überwachten oder beeinflußten Gruppierung beigetreten, elf weiteren verweigerte die Militärregierung aus meist nicht näher bekannten politischen Gründen das Vertrauen ${ }^{140}$. Soweit sich dies feststellen läßt - und solche Angaben sind aus verständlichen Gründen stets besonders schwer zu ermitteln -, nahmen mit Bernhard Burges, Karl Gronwald und Otto Schedl lediglich drei ehemalige Parteigenossen an den Sitzungen des (Erweiterten) Landesausschusses teil ${ }^{141} ; \mathrm{Au}$ gust Wilhelm Schmidt hatte seit 1941 zu den Anwärtern der NSDAP gezählt. Fritz Gerathewohl, Richard Jaeger, Georg Nentwig und Paul Nerreter gehörten als Mitglieder oder Anwärter der SA ebenso zum Personenkreis der aus formalen Gründen politisch Belasteten ${ }^{142}$ wie sieben weitere CSU-Politiker der ersten Stunde, die den Gliede-

137 ACSP, NL Müller 20, „Protokoll über die Sitzung der politisch Verfolgten des Bezirksverbands München der Christlich-Sozialen Union“ am 5. 7. 1946, und NL Müller 48, Einladung zu einer Tagung der „Widerstandsgruppe der Christlich-Sozialen Union“ am 11. 5. 1947 vom 30. 4. 1947. Zur sogenannten Bayerischen Widerstandsbewegung allgemein IfZ-Archiv, RG 84, 747/30, Bericht für Robert Murphy vom 23. 2. 1946.

138 ACSP, NL Müller 20, „Protokoll über die Sitzung der politisch Verfolgten des Bezirksverbands München der Christlich-Sozialen Union“ am 5.7. 1946. Zur Kritik an der "Generalstabs- und OKW-Clique im Landessekretariat“ ACSP, NL Müller 18, Aktennotiz vom 5. 10. 1946 und Achim Oster an Karl Theodor Freiherr von und zu Guttenberg vom 9. 9. 1946.

139 ACSP, CSU-LTF II/1, 15-12/1, Resolution der „Widerstandsgruppe“ in der CSU zum Fall Josef Müller vom 12.11. 1946.

140 Darüber hinaus gibt es Hinweise auf eine politische Belastung der späteren CSU-Landtagsabgeordneten Josef Prüschenk und Pius Haugg. BayHStA, NL Schwalber 50, Bericht Josef Schwalbers über die Arbeit des Wahlprüfungsausschusses während der Sitzung des Landtags am 25.6. 1947. Pius Haugg, dem man vorwarf, 1943 einen Vorgesetzten denunziert zu haben, wurde jedoch 1949 in einem Spruchkammerverfahren rehabilitiert. Vgl. Bernd Lerch, Klaus Stephan, Josef Walter König, Eine Stadt und ihre Christlich-Soziale Union. Donauwörth 1945-1995, Donauwörth 1995, S. $74 \mathrm{f}$.

${ }^{141}$ Bernhard Burges und Otto Schedl waren der NSDAP 1937 beigetreten, für Karl Gronwald ließ sich kein Beitrittsdatum ermitteln. Georg Barth gab 1946 an, 1933-1935 ohne sein Wissen als NSDAPMitglied geführt worden zu sein. Zum Fall Barth, der sich nicht genau klären ließ, vgl. das Protokoll der Sitzung des Landesarbeitsausschusses der CSU am 13.6. 1946 in München, in: Protokolle und Materialien, S. $372 \mathrm{f}$.

142 Andreas Tremmel, Mitbegründer der CSU in Straubing und 1945 kurzzeitig Oberbürgermeister der Stadt, wurde im Juli von den Besatzungsbehörden seines Amtes mit der Begründung enthoben, er sei 
rungen der NSDAP und anderen Organisationen unter NS-Einfluß beigetreten waren $^{143}$; dazu kam der ehemalige BVP-Reichstagsabgeordnete Hans Ritter von Lex, der 1933 vorübergehend bei der NSDAP-Reichstagsfraktion hospitiert hatte ${ }^{144}$.

Wer jedoch erwartet, regelrechte NS-Aktivisten im (Erweiterten) Landesausschuß zu finden, wird enttäuscht. Dort waren lediglich Mitläufer vertreten, die unter den Bedingungen totalitärer Herrschaft entweder dem „strukturell-bedingten Opportunismus “ ${ }^{145}$ erlegen und mit dem Eintritt in eine der zahlreichen NS-Organisationen den Weg des geringsten Widerstandes gegangen waren oder die partiell mit den Ideen des Nationalsozialismus sympathisiert, sich jedoch bald wieder davon abgewandt hatten ${ }^{146}$. Paul Nerreter beispielsweise, Mitbegünder der CSU in Nürnberg, war 1933 der SA beigetreten, weil er „einen positiven Versuch mit dem Nationalsozialismus machen wollte “147. Das Experiment währte bis 1935; dann schied Nerreter aus dieser nationalsozialistischen Kampforganisation aus. Die Militärregierung reagierte auf diese kurze Liaison Nerreters zwiespältig. Zwar gewährte sie dem Juristen 1945 die Zulassung als Rechtsanwalt, lehnte ihn aber einige Monate später sowohl als Kandidat für den Bayerischen Beratenden Landesausschuß als auch als Landrat ab; gegen seine Mitarbeit beim Aufbau der CSU hatte sie dagegen nichts einzuwenden.

Von Bedeutung ist darüber hinaus die Tatsache, daß von den 28 Mitgliedern des (Erweiterten) Landesausschusses, die aus formalen Gründen politisch belastet oder der Militärregierung suspekt waren, immerhin 14 auch auf die eine oder andere Weise mit dem NS-Regime in Konflikt gekommen waren. So war etwa Fritz Gerathewohl, Lektor für Sprechkunde und Rhetorik an der Universität München und Mitbegünder der DDP in Bayern, 1933 in die SA eingetreten, ohne sich dort besonders zu engagieren, und hatte sich auch bereit gefunden, im Auftrag der DAF zu arbeiten ${ }^{148}$. Dennoch galt er weiterhin als politisch unzuverlässig und blieb von Beförderungen ausgeschlossen. 1938 wurde Gerathewohl wegen fehlender Aktivitäten aus der SA entfernt, in den Jahren 1940 und 1942 erhielt er Redeverbot durch die Gauleitung der NSDAP für München und Oberbayern. Bei Kriegsende zählte Gerathewohl zu den entschlossenen Gegnern der Nationalsozialisten. Als die Freiheitsaktion Bayern zum Sturz der morsch gewordenen Tyrannis aufrief, war Gerathewohl unter denen, die ihr Leben

förderndes Mitglied der SS gewesen und habe dies in seinem Fragebogen verschwiegen. Ein Militärgericht sprach Tremmel wenig später aus Mangel an Beweisen frei; Tremmel hatte angegeben, lediglich aufgrund eines Mißverständnisses als förderndes SS-Mitglied geführt worden zu sein. Regensburger Post vom 13. 7. 1945: „Bankier Tremmel freigesprochen“.

${ }^{143}$ Diese Einstufung nach der Liste in der Direktive Nr. 24 des Alliierten Kontrollrats vom 12. 1. 1946; in: Sammlung der vom Alliierten Kontrollrat und der amerikanischen Militärregierung erlassenen Proklamationen, Gesetze, Verordnungen, Befehle, hrsg. von Ruth Hemken, Bd. 1, Stuttgart o. J. Mitgliedschaft in der DAF blieb unberücksichtigt.

144 Vgl. Peter Hubert, Uniformierter Reichstag. Die Geschichte der Pseudo-Volksvertretung 1933-1945, Düsseldorf 1992, S. $75 \mathrm{f}$.

${ }^{145}$ Hans Buchheim, Die Lebensbedingungen unter totalitärer Herrschaft, in: Karl Forster (Hrsg.), Möglichkeiten und Grenzen für die Bewältigung historischer und politischer Schuld in Strafprozessen, Würzburg 1962, S. 89-106, hier S. 95.

146 Vgl. auch das Fallbeispiel Ansbach bei Woller, Gesellschaft und Politik, S. 192.

${ }_{147}$ Protokoll der Sitzung des Vorläufigen Landesausschusses der CSU am 25. 2. 1946 in München, in: Protokolle und Materialien, S. 31.

${ }^{148}$ Vgl. Fritz Gerathewohl, Jederzeit redebereit, hrsg. von der DAF, München o. J.; vgl. auch das Vorwort zu Gerathewohls 1934 in zweiter Auflage erschienenem Werk Die Quellen erfolgreicher Lebensführung, aus dem sich deutliche Konzessionen an die neuen Machthaber herauslesen lassen. 
für diese Sache einsetzten ${ }^{149}$. Dennoch wurde er nicht nur von der Militärregierung als Universitätslektor entlassen, sondern auch aus der eigenen Partei heraus angefeindet, der er als für die Schulung politischer Redner zuständiger Abteilungsleiter in der Landesgeschäftsstelle diente ${ }^{150}$.

Auch wenn diese Angaben über die politische Belastung von Mitgliedern des (Erweiterten) Landesausschusses unvollständig sein sollten $^{151}$, so kristallisiert sich doch ein Punkt heraus: Der Anteil politisch Belasteter in den Führungsgremien der CSU war in der unmittelbaren Nachkriegszeit vergleichsweise gering. Schon die Zusammensetzung der Führungsgremien erschwerte in dieser Phase die Infiltration der bayerischen Unionspartei durch politisch schwerer belastete Personen. Welchen Affront hätte es für die vielen Opfer des Nationalsozialismus unter den Mitbegründern der CSU bedeutet, hätten sie mit wirklichen Nazis an einem Tisch sitzen müssen? Wie tief der Stachel der totalitären Erfahrung saß, zeigt ein Redebeitrag der Augsburger CSU-Politikerin Franziska Wittmann im Landesausschuß der bayerischen Unionspartei zum Thema Entnazifizierung. Zu einer Zeit, als die politische Säuberung in der praktizierten Form bereits reichlich diskreditiert war, führte die im Dritten Reich selbst verfolgte Lehrerin aus:

„Diejenigen, die ein Volk in diesen Abgrund von Not und Elend getrieben haben, sie sind alle mitgegangen. Auch die 1937-er [Parteigenossen] waren mit schuld. [...] Warum sind die Leute mitgelaufen? Aus Geldbeutelzwang, aus Feigheitszwang! Heute redet man von Zwang, nur von Zwang. Und was für ein Zwang! Es ist ganz schrecklich. Dann sitzen wir in der Spruchkammer und lesen alle diese Gesuche. Es könnte einem übel werden. [...] Was wäre, wenn es anders hinausgegangen wäre? [...] Glauben Sie, daß einer von uns heute noch auf diesem Stuhl sitzen würde? [... . Aber nicht bloß die großen Nazi, auch die Mitläufer hätten uns mit ihren Stiefeln totgetreten, erst recht die, die sich heute so unschuldig gebärden und nichts haben als ihre furchtbar christliche Einstellung und die behaupten, daß sie immer und alle Zeiten darüber [über den Nationalsozialismus] geschimpft haben. "152

Auch die Besatzungsbehörden reagierten allergisch darauf, wenn Politiker mit brauner Vergangenheit in den neuen demokratischen Parteien Ämter oder Mandate bekleideten ${ }^{153}$. So griff die amerikanische Militärregierung vor allem im Jahr 1946 massiv in die Geschicke der bayerischen Unionspartei ein und erzwang die Ablösung einiger Persönlichkeiten, die sie wegen ihrer Vergangenheit für kompromittiert hielt oder deren antinationalsozialistische Einstellung sie in Zweifel zog. Den Auftakt dieser Interventionen bildete am 24. April 1946 die Ausschaltung Fritz Schäffers aus dem politi-

149 ACSP, NL Müller 18, Fritz Gerathewohl an Josef Müller vom 29. 1. 1946; dieses Schreiben, das Gerathewohl als Reaktion auf erste Angriffe und Verdächtigungen verfaßte, scheint glaubwürdiger zu sein als vergleichbare Verteidigungsschriften, da es bewußt als Nachtrag zu den Angaben konzipiert wurde, die Gerathewohl in seinem OMGUS-Fragebogen gemacht hatte.

150 Sitzung des Dienstag-Clubs am 8. 10. 1946, in: Lehrjahre, S. 103.

151 Das ist angesichts der nach 1945 unternommenen Versuche, Mitgliedschaften in NS-Organisationen zu verschweigen, durchaus möglich. Dagegen ist kaum vorstellbar, daß schwererwiegende Fälle von politischer Belastung verborgen geblieben sind. Schließlich achteten die Amerikaner akribisch auf das Führungspersonal der demokratischen Parteien, und der politische Gegner versuchte alles, um die CSU durch Enthüllungen über belastete Personen in ihren Reihen zu diskreditieren. Vgl. z. B. den Artikel „Entlassene Landräte der CSU in Bayern“ im Sopade-Informationsdienst vom 8. 3. 1947.

152 Protokoll der Sitzung des Landesausschusses der CSU am 4. 10. 1946 in München, in: Protokolle und Materialien, S. $663 \mathrm{f}$.

153 Vgl. Michael Schröder, Die Parteien-Lizenzierungspolitik der amerikanischen Militärregierung in Bayern nach 1945, in: ders., Bayern 1945: Demokratischer Neubeginn. Interviews mit Augenzeugen, München 1985, S. 9-14, hier S. $11 \mathrm{ff}$. 
schen Leben ${ }^{154}$. Begründet wurde dies mit Untersuchungen der Special Branch von OMGBY, die ergeben hätten, daß der ehemalige BVP-Vorsitzende als „Nazi sympathizer and collaborator" sowie als Exponent ultranationalistischer und militaristischer Ideologie angesehen werden müsse und daß er als vorläufiger Ministerpräsident versucht habe, die amerikanische Entnazifizierungspolitik zu unterlaufen ${ }^{155}$. Diese Aktion der Militärregierung gegen den profiliertesten Vertreter des bayerisch-konservativen Flügels der CSU schlug in der Partei hohe Wellen, doch die Anhänger der Union hatten nur wenig Zeit, sich davon zu erholen. Nur vier Wochen später enthob die Militärregierung den Vorsitzenden des CSU-Kreisverbands Würzburg, Kaspar Dürr, seines Amtes, da er in den Augen der zuständigen Besatzungsoffiziere sowohl gegen die geltenden Säuberungsrichtlinien als auch gegen die Verpflichtung zur demokratischen Amtsführung verstoßen hatte. Nachdem die Delegierten der Kreisversammlung Dürr aufgrund eines Mißverständnisses erneut zu ihrem Vorsitzenden gewählt hatten, griff das Würzburger Detachment der Militärregierung zu drastischen Maßnahmen: Am 1. Juni, vier Wochen vor den Wahlen zur Verfassunggebenden Landesversammlung, wurde die CSU im Stadt- und Landkreis Würzburg suspendiert ${ }^{156}$. Am 13. Juni erreichte die in München tagenden Mitglieder des Landesarbeitsausschusses eine weitere Hiobsbotschaft. Georg Barth, Vorsitzender des CSU-Bezirksverbands Oberfranken und prominenter evangelischer Vertreter in den Führungsgremien der bayerischen Unionspartei, wurde verdächtigt, von 1933 bis 1935 der NSDAP angehört zu haben. Die Militärbehörden reagierten prompt, und Barth mußte sein Amt als Bezirksvorsitzender niederlegen ${ }^{157}$. Fast gleichzeitig verboten die lokalen Besatzungsbehörden die CSU im niederbayerischen Landkreis Viechtach wegen Verstößen gegen Auflagen der Militärregierung und - was weit schwerer wog - wegen der Unterstützung eines angeblich politisch belasteten Kandidaten für das Amt des Landrats ${ }^{158}$.

${ }^{154}$ Vgl. dazu die ausführliche Darstellung bei Henzler, Fritz Schäffer, S. 190-199.

155 Peter Vacca an Josef Müller vom 24. 4. 1946, abgedruckt in: Peter Claus Hartmann, Otto Altendorfer (Hrsg.), 100 Jahre Fritz Schäffer. Politik in schwierigen Zeiten. Katalog der Ausstellung im Museum Kloster Asbach 12. Mai-15. August 1988, Passau 1988, S. 125. Müller teilte Fritz Schäffer die Anordnungen der Militärregierung noch am selben Tag in zwei Schreiben mit; BAK, NL Schäffer 9, Bl. $115 \mathrm{f}$.

${ }^{156}$ Vgl. Schott, Amerikaner als Besatzungsmacht, S. $56 \mathrm{ff}$., sowie die ausführliche Diskussion im Landesarbeitsausschuß der CSU am 13.6. 1946 in München und im Erweiterten Landesausschuß am 6. 7. 1946 in München, in: Protokolle und Materialien, S. 377-391 und S. $457 \mathrm{ff}$. Interessant auch IfZ-Archiv, RG 260, 10/89-3/5, Berichte von Versammlungen der CSU in Würzburg am 4.6., 20.6. und 26. 6. 1946. Daß die Besatzungsoffiziere in Würzburg besonders sensibel auf angebliche oder tatsächliche Verstöße gegen die geltenden Säuberungsrichtlinien reagierten, war auch darauf zurückzuführen, daß sie einem Detachment angehörten, das nach vehementer Kritik an der Zusammensetzung der Stadtverwaltung von Aachen nach Würzburg strafversetzt worden war. Zum „Aachen Scandal" und zur Versetzung des Detachments vgl. Henke, Amerikanische Besetzung, S. 284-297. So viel Staub der Fall Würzburg anfangs aufwirbelte, so unspektakulär wurde er zu den Akten gelegt: Am 24. 6. 1946 hob die Militärregierung die Suspendierung wieder auf; Major Vorhees, der die Angelegenheit zu verantworten hatte, wurde im Dezember 1946 durch eine "special order" abgelöst. Vgl. Schott, Amerikaner als Besatzungsmacht, S. 58.

157 Protokoll der Sitzung des Landesarbeitsausschusses der CSU am 13. 6. 1946 in München, Protokoll der Sitzung des Erweiterten Landesausschusses am 6. 7. 1946 in München und Protokoll der Sitzung des Landesausschusses der CSU am 6. 12. 1946 in München, in: Protokolle und Materialien, S. 372 f., S. 392, S. 460 und S. 812 . Georg Barth wurde erst 1947 rehabilitiert.

${ }^{158}$ Protokoll der Sitzung des Landesarbeitsausschusses der CSU am 13.6. 1946 in München und Protokoll der Sitzung des Erweiterten Landesausschusses der CSU am 6. 7. 1946 in München, in: Protokolle und Materialien, S. 382 und S. 459f., sowie SZ vom 25. 6. 1946: „CSU im Landkreis Viechtach aufgelöst" und vom 2. 7. 1946: „CSU in Viechtach wieder zugelassen“" 
Diese Vorfälle, die auch von der Öffentlichkeit interessiert aufgenommen wurden ${ }^{159}$, lösten in der CSU Bestürzung und Verunsicherung aus. Schließlich befand man sich in den ersten sechs Monaten des Jahres 1946 in einer Art improvisiertem Dauerwahlkampf, und die Furcht, derartige Vorfälle könnten den Ausgang der Wahlen negativ beeinflussen, war groß. Darüber hinaus gab es Befürchtungen, die Militärregierung könnte die CSU, die von ihren Gegnern immer wieder als reaktionäre Partei und Sammelbecken für ehemalige Nationalsozialisten gebrandmarkt worden war ${ }^{160}$, in ihrer Bewegungsfreiheit beschneiden oder gar in toto verbieten ${ }^{161}$. Tatsächlich gab es in den Reihen der Militärregierung eine Reihe linksliberaler Offiziere, die mit der Sozialdemokratie sympathisierten und denen die CSU gerade nach ihren großen Erfolgen bei den ersten Kommunalwahlen ein Dorn im Auge war ${ }^{162}$. Einige führende Mitbegründer der bayerischen Unionspartei machten es ihren Kontrahenten aber auch nicht gerade schwer, sie als unverbesserliche Reaktionäre abzustempeln und so den Unionsgedanken insgesamt zu diskreditieren. So kündigte die Rosenheimer CSU im November 1945 eine öffentliche Versammlung mit Schäffer als Hauptredner mit einem Flugblatt an, auf der sie als „Volksbund zur Sammlung aller rechtsstehenden Kreise“ firmierte ${ }^{163}$. Das SPD-nahe Oberbayerische Volksblatt griff dieses Schriftstück noch im Mai 1946 geradezu genüßlich auf, als sich die Führung der CSU bemühte, den durch die Ausschaltung Schäffers entstandenen Eindruck zu entkräften, die Militärregierung sehe in der Union einen Hort der Reaktion ${ }^{164}$. Daß die neue Sammlungspartei mit besonderen "Geburtswehen“ zu kämpfen habe, stand dort zu lesen, sei nicht verwunderlich; wie jedoch mit „rechtsstehenden Elementen“ - und darunter seien doch nur „begüterte ehemalige Nazi bzw. Nutznießer des Dritten Reiches“ zu verstehen - ein demokratischer Staat aufgebaut werden könne, sei schleierhaft ${ }^{165}$.

Die Interventionen der Militärregierung, aber auch die permanenten Angriffe der politischen Gegner führten zu einer Sensibilisierung gegenüber tatsächlichen oder angeblichen Versuchen politisch Belasteter, in der Union Karriere zu machen. Zugleich wurden die im Raum stehenden Vorwürfe in den parteiinternen Führungs- und Flügelkämpfen instrumentalisiert. Antinationalsozialistische Gesinnung, politische Überzeugung und persönliches Interesse verbanden sich schon bald zu einem vielschichtigen, nur schwer durchschaubaren Komplex. Flüsterpropaganda, dieser oder jener sei poli-

159 SZ vom 7. 6. 1946: „Verbot der Christlich-Sozialen Union. Im Stadt- und Landkreis Würzburg“.

160 Protokoll der Landesversammlung der CSU am 17. 5. 1946 in München, Protokoll der Sitzung des Landesarbeitsausschusses der CSU am 13.6.1946 in München und Protokoll der Sitzung des Erweiterten Landesausschusses der CSU am 6.7.1946 in München, in: Protokolle und Materialien, S. $310 \mathrm{f} .$, S. 383 und S. $456 \mathrm{f}$.

161 Protokoll der Sitzung des Erweiterten Landesausschusses der CSU am 6. 7. 1946 in München, in: Protokolle und Materialien, S. 424 f., und Sitzung des Dienstag-Clubs am 4. 6. 1946 (Zusatzbericht), in: Lehrjahre, S. 58.

162 IfZ-Archiv, RG 260, 17/162-1/7, Memorandum „Political Reaction in Bavaria“, ungezeichnet, undatiert, und Memorandum Walter L. Dorns „The Anti-Democratic Reaction in Bavaria and a Proposal for a Council for Cultural Affairs“ vom 22. 5. 1946, sowie IfZ-Archiv, RG 260, 10/90-1/26, Manifest gegen eine neue Reaktion, ungezeichnet, undatiert. Interessant sind in diesem Zusammenhang auch die Ausführungen Karl Scharnagls während einer Sitzung des Dienstag-Clubs am 4.6. 1946 und Fritz Gerathewohls vor dem Ochsen-Club am 26. 6. 1946; Lehrjahre, S. 56 f. und S. 69.

163 IfZ-Archiv, Fh 56.

164 Vgl. z. B. die Rede Müllers „Der neue Weg“ am 30. 4. 1946 in München (ACSP, NL Müller 416) und seine Ausführungen vor der Landesversammlung der CSU am 17. 5. 1946 in München, in: Protokolle und Materialien, S. $310 \mathrm{f}$.

165 Oberbayerisches Volksblatt vom 7. 5. 1946: „CSU nicht reaktionär“. 
tisch belastet, oder eine gezielte Indiskretion gegenüber den Besatzungsbehörden mit dem Ziel, Mißtrauen zu erzeugen und sich auf elegante Weise mißliebiger Gegner zu entledigen, waren scharfe Waffen in den innerparteilichen Auseinandersetzungen, die bald die eine und bald die andere Seite trafen. Als die Amtsenthebung Kaspar Dürrs bekannt wurde, rieben sich die Gegner der Parteiführung um Josef Müller die Hände: "Jetzt hammer wieder einmal Gelegenheit, im Landessekretariat zu ,schießen'“, freute sich ein Mitglied des Dienstag-Clubs, in dem sich jüngere CSU-Mitglieder, die nicht gerade zu den politischen Freunden des Ochsensepp zählten, regelmäßig zu Diskussionen trafen ${ }^{166}$.

Daß in der Landesgeschäftsstelle Personen beschäftigt waren, die als politisch belastet gelten mußten und noch nicht entnazifiziert waren, war sowohl der Militärregierung als auch informierten Kreisen in der CSU nicht unbekannt ${ }^{167}$. Zumeist handelte es sich um kleine Mitläufer, die sich der NSDAP erst 1937 oder später angeschlossen und zu keiner Zeit größere Aktivitäten entfaltet hatten. Darunter befand sich mit August Wilhelm Schmidt auch der Landesgeschäftsführer, der von 1941 bis 1943 zu den Anwärtern der NSDAP gehört hatte. Schmidt, ein loyaler Gefolgsmann Müllers und eine Schlüsselfigur beim Aufbau eines schlagkräftigen Parteiapparats, stand seit längerem auf der Schwarzen Liste der innerparteilichen Opposition, die nun nicht nur die Chance sah, wichtige Stützen des Parteivorsitzenden auszuschalten, sondern überhaupt Einfluß auf die Personalpolitik der Landesleitung zu gewinnen, die bisher fast ausschließlich eine Domäne Müllers gewesen war ${ }^{168}$. Einmal mehr ging die Initiative von Alois Hundhammer aus. Während in den Führungsgremien der CSU noch über die Fälle Viechtach und Würzburg sowie über die Vorwürfe gegen Georg Barth diskutiert wurde, forderte der kämpferische Vorsitzende des oberbayerischen Bezirksverbands am 13. Juni 1946 den Landesarbeitsausschuß auf zu beschließen, daß „im Landessekretariat der Partei frühere Mitglieder der NSDAP, Anwärter oder Angehörige nationalsozialistischer Formationen nicht beschäftigt werden können“. Die politisch belasteten Personen, die bereits angestellt seien, hätten aus der Parteizentrale auszuscheiden ${ }^{169}$. Josef Müller gelang es diesmal nicht, eine Abstimmung über diesen Antrag zu verhindern. Er konnte lediglich eine Formulierung durchsetzen, die es ermöglichte, die zu entlassenden Personen nach erfolgter Entnazifizierung erneut zu beschäftigen. In dieser Form wurde Hundhammers Antrag vom Landesarbeitsausschuß einstimmig angenommen ${ }^{170}$. Der Ochsensepp war ein Meister in der Kunst, Aktivitäten der Opposition mit Geschäftsordnungstricks ins Leere laufen zu lassen, auf Zeit zu spielen, wenn es darum ging, seine Gegner auszumanövrieren, oder den

${ }^{166}$ Sitzung des Dienstag-Clubs am 4. 6. 1946 (Zusatzbericht), in: Lehrjahre, S. 58.

${ }^{167}$ Protokoll der Sitzung des Erweiterten Landesausschusses der CSU am 6.7. 1946 in München, in: Protokolle und Materialien, S. 501.

168 Kurt Heinrich Heizmann, der Informant der Militärregierung, notierte nach der Sitzung des Dienstag-Clubs am 4. 6. 1946: „Der Generalsekretär der CSU, Schmidt, ein unbedingter Steigbügelhalter Dr. Josef Müllers, und darum ebenso wie dieser im Club wie fast bei allen Jüngeren unbeliebt, ja fast verhaßt, war Parteianwärter und steht schon lange auf der Liste der ,Abzuschießenden'“" Lehrjahre, S. 59.

169 Protokoll der Sitzung des Landesarbeitsausschusses der CSU am 13. 6. 1946 in München, in: Protokolle und Materialien, S. 396. Vgl. dazu auch die - leicht fehlerhafte - Darstellung bei Mintzel, Anatomie, S. $153 \mathrm{ff}$., und den unbefriedigenden Abschnitt bei Hettler, Josef Müller, S. $263 \mathrm{f}$.

170 Protokoll der Sitzung des Landesarbeitsausschusses der CSU am 13. 6. 1946 in München, in: Protokolle und Materialien, S. 404. 
materiellen Gehalt ihm nicht genehmer Resolutionen zu verwässern. Doch diesmal war alle Mühe vergeblich. Daran änderte weder das Argument etwas, es sei unanständig, jemanden, der sich Tag und Nacht für die Union eingesetzt habe, sang- und klanglos zu entlassen, noch der Hinweis, man solle nicht "päpstlicher als der Papst“ sein und gegen leicht belastete Personen vorgehen, gegen deren Tätigkeit im Landessekretariat bislang nicht einmal die Militärregierung Einwände erhoben habe ${ }^{171} . \mathrm{Zu}$ tief saß der „Nervenschock“"172, den die Interventionen der Besatzungsbehörden ausgelöst hatten, zu stark war bei vielen Mitbegründern der CSU noch der antinationalsozialistische Impuls ${ }^{173}$. Zudem blieb Hundhammer hartnäckig. Nur vier Tage nach seinem ersten Vorstoß im Landesarbeitsausschuß forderte er in einer internen Besprechung erneut die Ablösung politisch belasteter Mitarbeiter, ohne jedoch etwas zu erreichen ${ }^{174}$. Als Hundhammer dieses Problem am 6. Juli erneut zur Sprache brachte, setzten die Delegierten des Erweiterten Landesausschusses einen fünfköpfigen Ausschuß ein, der das Personal des Parteiapparats auf seine politische Unbedenklichkeit prüfen sollte ${ }^{175}$.

Der „Sonderausschuß der CSU zur Beurteilung von Personalfragen“ nahm wenig später seine Arbeit auf ${ }^{176}$. Neben Hundhammer, dem auch der Vorsitz im „Prüfungsausschuß“ übertragen wurde, gehörten Elisabeth Hahn, Karl Köhler, Hans Ritter von Lex und Friedrich Wilhelm von Prittwitz und Gaffron diesem Gremium an. Damit waren zwar die Anhänger Josef Müllers und die innerparteiliche Opposition etwa gleich stark vertreten, was einer einseitigen politischen Instrumentalisierung des Prüfungsausschusses entgegenwirkte. Dennoch war die Zusammensetzung der Kommission nicht unumstritten. Schließlich saß mit Ritter von Lex ein ehemaliger Reichstagsabgeordneter der BVP am Tisch, der im März 1933 die Zustimmung der BVP-Fraktion zum Ermächtigungsgesetz begründet ${ }^{177}$ und später einige Zeit bei der NSDAP-Fraktion hospitiert hatte ${ }^{178}$. Schon dies ist ein Indiz dafür, daß es nicht nur um die Frage politischer Belastung und politischer Verantwortung ging, sondern auch um die Destabi-

171 Protokoll der Sitzung des Erweiterten Landesausschusses der CSU am 6. 7. 1946 in München, in: Protokolle und Materialien, S. 501.

172 Protokoll der Sitzung des Landesarbeitsausschusses der CSU am 13. 6. 1946 in München, in: Protokolle und Materialien, S. 404.

173 Protokoll der Sitzung des Landesausschusses der CSU am 4. 10. 1946 in München, in: Protokolle und Materialien, S. $651 \mathrm{f}$.

174 Sitzung des Dienstag-Clubs am 18. 6. 1946, in: Lehrjahre, S. 66.

175 Protokoll der Sitzung des Landesausschusses der CSU am 6. 7. 1946 in München, in: Protokolle und Materialien, S. 500. Der Arbeitsauftrag des Ausschusses war nur verschwommen formuliert, seine Kompetenzen nicht klar umrissen, was für die Gegner Müllers nur positiv war.

176 ACSP, NL Müller 33, Protokoll der ersten Sitzung des Sonderausschusses am 9. 7. 1946; der wohl offizielle Titel erscheint erstmals im Protokoll der zweiten Sitzung am 12.7. 1946, meist wurde jedoch der Terminus „Prüfungsausschuß“ verwendet.

177 Stenographisches Protokoll der Sitzung des Reichstags am 23. 3. 1933, auszugsweise abgedruckt in: Das „Ermächtigungsgesetz“ vom 24. März 1933. Quellen zur Geschichte und Interpretation des „Gesetzes zur Behebung der Not von Volk und Reich“, hrsg. von Rudolf Morsey, Düsseldorf 1992, S. 64-75, die Ausführungen von Lex‘ auf S. 71 f. Vgl. dazu auch BAK, NL Lex 16, Aufzeichnung Hans Ritter von Lex‘ über die Zustimmung der BVP zum Ermächtigungsgesetz vom 8. 4. 1946, und ACSP, NL Müller 298, Memorandum „Hitlers Ermächtigungsgesetz und die bürgerliche Mitte“, ungezeichnet, undatiert; beide Dokumente sind von apologetischen Argumenten nicht frei.

178 ACSP, NL Müller 18, Franz Liedig an Alois Hundhammer vom 21. 8. 1946. Ritter von Lex schied im August 1946 bis zur Klärung der gegen ihn erhobenen Vorwürfe aus dem Prüfungsausschuß aus. 
lisierung der im Aufbau begriffenen Parteiverwaltung, die zu Müllers wichtigsten Trümpfen im innerparteilichen Machtkampf zählte.

Der erste und zugleich prominenteste Fall war der des Landesgeschäftsführers Schmidt. Da Einigkeit darüber bestand, daß „die Union unbedingt von früheren Parteigenossen, die noch nicht das Spruchkammerverfahren durchlaufen hatten, in den leitenden Positionen zu reinigen" sei, standen Schmidts Chancen von vornherein schlecht ${ }^{179}$. Dabei fiel auch die Tatsache kaum ins Gewicht, daß Schmidt erst nach Rücksprache mit dem amerikanischen Nachrichtendienst CIC mit dem organisatorischen und technischen Aufbau der Union in Bayern betraut worden war ${ }^{180}$ und vor dem Prüfungsausschuß mit einigen entlastenden Erläuterungen aufwarten konnte. Die Kommission beschloß, der Parteiführung nahezulegen, Schmidt „bei aller Anerkennung seiner Verdienste" als Landesgeschäftsführer zu entlassen und ihn im Interesse der CSU auch von seinem Amt als stellvertretender Vorsitzender des Organisationsund Werbeausschusses zu entbinden ${ }^{181}$. Doch der Prüfungsausschuß mußte noch einmal ausdrücklich auf seiner Entscheidung bestehen, bis sich Josef Müller dazu bereit fand, das Dienstverhältnis zum 31. August 1946 zu beenden und Schmidt bis dahin mit sofortiger Wirkung zu beurlauben ${ }^{182}$. Mit der Entlassung des Landesgeschäftsführers - zweifellos ein Erfolg der innerparteilichen Opposition - war die Arbeit des Ausschusses keineswegs zu Ende. Soweit sich feststellen läßt, wurden die politische Vergangenheit von 27 Parteiangestellten in leitenden und untergeordneten Positionen überprüft und zwei weitere Fälle, in denen die Militärregierung aktiv geworden war, beraten; mindestens fünf Personen sollten nach dem Willen der Kommission aus ihren Stellungen ausscheiden ${ }^{183}$. Zwar gerieten im Zuge dieser nur teilweise als Säuberungsaktion zu verstehenden Initiative vor allem Mitarbeiter Josef Müllers ins Schußfeld der innerparteilichen Opposition, doch auch der Parteivorsitzende konnte einen Erfolg verbuchen. Mit Richard Jaeger, der sich schon als zukünftigen Landesgeschäftsführer gesehen hatte, mußte auch einer der wenigen in der Parteizentrale beschäftigten Gefolgsleute des katholisch-konservativen CSU-Flügels wegen seiner Mitgliedschaft in der SA den Hut nehmen ${ }^{184}$.

179 ACSP, NL Müller 33, Protokoll der ersten Sitzung des Sonderausschusses am 9. 7. 1946.

180 ACSP, NL Müller 18, Josef Müller an das Arbeitsamt München vom 4. 3. 1946.

181 ACSP, NL Müller 33, Protokoll der ersten Sitzung des Sonderausschusses am 9. 7. 1946.

182 ACSP, NL Müller 33, Protokoll der zweiten Sitzung des Sonderausschusses am 12. 7. 1946, und NL Müller 18, zwei Schreiben Josef Müllers an August Wilhelm Schmidt vom 15. 7. 1946; daraus geht auch hervor, daß Schmidt nach der für ihn wenig erfreulichen Sitzung des Landesarbeitsausschusses am 13.6. 1946 darum gebeten hatte, von seinen Geschäften entbunden zu werden, um wieder in seine alte Stellung bei der Allianz-Versicherungsgesellschaft zurückkehren zu können. Vgl. auch die Sitzung des Ochsen-Clubs am 17. 7. 1946, in: Lehrjahre, S. 81.

183 Zahlen nach den vier vorliegenden Sitzungsprotokollen des Sonderausschusses (ACSP, NL Müller 33); weitere Sitzungen sind nicht dokumentiert, haben aber möglicherweise stattgefunden. Danach waren elf Personen Mitglieder bzw. Anwärter der NSDAP (Eintrittsdatum: drei 1937, drei 1939, zwei 1940, zwei 1941, einer unbekannt) und drei Personen Mitglieder von SA oder SS. Von den fünf Angestellten, deren Entlassung bis zum 2. 8. 1946 gefordert wurde, schieden nachweislich Georg Banzer und August Wilhelm Schmidt aus ihren Stellungen aus, Otto Schedl dagegen blieb Geschäftsführer der Partei im Bezirk Oberpfalz und wechselte 1947 in die Landesgeschäftsstelle. Nach der Liste der vom Prüfungsausschuß als belastet angesehenen Personen liegt die Vermutung nahe, daß die Entlassung weiterer Mitarbeiter gefordert wurde; wie viele Angestellte insgesamt im Zuge dieser Aktion ihren Platz räumen mußten, ist unbekannt.

${ }^{184}$ Sitzung des Dienstag-Clubs am 8. 10. 1946, in: Lehrjahre, S. 103. 


\section{e) Frübe CSU-Programme im Vergleich}

Die erbitterten innerparteilichen Auseinandersetzungen, die die CSU bis 1949 kaum zur Ruhe kommen ließen, legen die Vermutung nahe, daß die Positionen der diversen Flügel und Gruppierungen in zentralen programmatischen Fragen von Anfang an nur schwer zu vereinbaren gewesen sind. Als Partei der Sammlung, als Union unterschiedlicher politischer Strömungen mit eigenen Traditionen tat sich die CSU naturgemäß schwerer als andere Parteien, tragfähige Kompromisse und eine allseits akzeptierte programmatische Linie zu finden - zumal unter den schwierigen Bedingungen der Besatzungsszeit. In einem Programm "nach altem Muster“ zu fordern und zu versprechen, so Josef Müller im April 1946, sei einfach, aber nach der deutschen Katastrophe gebe es nichts mehr zu versprechen. „Wir können nur vor euch hintreten [...] und sagen, daß wir eine klare Grundlinie haben“, rief der Ochsensepp seinem Publikum zu, „darüber hinaus sind wir Suchende wie ihr alle!“"185 Diese „klare Grundlinie“ ging in den Führungs- und Flügelkämpfen oft verloren, wenn sie in dieser Form überhaupt vorhanden war. Untersucht man jedoch programmatische Texte aus den Gründungstagen der $\mathrm{CSU}^{186}$, so zeigt sich - allen Differenzen zum Trotz - in bestimmten Bereichen ein erstaunliches $\mathrm{Maß}$ an Gemeinsamkeiten. Daß viele von diesen Schriftstücken „niemals von einem legitimierten Organ der Partei in einem geregelten Verfahren als Programm anerkannt" wurden, ist sicherlich richtig; auch der Einwand, daß sie oft bereits nach kurzer Zeit ersetzt wurden und sich über ihre politische Relevanz nur wenig aussagen läßt, ist bedenkenswert ${ }^{187}$. Die Bedeutung dieser Texte liegt jedoch in ihrer

185 SZ vom 3. 5. 1946: „Die CSU und der Fall Schäffer. Eine Stellungnahme des Landesvorsitzenden Dr. Müller".

186 Soweit wie möglich wurden alle Zentren der Unionsgründung in Bayern berücksichtigt und aus jedem Regierungsbezirk zumindest ein Beispiel ausgewählt. Für den Münchner Gründerkreis: BayHStA, NL Pfeiffer 41, Entwurf für das Grundsatzprogramm einer „Christlichen Volkspartei in Bayern“ vom 5.9. 1945, das eventuell als begleitender Aufruf konzipierte „Grundsatz-Programm einer Christlich-Demokratischen Volkspartei in Bayern“, zwei Entwürfe eines Programms für die "Christlich-Soziale Union in Bayern“" vom 10. 9. 1945 bzw. undatiert sowie ein undatierter Programmentwurf Anton Pfeiffers, und BayHStA, NL Pfeiffer 142, Entwurf für ein Programm der CSU München, undatiert, sowie dessen endgültige Fassung vom November 1945 (IfZ-Archiv, Fh 56); die vorwiegend im Münchner Gründerkreis erarbeiteten „Zehn Punkte der Union“ vom 31. 12. 1945, abgedruckt in: Protokolle und Materialien, S. $1713 \mathrm{f}$., wurden ebenfalls berücksichtigt; für Oberbayern: IfZ-Archiv, Fh 56, „Politisches Glaubensbekenntnis und Arbeitsprogramm der christlich-sozialen Union bayerischer Demokraten“ (Landkreis Altötting), undatiert; für Augsburg und Schwaben: Eugen Rindt, „Gedanken zu dem Programm einer christlich-politischen Partei in Bayern“ vom August 1945, abgedruckt in: Protokolle und Materialien, S. $1705 \mathrm{ff}$.; für Niederbayern: BayHStA, NL Pfeiffer 144, Aufruf der Christlich-Sozialen Volkspartei in Bayern (Landkreis Rottenburg an der Laaber), undatiert; für die Oberpfalz: Grundsatz- und Aktionsprogramm der Partei der Christlich-Sozialen Einigung in Bayern, abgedruckt in: Geschichte einer Volkspartei, S. 433-436; für Nürnberg und Mittelfranken: IfZ-Archiv, Fh 56, Programm der CSU, undatiert; für Oberfranken: IfZ-Archiv, Fh 56, Programm der CSU, Ortsverband Hof, undatiert; für Unterfranken: IfZ-Archiv, Fh 56, Aufruf und Programm der CSU im Landkreis Marktheidenfeld vom Dezember 1945/Januar 1946, und die Manuskripte programmatischer Reden von Adam Stegerwald, "Wo stehen wir?", „Wohin gehen wir?" und „Von deutscher Zukunft“, die 1946 nach Stegerwalds Tod in Würzburg publiziert wurden; das „Programm der Christlich-Sozialen Union für Würzburg Stadt und -Land“, undatiert, ist abgedruckt in: Herde, Unionsparteien, in: Becker (Hrsg.), Kapitulation, S. 287-291. Wichtig sind in diesem Zusammenhang auch die bereits mehrfach zitierten Denkschriften von Richard Jaeger (in: Lehrjahre, S. 145-186) und Gerhard Kroll (IfZ-Archiv, ED 720 Smlg. Mintzel 1).

187 Vgl. Mintzel, Geschichte der CSU, S. 205, mit Blick auf das Zehn-Punkte-Programm vom 31. 12. 1945. 
Funktion als Orientierungspunkte für einen demokratischen Neubeginn im Chaos des Zusammenbruchs, gespeist aus den Motiven und Zielen derer, die mit der Gründung der Union letztlich ein neues Kapitel in der deutschen Parteiengeschichte aufschlugen.

So war die Einsicht, daß die Erneuerung von Staat und Gesellschaft nur aus dem christlichen Glauben heraus möglich sei und nur durch „die in zwölfjähriger Verfolgung wiedergeborene Einheitsfront aller christlichen Bekenntnisse" verwirklicht werden könne ${ }^{188}$, unumstrittene Grundlage aller wichtigen Programmentwürfe, Aufrufe und Denkschriften. Auch wenn die evangelische Kirche dem Gedanken, durch eine politische Partei „die christliche Sache gegenüber dem Staat und der Öffentlichkeit zu stärken “, skeptisch gegenüberstand ${ }^{189}$, machten sich die protestantischen Mitbegründer der CSU diese Idee zu eigen ${ }^{190}$, die den Katholiken seit langem vertraut war. Daß es dabei „niemals Hauptaufgabe des Christen in der Welt" sein könne, „die Rechte der Kirche zu verteidigen“, sondern daß "das gesamte private und öffentliche Leben aus dem Geist des Evangeliums" erneuert werden müsse, war eine Meinung, die in Würzburg, Bamberg oder München ebenso weit verbreitet war wie die Erkenntnis, daß die Zusammenarbeit von katholischen und evangelischen Christen in einer Partei „keine dogmatische Vereinigung "voraussetze, wohl aber gegenseitige Rücksichtnahme und Anerkennung der bestehenden Gegensätze ${ }^{191}$.

Auch auf dem Feld der Sozial- und Wirtschaftspolitik gab es durchaus eine gemeinsame Basis. Meist an den Prinzipien der katholischen Soziallehre orientiert ${ }^{192}$, wurden weitgehende Forderungen nach einer evolutionären Umgestaltung der bestehenden Ordnung erhoben. Umverteilung des noch vorhandenen Volksvermögens, Ausgleich der Kriegsfolgelasten zwischen den besitzenden und den verarmten Bevölkerungsschichten, Entproletarisierung der Arbeiterschaft und Förderung von Eigentumsbildung, Schutz von Ehe und Familie waren immer wieder gebrauchte Schlagworte zur Charakterisierung eines gesellschaftspolitischen Leitbildes, das teilweise ständisch-korporatistische Züge trug und zuweilen an die Volksgemeinschaftsideologie des Dritten Reiches erinnerte ${ }^{193}$. Was die Organisation der Wirtschaft betrifft, so lehnte man planwirtschaftliche Konzepte sozialistischer Prägung weitgehend ab und forderte dagegen eine Kontrolle und Lenkung der Wirtschaft durch den Staat bei prinzipieller Anerken-

188 Denkschrift Richard Jaegers, in: Lehrjahre, S. 147.

189 Vortrag auf einem evangelischen Pfarrkonvent in Leutershausen am 6. 5. 1946; zit. nach Woller, Gesellschaft und Politik, S. 189.

190 Fränkische Volksstimme vom 31.1. 1946: „Was lehren uns die Gemeindewahlen?“ Der Artikel stammt aus der Feder des Protestanten Paul Nerreter.

191 Denkschrift Richard Jaegers, in: Lehrjahre, S. 148 (Zitat), und IfZ-Archiv, ED 720 Smlg. Mintzel 1, "Christliche Union. Bamberger Denkschrift zur Schaffung einer politischen Einheitsfront aller Christen Deutschlands“. Die Frage, wie eng das Verhältnis von Staat und Kirche gestaltet werden sollte, war dagegen nicht unumstritten. Am weitesten ging Adam Stegerwald, der für eine „stärkere Auflockerung des Verhältnisses zwischen Staat und Kirche“ plädierte. Vgl. Stegerwald, Wohin gehen wir, S. 55-59, Zitat S. 57. Für eine enge Kooperation sprach sich dagegen Gerhard Kroll in seiner Bamberger Denkschrift aus.

192 Am explizitesten formuliert in der Denkschrift Richard Jaegers, in: Lehrjahre, S. 162-166.

193 Im Herbst 1945 hatte man sich auch noch nicht gänzlich von der NS-Terminologie gelöst: So war im "Grundsatz-Programm einer Christlich-Demokratischen Volkspartei in Bayern" (BayHStA, NL Pfeiffer 41) vom Ziel einer „soziale[n] Volksgemeinschaft“, basierend auf dem christlichen Sittengesetz und den Grundsätzen christlicher Solidarität die Rede, und in einem undatierten Entwurf für ein Programm für die "Christlich-Soziale Union in Bayern" (BayHStA, NL Pfeiffer 41) von „Volksgemeinschaft aus wahrer sozialer Gesinnung“. 
nung der unternehmerischen Eigeninitiative ${ }^{194}$. Zugleich wurden verschiedene Modelle innerbetrieblicher Mitbestimmung und Gewinnbeteiligung diskutiert ${ }^{195}$. Das private Eigentum sollte zwar unter staatlichem Schutz stehen, zugleich jedoch dem Gemeinwohl verpflichtet sein. In diesem Zusammenhang scheuten sich die Verfasser der hier ausgewerteten programmatischen Texte auch nicht, die Sozialisierung oder Verstaatlichung bestimmter Wirtschaftszweige zu befürworten ${ }^{196}$. In den ersten Nachkriegsmonaten wurde diese Position noch wiederholt mit dem umstrittenen Begriff „christlicher Sozialismus “ gekennzeichnet ${ }^{197}$; im Grundsatzprogramm der CSU von 1946 hieß es dagegen nur:

„Die Wirtschaft ist nicht Selbstzweck; sie muß dem Wohl der Gesamtheit wie des einzelnen dienen. Wir anerkennen das Recht des Staates, die Wirtschaft nach Gesichtspunkten des Gemeinwohls zu lenken. Wir lehnen die Planwirtschaft als Ausfluß eines kollektivistischen Denkens ab. Wir kämpfen gegen den Wirtschaftsliberalismus und treten ein für freie Entfaltung der Einzelpersönlichkeit im Rahmen [ihrer] sozialen Pflichten. " ${ }^{198}$

Selbst auf dem so heiklen Feld der Verfassungspolitik existierten nicht nur Gegensätze. $\mathrm{Daß}$ die Menschen- und Bürgerrechte in einem künftigen demokratischen Staatswesen zu verankern seien, war eine Forderung, die nach dem Ende des Dritten Reiches in den

${ }^{194}$ Es herrschte jedoch vielfach Unklarheit darüber, wie weit der staatliche Einfluß gehen und wie die künftige Wirtschaftsordnung im einzelnen aufgebaut werden sollte. Die detailliertesten und interessantesten Vorstellungen dazu entwickelte in dieser frühen Phase der Volkswirt Gerhard Kroll, der unter anderem die von John M. Keynes entwickelten Theorien in seine Überlegungen einbezog. IfZ-Archiv, ED 720 Smlg. Mintzel 1, „Christliche Union. Bamberger Denkschrift zur Schaffung einer politischen Einheitsfront aller Christen Deutschlands“. Im Programm der Nürnberger CSU (IfZ-Archiv, Fh 56) hieß es lediglich: „Der Staat hat die Wirtschaft nach den Bedürfnissen des gesamten Volkes zu lenken.“ Ähnliche Formulierungen auch in den beiden Entwürfen eines Programms für die "Christlich-Soziale Union in Bayern" vom 10. 9. 1945 bzw. undatiert (BayHStA, NL Pfeiffer 41). Im Programm des CSU-Ortsverbands Hof (IfZ-Archiv, Fh 56) war dagegen zu lesen: „Wir fordern den Wiederaufbau der deutschen Wirtschaft nach den Grundsätzen der Unternehmerinitiative und des Privateigentums."

195 So empfahl Gerhard Kroll, Stiftungen ähnlich der Carl-Zeiß-Stiftung zu schaffen und dadurch bestimmte Betriebe „in das Gemeineigentum aller Arbeiter und Angestellten“ zu überführen. IfZ-Archiv, ED 720 Smlg. Mintzel 1, „Christliche Union. Bamberger Denkschrift zur Schaffung einer politischen Einheitsfront aller Christen Deutschlands".

${ }^{196}$ Im „Programm der Christlich-Sozialen Union für Würzburg Stadt und -Land“ (abgedruckt in: Herde, Unionsparteien, in: Becker (Hrsg.), Kapitulation, S. 289) heißt es: „Wir bejahen das Privateigentum, das die Entfaltung der Persönlichkeit verbürgt und den Eigentümer zum verantwortlichen Gebrauch gegenüber der Allgemeinheit verpflichtet. Um in dieser Notzeit Arbeit und Nahrung, Kleidung und Wohnung zu sichern, ist das Wirtschaftsleben planmäßig zu lenken. Die Schlüsselindustrien, die Bodenschätze, der Bergbau, die Energiewirtschaft und alle monopolartigen Unternehmungen sind entweder in das Staatseigentum zu überführen oder dem Einfluß der öffentlichen Gewalt zu unterstellen, um das Staatsleben vor illegitimen Einmischungen und vor Mißbrauch wirtschaftlicher Machtzusammenballungen zu bewahren". Das politische "Glaubensbekenntnis und Arbeitsprogramm der christlich-sozialen Union bayerischer Demokraten“ im Landkreis Altötting (IfZ-Archiv, Fh 56) nahm eine mittlere Position ein: „Wir fordern schärfstes Einschreiten der Volksvertretung und des Staates gegen alle privatwirtschaftlichen Monopolstellungen, nötigenfalls durch Vergesellschaftung einzelner Industriezweige als staatliche oder kommunale Versorgungsbetriebe. Im übrigen fordern wir [...] grundsätzliche Anerkennung und Gewährleistung des Privateigentums und freie Wirtschaft für alle Berufsstände." Das Programm des CSU-Ortsverbands Hof (IfZ-Archiv, Fh 56) gehört zu den Ausnahmen, da jeder Bezug auf die Sozialisierungsfrage fehlt.

197 Fränkische Volksstimme vom 26. 1. 1946: „Der Weg ist frei“, oder das „Programm der ChristlichSozialen Union für Würzburg Stadt und -Land“, undatiert, abgedruckt in: Herde, Unionsparteien, in: Becker (Hrsg.), Kapitulation, S. 287-291.

198 Grundsatzprogramm der CSU von 1946, abgedruckt in: Protokolle und Materialien, S. 1723-1728, hier S. 1726. 
Gründungszirkeln der bayerischen Unionspartei auf breite Zustimmung stieß ${ }^{199} . \mathrm{Zu}$ gleich stand man jedoch einer weitgehenden Demokratisierung von Staat und Gesellschaft nicht ohne Skepsis gegenüber ${ }^{200}$. Eine „radikale Demokratie entspricht nicht dem bayerischen und deutschen Wesen“, erklärte Richard Jaeger im Herbst 1945 und forderte in diesem Sinne, die „deutsche Demokratie der Zukunft“ müsse „staatsrechtlich (nicht sozial!) konservativ aufgebaut werden “201. Demokratie- und Parlamentarismuskritik, wie sie in den bürgerlichen Parteien vor 1933 weit verbreitet gewesen war, und die Erfahrung des Untergangs der Weimarer Republik verbanden sich vielfach zu Vorstellungen von einem zwar demokratischen, aber am Primat der Stabilität orientierten politischen System mit einer übermächtigen Exekutive als Garant für die Funktionsfähigkeit des Staates auch in Krisenzeiten ${ }^{202}$.

Diese frühen Parteiprogramme waren sicherlich nicht mehr als eine Plattform zur Diskussion über Formulierung und Umsetzung detaillierterer politischer Konzepte. Möglicherweise hätte das jedoch ausgereicht, um Kompromisse zu erarbeiten, die für alle Seiten einigermaßen akzeptabel gewesen wären. Daß dies nicht gelang, ist vor allem auf die tiefgreifenden Differenzen in der „bayerischen Frage“ zurückzuführen, die alles überschatteten ${ }^{203}$. Die Programme, Aufrufe und Denkschriften, die in altbayerischen Landkreisen erarbeitet wurden, trugen überwiegend bayerisch-etatistische Züge und sollten als Richtlinien für eine bayerische Partei dienen. In frühen Unionsprogrammen aus Franken überwogen dagegen reichsorientierte Überlegungen mit einem deutlichen Schwerpunkt im Bereich der Sozial- und Wirtschaftspolitik; man dachte dort auch weniger an die Gründung einer autonomen Landespartei als an eine Eingliederung der CSU in statu nascendi in eine länder- und zonenübergreifende Organisation ${ }^{204}$. Diese unterschiedliche Prioritätensetzung und die daraus resultierende Unvereinbarkeit der Positionen überdeckte die auf anderen Politikfeldern bestehenden Gemeinsamkeiten. Richard Jaeger umriß im Herbst 1945 das Programm der zu gründenden Partei mit folgenden Schlagworten: „Die Union ist christlich, aber nicht konfessionell begrenzt;

199 So hieß es im „Programm der Christlich-Sozialen Union für Würzburg Stadt und -Land“ (abgedruckt in: Herde, Unionsparteien, in: Becker (Hrsg.), Kapitulation, S. 288) an exponierter Stelle: „Das Recht muß wieder die Grundlage des gesamten Volkslebens bilden. Die Justiz darf nicht wieder zur Dirne der Politik werden. Die Rechtspflege ist unabhängigen, gerechten Richtern anzuvertrauen; ihr Leitstern ist das Gesetz, vor dem alle gleich sind. Auch die obersten Führer des Volkes unterliegen dem Gesetz."

200 So schrieb beispielsweise Gerhard Kroll im Herbst 1945: „Der verantwortungslose Parlamentarismus, der in Deutschland nach der Weltkriegszeit zu einem System der Parteisplitter führte und sich unfähig erwies, eine Regierung für längere Dauer zu bilden, soll ebenso vermieden werden, wie jede Staatsform, die aufs neue, verhüllt oder offen, die Gewaltherrschaft anstrebt." IfZ-Archiv, ED 720 Smlg. Mintzel 1, „Christliche Union. Bamberger Denkschrift zur Schaffung einer politischen Einheitsfront aller Christen Deutschlands".

201 Denkschrift Richard Jaegers, in: Lehrjahre, S. $172 \mathrm{f}$.

202 Besonders deutlich bei Gerhard Kroll, der zur Stabilisierung des politischen Systems neben den parlamentarischen Gremien und der von den Abgeordneten gewählten Regierung einen überparteilichen Landes- bzw. Reichsrat und einen mit umfassenden Kompetenzen ausgestatteten Landesbzw. Reichsberater vorschlug. IfZ-Archiv, ED $720 \mathrm{Smlg}$. Mintzel 1, „Christliche Union. Bamberger Denkschrift zur Schaffung einer politischen Einheitsfront aller Christen Deutschlands“.

203 So erklärte Karl Scharnagl am 4. 6. 1946 vor dem Dienstag-Club, es herrsche in der Union immerhin Übereinstimmung über bestimmte Grundprinzipien, aber leider „sei in einer so wichtigen Frage wie der des Staatsaufbaus keine Einigkeit vorhanden“. Lehrjahre, S. 56.

204 Im Programm der Nürnberger CSU (IfZ-Archiv, Fh 56) hieß es nur: „Das Deutsche Reich muß als Einheit erhalten bleiben. Die Länder sind seine organischen Glieder. Ländern und Gemeinden soll ein weitgehendes Recht zur Selbstverwaltung eingeräumt werden.“ 
bayerisch, aber nicht partikularistisch; deutsch, aber antipreußisch; radikal-sozial, aber nicht sozialistisch; demokratisch, aber nicht liberal.“ ${ }^{205} \mathrm{Daß}$ die CSU am „Leitstern [...] der christlichen Weltanschauung “206 ausgerichtet sein sollte, war unter den Mitbegründern der bayerischen Unionspartei ebensowenig umstritten wie die Forderung nach weitgehenden sozialen Reformen oder das Bekenntnis zur Demokratie. Soweit sie aus dem Süden Bayerns stammten oder der Tradition der untergegangenen BVP verhaftet waren, hätten viele CSU-Politiker der ersten Stunde auch die übrigen Punkte in Jaegers skizzenhaftem Rahmenprogramm unterschreiben können. Dagegen mußten diese Aussagen zur künftigen Stellung Bayerns in den fränkischen Landesteilen trotz der vagen Zugeständnisse vor allem bei der reichsorientierten protestantischen Bevölkerung, die es für die Union zu gewinnen galt, auf tiefe Skepsis stoßen.

\section{Im Zentrum des Geschehens: Der Münchner Gründerkreis}

\section{a) Die Regierung Schäffer und der politische Neubeginn}

Am 28. Mai 1945, nur zwanzig Tage nach der bedingungslosen Kapitulation des Deutschen Reiches, wurde Fritz Schäffer, der zwischen 1929 und 1933 als Vorsitzender der BVP zu den führenden Persönlichkeiten der bayerischen Politik gehört hatte, zum „einstweiligen Bayerischen Ministerpräsidenten“ ernannt ${ }^{207}$. Die Einsetzung eines Ministerpräsidenten mußte - auch wenn sie ausdrücklich nur ein Provisorium darstellte - im verfassungsrechtlichen Vakuum der unmittelbaren Nachkriegszeit geradezu als eine Bestätigung der staatlichen Tradition Bayerns verstanden werden ${ }^{208}$. Damit hatte das Regional Military Government einen „politischen Raum Bayern“ geschaffen, dessen staatsrechtliche Position freilich erst noch zu bestimmen war ${ }^{209}$. Mit der Proklamation Nr. 2 der Militärregierung erfolgte am 19. September 1945 die Einteilung der USZone in die „Staaten“ Bayern, Groß-Hessen und Württemberg-Baden ${ }^{210}$. Dies war ein weiterer Schritt auf dem Weg zur Beendigung des Schwebezustands Bayerns ${ }^{211}$, und

205 Denkschrift Richard Jaegers, in: Lehrjahre, S. 183.

${ }^{206}$ ACSP, NL Müller 201, von Fritz Schäffer gezeichneter „Wahlaufruf der Bayerischen Christlichen Sozialen Union zu den Bayerischen Gemeindewahlen“ am 27.1. 1946.

207 Ernennungsschreiben für Fritz Schäffer, abgedruckt in: Fritz Baer, Die Ministerpräsidenten Bayerns 1945-1962. Dokumentation und Analyse, München 1971, S. 255; zu Schäffers Ernennung vgl. die Einleitung zu den Protokollen des Bayerischen Ministerrats 1945-1954: Das Kabinett Schäffer 28. Mai bis 28. September 1945, bearb. von Karl-Ulrich Gelberg, München 1995, S. 20-33. Zum Gesamtzusammenhang vgl. Lutz Niethammer, Die amerikanische Besatzungsmacht zwischen Verwaltungstradition und politischen Parteien in Bayern 1945, in: VfZ 15 (1967), S. 153-210, sowie Wolf D. Gruner, Fritz Schäffer und der Neubeginn in Bayern nach 1945, in: Wolfgang J. Mückl (Hrsg.), Föderalismus und Finanzpolitik. Gedenkschrift für Fritz Schäffer, Paderborn u. a. 1990, S. 37-66, insbesondere S. 40-59, und Reinhard Heydenreuter, Office of Military Government for Bavaria, in: Christoph Weisz (Hrsg.), OMGUS-Handbuch. Die amerikanische Militärregierung in Deutschland 1945-1949, München 1994, S. 143-315, hier S. 154 ff.

${ }_{208}$ Vgl. Anton Pfeiffer, Wie Bayern wieder ein Staat wurde, in: Unser Bayern. Politik, Wirtschaft, Kultur, hrsg. von der Bayerischen Staatskanzlei, München 1950, S. 7-10.

209 Henzler, Fritz Schäffer, S. 100; ähnlich auch Niethammer, Amerikanische Besatzungsmacht, S. 164.

210 Proklamation Nr. 2 Dwight D. Eisenhowers vom 19. 9. 1945, abgedruckt in: Baer, Ministerpräsidenten, S. $256 \mathrm{f}$.

21 Zur Bedeutung der Proklamation Nr. 2 aus staatsrechtlicher Sicht vgl. Eduard Schmidt, Staatsgründung und Verfassungsgebung in Bayern. Die Entstehung der Bayerischen Verfassung vom 8. Dezember 1946, Bd. 1, München 1997, S. 55-59. 
die Protagonisten der "bayerischen Bewegung" verstanden die Proklamation Nr. 2 als ein positives Signal der Besatzungsmacht für ihr Streben nach einem weitgehend selbständigen Staat ${ }^{212}$.

Daß das Regional Military Government großen Wert auf die zügige Rekonstruktion administrativer Effizienz legte, kam den Vorstellungen Schäffers durchaus entgegen. Der bayerische Ministerpräsident folgte der Konzeption einer zumindest vordergründig apolitischen Notstandsverwaltung unter Ausschaltung parteipolitischer Einflüsse und versuchte, die Lizenzierung von Parteien - für ihn gleichbedeutend mit der baldigen Abhaltung von Wahlen - möglichst weit hinauszuzögern ${ }^{213}$. In diesem Sinne traf sich Schäffers Konzeption mit den Vorgaben und Vorstellungen der amerikanischen Besatzungsmacht, die noch im Mai 1945 der Freiheitsaktion Bayern und dem in Dachau gegründeten Nationalkomitee Freies Deutschland auf der Basis der grundlegenden Besatzungsdirektive JCS 1067 die politische Betätigung untersagt hatte ${ }^{214}$. Diese zurückhaltende Politik wurde allerdings von den sowjetischen Militärbehörden durchkreuzt, als sie am 10. Juni 1945 die Bildung antifaschistischer Parteien und Gewerkschaften in ihrer Besatzungszone gestatteten. Spätestens mit den während der Potsdamer Konferenz verabschiedeten Grundsätzen zur Besatzungspolitik, die ausdrücklich nicht nur die Erlaubnis, sondern auch die Förderung demokratischer Parteien vorsahen ${ }^{215}$, war die Entwicklung auch in der US-Zone nicht mehr aufzuhalten. Am 14. August 1945 teilte Colonel Robert Reese dem Ministerpräsidenten mit, daß sich die Militärregierung „zwar nicht unter dem Druck des russischen Vorgehens, aber doch veranlaßt hiedurch", gezwungen sähe, die Bildung und Tätigkeit politischer Parteien früher zuzulassen, als dies ursprünglich geplant gewesen $\operatorname{se}^{216}$. Man sicherte Schäffer jedoch zu, „für München und Bayern trotzdem die Erlaubnis noch etwas zurück[zu]halten“. Auch wenn Schäffer vor den möglichen Folgen der Lizenzierung politischer Parteien für das öffentliche Leben und für sein Kabinett warnte, erkannte er wohl, daß sich dies nicht mehr würde umgehen lassen, bat aber darum, politische Tätigkeit nur stufenweise zuzulassen ${ }^{217}$. Somit kam es dem Ministerpräsidenten sicherlich entgegen, daß die amerikanischen Militärbehörden bei der Lizenzierung politischer Parteien sehr restriktiv verfuhren und diese seit August 1945 nur auf Kreisebene und nur nach einem aufwendigen Genehmigungsverfahren zuließen ${ }^{218}$.

212 So z. B. Michael Horlacher; Protokoll der Sitzung des Erweiterten Landesausschusses der CSU am 6. 7. 1946 in München, in: Protokolle und Materialien, S. 511.

${ }^{213}$ Vgl. Niethammer, Amerikanische Besatzungsmacht, S. 186f. Schäffer war nicht der einzige, der einer raschen Demokratisierung des öffentlichen Lebens skeptisch gegenüberstand. Vor allzu frühen Wahlen hatte auch Adam Stegerwald gewarnt; Wilhelm Hoegner glaubte noch in seinen Memoiren, daß die ersten Wahlen im Frühjahr 1946 von der Besatzungsmacht "viel zu früh angesetzt“ gewesen seien, ähnlich äußerte sich auch Josef Müller. BAK, NL Schäffer 19, Bl. 127-129, Adam Stegerwald an Fritz Schäffer vom 23. 6. 1945; Wilhelm Hoegner, Der schwierige Außenseiter. Erinnerungen eines Abgeordneten, Emigranten und Ministerpräsidenten, München 1959, S. 242; BayHStA, NL Pfeiffer 41, Notizen Anton Pfeiffers über eine Besprechung am 14. 8. 1945.

${ }^{214}$ Vgl. dazu Benz, Parteigründungen und erste Wahlen, in: ders. (Hrsg.), Neuanfang in Bayern, S. $13-17$.

215 Vgl. Schröder, Parteien-Lizenzierungspolitik, in: ders., Bayern 1945, S. 10.

${ }^{216}$ BayHStA, NL Pfeiffer 142, Aktennotiz über ein Gespräch zwischen Fritz Schäffer und Robert R. Reese am 14. 8. 1945; das folgende Zitat ebenda.

217 BayHStA, NL Pfeiffer 142, Fritz Schäffer an Robert R. Reese vom 17. 8. 1945.

${ }^{218}$ BayHStA, NL Pfeiffer 142, ungezeichnete „Richtlinien über die Parteibildung“ vom 21. 9. 1945. Vgl. auch Schröder, Parteien-Lizenzierungspolitik, in: ders., Bayern 1945, S. $11 \mathrm{ff}$. 
Schäffer sollte jedoch nur noch wenige Wochen im Amt bleiben. Wegen unüberbrückbarer Differenzen wurde der frühere BVP-Vorsitzende am 28. September 1945, genau vier Monate nach seiner Ernennung, entlassen. Zum neuen bayerischen Ministerpräsidenten berief die Militärregierung den Sozialdemokraten Wilhelm Hoegner ${ }^{219}$.

$\mathrm{Zu}$ diesem Zeitpunkt war die Entstehung politischer Parteien bereits im Gange. Während ehemalige Funktions- und Mandatsträger der beiden Arbeiterparteien SPD und KPD bereits kurze Zeit nach dem Zusammenbruch des NS-Regimes an den Wiederaufbau ihrer Organisationen gingen, war die Frage höchst umstritten, ob die BVP als spezifisch bayerische Variante des politischen Katholizismus wieder gegründet werden sollte oder ob nicht der bald diskutierten Alternative einer christlichen Sammlungsbewegung der Vorzug zu geben sei. Noch im Mai 1945, wenige Tage nach seiner Ernennung zum bayerischen Ministerpräsidenten, erklärte Schäffer in einem Interview, er sei sehr dafür, die BVP wieder ins Leben zu rufen, selbstverständlich aber erst dann, wenn die Militärregierung ihr Placet dazu gegeben habe ${ }^{220}$. Schäffer war überzeugt davon, die BVP binnen kurzer Zeit in ihrer alten Form wiederbeleben zu können, ja es schien für den ehemaligen BVP-Vorsitzenden geradezu selbstverständlich, die in der Weimarer Republik stärkste Partei Bayerns neu zu gründen ${ }^{221}$. Schäffer hielt es allerdings zunächst für geboten, zusammen mit den Mitgliedern seines Kabinetts jeder parteipolitischen Tätigkeit zu entsagen. Als Colonel Reese den Ministerpräsidenten am 14. August über die Pläne der amerikanischen Militärregierung zur Genehmigung politischer Parteien informierte, forderte er Schäffer zugleich auf, zu der Frage Stellung zu nehmen, ob „bei der Bildung der neuen Parteien auch Mitglieder der Landesregierung aktiv hervortreten “ könnten $^{222}$. Mit sichtlichem Unbehagen antwortete Schäffer wenige Tage später, und er machte keinen Hehl daraus, daß er die Zulassung politischer Parteien für verfrüht und den Zeitpunkt für ungünstig gewählt hielt. Die Frage nach der Beteiligung von Kabinettsmitgliedern an parteipolitischen Aktivitäten verneinte Schäffer und verwies - nicht ganz zutreffend - darauf, daß er bei der Besetzung von Ämtern bewußt auf die Berücksichtigung früherer politischer Bindungen verzichtet habe. Zugleich warnte Schäffer davor, daß parteipolitische Einflüsse die Arbeit der Regierung erschweren würden ${ }^{223}$. Damit waren neben Schäffer auch so prominenten Politikern der untergegangenen BVP wie Anton Pfeiffer oder Kultusminister Otto Hipp mehr oder weniger die Hände gebunden, als sich im August 1945 die Gründung einer christlichen Partei anbahnte ${ }^{224}$.

219 Die Absetzung Schäffers und seine eigene Ernennung beschreibt Hoegner, Außenseiter, S. 200. Schäffers Version der Ereignisse findet sich in einer umfangreichen Aktennotiz Josef Helds vom 6. 2. 1946; IfZ-Archiv, Fh 56. Vgl. auch die Einleitung zu den Protokollen des Bayerischen Ministerrats: Kabinett Schäffer, S. 56-80.

$220 \mathrm{Vgl}$. Niethammer, Amerikanische Besatzungsmacht, S. 181.

221 IfZ-Archiv, RG 260, 13/142-2/1, Weekly Historical Report for Bavaria No.6, June 15th - June 22nd. Auch Anton Pfeiffer, Leiter der Staatskanzlei, wollte die Möglichkeit einer Neugründung der BVP nicht ausschließen; BayHStA, NL Pfeiffer 32, Notiz Anton Pfeiffers über ein Gespräch mit Vertretern der Militärregierung am 6. 7. 1945.

222 BayHStA, NL Pfeiffer 142, Aktennotiz über ein Gespräch zwischen Fritz Schäffer und Robert R. Reese am 14. 8. 1945.

223 BayHStA, NL Pfeiffer 142, Fritz Schäffer an Robert R. Reese vom 17. 8. 1945.

${ }^{224}$ Zur parteipolitischen Zurückhaltung der ehemaligen BVP-Spitzenpolitiker vgl. Henzler, Fritz Schäffer, S. 165-171. Von indirekten Versuchen Schäffers, die Gründung einer „Art Bayerische[r] Volkspartei“ zu forcieren, berichtet dagegen der zum Kreis um Josef Müller gehörende Karl Köhler, Der Mittwochskreis beim „Ochsensepp“. Die Union wird geboren, in: Schröder, Bayern 1945, S. 67-88, hier S. 72. 


\section{b) Zwischen Bayerischer Volkspartei und Christlich-Sozialer Union}

Seit Juli 1945 wurden in einem Kreis um den Münchner Rechtsanwalt Josef Müller Gespräche über die Gründung einer neuen Partei auf interkonfessioneller Grundlage unter bewußter Abgrenzung von der ehemaligen BVP geführt ${ }^{225}$. Müller und die Teilnehmer des "Mittwochskreises“, dem neben anderen Joseph Baumgartner, Michael Horlacher, Heinrich Krehle, Walther von Miller, Emil Muhler, Friedrich Wilhelm von Prittwitz und Gaffron, Karl Scharnagl und gegen Ende des Jahres auch Franz Josef Strauß angehörten, waren sich mehrheitlich einig darüber, daß die neue Partei eine auf christlichem Solidarismus beruhende, dynamische Bewegung mit stark sozialevolutionären Impulsen sein sollte. Am 8. Juli 1945, nur wenige Wochen nachdem er in Südtirol aus den Händen der SS-Schergen befreit worden war, traf Josef Müller in Rothenburg ob der Tauber mit Adam Stegerwald zusammen, den die amerikanische Besatzungsmacht im April zum Regierungspräsidenten von Unterfranken ernannt hatte ${ }^{226}$. Bei diesem Meinungsaustausch fanden Müller und Stegerwald schnell einen gemeinsamen Nenner. Da kein Protokoll dieser Unterredung überliefert ist, sind wir auf Müllers Erinnerungen angewiesen ${ }^{227}$. Demnach waren der noch weitgehend unbekannte Rechtsanwalt und der ehemalige preußische Ministerpräsident der Meinung, daß eingedenk des Widerstandes evangelischer und katholischer Christen gegen das nationalsozialistische Regime eine neue christliche Partei nur auf interkonfessioneller Grundlage aufgebaut werden könne. Überdies waren beide dafür, „das starre Parteiensystem früherer Zeit" durch eine "dynamische Gruppierung" aufzubrechen. Es sollte jedoch nicht darum gehen, "Katholisches und Evangelisches [zu] addieren, um Mehrheiten zu schaffen“, sondern um „eine geistige Erneuerung“ mit dem Ziel, dem „zu erwartenden Trend zur Vermassung und zum politischen Kollektiv“ durch die „Dynamik dessen entgegen[zu]wirken, was man unter christlicher Kultur verstand“. Was den Namen der zu gründenden Partei anging, so plädierten beide für das Doppelattribut christlichsozial, umstritten war lediglich der letzte Bestandteil des Parteinamens. Stegerwalds Vorschlag, die neue Gruppierung als Christlich-Soziale Arbeiter- und Bauernpartei ins Leben zu rufen, konnte sich nicht durchsetzen. Müller hielt es überhaupt für falsch, Begriffe wie Partei oder Bewegung zu gebrauchen, da sie ihm durch ihre spezifische Bedeutung in der NS-Zeit diskreditiert schienen. Daher legte man sich im Münchner Kreis um Müller wenig später auf den Terminus Union fest, der im Juni 1945 in Berlin aufgekommen war ${ }^{228}$.

${ }^{225}$ Vgl. ebenda sowie Müller, Konsequenz, S. $304 \mathrm{f}$., und Hettler, Josef Müller, S. $203 \mathrm{ff}$. Mitschriften dieser Gesprächsrunden wurden offensichtlich nicht angefertigt. Kurt Heinrich Heizmann, der Informant der Militärregierung, stieß erst im Frühjahr 1946 zum Kreis um Josef Müller; vgl. Lehrjahre, S. $27 \mathrm{f}$.

${ }^{226}$ Müller, Konsequenz, S. 306, verlegt dieses Treffen irrtümlich in den Juni; die korrekte Datierung bei Walter Berberich, Die historische Entwicklung der Christlich-Sozialen Union in Bayern bis zum Eintritt in die Bundespolitik, Diss., Würzburg 1965, S. 34.

$227 \mathrm{Vgl}$. hierzu und zum folgenden Müller, Konsequenz, S. $306 \mathrm{ff}$.

${ }^{228}$ Müller schildert dies in seinen Erinnerungen so: „Plötzlich kam mir der Gedanke, daß im 30 jährigen Krieg die protestantischen Fürsten sich unter dem Namen ,Union' gegen den katholischen Feldherrn Tilly gestellt hatten. Ich bat meinen Gast zu überlegen, ob nicht gerade den evangelischen Christen von der in der Politik, vor allem in Bayern, fester gefügten katholischen Gruppe der Beweis paritätischer Gesinnung am besten dadurch zu erbringen sei, daß wir in Erinnerung an vergangene Zeiten den bei evangelischen Christen im Gedächtnis verbliebenen Namen ,Union“ präsentierten." Ebenda, 
Während sich Adam Stegerwald in Würzburg um den Aufbau der Union bemühte, fielen im Münchner Gründerkreis seit August 1945 Vorentscheidungen, die für die Frühgeschichte der CSU von grundlegender Bedeutung waren. Am 10. August traten die Gründerväter erstmals mit einem Rundschreiben an die Öffentlichkeit ${ }^{229}$. Der Zeitpunkt für diesen Schritt war kaum zufällig gewählt, die Initiative erscheint vielmehr als vorbereitete Reaktion auf die erwartete Genehmigung politischer Betätigung durch die Militärregierung ${ }^{230}$. Als Autor dieser programmatischen Ausführungen zeichnete lediglich der vorläufige Münchner Oberbürgermeister Karl Scharnagl, doch sie erinnern so sehr an die zwischen Josef Müller und Adam Stegerwald abgestimmten Vorstellungen, daß Müllers Mitverfasserschaft nicht auszuschließen ist ${ }^{231}$. Scharnagl skizzierte eine neue politische Partei, die sich „bewußt und entschieden zu einer christlichen Staats- und Gesellschaftsauffassung bekennen und dieses Bekenntnis, soweit wie möglich, praktisch werden lassen " müsse. Zugleich verlieh der Oberbürgermeister der Hoffnung Ausdruck, daß diese Partei „den Hauptteil der Bevölkerung erfassen“ würde, und zwar Menschen „aller Berufskreise und aller Schichten“. In diesem Sinne plädierte er für eine Abkehr von bisherigen Traditionen und dafür, „neue Wege“ zu gehen. Die „bisherigen Formen politischer Betätigung der Parteien“ müßten „verschwinden“, da sie ihrer Zersplitterung und „ihrer beengten Zielsetzungen wegen überholt und in der Zukunft unmöglich“ seien. Es stand für Scharnagl auch fest, daß man keinesfalls an die Namen von ehemaligen Parteien anknüpfen konnte; er schlug in Anlehnung an die Entwicklungen im Rheinland die Bezeichnungen "Christliche Demokraten" und "Christliche Demokratische Volksbewegung" vor ${ }^{232}$.

Bereits vier Tage später fand im Münchner Rathaus eine erste Besprechung statt, die mehr war als die bisherigen Aktivitäten der eher privaten Zirkel ${ }^{233}$. Die Einladung dazu war von Karl Scharnagl ausgegangen, wie Müller später berichtete, auf seine Bitte hin $^{234}$. Unter denjenigen, die sich am 14. August im Rathaus einfanden, waren neben Scharnagl und Josef Müller Persönlichkeiten wie der Münchner Stadtpfarrer Emil Muhler, der spätere Vorsitzende des Satzungsausschusses der CSU Max Gerstl, Heinrich Krehle, in den Kabinetten Hoegners und Ehards Staatssekretär und Arbeitsminister, der spätere Landwirtschaftsminister und Vorsitzende der Bayernpartei Joseph Baumgartner, Franz Xaver Stadelmayer, im Mai 1945 von den amerikanischen Militär-

S. $308 \mathrm{f}$. Ob Müller und Stegerwald von den Berliner Entwicklungen zu diesem Zeitpunkt bereits Kenntnis hatten, ist unklar. Vgl. Herde, Unionsparteien, in: Becker (Hrsg.), Kapitulation, S. 267 f. und Anm. 79.

229 IfZ-Archiv, ED 120 NL Hoegner 331, Rundschreiben Karl Scharnagls vom 10. 8. 1945.

230 Das Rundschreiben beginnt mit dem Satz: „General Eisenhower hat in seiner Proklamation betont, $\mathrm{daß}$ nunmehr auch wieder eine örtliche politische Betätigung zugelassen werden soll.“

231 Vgl. Fait, Einleitung zu: Protokolle und Materialien, S. IX f.

232 Konrad Adenauer setzte Scharnagl wenig später ausführlicher über die Gründung einer christlichen Partei im Rheinland in Kenntnis und bat den Münchner Oberbürgermeister und seine Gesinnungsgenossen "sich dieser Entwicklung anschließen zu wollen“. Konrad Adenauer an Karl Scharnagl vom 21.8. 1945, in: Adenauer, Briefe 1945-1947, S. $77 \mathrm{ff}$.

233 BayHStA, NL Pfeiffer 41, Notizen Anton Pfeiffers über eine Besprechung am 14. 8. 1945. Die Übertragung der stenographischen Mitschrift Pfeiffers wurde nachträglich in den Nachlaß eingefügt. Die Notizen Pfeiffers von den Sitzungen am 14.8. und am 12.9. 1945 wurden erstmals ausgewertet von Reuter, Anton Pfeiffer, S. 121-135; vgl. auch Fait, Einleitung zu: Protokolle und Materialien, S. VIII-XX, und Fait, Anfänge, S. 26-36.

${ }^{23}$ Vgl. Müller, Konsequenz, S. 310. Berberich, Historische Entwicklung, S. 38, und Reuter, Anton Pfeiffer, S. 121, gehen dagegen davon aus, daß Scharnagl im Einvernehmen mit Müller und Schäffer zu den Gründungsgesprächen einlud, ohne jedoch einen Quellenbeleg dafür zu nennen. 
behörden zu einem der Stellvertreter Scharnagls ernannt, sowie Max Grasmann, der zwischen 1946 und 1948 das undankbare Amt des Landesschatzmeisters der CSU bekleiden sollte. Adam Stegerwald war in diesem Kreis nicht vertreten ${ }^{235}$, und auch Fritz Schäffer war nicht erschienen. Als Vertreter des Ministerpräsidenten fungierte jedoch Anton Pfeiffer, der Leiter der Staatskanzlei und ehemalige Generalsekretär der $\mathrm{BVP}^{236}$. Im Zentrum der Besprechung stand eine programmatische Rede Müllers, der die Anwesenden über die politische Lage informierte und dann seine Vorstellungen von einer neuen, interkonfessionellen Sammlungspartei als Alternative zu sozialdemokratischen und kommunistischen Gruppierungen skizzierte. Nach den stichpunktartigen Notizen Pfeiffers führte Müller aus:

„Für uns: Gruppierung, die auf Reichsgruppierung hinausläuft, Reichstreue und R[eichs]-Verfassung. Hauptfrage: die christl[ichen] Bekenntnisse. Nicht in alte Parteigliederungen und alte Personen. In N[ord]-Deutschland auch P[artei]-Bildung schon begonnen. Christl[iche] Bekenntnisse die aktivsten Kräfte gegen N. S. . . [Unter]grundkampf. Front der Anständigen. Zuerst Fühlung gesucht mit den kirchlichen Kreisen, dann mit den anderen Kreisen, besonders mit der linken Seite [...] Schwierig, wenn der Personenkreis angelehnt wird an die Kreise der alten B. V.[P.] oder der alten D. N. V.[P.] Zuerst Programm aufstellen und dann die Personen feststellen. [...] Man kommt nicht mit den alten Methoden des Denkens und der Parteien durch. [. . . Überalterung im Augenblick. Wird von den Amerikanern jetzt betont. Wird auch in der Parteiführung zum Ausdruck kommen." ${ }^{\text {237 }}$

Damit machte Müller unmißverständlich klar, daß er die Wiederbelebung von 1933 verbotenen oder aufgelösten Organisationen ebenso ablehnte wie die Gründung einer auf Bayern begrenzten Partei nach dem Vorbild der BVP. Auch eine rein bürgerliche Partei kam für ihn nicht in Frage; „Bürgertum“, so Müller, sei ein überholter Begriff.

Obwohl auch Bedenken gegen die frühzeitige Wiederzulassung politischer Parteien laut wurden, besteht kein Zweifel, daß sich der Münchner Gründerkreis als Kristallisationskern einer künftigen landesweiten Partei verstand und einen entsprechenden Führungsanspruch erhob. Max Grasmann betonte, es sei „höchste Zeit, die Organisation hinzustellen“, und forderte, „Fühlung mit außerhalb [zu] nehmen“ und eine „Dachorganisation auf[zu]bauen für das Land“. Zugleich beklagte Grasmann die bisher fehlende Koordination zwischen den regionalen und lokalen Initiativen ${ }^{238}$.

Während der Diskussion zeichnete sich bereits ein Konfliktpunkt ab, der die Gründung der bayerischen Unionspartei und ihre weitere Entwicklung stark belasten sollte: das von Anfang an problematische Verhältnis zwischen führenden Repräsentanten der untergegangenen BVP und den Vertretern der neuen Konzepte, die sich bewußt von

${ }^{235}$ Nach Herde, Unionsparteien, in: Becker (Hrsg.), Kapitulation, S. 268, war Stegerwald nicht eingeladen, was angesichts der politischen Rahmenbedingungen durchaus wahrscheinlich ist. Ob Franziska Kimpfler, die Privatsekretärin Stegerwalds, in dessen Auftrag an der Sitzung am 14. August teilgenommen hat oder erst an der Sitzung am 12. September, ist nicht zweifelsfrei zu klären; vgl. ebenda, S. 268 f. und Anm. 80.

${ }^{236}$ Vgl. Reuter, Anton Pfeiffer, S. 121.

${ }^{237}$ BayHStA, NL Pfeiffer 41, Notizen Anton Pfeiffers über eine Besprechung am 14. 8. 1945; das folgende nach ebenda.

${ }^{238}$ Nach Müllers Ausführungen erwartete man offenbar nicht, daß die Militärregierung die Gründung politischer Parteien auf Orts- und Kreisebene begrenzen würde; darauf verwies Fritz Schäffer erst in einer Besprechung am 12. September; BayHStA, NL Pfeiffer 41, Notizen Anton Pfeiffers über eine Besprechung (Aktionsausschuß), undatiert. Die Übertragung der stenographischen Mitschrift Pfeiffers wurde nachträglich in den Nachlaß eingefügt. 
dieser katholisch-konservativen, extrem föderalistischen Landespartei absetzten ${ }^{239}$. Nach Müllers Erinnerungen verwies Anton Pfeiffer in der Besprechung am 14. August ,auf die einstige Größe und Bedeutung der BVP und vertrat die Meinung, Fritz Schäffer als ihr einstiger Vorsitzender habe ein primäres Recht, auch an die Spitze einer Neugründung zu treten ${ }^{\text {“240. }}$. Doch diese Worte stießen offensichtlich auf taube Ohren; lediglich Max Gerstl verwies auf die Notwendigkeit, den „bayer[ischen] Anhang“ in die Überlegungen zur Parteigründung einzubeziehen. Ansonsten sprachen sich alle Diskussionsteilnehmer mehr oder weniger eindeutig gegen eine Anknüpfung an überkommene Traditionen aus.

Die Auseinandersetzung über die Rolle der BVP in der Weimarer Republik und über die künftige Rolle von ehemaligen BVP-Politikern in der neu zu gründenden Partei begann wenige Wochen später zu eskalieren. Am 12. September kam die Kommission, die im August zur Erarbeitung eines Programmentwurfes bestellt worden war ${ }^{241}$, zu einer Sitzung zusammen. Neben den fünf Mitgliedern - Grasmann, Krehle, Müller, Schlögl und Pfeiffer - hatten sich unplanmäßig auch andere Personen eingefunden, darunter erstmals auch Fritz Schäffer, der seine parteipolitische Zurückhaltung allmählich aufzugeben begann ${ }^{242}$. Im Mittelpunkt der Besprechung standen die Wahl eines „arbeitsfähigen“ Ausschusses, der mit vordringlichen Satzungs-, Organisations- und Programmfragen betraut werden sollte, sowie die zumindest vorläufige Festlegung eines Parteinamens. Da beide Entscheidungen eng mit der Frage zusammenhingen, ob man an die Tradition der BVP anknüpfen oder sich davon abgrenzen sollte, war die Atmosphäre von Anfang an gespannt. Wieder machte sich Anton Pfeiffer Notizen, und bereits die einleitenden Worte über die Führungsmannschaft der neu zu gründenden Partei mußten den ehemaligen Generalsekretär der BVP alarmieren:

„Entscheidend [ist] die Personenauswahl. - Darf keine Fortsetzung der alten Bayerischen Volkspartei sein. 1.) In 1. Linie Personen wählen, die politisch Neuland sind, für die Masse, die politisch Neuland ist. 2.) Nach den Gesichtspunkten, wie sie sich in den letzten 12 Jahren kämpferisch bewährt haben."

So dachte die Mehrheit, Schäffer hingegen war anderer Meinung. Aus der vorsichtigen Stellungnahme des Ministerpräsidenten sprach Skepsis gegen den Gedanken einer Sammlungspartei, und er warnte davor, ein „Beispiel aus der russischen Zone nach[zu]machen“243. Man müsse, so Schäffer weiter, entweder versuchen, „alles, was

${ }^{239}$ Noch elf Monate später bezeichnete Wilhelm Eichhorn „die personellen Schwierigkeiten innerhalb der Union als Erbe der Bayerischen Volkspartei“. Protokoll der Sitzung des Landesarbeitsausschusses der CSU am 5. 7. 1946 in München, in: Protokolle und Materialien, S. 413.

${ }^{240}$ Müller, Konsequenz, S. 310.

${ }^{241}$ Mehrere Programmentwürfe finden sich im BayHStA, NL Pfeiffer 41. Der Entwurf des Grundsatzprogramms einer "Christlichen Volkspartei in Bayern" vom 5. 9. 1945 und das eventuell als begleitender Aufruf konzipierte "Grundsatz-Programm einer Christlich-Demokratischen Volkspartei in Bayern" vom selben Tag sind auch abgedruckt bei Repgen, Anfänge des CSU-Programms, in: Kraus (Hrsg.), Land und Reich, Bd. 3, S. 467-471.

${ }^{242}$ BayHStA, NL Pfeiffer 41, Notizen über eine Besprechung (Aktionsausschuß), undatiert; das folgende nach ebenda. Zur Datierung auf den 12. 9.1945 vgl. Fait, Einleitung zu: Protokolle und Materialien, S. XVI. Vgl. auch Fait, Anfänge, S. 37-42.

${ }^{243}$ Es wird aus den Notizen Pfeiffers nicht ganz klar, worauf Schäffer mit dieser Bemerkung anspielte, ob auf die am 26.6. 1945 in Berlin gegründete CDU oder die seit dem 14.7. 1945 bestehende „Einheitsfront der antifaschistisch-demokratischen Parteien“. Im Kontext der Ausführungen des Ministerpräsidenten erscheint jedoch ersteres wahrscheinlicher. 
rechts von den Soz[ialisten] steht, zu nehmen, oder es macht jeder seinen alten Laden auf ". Zugleich mahnte er jedoch zur Eile, da sozialdemokratische und kommunistische Gruppierungen schon aktiv geworden seien. Ob dies tatsächlich das alleinige Motiv für sein Drängen war, läßt sich nicht sagen, vielleicht hoffte Schäffer auch darauf, daß Zeitdruck notwendige Diskussionen im heterogenen Münchner Gründerkreis verhindern und den Sammlungsgedanken obsolet machen würde. In diesem Sinne könnte man jedenfalls seine Äußerung verstehen, an das Land die Empfehlung herauszugeben, vorerst wieder auf den alten Namen Bayerische Volkspartei zurückzugreifen, sofern keine anderen Richtlinien ergingen.

Diese Ausführungen riefen massiven Widerspruch hervor. Max Grasmann warf Schäffer vor, daß der Nationalsozialismus nicht zum Durchbruch gekommen wäre, „wenn die Parteien nicht so gefehlt hätten “244, und der Münchner Domkapitular Erwin von Kienitz betonte, daß auch die katholische Kirche am Zustandekommen einer interkonfessionellen Partei interessiert sei und sich „nicht mehr hergeben [würde], einer früheren Bayerischen Volkspartei den Segen der Kirche zu geben “245. Auch Karl Scharnagl sah sich gezwungen, diesbezügliche Bedenken zu zerstreuen. „Niemand denkt ernsthaft daran“, so der Oberbürgermeister, der vor 1933 selbst ein prominentes Mitglied der BVP gewesen war, „die Bayerische Volkspartei wieder zum Leben erstehen zu lassen. Weder im Namen noch im Programm noch im Umriß der zu benennenden Personen. " ${ }^{246}$ Damit hatte er sich nicht nur von der Tradition der BVP distanziert, sondern vor allem auch ihrem politisch ambitionierten Führungspersonal eine Absage erteilt. Ehemalige Spitzenpolitiker der BVP sollten in der neu zu gründenden Partei lediglich aus Gründen des inneren Proporzes und der Propaganda Verwendung finden. Grasmann sprach dies offen aus, allerdings nicht ohne versöhnlichere Töne anzuschlagen: „Es ist nicht so auf dem Land und nicht in der Stadt, daß man die früheren Parteien so ablehnt. Aus propagandistischen Gründ[en] eine Reihe von diesen Persönlichkeiten aufnehmen, weil wir ihre Arbeit und ihre Namen brauchen.“

Die BVP-Traditionalisten wiesen die Vorwürfe gegen ihre alte Partei mit dem durchaus apologetischen Argument zurück, die BVP hätte seit 1919 „bewiesen, dass sie der stärkste Block i[n] Bayern im Kampf gegen den Nationalsozialismus und eine zentralistische Gewaltpolitik“ gewesen sei ${ }^{247}$. „In Anerkennung der bewährten Grundsätze“

244 Eine Zusammenfassung der Kritikpunkte an der Politik der BVP bei Müller, Konsequenz, S. 311.

245 Auf diese Äußerungen reagierte Pfeiffer nur einen Tag später besonders ungehalten. Die BVP, so ihr ehemaliger Generalsekretär, hätte es bestimmt nicht nötig gehabt, „auf den Krücken kirchlichen Segens so einherzuhumpeln [...], wie es aus Ihren Worten geschlossen werden mußte“. BayHStA, NL Pfeiffer 533, Anton Pfeiffer an Erwin von Kienitz vom 13. 9. 1945.

246 Diese Position vertrat Scharnagl auch in der Folgezeit nachdrücklich: „Die im Brief niedergelegte Befürchtung einer Wiederauferstehung der Bayerischen Volkspartei mit der Wirkung einer neuerlichen Aufsplitterung ist tatsächlich in sehr weiten Kreisen verbreitet. Es ist nun meine Auffassung von Anfang an gewesen, diesen Befürchtungen den Boden zu entziehen durch die immer wiederkehrende und nachdrückliche Erklärung, daß die Bayerische Volkspartei als solche erledigt ist. Mit einer solchen Stellungnahme verleugnet man in gar keiner Weise die Partei als solche, ihre Tätigkeit oder gar ihre früheren Führer und Mitglieder. Ich bedauere sehr, daß man diese an sich ebenso notwendige wie billige Stellungnahme vielfach bei uns nicht einnehmen will.“ BAK, NL Schäffer 17, Bl. 558, Karl Scharnagl an Fritz Schäffer vom 9. 2. 1946.

247 BayHStA, NL Pfeiffer 41, undatierter, vermutlich von Anton Pfeiffer oder Karl Schwend verfaßter Entwurf eines Aufrufs zur Gründung einer politischen Partei; das folgende Zitat ebenda. Ähnlich äußerte sich mehrere Monate später auch Fritz Schäffer, der warnend hinzufügte: „Wir können nicht die Leute der Bayerischen Volkspartei nur deshalb, weil sie dabei waren, als Unionsanhänger zweiter 
glaubte man darüber hinaus, wieder auf die Unterstützung der Bevölkerung für eine Nachfolgepartei der BVP rechnen zu können. Besonders verbittert, aber auch kämpferisch reagierte Anton Pfeiffer, der Scharnagl nicht nur Verrat an den eigenen politischen Grundsätzen vorwarf, sondern auch drohend bemerkte, die „totgesagte Bayerische Volkspartei [habe] bestimmt mehr Lebenskraft und Lebenswillen als manches Gebilde, an dem z.Zt. herumgezimmert wird“248.

Die Besprechung am 12. September brachte für die Anhänger der BVP eine doppelte Niederlage. Mit dem Terminus „Bayerische Christlich-Soziale Union“ entschied sich die Versammlung für einen Parteinamen, von dem Schäffer noch im März 1946 sagte, daß er ihm „ja noch nie sonderlich gefallen" habe ${ }^{249}$. Nach Pfeiffers Notizen bestanden zwei Alternativen, und zwar der Name „Bayerische Union“, da man - wie Schäffer betonte - das "Wort bayerische [...] gar nicht mehr vermeiden " könne, und die Empfehlung „Bayerische Arbeiter- und Bauernpartei“ von Franz Xaver Fackler ${ }^{250}$. Schließlich wurde über den von Prälat von Kienitz oder Josef Müller eingebrachten Vorschlag „Bayerische Christlich-Soziale Union“ abgestimmt, wobei die Anwesenden auf Antrag Pfeiffers die vier Namensbestandteile einzeln festlegten ${ }^{251}$. Die Entscheidung für das Prädikat "Christlich" fiel mit neun gegen acht Stimmen denkbar knapp aus, dagegen stimmten bei vier Gegenstimmen und einer Enthaltung zwölf Teilnehmer für das Attribut „Sozial“, während der Begriff „Union“ bei einer Gegenstimme und einer Enthaltung fast einstimmig angenommen wurde. Ein abschließendes Votum über den kompletten Namensvorschlag ließ trotz der teilweise heftigen Diskussion keine Differenzen mehr erkennen.

Auch bei der Wahl des zehnköpfigen Ausschusses, dem die weitere organisatorische und programmatische Vorbereitung übertragen werden sollte, konnte sich das Führungspersonal der BVP nicht durchsetzen. Fritz Schäffer selbst war nicht vertreten, und auch sein Vertrauter Anton Pfeiffer, der sich in der am 14. August bestellten Kommission stark engagiert hatte, fehlte im neugewählten Ausschuß. Dagegen gehörten diesem Gremium mit Josef Müller, Johannes Semler, Alois Schlögl, Erwin von Kienitz und Max Schnurr Persönlichkeiten an, die sich explizit dagegen ausgesprochen hatten, an die Tradition der BVP anzuknüpfen ${ }^{252}$.

Als dieser Ausschuß, der sich seit seiner konstituierenden Sitzung „Ausschuß zur Vorbereitung der Gründung einer Christlich-Sozialen Union" nannte ${ }^{253}$, am 21. Sep-

Klasse betrachten." Protokoll der Sitzung des Erweiterten Vorläufigen Landesausschusses der CSU am 30./31.3. 1946 in Bamberg, in: Protokolle und Materialien, S. 113.

248 BayHStA, NL Pfeiffer 533, Anton Pfeiffer an Karl Scharnagl vom 13. 9. 1945; das Antwortschreiben Karl Scharnagls an Anton Pfeiffer vom 16. 9.1945 ebenda.

${ }^{249}$ Protokoll der Sitzung des Erweiterten Vorläufigen Landesausschusses der CSU am 30./31. 3. 1946 in Bamberg, in: Protokolle und Materialien, S. 112. Die Militärregierung verlangte jedoch die Streichung des Attributs „Bayerische“, so daß die endgültige Bezeichnung Christlich-Soziale Union in Bayern lautete; vgl. Müller, Konsequenz, S. 310.

${ }^{250}$ BayHStA, NL Pfeiffer 41, Notizen über eine Besprechung (Aktionsausschuß), undatiert.

251 Nach Pfeiffers Notizen kam der Vorschlag von Erwin von Kienitz, nach Müller, Konsequenz, S. 310, brachte der spätere CSU-Vorsitzende diese Empfehlung selbst in die Debatte ein. Müller berichtet auch von Pfeiffers Antrag, über jeden Namensbestandteil einzeln abzustimmen.

${ }^{252}$ Daneben gehörten Heinrich Krehle, Baumeister, Dr. Straimer, Hans Hermann von Eicken und Franz Xaver Fackler dem neu gewählten Ausschuß an.

${ }^{253}$ Vgl. das Protokoll der ersten Besprechung des Ausschusses zur Vorbereitung der Gründung einer Christlich-Sozialen Union am 17. 9. 1945 in München, in: Protokolle und Materialien, S. 3 f. Vgl. auch Fait, Anfänge, S. 43. 
tember zu einer Besprechung zusammenkam, fiel eine weitere Vorentscheidung, die für neuen Konfliktstoff sorgen sollte ${ }^{254}$. Im Zuge der Vorbereitungen für eine Gründungsversammlung der CSU in der Landeshauptstadt nahmen die Mitglieder des Vorbereitenden Ausschusses eine „probeweise Abstimmung über die Meinung der Anwesenden über die Person des künftigen Parteivorsitzenden für München“ vor. Fünf der acht stimmberechtigten Teilnehmer, unter denen sich kein Vertreter Schäffers befand, votierten für Josef Müller, lediglich Baumeister stimmte dagegen, während sich Rudolf Schwarzer und Müller selbst der Stimme enthielten. Obwohl laut Protokoll Einvernehmen darüber bestand, „daß dieser Beschluß nur die Meinung des Ausschusses feststellen und der Abstimmung in der Gründungsversammlung nicht vorgreifen soll“, war man sich der Brisanz der Abstimmung durchaus bewußt.

Der Versuch, Schäffer am nächsten Tag durch eine Delegation unter der Führung Michael Horlachers und Karl Scharnagls möglichst schonend vom Ergebnis der Probeabstimmung zu unterrichten, kam jedoch zu spät, da die Neuigkeit schnell die Runde machte. Der Ministerpräsident und seine Mitstreiter reagierten sofort. Noch am Abend des 21. September fand eine von Schäffer und Pfeiffer initiierte Besprechung über alternative Möglichkeiten einer Parteigründung statt ${ }^{255}$. Nur einen Tag später lud Pfeiffer zu einer Veranstaltung, auf der eine Konkurrenzpartei aus der Taufe gehoben werden sollte $^{256}$. Dieser Versuch, die Initiative zurückzugewinnen, scheiterte jedoch, ja es läßt sich anhand der verfügbaren Quellen nicht einmal sagen, ob die für den 24. September angesetzte Versammlung überhaupt in der geplanten Form stattgefunden hat ${ }^{257}$. Vier Tage später teilte Josef Müller prominenten Vertretern der bayerischen Sozialdemokratie und der Kommunisten mit: „Die bayer[ische] christlich soziale Union ist gegründet worden, und zwar jetzt als einheitliches Gebilde.“ Es habe keine „Splitterungen“ gegeben, auch die vorhandenen „Dissonanzen“ seien behoben ${ }^{258}$. Man darf davon ausgehen, daß Müller die Konflikte in der eigenen Partei herunterzuspielen suchte, aber es spricht vieles dafür, daß die Kontrahenten zumindest eine vorübergehende Einigung erzielen konnten ${ }^{259}$.

${ }^{254}$ Vgl. Protokoll der Sitzung des Vorbereitenden Ausschusses der CSU am 21. 9. 1945, in: Protokolle und Materialien, S. 5 f.; das folgende nach ebenda.

${ }^{255} \mathrm{Ob}$ die Initiative Schäffers und Pfeiffers tatsächlich durch das Ergebnis der Probeabstimmung ausgelöst wurde, läßt sich nicht mit Sicherheit sagen; Josef Müller berichtete Vertretern der Sozialdemokraten und Kommunisten schon am 20. September, daß in der neu zu gründenden christlichen Partei eine von Schäffer geführte "Opposition" vorhanden sei, „die zurückkommen wollte auf die bayer[ische] Volkspartei." ACSP, NL Müller 8, Protokoll über Verhandlungen zwischen Vertretern von CSU, SPD und KPD am 20. 9. 1945.

256 BayHStA, NL Pfeiffer 533, Anton Pfeiffer an Karl Scharnagl vom 22. 9. 1945. Die Einladung erging im Auftrag Fritz Schäffers, der auch für den Vorsitz dieser Besprechung vorgesehen war. Vgl. Fait, Anfänge, $S .44 \mathrm{f}$.

${ }^{257}$ So auch Henzler, Fritz Schäffer, S. 171. Etwas konstruiert dagegen Fait, Einleitung zu: Protokolle und Materialien, S. XXI ff. Eine maschinenschriftliche Teilnehmerliste für die Besprechung am 24. 9. 1945, die sich im BayHStA, NL Pfeiffer 41, findet, ist kein Beweis dafür, daß diese auch tatsächlich stattgefunden hat. Der Vermerk "Weiter sollen noch angeschrieben werden“, gefolgt von einer Reihe weiterer Namen, ist eher ein Hinweis darauf, daß es sich hier um eine vorher angefertigte Einladungs- und nicht um eine Anwesenheitsliste handelt.

258 ACSP, NL Müller 8, Protokoll über Verhandlungen zwischen Vertetern von CSU, SPD und KPD am 28. 9. 1945.

259 Fritz Schäffer selbst berichtet von einem Versuch, in diesen Tagen mit Josef Müller „Frieden zu schließen“, ohne jedoch Hinweise für eine genaue Datierung zu liefern. Protokoll der Sitzung des Erweiterten Vorläufigen Landesausschusses der CSU am 30./31. 3. 1946 in Bamberg, in: Protokolle und Materialien, S. 108. 


\section{c) Der Sturz Fritz Schäffers und seine Folgen}

Während Josef Müller noch mit Politikern der beiden Arbeiterparteien konferierte, bahnte sich bereits die nächste Krise im Münchner Gründerkreis an, die alle Versuche, die Gegensätze zwischen Müller und Schäffer zu überbrücken, illusorisch werden ließ. Am Abend des 28. September wurde Ministerpräsident Schäffer von der amerikanischen Militärregierung entlassen und durch den Sozialdemokraten Hoegner ersetzt. Die Ablösung Schäffers war zweifellos primär das Ergebnis einer Umorientierung der amerikanischen Besatzungspolitik und einer Pressekampagne über den angeblich skandalösen Verlauf der politischen Säuberung in Bayern. Ohne die wirklichen Hintergründe zu kennen, lastete der ehemalige BVP-Vorsitzende die Hauptverantwortung für seinen Sturz den ungeliebten Widersachern Josef Müller und Adam Stegerwald $a^{260}$. Noch mehr als zwei Jahre später hatte der persönlich tief getroffene Schäffer seinen Groll gegen die vermeintlichen Intrigen nicht überwunden:

„Als ich noch Ministerpräsident war, merkte ich, daß es - nicht bei der Münchner Militärregierung, die Leute kannten mich und hatten zu mir persönliches Vertrauen, sondern außerhalb, in Frankfurt damals - deutsche Kreise gewesen sind, (hört!) die gegen mich intrigiert haben [...] Nun, es waren Leute unserer Richtung - ich darf einmal die Namen aussprechen: Stegerwald und Dr. Josef Müller (hört!) -, die in Frankfurt damals gegen mich Stimmung gemacht haben: (Pfui Teufel!) Das ist der sozialreaktionäre Mann!“261

Richtig ist, daß sich sowohl Müller als auch Stegerwald Chancen ausrechneten, bei einer Ablösung Schäffers selbst zu dessen Nachfolger berufen zu werden. Mitte September kursierte eine Kabinettsliste, in der Stegerwald oder Müller als Chef einer Regierung aus CSU, SPD und KPD geführt wurden ${ }^{262}$. Der spätere Vorsitzende der bayerischen Unionspartei hatte nie einen Hehl daraus gemacht, daß er das Kabinett Schäffer als „reine Notstandsregierung“ und „Übergangslösung“ betrachtete und daß er es für wünschenswert hielt, diese, „sobald die Verhältnisse dies erlaubten, durch eine Regierung zu ersetzen, in der die von der Bevölkerung vertretenen politischen Anschauungen etwa ihrem Gewicht entsprechend vertreten wären "263. In diesem Sinne äußerte sich Müller, der - um für alle Fälle gerüstet zu sein und Alternativen anbieten zu können - mit Vertretern der Kommunisten und Sozialdemokraten über ein gemeinsames Regierungsprogramm verhandelte ${ }^{264}$, Mitte September auch gegenüber

${ }^{260}$ Vgl. dazu Henzler, Fritz Schäffer, S. 156 ff., sowie Fait, Einleitung zu: Protokolle und Materialien, S. XXIII-XXVIII. Interessante Einblicke vermittelt auch IfZ-Archiv, RG 260, 15/108-2/17, OSS Field Intelligence Study 24: „The Position of Prime Minister Schaeffer and the Organization of the Bavarian Christian Social Union“, 27.9. 1945; auszugsweise abgedruckt in: Zwischen Befreiung und Besatzung, S. $191 \mathrm{ff}$.

261 BAK, NL Schäffer 22, Bl. 1-48 (hier Bl. 15f.), Protokoll der Bezirksversammlung der CSU Oberbayern am 14. 2. 1948 in München.

262 Vgl. Fait, Einleitung zu: Protokolle und Materialien, S. XXVII, und Schäffers eigene Ausführungen vor den Delegierten der Bezirksversammlung der CSU Oberbayern am 14.2. 1948 in München; BAK, NL Schäffer 22, Bl. 1-48 (hier Bl. 15 f). ACSP, NL Müller 225, Kabinettsliste, undatiert.

263 IfZ-Archiv, Fh 56, Aktennotiz Josef Müllers über sein Verhältnis zu Fritz Schäffer, undatiert (November/Dezember 1945). Müller hatte sich bereits während der Besprechung am 14. August skeptisch zu Schäffer und seiner provisorischen Regierung geäußert; BayHStA, NL Pfeiffer 41, Notizen Anton Pfeiffers über eine Besprechung am 14. 8. 1945.

264 IfZ-Archiv, Fh 56, Aktennotiz Josef Müllers über sein Verhältnis zu Fritz Schäffer, undatiert (November/Dezember 1945). 
der Militärregierung ${ }^{265}$. Müller führte seine Gespräche jedoch nicht hinter dem Rükken des Ministerpräsidenten, sondern setzte Anton Pfeiffer davon in Kenntnis und bat ihn, Schäffer zu informieren ${ }^{266}$. Ob der Ochsensepp seine Verbindungen zur Besatzungsmacht nutzte, um seine Vorbehalte gegen den ehemaligen BVP-Vorsitzenden geltend zu machen, sei dahingestellt. Ein Wochenbericht der amerikanischen Militärregierung in München zeigt jedoch ein anderes Bild. Nach seiner Meinung zur provisorischen Regierung Schäffer befragt, empfahl Müller der Militärregierung nachdrücklich, den Ministerpräsidenten entweder mehr als bisher zu unterstützen oder ihn zu ersetzen ${ }^{267}$. Zweifellos wurde auch Müller vom Zeitpunkt der Ablösung Schäffers überrascht, und es hieße seinen Einfluß zu überschätzen, wenn man ihm einen maßgeblichen Anteil an dieser Entscheidung zubilligte. Vor dem Hintergrund der sich abzeichnenden Führungs- und Flügelkämpfe in der jungen CSU hielten sich jedoch hartnäckig Gerüchte, Müller, der immer wieder mit seinen Verbindungen zu amerikanischen Stellen kokettierte, habe den Sturz des Ministerpräsidenten aktiv betrieben $^{268}$.

Mit seiner Entlassung war die Position des ehemaligen BVP-Vorsitzenden im Formierungsprozeß der CSU wesentlich schwächer geworden, da es ihm nun nicht mehr möglich war, aus seinem Staatsamt auch einen Anspruch auf die Führung der noch zu gründenden Partei abzuleiten ${ }^{269}$. Andererseits konnte sich Schäffer nun frei von allen Rücksichten, die die Ministerpräsidentschaft mit sich gebracht hatte, in den Aufbau der CSU einschalten. Nur wenige Tage nach seinem Sturz richtete Schäffer in einer Sitzung des Vorbereitenden Ausschusses scharfe Angriffe gegen Josef Müller und beschuldigte ihn, gemeinsam mit seinen politischen Freunden die provisorische Regierung gestürzt zu haben. Als Schäffer den Wahrheitsgehalt der Erklärungen seines Kontrahenten bezweifelte und sich weigerte, eine geforderte Ehrenerklärung für diesen abzugeben, kündigte Müller an, die Zusammenarbeit solange einzustellen, bis Schäffer

${ }^{265}$ IfZ-Archiv, Smlg. Henke, Bericht Richard G. Jacksons über ein Gespräch mit Josef Müller am 12.9. 1945; vgl. auch Ferdinand Kramer, Der Neuanfang des U. S.-Generalkonsulates in München nach 1945, in: Egon Johannes Greipl, Alois Schmid, Walter Ziegler (Hrsg.), Aus Bayerns Geschichte. Forschungen als Festgabe zum 70. Geburtstag von Andreas Kraus, St. Ottilien 1992, S. 465-496, hier S. 470 .

266 IfZ-Archiv, Fh 56, Aktennotiz Josef Müllers über sein Verhältnis zu Fritz Schäffer, undatiert (November/Dezember 1945); dies berichtete Müller auch Vertretern von SPD und KPD; ACSP, NL Müller 8, Protokoll über Verhandlungen zwischen Vertetern von CSU, SPD und KPD am 20.9. 1945.

267 IfZ-Archiv, Smlg. Henke, Bericht Richard G. Jacksons über ein Gespräch mit Josef Müller am 12.9. 1945. Eine andere Quelle spricht dagegen von einer "conspiracy" zum Sturz Schäffers, angeführt von Müller und Stegerwald, die viel dazu beigetragen habe, die Stellung des Ministerpräsidenten zu schwächen und für einen großen Teil des Drucks verantwortlich gewesen sei, der schließlich zu Schäffers Sturz geführt habe. IfZ-Archiv, RG 260, AG 1947/1/2, Memorandum Innes Randolphs für General Conrad vom 26. 10. 1945. Die unterschiedlichen Sichtweisen dürften auf die jeweiligen Gesprächspartner und Informanten ebenso zurückzuführen sein wie auf die Nähe der amerikanischen Beobachter zum Ort des Geschehens und auf den politischen Standort der Besatzungsoffiziere selbst.

${ }^{268}$ So z. B. Hoegner, Außenseiter, S. 201.

${ }^{269}$ Müller berichtete später, Schäffer habe unmißverständlich erklärt, die amerikanischen Militärbehörden hätten ihn als Vorsitzenden der untergegangenen BVP zum Ministerpräsidenten ernannt und daher „könnte er jetzt von seinen Freunden, von den Leuten erwarten, daß sie ihm das Vertrauen zum Ausdruck bringen würden, daß er hier die Gründung vollziehe und die Führung übernehme“. Protokoll der Sitzung des Erweiterten Vorläufigen Landesausschusses am 30./31.3. 1946 in Bamberg, in: Protokolle und Materialien, S. $130 \mathrm{f}$. 
seine Vorwürfe zurückgenommen habe ${ }^{270}$. Diese Entwicklungen überschatteten die Gründungsversammlung der Münchner CSU, die am 11. Oktober in größerem Rahmen abgehalten wurde ${ }^{271}$. Wieder stand die Wahl eines Ausschusses auf der Tagesordnung, der die Vorarbeiten für die Formulierung eines Parteiprogramms und einer Satzung übernehmen sollte. Um die persönlichen Gegensätze zwischen Müller und Schäffer nicht zu einer permanenten Belastung für den vorläufigen Vorstand der Münchner CSU werden zu lassen, entschied man sich nach einer Intervention Michael Horlachers für einen Kompromiß. In dem elfköpfigen Gremium, das mit großer Mehrheit gewählt wurde, waren weder Müller noch Schäffer vertreten, den Vorsitz übernahmen dagegen mit dem Katholiken Walther von Miller und dem Protestanten Wilhelm Eichhorn zwei „Verlegenheitskandidaten “272. Unterstützt von Alois Hundhammer, der erst wenige Wochen zuvor aus der Kriegsgefangenschaft entlassen worden war, erhob Schäffer Widerspruch gegen diese Entscheidungen, ohne jedoch etwas erreichen zu können. Josef Müller war auf der Gründungsversammlung nicht hervorgetreten, und die Tatsache, daß er in den folgenden Wochen den organisatorischen Aufbau von eher informellen Zirkeln aus energisch in Angriff nahm ${ }^{273}$, spricht dafür, daß er es nicht als allzu großes Unglück empfand, nicht in den vorläufigen Vorstand der Münchner CSU gewählt worden zu sein ${ }^{274}$.

Für Schäffer und die BVP-Traditionalisten bedeutete der Verlauf der Gründungsversammlung allerdings eine weitere Niederlage im Kampf um die Führung der entstehenden Partei. Entsprechend heftig dürften auch die Reaktionen auf die Personalentscheidungen des 11 . Oktober ausgefallen sein. Denn noch fast drei Wochen später sahen sich Wilhelm Eichhorn und Walther von Miller veranlaßt, die Erklärung abzugeben, daß der Beschluß, weder Müller noch Schäffer in den vorläufigen Vorstand zu wählen, „in keiner Weise eine Kritik der Tätigkeit des Herrn Staatsrat[s] Schäffer als Bayerischer Ministerpräsident bedeutet“ habe und daß man Schäffer Dank und Anerkennung „für seine aufopfernde Tätigkeit in der schwersten Zeit unseres Vaterlandes“ ausspreche ${ }^{275}$.

Schäffer nahm diese Niederlagen nicht tatenlos hin. Er rüstete zum Gegenangriff und setzte sich umgehend mit seinen politischen Freunden in Verbindung, sei es, um die Chancen für eine Revitalisierung der BVP zu sondieren ${ }^{276}$, oder um seine Anhänger

270 IfZ-Archiv, Fh 56, Aktennotiz Josef Müllers über sein Verhältnis zu Fritz Schäffer, undatiert (November/Dezember 1945), und Aktennotiz Josef Helds vom 6. 2. 1946.

271 Protokoll der Gründungsversammlung der CSU München am 11. 10. 1945 in München, in: Protokolle und Materialien, S. 7-12; das folgende nach ebenda; vgl. auch Fait, Einleitung zu: Protokolle und Materialien, S. XXIX ff.

272 BAK, NL Schäffer 17, Bl. 63, Wilhelm Eichhorn an Fritz Schäffer vom 2. 2. 1946.

273 Protokoll einer Besprechung über Organisations- und Pressefragen am 25. 10. 1945 in München, in: Protokolle und Materialien, S. $13 \mathrm{ff}$. Der vorläufige Vorstand der CSU München sollte sich demnach vorwiegend mit den Problemen vor Ort beschäftigen, während Karl Scharnagl nach einer Vereinbarung mit Walther von Miller „im Auftrag der Münchner Union vorläufig Landesfragen“ bearbeiten sollte.

274 Müller schrieb später, der vorläufige Vorstand der CSU München sei mit seiner Zustimmung berufen worden; IfZ-Archiv, Fh 56, Aktennotiz Josef Müllers über sein Verhältnis zu Fritz Schäffer, undatiert (November/Dezember 1945).

275 IfZ-Archiv, Fh 56, Erklärung Walther von Millers und Wilhelm Eichhorns im Namen des vorläufigen Vorstands der Münchner CSU vom 29. 10. 1945.

276 Die politischen Parteien in Bayern - Tendenzen im Landesmaßstab vom 8. 11. 1945, in: Zwischen Befreiung und Besatzung, S. 234. 
für die kommenden Auseinandersetzungen in der entstehenden CSU zu mobilisieren. Zugleich warb Schäffer dafür, die auf Landkreisebene gegründeten Gruppierungen nicht unter dem Namen Christlich-Soziale Union bei der Militärregierung anzumelden, sondern unter der Bezeichnung „Bayerischer Volksbund“277.

Tatsächlich wurden in verschiedenen Landkreisen Altbayerns Parteien unter diesem Namen oder sogar unter dem Namen Bayerische Volkspartei gegründet ${ }^{278}$. Joseph Baumgartner berichtete, daß „Schäffer und seine Leute jetzt seit Wochen täglich auf dem Lande tätig sind", und wies warnend auf die steigende Anzahl von Kreisparteiorganisationen hin, die als Bayerischer Volksbund lizenziert würden ${ }^{279}$. Die Aktivitäten des ehemaligen BVP-Vorsitzenden scheinen allerdings in den letzten Oktobertagen nicht darauf abgezielt zu haben, die CSU zu spalten, bevor sie überhaupt als Landespartei zugelassen war $^{280}$. Vielmehr plante Schäffer, seine Position in den ländlichen Regionen Ober- und Niederbayerns auszubauen, um die bisherigen Entscheidungen über den Namen und das Programm der neuen Partei auf einer Landesversammlung revidieren zu können ${ }^{281}$.

Ende Oktober 1945 gelang es Müller und Schäffer, ihre Streitigkeiten zumindest vorübergehend beizulegen. Nach Müllers Aufzeichnungen sagte Schäffer zu, seine Vorwürfe gegen ihn nicht weiter aufrechtzuerhalten und den Begriff „Union“ zumindest bedingt mitzutragen. Obwohl man sich auf die Formulierung einigte, „persönlich als Freunde auseinandergegangen" zu sein, und obwohl Müller und Schäffer nach dieser Aussprache dem vorläufigen Vorstand der Münchner CSU beitraten und in dessen Auftrag am Aufbau einer landesweiten Organisation arbeiteten ${ }^{282}$, sollte sich der Konsens bald als brüchig erweisen.

\section{Auf dem Weg zur Landespartei}

\section{a) Die Entwicklung der CSU bis zum 8. Januar 1946}

Wenige Wochen später waren die besatzungspolitischen und innerparteilichen Voraussetzungen für den Aufbau der bayerischen Unionspartei auf Landesebene soweit gediehen, daß dieses Vorhaben endgültig in Angriff genommen werden konnte. Am 25. November trat der vorläufige Vorstand der CSU München mit einem landesweiten Aufruf an die Öffentlichkeit ${ }^{283}$. Das Rundschreiben sollte ein Signal setzen für die Gründung „einer großen Sammel- und Volkspartei aller Kreise, die von dem Grundge-

277 IfZ-Archiv, Fh 56, Fritz Schäffer an Zeitungsverleger Bichlmeier (Moosburg), undatiert, und Rundschreiben Fritz Schäffers „Betreff: Parteienbildung“ vom 17. 10. 1945; IfZ-Archiv, RG 260, 13/ 147-2/16, Historical Report, Eastern Military District and OMGBY, 13.11. 1945-14. 12. 1945.

278 BayHStA, NL Schwalber 5, Flugblatt des Bayerischen Volksbunds Dachau "Was will der Bayerische Volksbund?"; vgl. Becker, CDU und CSU, S. 78.

${ }^{279}$ IfZ-Archiv, Fh 56, Joseph Baumgartner an Josef Müller vom 25. 10. 1945.

280 Die politischen Parteien in Bayern - Tendenzen im Landesmaßstab vom 8.11. 1945, in: Zwischen Befreiung und Besatzung, S. 234.

281 IfZ-Archiv, Fh 56, Aktennotiz Josef Helds vom 6. 2. 1946.

282 IfZ-Archiv, Fh 56, Aktennotiz Josef Müllers über sein Verhältnis zu Fritz Schäffer, undatiert (November/Dezember 1945).

${ }^{283}$ Rundschreiben des Vorbereitenden Ausschusses der Christlich-Sozialen Union München vom 25.11. 1945, abgedruckt in: Protokolle und Materialien, S. 1751 f.; das folgende Zitat ebenda. 
danken christlicher Kultur und des christlichen Sittengebotes ausgeht". Dieses Dokument ist in zweifacher Hinsicht äußerst bemerkenswert: Zum einen zeigt es den Führungsanspruch des Münchner Gründerkreises und der daraus hervorgegangenen vorläufigen Gründungs- und Führungsgremien, die den letztlich auch erfolgreichen Versuch unternahmen, die lokalen und regionalen Parteigründungen zu koordinieren und einheitlich unter dem Parteinamen CSU zusammenzuführen. Zum anderen enthielt der Aufruf Vorschläge für den vorläufigen Aufbau einer Parteiorganisation, die an die viergliedrige Organisationsstruktur der BVP auf Orts-, Landkreis-, Regierungsbezirks- und Landesebene angelehnt waren und die das organisatorische Gerüst der CSU präjudizierten, wie es sich in der Folgezeit herausbilden sollte ${ }^{284}$.

Eine weitere wesentliche Vorentscheidung fiel am 17. Dezember 1945 im Vorläufigen Landesausschuß ${ }^{285}$. Auf Vorschlag Michael Horlachers wählten die Mitglieder dieses Gremiums ohne längere Diskussion Josef Müller einstimmig zum vorläufigen Vorsitzenden des vorbereitenden Landesausschusses und ermöglichten ihm dadurch, trotz einer außerordentlich schmalen Legitimationsbasis als vorläufiger Landesvorsitzen$\operatorname{der}^{286}$ zu fungieren. Zugleich beschloß der Vorläufige Landesausschuß, für den 8. Januar 1946 eine Konferenz nach München einzuberufen, an der erstmals je fünf Vertreter aus den einzelnen Regierungsbezirken Bayerns teilnehmen sollten. Bevor diese erste landesweite Versammlung der CSU jedoch zustande kam, gab der Vorläufige Landesausschuß am letzten Tag des Jahres 1945 mit den „Zehn Punkte[n] der Christlich-Sozialen Union" den immer noch weitgehend unverbundenen Kreisverbänden erstmals programmatische Richtlinien an die Hand ${ }^{287}$.

Knapp drei Wochen vor den für den 27. Januar angesetzten Gemeindewahlen traf sich im Münchner Rathaus der Erweiterte Vorläufige Landesausschuß der $\mathrm{CSU}^{288}$. Auch dieses Gremium sprach Josef Müller das Vertrauen aus und beauftragte ihn einstimmig mit der weiteren Durchführung des organisatorischen Aufbaus. Dies gab Müller die Möglichkeit, die anstehenden organisationspolitischen Entscheidungen in seinem Sinne zu treffen und sich einen nur schwer einholbaren Einflußvorsprung zu verschaffen. Einen Tag später, am Vormittag des 9. Januar 1946, erhielt die CSU von der amerikanischen Militärregierung eine vorläufige Lizenz für die politische Betätigung auf Landesebene ${ }^{289}$.

Die von vielfältigen Disparitäten und Widersprüchen gekennzeichnete Lage der CSU zwischen Oktober 1945 und ihrer landesweiten Lizenzierung im Januar 1946 spiegelte auch die politisch-kulturelle Heterogenität der bayerischen Regionen wider.

${ }^{28+} \mathrm{Vgl}$. Mintzel, Anatomie, S. $91 \mathrm{f}$.

${ }^{285}$ Protokoll der Sitzung des Vorläufigen Landesausschusses der CSU am 17. 12. 1945 in München, in: Protokolle und Materialien, S. $17 \mathrm{ff}$. Zur Charakterisierung dieses Gremiums und zum Verlauf der Sitzung vgl. Mintzel, Anatomie, S. 92 ff.

286 Mit diesem Titel zeichnete Müller z. B. das Rundschreiben vom 31. 12. 1945; abgedruckt in: Protokolle und Materialien, S. $1751 \mathrm{f}$.

287 Die zehn Punkte der Christlich-Sozialen Union vom 31.12. 1945, abgedruckt in: Protokolle und Materialien, S. $1713 \mathrm{f}$.

${ }^{288}$ Protokoll der Sitzung des Erweiterten Vorläufigen Landesausschusses der CSU am 8.1.1945 in München, in: Protokolle und Materialien, S. 21-26. Zur Charakterisierung dieses Gremiums und zum Verlauf der Sitzung vgl. Mintzel, Anatomie, S. 95-99.

${ }^{289}$ Die auf den 8.1.1946 datierte Lizenzierungsurkunde ist in deutscher und englischer Fassung abgedruckt in: Müller, Konsequenz, S. 314-319. Zum Zeitpunkt der Übergabe IfZ-Archiv, RG 260, 13/ 142-2/3, Weekly Summary No. 35 von OMGBY für den Zeitraum 3.1.-10. 1. 1946. 
Da die Partei gemäß den Vorgaben der Militärregierung auf Stadt- und Landkreisebene entstanden war und sich der Münchner Gründerkreis erst allmählich zum Kristallisationspunkt einer landesweiten Organisation entwickelte, bestand die CSU aus einer Vielzahl von kaum zusammenhängenden Gruppierungen mit unterschiedlichen Zielsetzungen, die oft nicht einmal den Namen gemeinsam hatten ${ }^{290}$. In den drei altbayerischen Regierungsbezirken waren die Tradition der untergegangenen BVP und ihre ehemaligen Funktions- und Mandatsträger ein dominierender Faktor ${ }^{291}$. Dieses explizite Anknüpfen an Tradition und Struktur der BVP ermöglichte in diesen Regionen zwar den rascheren Aufbau einer geschlossenen Parteiorganisation, dafür trug die CSU in diesen Teilen Bayerns jedoch signifikant katholisch-konservative Züge ${ }^{292}$.

Im mehrheitlich protestantischen Franken stellte sich die Situation dagegen anders dar. Die Träger des Unionsgedankens repräsentierten dort verschiedene Traditionsstränge deutscher Parteiengeschichte. Neben BVP-Mitgliedern waren es vor allem Vertreter der ehemaligen liberalen Parteien, der DNVP und des Christlich-Sozialen Volksdienstes, die zu den Mitbegründern der CSU zählten. Anders als in Altbayern, wo die Betonung der bayerischen Eigenstaatlichkeit ein unverzichtbarer Programmpunkt war, dachte man in Franken mehr in nationalen Begriffen. Darüber hinaus ließen konfessionelle Gegensätze und Ressentiments des evangelischen Bevölkerungsteils gegen die Vertreter des politischen Katholizismus den Aufbau der CSU in den protestantischen Zentren Mittel- und Oberfrankens zu einem schwierigen Unterfangen werden ${ }^{293}$. Damit war gegen Ende des Jahres 1945 die paradoxe Situation entstanden, daß in den Schaltstellen der bayerischen Unionspartei in München Kräfte dominierten, die sich ausdrücklich für einen parteipolitischen Neubeginn und gegen eine Wiederbelebung der BVP aussprachen, während sich in den organisatorischen Gravitationszentren Altbayerns gerade die beharrenden Kräfte weitgehend durchgesetzt hatten.

Wenn diese explosive innerparteiliche Situation nicht zum Zerfall der neu gegründeten CSU führte, hatte daran auch die amerikanische Militärregierung und ihre Politik gegenüber den bayerischen Parteien großen Anteil. Das Interesse der Verantwortlichen bei OMGBY an einem stabilen Parteiensystem und die Ablehnung übertriebener parteipolitischer Fragmentierung wirkten auf die krisengeschüttelte CSU geradezu wie ein Schutzschirm. So weigerte sich die Militärregierung, Flüchtlings- und Vertriebenenparteien zuzulassen ${ }^{294}$, und verbot im Mai 1946 die in München gegründete Bayerische Heimat- und Königspartei, deren Existenz bei führenden Vertretern der CSU große Besorgnis hervorgerufen hatte ${ }^{295}$. Auch ließ die restriktive Lizenzierungspraxis

290 Vgl. Mintzel, Anatomie, S. $121 \mathrm{ff}$

291 Die politischen Parteien in Bayern - Tendenzen im Landesmaßstab vom 8. 11. 1945, in: Zwischen Befreiung und Besatzung, S. $231 \mathrm{ff}$.

292 Vgl. Mintzel, Anatomie, S. 120 f. und S. 130f., sowie den OSS-Bericht: Die politischen Parteien in Bayern - Tendenzen im Landesmaßstab vom 8.11. 1945, in: Zwischen Befreiung und Besatzung, S. $231 \mathrm{ff}$.; das folgende Zitat ebenda, S. 232.

${ }^{293}$ Ein instruktiver Einblick in die Schwierigkeiten der Unionsgründung in den protestantischen Teilen Frankens findet sich bei Woller, Gesellschaft und Politik, S. 187-194; vgl. auch Helmut Anzeneder, Willi Götz, 1946-1996. 50 Jahre CSU in Erlangen, Erlangen 1995, S. 38-47.

294 Vgl. Benz, Parteigründungen und erste Wahlen, in: ders. (Hrsg.), Neuanfang in Bayern, S. 22.

295 Zur BHKP und ihrem Verbot vgl. Konrad Maria Färber, Bayern wieder ein Königreich? Die monarchistische Bewegung in Bayern nach dem Zweiten Weltkrieg, in: Benz (Hrsg.), Neuanfang in Bayern, S. 163-182, insbesondere S. 171-177, und Joachim Selzam, Monarchistische Strömungen in der Bundesrepublik Deutschland 1945-1989, Diss., Erlangen 1994, S. 167-178. Wie unsicher die CSU- 
der Militärregierung - seit dem Frühjahr 1946 wurden zwei Jahre lang keine Parteien mehr landesweit zugelassen - potentiellen Konkurrenzparteien, insbesondere der Bayernpartei, die ihre Lizenz erst im März 1948 erhielt $^{296}$, nur geringe Entfaltungsmöglichkeiten. Indirekte Hilfe leistete die Militärregierung beim Ausbau der CSU zu einem geschlossenen Landesverband ${ }^{297}$. OMGBY forderte alle politischen Parteien Bayerns auf, spätestens bis zum 5. September 1946 für die formale Eingliederung der Kreisverbände in die jeweilige Parteiorganisation zu sorgen. Die Drohung, nach diesem Termin nicht eingegliederte Kreisverbände weder weiterhin anzuerkennen noch zu Wahlen zuzulassen, verlieh dieser Forderung im Vorfeld der ersten Landtagswahlen den entsprechenden Nachdruck. Immerhin waren es 54 Kreisverbände, die den Anschluß an den CSU-Landesverband bis zum 5. September noch nicht vollzogen hatten. Der Bezirksverband München stellte widerstrebend am letztmöglichen Termin einen Aufnahmeantrag und war erst vom 1. Januar 1947 an vollständig in die Parteiorganisation integriert.

Diese Politik der Militärregierung erzwang die Fusion der widerstrebenden Gruppierungen in der $\mathrm{CSU}^{298}$. Die Bedingungen der Besatzungsdemokratie trugen somit wesentlich zur zumindest nominellen Einheit der bayerischen Unionspartei bei. Das förderte zwar die internen Konflikte, war aber zugleich eine wichtige Voraussetzung für die Wahlerfolge der CSU zwischen 1946 und 1948.

\section{b) Wabljabr 1946: BVP und CSU im protestantischen Franken}

Trotz der anhaltenden Führungs- und Flügelkämpfe, trotz der bei der Parteibasis verbreiteten Unsicherheit wegen des Fehlens eines elaborierten Parteiprogramms und trotz eines noch im Aufbau begriffenen Parteiapparats ging die CSU aus den ersten Wahlen im Jahre 1946 als Siegerin hervor. Die Ergebnisse, die die bayerische Unionspartei erzielen konnte, waren beeindruckend ${ }^{299}$. Bei den Wahlen in Gemeinden mit bis zu 20000 Einwohnern am 27. Januar erhielt die CSU keine drei Wochen nach ihrer landesweiten Lizenzierung mit 43,6 Prozent mehr als doppelt so viele Stimmen wie die SPD, die sich als zweitstärkste Kraft mit nur 16,6 Prozent begnügen mußte. Als drei Monate später die Kreistage gewählt wurden, konnte die CSU ihren Stimmenanteil auf 67,9 Prozent ausbauen, während die SPD mit 22,9 Prozent noch weiter hinter die bayerische Unionspartei zurückfiel. Aber auch bei den Wahlen in den Stadtkreisen und Gemeinden mit mehr als 20000 Einwohnern am 26. Mai 1946 wurde die CSU -

Führung gegenüber der Königspartei war, zeigt auch die Diskussion im Landesarbeitsausschuß der CSU am 1.5. 1946, in: Protokolle und Materialien, S. 195f. und S. 206-209. Im Dienstag-Club empfand man das Verbot der Königspartei als „Erleichterung“. Richard Jaeger erklärte am 14. 5. 1946: „Wir können uns ja nicht ausdenken, was mit der CSU geschehen wäre, wenn die Königspartei hätte kandidieren dürfen. Mindestens $50 \%$ der Unionswähler hätten für die Königspartei gestimmt. “ Lehrjahre, S. 53.

${ }^{296}$ Vgl. Alf Mintzel, Die Bayernpartei, in: Stöss (Hrsg.), Parteien-Handbuch, Bd. 1: AUD-CDU, S. $395-489$, hier S. $398 \mathrm{f}$.

297 Das folgende nach Mintzel, Anatomie, S. $122 \mathrm{f}$.

298 Mintzel, Regionale politische Traditionen, in: Oberndörfer/Schmitt (Hrsg.), Parteien und regionale Traditionen, S. 142, sieht die CSU bis 1948/1949 als „besatzungspolitisch verordnete bürgerliche Integrationspartei“.

299 Eine Tabelle mit allen Wahlergebnissen des Jahres 1946 ist abgedruckt in: Benz (Hrsg.), Neuanfang in Bayern, S. 35; die folgenden Zahlenangaben nach ebenda. 
wenn auch mit deutlich geringerem Vorsprung - stärkste Partei; sie konnte 45,1 Prozent der Wählerstimmen auf sich vereinigen und überflügelte die SPD (38 Prozent) erneut. Am 30. Juni war die Bevölkerung Bayerns erstmals seit 1932 wieder aufgerufen, eine landesweite parlamentarische Vertretung in freier Wahl zu bestimmen, und auch diese Wahl zur Verfassunggebenden Landesversammlung konnte die CSU mit 58,3 Prozent der Stimmen vor der SPD mit 28,8 Prozent gewinnen. Zwar glich dieser Vertrauensvorschuß für eine Partei, die ihre Integrationskraft und Regierungsfähigkeit erst noch unter Beweis stellen mußte, einem unsicheren Wechsel auf die Zukunft, aber die Wahlsiege der CSU zeigten auch, wie groß das Potential für eine liberal-konservative, christlich-interkonfessionelle Sammlungspartei in Bayern war und wie attraktiv die Unionsidee auf die von Krieg und Diktatur verunsicherten Menschen wirkte.

Mit Blick auf die unausgewogene Mitgliederstruktur der CSU hat Alf Mintzel dagegen betont, „daß der christlich-interkonfessionelle Gedanke nicht so gezündet“ habe, wie dies seitens der Parteiführung erwartet worden sei ${ }^{300}$. Nach Erhebungen der Landesgeschäftsstelle seien Ende 1947/Anfang 1948 lediglich 8,4 Prozent der Parteimitglieder Protestanten gewesen, während sich 91,3 Prozent zum katholischen Glauben bekannt hätten. Damit seien die evangelischen Christen, deren Anteil in Bayern etwas mehr als ein Viertel der Gesamtbevölkerung ausmachte, signifikant unterrepräsentiert gewesen. Insgesamt kam Mintzel zu dem Schluß, daß die Mitgliederstruktur der CSU von einem starken Süd-Nord- und Land-Stadt-Gefälle geprägt gewesen sei und daß sie als „Partei des alten gegenreformatorischen Bayern“ dort besonders mitgliederstark gewesen sei, wo vor 1933 BVP und BBB ihre Hochburgen gehabt hätten.

Die Erkenntnis, der CSU sei es in weit größerem Umfang gelungen, die katholischkonservative Bevölkerung zu mobilisieren als die Protestanten in den fränkischen Landesteilen, ist sicherlich richtig. Aber ein Urteil über den Erfolg oder Mißerfolg der bayerischen Unionspartei ist immer auch vom Vergleichspunkt abhängig. Bezogen auf die Ansprüche der CSU-Führung und auf die Gesamtbevölkerung Bayerns fällt die Eröffnungsbilanz der bayerischen Unionspartei tatsächlich nicht unbedingt günstig aus. Vergleicht man die CSU in der Ära Müller jedoch mit der BVP, deren Erbe die CSU 1945 antrat, und berücksichtigt weiterhin neben organisationssoziologischen Faktoren auch die Wahlergebnisse von 1946, dann erscheint die bayerische Unionspartei in wesentlich besserem Licht, insbesondere dann, wenn man die Zähigkeit der innerbayerischen Spannungslinien und Regionalismen in Rechnung stellt, die dem Unionsgedanken entgegenstanden. Eine Untersuchung der Landtagswahlen vom 24. April 1932 und der Wahlen zur Verfassunggebenden Landesversammlung am 30. Juni 1946 in vergleichender Perspektive soll diese Überlegungen verdeutlichen.

Die BVP konnte bei den Wahlen im April 1932 mit 1272005 Stimmen oder 32,6 Prozent das beste Ergebnis ihrer Geschichte erzielen ${ }^{301}$. Gegenüber 1928 gewann die BVP 217000 Stimmen hinzu, und es gelang ihr, sich knapp als stärkste Partei vor der NSDAP zu behaupten. Unter den Bedingungen der sich mehr und mehr verschärfen-

300 Mintzel, Anatomie, S. 177; eine ausführliche Analyse der Mitgliederstruktur der CSU um die Jahreswende 1947/1948 mit einer kritischen Würdigung der zugrundeliegenden Daten ebenda, S. 170-187.

301 Vgl. Hartmann, Bayerns Weg, S. 499-502; Bergmann, BBB und BCBV, S. 395; Alois Egger, Die Landtagswahl am 24. April 1932, in: ZBSL 64 (1932), S. 357-424. 
den Krise der Weimarer Republik hatte die BVP damit ihr Wählerpotential weitgehend ausgeschöpft, das durch die Spaltung der katholisch-bäuerlichen Bevölkerung Altbayerns einerseits und durch die einseitig konfessionelle Ausrichtung der BVP andererseits strukturell begrenzt war. In den Regierungsbezirken Oberpfalz (53,6 Prozent) und Unterfranken (49,3 Prozent) erreichte sie ihre besten Ergebnisse; in Oberbayern (37,3 Prozent), Niederbayern (40,7 Prozent) und Schwaben (36,1 Prozent), wo auch der Bayerische Bauernbund seine Hochburgen hatte, gelang es der BVP dagegen nicht, die 40-Prozent-Marke deutlich zu überschreiten und in den Bereich der absoluten Mehrheit vorzustoßen.

Ergebnisse der BVP bei den Landtagswablen 1932 und der CSU bei den Wablen zur Verfassunggebenden Landesversammlung 1946 in ausgewäblten ober- und mittelfränkischen Stimmkreisen ${ }^{302}$

Stimmkreis

Bayreuth-Pegnitz

Coburg

Hersbruck-Lauf

Hof

Münchberg-Naila

Selb-Rehau

Uffenheim-Neustadt a. d. Aisch-Scheinfeld
BVP 1932

5,6 Prozent

1,7 Prozent

CSU 1946

30,2 Prozent
45,0 Prozent
68,8 Prozent

26,8 Prozent 17,3 Prozent

7,5 Prozent

2,8 Prozent

4,2 Prozent

3,0 Prozent

8,4 Prozent
43,0 Prozent 33,6 Prozent

35,4 Prozent 27,1 Prozent

36,5 Prozent 31,4 Prozent

37,2 Prozent

72,2 Prozent 59,1 Prozent 76,8 Prozent
Stimmkreis

Bayreuth-Stadt

Bayreuth-Land

Pegnitz

Coburg-Stadt

Coburg-Land

Hersbruck

Lauf

Hof-Stadt

Hof-Land

Münchberg

Naila

Rehau

Uffenheim

Neustadt a.d. Aisch

Scheinfeld

Von solchen Resultaten konnte man in den mehrheitlich protestantischen Regierungsbezirken Oberfranken und Mittelfranken dagegen nur träumen; in Oberfranken kam die BVP noch auf 22,2 Prozent, während sie sich in Mittelfranken mit 11,3 Prozent zufrieden geben mußte ${ }^{303}$. Für den Erfolg der CSU, die sich nicht nur als Union katholischer und evangelischer Christen verstand, sondern auch die Traditionen von BVP und $\mathrm{BBB}$ in sich vereinigte, war es von entscheidender Bedeutung, die historisch gewachse-

302 Zahlen für 1932 nach ebenda, S. 380 f., und für 1946 nach dem Statistischen Jahrbuch für Bayern für 1947, hrsg. vom Bayerischen Statistischen Landesamt, München o. J. (1948), S. 320-323. Die Stimmkreise, in denen 1946 der Anteil der Protestanten an der Wohnbevölkerung mehr als 50 Prozent betrug, sind kursiv gesetzt, die Stimmkreise mit einem Anteil von mehr als 75 Prozent dagegen fett. Im Kreis Pegnitz betrug der Anteil von Protestanten 44,5, im Kreis Scheinfeld 47,7 Prozent. Diesbezügliche Zahlenangaben nach dem Statistischen Jahrbuch für Bayern 1947, S. 386 f. und S. 394 f. Fehlerhafte Daten bei Berberich, Historische Entwicklung, S. 145.

${ }^{303} \mathrm{Zu}$ den politischen Präferenzen, Wahlergebnissen und Wählerwanderungen in Ober- und Mittelfranken vgl. Dietrich Thränhardt, Wahlen und politische Strukturen in Bayern 1848-1953. Historischsoziologische Untersuchungen zum Entstehen und zur Neuerrichtung eines Parteiensystems, Düsseldorf 1973, S. 152-162. 
nen innerbayerischen Spannungslinien zu überwinden und Bevölkerungsschichten dauerhaft an sich zu binden, die der BVP vor 1933 ablehnend gegenübergestanden hatten. Wie das Ergebnis der Wahlen zur Verfassunggebenden Landesversammlung im Juni 1946 zeigte, waren diesbezügliche Hoffnungen nicht unbegründet ${ }^{304}$. Ihre Spitzenergebnisse erreichte die CSU mit 69,2 Prozent in Unterfranken, dicht gefolgt von Niederbayern/Oberpfalz $z^{305}$ mit 67,2 Prozent und Schwaben mit 66,0 Prozent; in Oberbayern kam sie immerhin noch auf beachtliche 54,8 Prozent. Damit hatte die CSU die BVP selbst dort weit überflügelt, wo diese besonders erfolgreich gewesen war.

Doch wie stand es in der katholischen Diaspora Ober- und Mittelfrankens? Zwar blieb die CSU hier deutlich hinter den Ergebnissen der anderen Bezirke zurück, doch mit 46,2 Prozent hatte sich die neu gegründete Union mehr als achtbar aus der Affäre gezogen. Die BVP hatte 1932 bei den Landtagswahlen in Ober- und Mittelfranken lediglich 162.361 Stimmen errungen; die CSU konnte dieses Ergebnis im Juni 1946 mit 353.305 Stimmen mehr als verdoppeln und lag damit erheblich vor der SPD, die in diesem Wahlkreis mit vielen sozialdemokratischen Hochburgen nur 283.624 Stimmen (37,1 Prozent) gewann ${ }^{306}$. Daß dieser Erfolg unter anderem auf einen signifikanten Einbruch der bayerischen Unionspartei in das protestantische Wählerreservoir zurückzuführen war, den die BVP zu keiner Zeit geschafft hatte, zeigt ein Blick auf die Wahlergebnisse von BVP und CSU in ober- und mittelfränkischen Stimmkreisen mit einem hohen protestantischen Bevölkerungsanteil. In diesen protestantisch geprägten Landund Stadtkreisen lagen die Ergebnisse der CSU - von den vier Ausnahmen Pegnitz, Uffenheim, Neustadt an der Aisch und Scheinfeld abgesehen - erheblich unter dem Landesdurchschnitt von 58,3 Prozent. Dieser Befund stützt zwar die gängige These von der Distanz der protestantischen Bevölkerung gegenüber der CSU; während die BVP in den untersuchten Kreisen jedoch eine Splitterpartei geblieben war und die 10Prozent-Marke nirgends hatte überspringen können, kam die bayerische Unionspartei in 12 von 15 Stimmkreisen auf einen Stimmenanteil von mehr als 30 Prozent. Damit wurde die CSU auch im fränkisch-protestantischen Raum zu einer bedeutenden politischen Kraft, und es schien die Chance zu bestehen, die Union zu einer in allen Teilen Bayerns fest verankerten Partei auszubauen. In einigen stark protestantisch geprägten Stimmkreisen Ober- und Mittelfrankens konnte die CSU sogar geradezu sensationelle Ergebnisse verbuchen: so in Scheinfeld mit 76,8 Prozent, in Uffenheim mit 72,2 Prozent oder in Pegnitz mit 68,8 Prozent. Selbst dort, wo die CSU ihre schlechtesten Ergebnisse aufzuweisen hatte, nämlich in den Stimmkreisen Coburg-Stadt und -Land, schnitt sie im Vergleich zur BVP gut ab; mit 1,7 Prozent der Wählerstimmen hatte die BVP 1932 in dieser Region ein Debakel erlitten ${ }^{307}$.

304 Die folgenden Zahlenangaben nach dem Statistischen Jahrbuch für Bayern 1947, S. 316-325.

305 Niederbayern und die Oberpfalz bildeten 1946 ebenso wie Ober- und Mittelfranken einen Wahlkreis.

306 Zu den Hochburgen und Diaspora-Gebieten der bayerischen SPD vgl. Wolfgang Behr, Sozialdemokratie und Konservatismus. Ein empirischer und theoretischer Beitrag zur regionalen Parteianalyse am Beispiel der Geschichte und Nachkriegsentwicklung Bayerns, Hannover 1969, S. $155 \mathrm{ff}$.

307 Neben Hof war in Coburg die Zahl der Katholiken am geringsten; die Kirchlichkeit dieser evangelischen Dekanate lag an der unteren Grenze. Von der Schwäche der CSU profitierte in Coburg die FDP, die hier eine ihrer Hochburgen hatte. Das ehemalige Herzogtum, das erst seit 1920 zu Bayern gehörte, wies zwar eine lange nationalliberale Tradition und ein nicht zu verachtendes sozialdemokratisches Potential auf, Coburg war jedoch zwischen 1924 und 1932 die Stadt mit dem höchsten 
Aus dem Vergleich der Ergebnisse der Landtagswahlen 1932 und der Wahlen zur Verfassunggebenden Landesversammlung 1946 wird zweierlei deutlich: Zum einen zeigt sich, daß Mintzels auf die Analyse von Mitgliederstatistiken gestützte These, die CSU sei eine dominant katholische Partei mit Schwerpunkt in den alten kurbayerischen Territorien gewesen, der Relativierung bedarf. Bei Wahlen war die evangelische Bevölkerung Frankens zwischen 1946 und 1948 in erheblich größerem Maße bereit, für die CSU zu stimmen, als sich das in den Mitgliederzahlen ausdrückt. Offensichtlich standen viele Protestanten der Unionsidee zwar positiv gegenüber, wollten jedoch zunächst die weitere Entwicklung der CSU abwarten, ehe sie sich der Union anschlossen. Für eine neu gegründete Partei, deren Programmatik ebenso noch in den Anfängen steckte wie der Aufbau eines funktionsfähigen Parteiapparats, war das Abschneiden in den ober- und mittelfränkischen Stimmkreisen jedoch ein Erfolg, auf den sich aufbauen ließ. Zum anderen zeigt der Vergleich mit der BVP, daß die CSU durchaus in der Lage war, die Grenzen der großen bayerischen Traditionszonen zu überwinden. Es mußte den Verantwortlichen jedoch klar sein, daß dies angesichts der vielfältigen historischen Belastungen nicht von heute auf morgen geschehen konnte und daß mit Konflikten und Auseinandersetzungen durchaus zu rechnen war. Aber auch nachdem sich viele protestantische Mitbegründer der CSU von der bayerischen Unionspartei abgewandt hatten und der Elan der Gründungsmonate einem zähen innerparteilichen Kleinkrieg gewichen war, fiel die CSU in Ober- und Mittelfranken nicht auf den Stand der BVP zurück. Obwohl sie nach 1946 teilweise dramatische Stimmenverluste zu verzeichnen hatte, blieb die CSU auch in ihren Diaspora-Gebieten politisch präsent und war selbst in den frühen fünfziger Jahren, als sich das Profil der Partei stark veränderte, fränkischer und protestantischer, als es die BVP jemals gewesen war ${ }^{308}$.

\section{Neubeginn oder Restauration? Das Führungspersonal der CSU 1945/1946}

\section{a) Der Personenkreis}

Über die Trägerschichten der CSU in der schwierigen und für ihre Entwicklung prägenden Formierungsphase ist bisher so gut wie nichts bekannt. Zwar kennt man die wichtigsten Protagonisten der Flügelkämpfe wie Müller, Schäffer und Hundhammer. Aber wie sah die Gründergeneration der CSU ansonsten aus? Wer waren ihre Repräsentanten auf regionaler und lokaler Ebene? Weist das gruppenbiographische und sozialstatistische Profil dieses Personenkreises in eine andere Richtung, als es die Zusammensetzung der vorläufigen Parteiführung vermuten läßt? Oder mit anderen Worten: Bestätigt die Untersuchung der Führungselite der CSU im Jahre 1946 die Befunde, die bereits die vergleichende Wahlanalyse nahegelegt hat? Antworten auf diese und ähnliche Fragen sollen dazu dienen, das Wissen über die Mitbegründer der CSU zu verbreitern, allzu wohlfeile, aber empirisch kaum abgestützte Befunde zu überprüfen

Anteil an NSDAP-Stimmen. Vgl. Thränhardt, Wahlen und politische Strukturen, S. 160ff. und S. 309.

308 Ähnlich auch Thränhardt, ebenda, S. 317. 
und Erkenntnisse über die regionalspezifische Ausprägung des Führungspersonals der CSU zu gewinnen.

Am 8. Januar 1946 traf sich mit dem Erweiterten Vorläufigen Landesausschuß erstmals ein Gremium, in dem neben den wichtigsten Vertretern des Münchner Gründerkreises auch Repräsentanten aller bayerischer Regierungsbezirke vertreten waren; an diesem Tag wurde auch eine erste Satzung verabschiedet, die der CSU für die nächsten Monate ein provisorisches Gerüst geben sollte. Der Erweiterte Vorläufige Landesausschuß bildete bis zur ersten Landesversammlung am 17. Mai 1946 die einzige landesweite Vertretung der CSU und fungierte in den folgenden Monaten unter den Bezeichnungen Erweiterter Landesausschuß und Landesausschuß als eigentliches Führungsgremium des Parteivorsitzenden Josef Müller $^{309}$. Dem Landesausschuß, der zwischen Januar und Oktober 1946 durch Änderungen des heftig umstrittenen Delegiertenschlüssels und durch die Aufnahme bestimmter Personen qua Amt sein Gesicht mehrmals veränderte, gehörten im Januar 1946 ca. 50 stimmberechtigte Mitglieder und im Oktober ca. 100 stimmberechtigte Mitglieder an $^{310}$. Dieses Gremium eignet sich aus zwei Gründen besonders für eine Untersuchung: zum einen wegen seiner Bedeutung in der Formierungsphase, zum anderen wegen seiner Zusammensetzung. Im Landesausschuß saßen nämlich neben den Mitgliedern der eigentlichen Parteiführung vor allem Vertreter der Bezirksverbände. Diese Delegierten nahmen auf regionaler und lokaler Ebene oft wichtige Funktionen wahr, ohne aber auf Landesebene stärker hervorzutreten.

An den Sitzungen des Landesausschusses nahmen zwischen Januar und Oktober 1946 circa 220 Personen teil; eine genauere Zahlenangabe ist aufgrund der teilweise lückenhaften Anwesenheitslisten nicht möglich. Von 178 Personen konnten die wesentlichen biographischen Daten erhoben werden, während sich bei 42 Personen entweder die Identität nicht klären ließ oder überhaupt keine Angaben zu finden waren $^{311}$. Von den ermittelten Tagungsteilnehmern handelt es sich bei 151 Personen um

${ }^{309}$ Neben dem Erweiterten Vorläufigen Landesausschuß fungierten der wesentlich klcinere Vorläufige Landesausschuß bzw. seit April 1946 der Landesarbeitsausschuß als eine Art vorläufiger Parteivorstand. Zum Stellenwert, der dem Erweiterten Vorläufigen Landesausschuß in Müllers Kalkül zukam, vgl. dessen Ausführungen vor der CSU-Fraktion in der Verfassunggebenden Landesversammlung am 2. 9. 1946; ACSP, NL Müller 208.

310 Zum Erweiterten Vorläufigen Landesausschuß vgl. Mintzel, Anatomie, S. 95-99; zu den Auseinandersetzungen um den Delegiertenschlüssel vgl. Fait, Einleitung zu: Protokolle und Materialien, S. XLVIII-LI.

311 Die biographischen Daten für die folgende Untersuchung sind zum Teil dem umfangreichen Fundus entnommen, der zwischen 1991 und 1993 für die Dokumentation "Die CSU 1945-1948“ im Institut für Zeitgeschichte angelegt wurde. Zur Entstehungsgeschichte vgl. Thomas Schlemmer, Kurzbiographien der erwähnten Personen, in: Protokolle und Materialien, S. 1835-1840. Zum Teil beruhen die Angaben zum hier untersuchten Personenkreis auf eingehenden Recherchen in verschiedenen Archiven und auf der umfassenden Auswertung einschlägiger Nachschlagewerke wie Parlamentshandbüchern, Kompendien mit Angaben zu Land- und Reichstagsabgeordneten, Wer ist Wer? oder dem Munzinger-Archiv. Da es sich bei den Mitgliedern des (Erweiterten) Landesausschusses der CSU vielfach um Personen handelt, die lediglich auf lokaler und regionaler Ebene bekannt waren oder nach wenigen Monaten bereits wieder von der politischen Bühne verschwanden, war es nicht immer möglich, alle wünschenswerten Informationen lückenlos und widerspruchsfrei zu ermitteln. Die folgenden Ausführungen enthalten deshalb eine gleichsam natürliche Fehlerquote, die auf das zugrundeliegende Quellenmaterial und auf den schwierigen Untersuchungsgegenstand zurückgeht. Aufgrund der vergleichsweise hohen Zahl der hier untersuchten Personen dürften einzelne fehlerhafte Angaben jedoch nicht so stark ins Gewicht fallen, daß sie die erzielten Ergebnisse insgesamt verfälschen. 
reguläre Mitglieder des Landesausschusses, bei den restlichen 27 um Gäste, die aus zwei Gründen in den zu untersuchenden Personenkreis aufgenommen wurden: Zum einen war es nicht immer zweifelsfrei möglich, Delegierte und Gäste zu unterscheiden, zum anderen handelt es sich bei vielen Gästen um wichtige Mitbegründer der CSU oder um Angehörige der Parteizentrale, die als Fachleute zu bestimmten Fragen gehört wurden oder für den organisatorischen Ablauf der Tagungen verantwortlich waren. Die Angaben über die Gäste verfälschen die Ergebnisse über das Profil der Gründergeneration der CSU deshalb in keiner Weise, sondern verbreitern lediglich die Basis der Untersuchung ${ }^{312}$.

Im Oktober 1946 verabschiedete der Landesausschuß die von der Militärregierung genehmigte erste ordentliche Satzung der CSU, die mit einigen Änderungen bis 1952 in Kraft blieb ${ }^{313}$. Damit war eine wesentliche Grundlage für die organisatorische Konsolidierung der Partei geschaffen, die nun dazu übergehen konnte, die provisorischen Gremien der Gründungs- und Formierungsphase durch die satzungsgemäßen zu ersetzen. Mit der Sitzung des Landesausschusses am 31. Oktober 1946 endet somit auch die Analyse des Führungspersonals der CSU im Jahre 1946.

\section{b) Parteizugehörigkeit vor 1933}

Unter den Mitbegründern der bayerischen Unionspartei stellten die Mitglieder der 1933 untergegangenen Parteien des politischen Katholizismus zweifellos die zahlenmäßig stärkste Gruppe. Von den 178 erfaßten Personen hatten mindestens 65 der Bayerischen Volkspartei und sieben weitere dem Zentrum angehört. Da zu einer ganzen Reihe von Delegierten nur spärliche Angaben vorliegen, dürfte der tatsächliche Anteil dieses Personenkreises insgesamt noch höher gelegen haben. Nur ein Drittel der ehemaligen Mitglieder von BVP und Zentrum, die 1946 an den Tagungen des (Erweiterten) Landesausschusses teilnahmen, hatte sich vor 1933 auf einfache Parteimitgliedschaft beschränkt. Dagegen lassen sich 42 Politikerinnen und Politiker aufgrund ihrer Aktivitäten der Führungselite der BVP, fünf der Führungselite des Zentrums zuordnen. Allein 17 hatten als Landtags- oder Reichstagsabgeordnete die Politik ihrer Partei an entscheidender Stelle mitbestimmt, darunter Persönlichkeiten wie Anton Pfeiffer, Karl Scharnagl oder Fritz Schäffer. Die übrigen waren zumeist auf kommunalpolitischer Ebene als Bürgermeister, Gemeinde- oder Stadträte aktiv gewesen, hatten Führungsfunktionen in den lokalen und regionalen Untergliederungen ihrer Partei ausgeübt oder wichtige Ämter in Suborganisationen der BVP wie der Bayernwacht, dem Jungbayern-Ring oder dem Wirtschaftsbeirat bekleidet.

Diese Angaben legen die Vermutung nahe, daß die Mehrheit der ehemaligen Funktions- und Mandatsträger der BVP nach Kriegsende bereit war, am Aufbau der CSU mitzuwirken, soweit sie die NS-Zeit und die Wirren des Krieges unbeschadet und unbelastet überstanden hatten. Ein Blick auf die politische Biographie der im April 1932 gewählten BVP-Landtagsabgeordneten scheint diese These zu bestätigen: Von den 45

${ }^{312}$ Interessant wäre in diesem Zusammenhang ein punktueller Vergleich zwischen der im (Erweiterten) Landesausschuß repräsentierten Führungselite und Parteimitgliedern ohne Amt. Ein Ansatzpunkt hierfür wäre etwa die detaillierte Mitgliederliste des CSU-Kreisverbandes Alzenau in Unterfranken vom 15. 9. 1946 (am Stichtag ca. 470 Mitglieder); StA Würzburg, LRA Alzenau 127.

313 Vgl. dazu Fait, Einleitung zu: Protokolle und Materialien, S. XIVIII-LXVI. 
Mitgliedern der Fraktion finden sich 1946 immerhin 15 in den Reihen der CSU wieder; zehn weitere waren 1875 und früher geboren, mit über 70 Jahren also vermutlich zu alt, um die Strapazen der Parteiarbeit noch einmal auf sich zu nehmen; die vier Abgeordneten aus der bayerischen Pfalz dürften - wenn überhaupt - in ihrer engeren Heimat wieder aktiv geworden sein; mindestens fünf Mitglieder der Landtagsfraktion des Jahres 1932 waren vor Kriegsende verstorben ${ }^{314}$.

Die ehemaligen BVP-Politiker haben das Erscheinungsbild der Union in Bayern ebenso geprägt wie ihre programmatischen Grundsätze und die von ihr vertretene Politik. Doch allein deswegen zu behaupten, die CSU sei nichts anderes gewesen als die verkappte Neuauflage der Bayerischen Volkpartei, ginge weit an der Realität vorbei. Aufgrund ihrer Erfahrung aus der Weimarer Zeit waren viele frühere BVP-Politiker zwar gleichsam natürliche Anwärter auf Ämter in der CSU, doch sie stellten weder im (Erweiterten) Landesausschuß noch unter den einfachen Parteimitgliedern die Mehrheit. Wenn man den Mitgliederlisten trauen darf, hatten im Kreisverband Ingolstadt-Stadt und -Land Anfang 1946 beispielsweise von 519 Mitgliedern nur 27 der BVP angehört, also gerade einmal etwas mehr als fünf Prozent ${ }^{315}$. Auch scheint die bloße Mitgliedschaft in der BVP für die Stellung der einzelnen Politiker in den parteiinternen Führungs- und Flügelkämpfen nicht unbedingt ausschlaggebend gewesen zu sein, wie im nachhinein oft unterstellt wurde. Entscheidend war wohl vielmehr, welcher Gruppierung der BVP sie zuzurechnen waren und welche Position sie dort bekleidet hatten. Fragt man zum Beispiel danach, welche Stellung die ehemaligen Land- und Reichstagsabgeordneten der BVP im (Erweiterten) Landesausschuß in den innerparteilichen Auseinandersetzungen einnahmen, so ergibt sich folgendes Bild: Lediglich der unterfränkische Reichstagsabgeordnete und christliche Gewerkschafter Hugo Karpf trug die Konzeption Josef Müllers vorbehaltlos mit, neun ehemalige Mandatsträger darunter mit Alois Hundhammer, Anton Pfeiffer und bis 1946 Fritz Schäffer auch die Speerspitzen der Opposition gegen den Ochsensepp - standen dagegen auf der anderen Seite. Karl Scharnagl und die Bauernvertreter Michael Horlacher, Fridolin Rothermel und Alois Schlögl gerieten zeitweise zwischen die Fronten. Sie unterstützten Müller und seine Mitstreiter zwar in ihrem Bemühen, eine Revitalisierung der BVP zu verhindern und dem Unionsgedanken zum Durchbruch zu verhelfen, in der „bayerischen Frage" konnte es aber auch für sie keine Zugeständnisse geben. In den erbitterten Auseinandersetzungen um die Stellung Bayerns in einem künftigen deutschen Staat standen diese wichtigen "Geburtshelfer" Josef Müllers ${ }^{316}$ auf der Seite seiner Gegner.

Gemessen an der Zahl der ehemaligen Mitglieder von BVP und Zentrum war die Zahl derer, die vor 1933 anderen Parteien angehört hatten, gering. Soweit sich feststellen läßt, nahmen an den Landesausschußsitzungen lediglich 14 Personen teil, die in der Weimarer Republik parteipolitische Erfahrungen außerhalb von BVP und Zentrum gesammelt hatten. Davon waren fünf im Bayerischen Bauernbund, der ebenfalls in den katholischen Regionen Bayerns besonders starken liberal-konservativen Alternative

${ }^{314}$ Diese Angaben beruhen auf eigenen Recherchen sowie auf den diesbezüglichen Daten bei Schumacher (Hrsg.), M. d. L.

315 Stadtarchiv Ingolstadt, XXI/25, Mitgliederlisten der CSU im Stadt- und Landkreis Ingolstadt, 1945/ 1946.

316 So bezeichnete sich Michael Horlacher in seiner Rede vor der außerordentlichen Landesversammlung der CSU am 30./31. 8. 1947 in Eichstätt, in: Protokolle und Materialien, S. 1202. 
zur BVP, aktiv gewesen, einer im protestantischen Bayerischen Landbund und je zwei in der DVP, der DDP/StP und der SPD; Karl Gronwald hatte der DNVP angehört, ebenso Hermann Strathmann, der jedoch 1930 zum Christlich-Sozialen Volksdienst übergetreten war ${ }^{317}$. Damit waren im (Erweiterten) Landesausschuß alle Gruppierungen vertreten, die nach 1945 in der Union zusammengefaßt werden sollten, wobei das Spektrum von ehemaligen Deutschnationalen bis hin zu früheren Sozialdemokraten reichte, die sich nun zum Christentum als politischer Leitidee bekannten. Daß unter diesen 14 Delegierten immerhin fünf Politiker des Bayerischen Bauernbundes wie Konrad Kübler oder Josef Piechl waren, ist kein Zufall. Die Berührungsängste zwischen frühreren Anhängern von BVP und BBB waren - verglichen mit den Aversionen, die in den protestantischen Teilen Frankens gegen den politischen Katholizismus bestanden - relativ gering. Man hatte auch schon vor 1933 in verschiedenen Koalitionsregierungen zusammengearbeitet und vertrat gerade im Bereich der Agrarpolitik, aber auch auf dem Feld der „Reichspolitik“, ähnliche Positionen ${ }^{318}$. Die Tatsache, daß die Verfechter der Unionsidee um Josef Müller den Einfluß des Klerus in der Partei gering zu halten gedachten, erleichterte die Integration der teilweise antiklerikalen BBBKlientel zusätzlich.

Die wenigen Liberalen und Deutschnationalen im (Erweiterten) Landesausschuß der CSU konnten ihre Rolle als Bannerträger des Sammlungsgedankens dagegen nur mit begrenztem Erfolg ausfüllen. So gelang es 1946 zwar, Teile des nationalliberalen und deutschnationalen Wählerpotentials für die bayerische Unionspartei zu gewinnen $^{319}$, doch es blieben deutliche Vorbehalte gegen eine Partei spürbar, die sich zu einem guten Teil aus den Anhängern der BVP rekrutierte. Dies zeigte sich auch darin, daß ehemalige Mitglieder von DDP/StP, DVP und DNVP nur selten bereit waren, der CSU beizutreten, und auch die Wahlentscheidung vieler liberal oder national Gesonnener für die bayerische Unionspartei glich einer Art Ehe auf Probe. Dagegen darf man den Einfluß der zahlenmäßig schwachen liberalen und deutschnationalen Kräfte in den Führungsgremien der CSU auf die organisationspolitischen und programmatischen Grundsatzentscheidungen der Gründungs- und Formierungsphase nicht unterschätzen. Während die ehemaligen Politiker des Bayerischen Bauernbundes im (Erweiterten) Landesausschuß zumeist keine klare Position bezogen, standen Fritz Gerathewohl (DDP), Karl Gronwald (DNVP), August Haußleiter (DVP), Friedrich Wilhelm von Prittwitz und Gaffron (DDP) und Hermann Strathmann (DNVP/ CSVD) geschlossen auf der Seite Josef Müllers. Im Grunde genommen blieb beiden Seiten auch kaum etwas anderes übrig. Müller verkörperte wie kein zweiter den Gedanken der Sammlung, auf dessen glaubwürdige Umsetzung wiederum die ehemaligen Mitglieder der liberalen und deutschnationalen Parteien angewiesen waren, wollten sie nicht ihren Kredit bei den Wählern verspielen. Müller dagegen konnte nur mit der Unterstützung von Persönlichkeiten wie Strathmann oder Prittwitz-Gaffron hoffen, seine politische Basis in Franken in dem Maße auszubauen, wie es nötig war, um die Auseinandersetzungen mit den katholisch-konservativen Kräften erfolgreich zu führen.

\footnotetext{
$317 \mathrm{Zu}$ Strathmanns politischer Tätigkeit vor 1933 vgl. Anzeneder/Götz, 50 Jahre CSU in Erlangen, S. 26-34.

318 Vgl. dazu Bergmann, BBB und BCBV, passim.

319 Vgl. Thränhardt, Wahlen und politische Strukturen, S. 289-327.
} 
Viele Unionsgründer, die sich 1946 im (Erweiterten) Landesausschuß zusammenfanden, betraten jedoch nach dem Zusammenbruch der nationalsozialistischen Dikatur Neuland ${ }^{320}$. Parteipolitik war ihnen bisher fremd gewesen, sei es, daß sie vor $1933 \mathrm{zu}$ jung gewesen waren, um einer Partei beizutreten, oder daß sie erst durch die totalitäre Erfahrung des Dritten Reiches zu der Einsicht gelangten, es sei notwendig, für Freiheit und Demokratie einzutreten. Dieser Teil der Gründergeneration brachte zwar kaum politische, organisatorische oder administrative Erfahrungen in die neue Partei ein, war dafür aber auch am wenigsten auf bestimmte Positionen und Traditionen festgelegt.

\section{c) Konfessionszugehörigkeit}

Angesichts der besonderen Problematik, evangelische und katholische Christen in einer Partei zusammenzuführen, ist die konfessionelle Zusammensetzung der Gründergeneration der CSU von besonderer Bedeutung. Wie schon die vergleichende Untersuchung der Wahlergebnisse von BVP und CSU bei den Landtagswahlen von 1932 und bei den Wahlen zur Verfassunggebenden Landesversammlung 1946 gezeigt hat, muß die Aussage Mintzels, die CSU sei nach der konfessionellen Struktur ihrer Mitgliederschaft auch in der Ära Müller eine dominant katholische Partei gewesen, in ihrer Bedeutung relativiert werden ${ }^{321}$. Betrachtet man überdies den Anteil evangelischer Christen in den Führungsgremien der CSU und setzt diesen in Beziehung zum Anteil der Protestanten in der bayerischen Unionspartei und zum Prozentsatz der protestantischen Bevölkerung Bayerns, dann läßt sich das bisherige Bild noch weiter differenzieren. Während die um die Jahreswende 1947/1948 erhobene Mitgliederstatistik mehr als 91 Pozent Katholiken und nur 8,4 Prozent Protestanten aufweist ${ }^{322}$, war die konfessionelle Zusammensetzung des (Erweiterten) Landesausschusses für die protestantische Seite erheblich günstiger. 135 Katholiken (75,84 Prozent) standen 31 Protestanten (17,42 Prozent) gegenüber ${ }^{323}$. Gemessen am Anteil der evangelischen Christen an der Gesamtbevölkerung Bayerns von 26,46 Prozent waren die Protestanten damit zwar signifikant unterrepräsentiert ${ }^{324}$; im (Erweiterten) Landesausschuß war die evangelische Seite aber mehr als doppelt so stark vertreten, als es ihr nach der konfessionellen Zusammensetzung der Unionsmitglieder zugekommen wäre.

Im Landesvorstand der CSU, der sich im Dezember 1946 konstituierte, war diese faktische Bevorzugung der evangelischen CSU-Mitglieder noch augenfälliger: Von den 43 Mitgliedern des Landesvorstands bekannten sich immerhin elf zum evangelischen Glauben (26,19 Prozent) ${ }^{325}$. Daß sich dieser Prozentsatz fast mit dem prozentualen Anteil der Protestanten an der bayerischen Bevölkerung deckte, ist sicherlich kein

320 Vgl. Becker, Gründung und Wurzeln, in: Geschichte einer Volkspartei, S. 87.

321 Vgl. Mintzel, Anatomie, S. $176 \mathrm{f}$.

322 Vgl. ebenda, S. 176.

${ }^{323}$ Bei 12 Mitgliedern des (Erweiterten) Landesausschusses (6,74 Prozent) ließ sich die Konfession nicht ermitteln.

$324 \mathrm{Vgl}$. Adolf Voelcker, Die Verteilung der katholischen und evangelischen Bevölkerung in Bayern 1933 und 1946, in: ZBSL 81 (1949), S. 37-44.

325 Zum ersten Landesvorstand der CSU vgl. S. 158-165. Dort auch Angaben zur Konfessionsstruktur der Landtagsfraktion, die sich erheblich von der Konfessionstruktur des (Erweiterten) Landesausschusses und des Landesvorstands unterschied. 
Zufall. Mit der paritätischen Besetzung des Landesvorstands sollte nicht nur eine immer wieder erhobene Forderung der Evangelischen Landeskirche erfüllt ${ }^{326}$ und die dort vorhandene Skepsis gegen eine interkonfessionelle Sammlungspartei abgebaut werden. Es entsprach auch dem Konzept der Parteiführung um Josef Müller, den Protestanten die Ernsthaftigkeit und Tragfähigkeit des Unionsgedankens zu demonstrieren und durch eine Politik der Vorleistungen die evangelische Bevölkerung an die CSU heranzuführen und dieses Potential dauerhaft zu binden ${ }^{327}$.

Bedenkt man die bisherigen Ausführungen, dann kann es nicht verwundern, daß die übergroße Mehrheit der Protestanten im (Erweiterten) Landesausschuß in den parteiinternen Führungs- und Flügelkämpfen auf der Seite Josef Müllers stand. Von den 31 evangelischen Delegierten zählten mindestens 23 zu den Stützen des Parteivorsitzenden; lediglich Richard Pflaum und Hans Hermann von Eicken standen von vornherein im oppositionellen Lager oder hatten sich schon früh von Müller abgewandt. Der Münchner Verleger Richard Pflaum traf sich in seiner föderalistischen Gesinnung mit der katholisch-konservativen Opposition um Alois Hundhammer und Fritz Schäffer; nach dessen Absetzung als Vorsitzender des Bezirksverbands München durch die amerikanische Militärregierung führte er vorübergehend den Bezirksverband in seinem Sinne weiter ${ }^{328}$. Von Eicken dagegen, der lange Zeit in Oberschlesien gelebt hatte, stand der programmatischen und organisationspolitischen Konzeption Müllers positiv gegenüber und zählte 1945/1946 zu seinen treuen Gefolgsleuten. Das Zerwürfnis zwischen Müller und von Eicken beruhte nicht auf politischen, sondern auf persönlichen Differenzen. Von Müller menschlich enttäuscht, begann er, an dessen Qualifikation für das Amt des Parteivorsitzenden zu zweifeln und schloß sich schließlich denen an, die in Hans Ehard den Retter der bayerischen Unionspartei sahen ${ }^{329}$.

Bei näherer Betrachtung der Protestanten im (Erweiterten) Landesausschuß der CSU zeigt sich ferner: Das liberale, aber auch das deutschnationale Element in der frühen CSU wurde nahezu ausschließlich von Protestanten repräsentiert. So hatten von den acht evangelischen Delegierten, für die eine parteipolitische Betätigung vor 1933 nachweisbar ist, je zwei der DDP/StP und der DVP angehört und je einer dem BLB, dem BBB und der DNVP; der ehemalige Land- und Reichstagsabgeordnete Hermann Strathmann aus Erlangen war bis 1930 ebenfalls für die DNVP aktiv gewesen, dann aber zum CSVD übergetreten. Hinzu kommt, daß von den 31 evangelischen Delegierten des (Erweiterten) Landesausschusses lediglich 17 in Bayern, 13 dagegen in anderen Teilen Deutschlands oder außerhalb der Reichsgrenzen geboren worden waren. Für

326 Zur Forderung nach konfessioneller Parität vgl. Michael Renner, Nachkriegsprotestantismus in Bayern. Untersuchungen zur politischen und sozialen Orientierung der Evangelisch-Lutherischen Kirche Bayerns und ihres Landesbischofs Hans Meiser in den Jahren 1945-1955, München 1991, S. $16-34$.

327 Eine gute Zusammenfassung der Gravamina der Protestanten in der CSU bietet das von August Haußleiter verfaßte Memorandum „Die Evangelische Gruppe in der Union. Eine Analyse ihrer Stellung nach den Wahlen vom 30. Juni“ vom Juli 1946; IfZ-Archiv, Fh 56.

328 Protokoll der Sitzung des Landesausschusses der CSU am 6. 9.1946 in München und Protokoll der Landesversammlung der CSU am 14./15. 12. 1946 in Eichstätt, in: Protokolle und Materialien, S. 515 f., S. 528, S. 530 f., S. 534 und S. 849.

${ }^{329}$ IfZ-Archiv, Fh 56, Hans Hermann von Eicken an Hans Ehard vom 4. 9. 1947, sowie ACSP, NL Müller 6, Aktennotiz Franz Liedigs über ein Gespräch mit Hans Hermann von Eicken am 23. 9. 1946, NL Müller 18, Aktennotiz Achim Osters über ein Gespräch mit Hans Hermann von Eicken am 23. 11. 1946. 
eine Partei, deren Mitglieder sich überwiegend aus Einheimischen rekrutierten, war dies ein außergewöhnlich hoher Prozentsatz. Man könnte demnach die - zugegeben überspitzte - These aufstellen, daß die protestantische Gruppe im (Erweiterten) Landesausschuß nicht nur für die liberalen und nationalen Kräfte in der CSU stand, sondern auch so etwas wie Weltoffenheit in den Gründungsprozeß der bayerischen Unionspartei einbrachte, während die katholisch-konservative Seite vielfach in provinzieller Begrenztheit gefangen blieb.

Die bloße Zugehörigkeit zu einer Glaubensgemeinschaft sagt bekanntlich noch nichts über die tatsächliche Kirchenbindung aus. Von den protestantischen Delegierten des (Erweiterten) Landesausschusses waren jedoch nachweisbar 13 stark in der Evangelischen Landeskirche engagiert. Mit Hermann Strathmann und Kurt Blaser gehörten sogar zwei evangelische Theologen dem Landesausschuß an und bildeten das Gegengewicht zu den politisierenden Geistlichen auf katholischer Seite, die bereits in der BVP aktiv gewesen waren. Else Dahm und Elisabeth Meyer-Spreckels waren führende Vertreterinnen der evangelischen Frauenbewegung, vier weitere Delegierte gehörten der Synode der Evangelisch-Lutherischen Kirche in Bayern an, darunter ihr Präsident Wilhelm Eichhorn. Zu den prominenten evangelischen Repräsentanten zählten auch Johannes Semler, einer der Vertrauensmänner von Landesbischof Meiser im Münchner Gründerkreis, sowie August Haußleiter und Karl Sigmund Mayr, die im Laufe des Jahres 1946 mehr und mehr in die Rolle von Sprechern der Protestanten in der CSU hineinwuchsen ${ }^{330}$.

Daß die Protestanten im (Erweiterten) Landesausschuß der CSU keineswegs nur die Rolle von Gallionsfiguren spielten, zeigt ihre Verankerung in der Parteiorganisation. Mit Alfred Euerl (Nürnberg/Fürth), K. S. Mayr (Mittelfranken), Konrad Kübler (Niederbayern) und bis zu seiner Absetzung durch die Militärregierung auch Georg Barth (Oberfranken) waren zeitweise vier von zehn Bezirksvorsitzenden Protestanten; lediglich für zwei der 31 evangelischen Landesausschußmitglieder lassen sich keine weiteren Parteiämter nachweisen. Viele Delegierte hatten dagegen eine ganze Reihe von Funktionen und Mandaten inne - von kommunalpolitischen Ämtern bis zu Mandaten in der Verfassunggebenden Landesversammlung, von Parteiämtern auf Kreis- und Bezirksebene bis zu führenden Positionen in den Ausschüssen und Arbeitsgemeinschaften der CSU. Der protestantischen Gruppe im (Erweiterten) Landesausschuß fiel, so könnte man bilanzieren, eine Multiplikatorenrolle zu. Sie sollte für eine Verbreitung des Unionsgedankens in der evangelischen Bevölkerung sorgen, die der CSU skeptisch oder abwartend gegenüberstand. Dies konnte jedoch nur gelingen, wenn auch Programmatik und Politik der Partei für die Protestanten glaubwürdig waren.

\section{d) Altersstruktur}

Mit einem Durchschnittsalter von 46,32 Jahren war der (Erweiterte) Landesausschuß ein vergleichsweise junges Gremium ${ }^{331}$. Der Altersdurchschnitt der CSU-Mitglieder

\footnotetext{
330 Vgl. dazu Mintzel, Anatomie, S. 217.

331 Stichtag für die Berechnung des Durchschnittsalters der Mitglieder des (Erweiterten) Landesausschusses ist der 1. 1. 1946, Stichtag für die Berechnung des Durchschnittsalters der Mitglieder von Landesvorstand und Landtagsfraktion dagegen der 1. 12. 1946. Bei einem von den untersuchten Mitgliedern des (Erweiterten) Landesausschusses ließ sich das Geburtsdatum nicht ermitteln.
} 
betrug dagegen um die Jahreswende 1947/1948 circa 51 Jahre und deckte sich damit in etwa mit dem Altersdurchschnitt des im Dezember 1946 konstituierten Landesvorstands, der bei 50,21 Jahren lag; auch das Durchschnittsalter der Landtagsfraktion blieb mit 51,28 Jahren in diesem Rahmen. Die genannten Zahlen verweisen vor allem auf zweierlei: Während Parteivorstand und Landtagsfraktion zu den wichtigsten Entscheidungszentren der bayerischen Unionspartei zählten, war der (Erweiterte) Landesausschuß mit seinen bis zu 100 Mitgliedern mehr ein Ort der Diskussion und der Bestätigung bereits präformierter Beschlüsse. Dementsprechend gehörten sowohl dem Landesvorstand als auch der Landtagsfraktion tendenziell ältere und erfahrenere Politikerinnen und Politiker an, die ihre Nominierung oft auch der Tatsache verdankten, daß sie berufsständische Interessenverbände, konfessionelle Vereinigungen oder andere gesellschaftliche Gruppierungen vertraten, auf die die CSU Rücksicht zu nehmen hatte. Die Delegierten des (Erweiterten) Landesausschusses wurden dagegen weniger nach solchen Kriterien ausgewählt. Sie sollten vielmehr die Partei als ganzes repräsentieren, und zwar nicht unbedingt eine Partei, die in dieser Form bereits bestand, sondern eine weitgespannte Union, wie sie Josef Müller und seine Mitstreiter aufzubauen gedachten. In diesem Sinne sah die Satzung beispielsweise vor, daß die Frauen und die jüngere Generation im (Erweiterten) Landesausschuß besonders vertreten sein sollten $^{332}$. Vor allem diese zehn Vertreter der Parteijugend, einer für jeden Bezirksverband, waren für den vergleichsweise niedrigen Altersdurchschnitt des hier untersuchten Personenkreises verantwortlich. Dies entsprach auch ganz der Konzeption Josef Müllers, der auf die jugendliche Dynamik des Parteinachwuchses setzte und immer wieder die „Vergreisung“ der CSU beklagte ${ }^{333}$.

Weitere interessante Aufschlüsse über die Gründergeneration der bayerischen Unionspartei liefert die Untersuchung der Altersstruktur des (Erweiterten) Landesausschusses, die auch Rückschlüsse auf die Zugehörigkeit der Delegierten zu bestimmten politischen Generationen erlaubt. In Anlehnung an den klassischen Entwurf Karl Mannheims ${ }^{334}$ hat Helmut Fogt als politische Generation alle Mitglieder einer Alterskohorte bezeichnet, die durch bestimmte Schlüsselereignisse geprägt wurden und dadurch zu einer "gleichgesinnten bewußten Auseinandersetzung mit den Leitideen und Werten der politischen Ordnung gelangten, in der sie aufwuchsen “335. Diese Auseinandersetzung findet normalerweise in der politisch prägenden Lebensphase statt (von 16 bis 21 Jahren) und führt zu langfristig stabilen - wenn auch nicht unveränderlichen Orientierungen und grundlegenden Einstellungen ${ }^{336}$. Angehörige einer politischen Generation zeichnen sich demnach durch einen „Grundbestand gemeinsamer Einstellungen, Verhaltensdispositionen und Handlungspotentiale“ aus sowie durch gemeinsame politisch relevante Normen und Werte, die ihr Handeln in spezifischer Weise beein-

332 Satzung der CSU in der Fassung vom 4. 10. 1946, abgedruckt in: Protokolle und Materialien, S. 1783-1803.

333 Sitzung des Ochsen-Clubs am 24. 7. 1946, in: Lehrjahre, S. 84.

334 Vgl. Karl Mannheim, Das Problem der Generationen, in: Martin Kohli (Hrsg.), Soziologie des Lebenslaufs, Darmstadt, Neuwied 1978, S. 38-53.

335 Vgl. Helmut Fogt, Politische Generationen. Empirische Bedeutung und theoretisches Modell, Opladen 1982, S. 6-25; dic folgenden Zitate ebenda, S. 21.

336 Zum Konzept der politischen Sozialisation vgl. Bernhard Claußen, Was ist und wie erforscht man politische Sozialisation?, in: ders., Klaus Wasmund (Hrsg.), Handbuch der politischen Sozialisation, Braunschweig 1982, S. 1-22. 


\section{Altersstruktur des (Erweiterten) Landesausschusses}

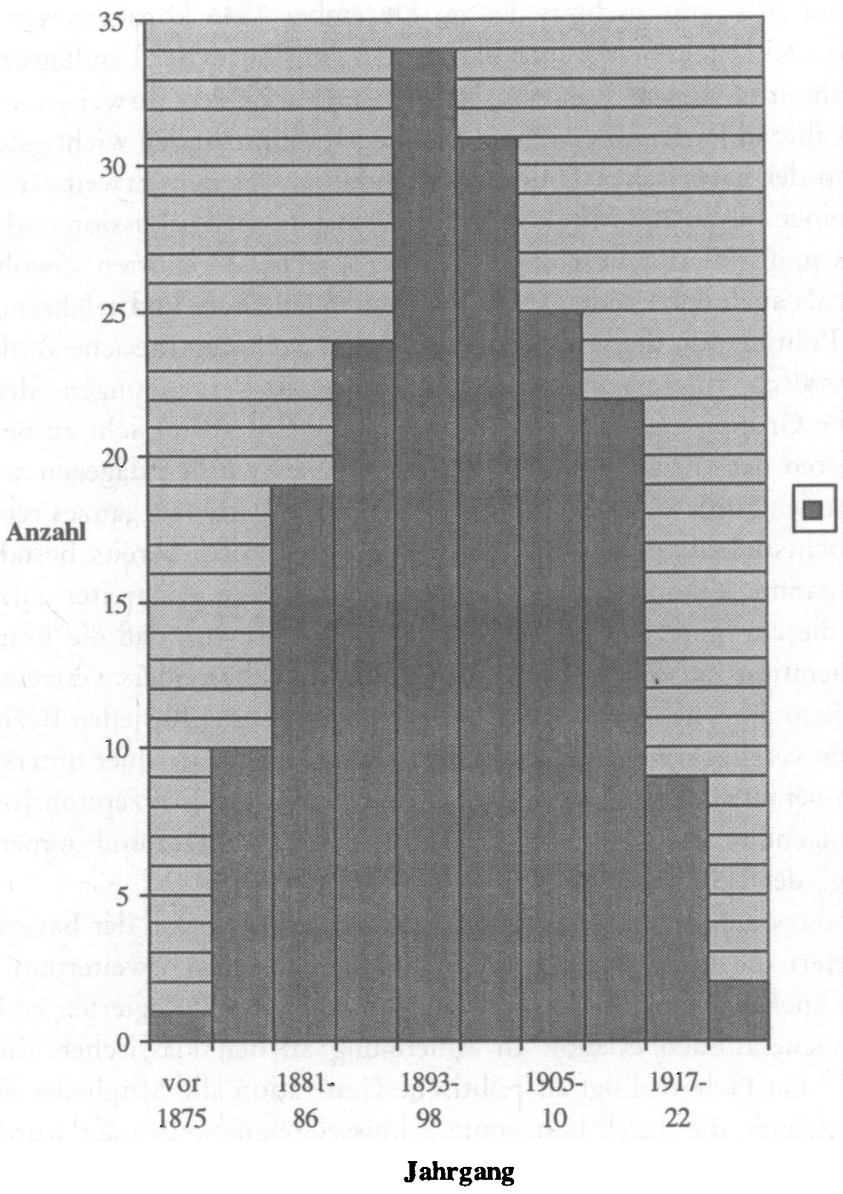

flussen können. Die notwendige Berücksichtigung einer Viclzahl intermittierender Variablen, beispielsweise regionale, konfessionelle oder sozioökonomische Disparitäten, macht es allerdings schwierig, zu Ergebnissen zu gelangen, die einerscits den empirischen Daten gerecht werden, andererseits aber noch ausreichende Erklärungskraft beanspruchen können. Hans Jacger hat bereits vor längerer Zeit darauf verwiesen, daß man eine politische Generation vorwiegend als „Problemgemeinschaft, nicht aber als cine Problemlösungsgemeinschaft" zu betrachten habe ${ }^{3.37}$. Daraus ergibt sich die Notwendigkeit, Konzepte wie das der politischen Generation primär als heuristische Instrumente bei der Untersuchung sozialer Gruppen einzusetzen, wobei es weniger darum geht, zu allgemeingültigen Aussagen zu kommen, als darum, Indikatoren, Arbeitshypothesen oder Modelle zu entwickeln.

3:7 Hans Jaeger, Generationen in der Geschichte. Überlegungen zu einer umstrittenen Konzeption, in: GuG 3 (1977), S. 429-452, hier S. 444. 
In Anlehnung an ein von Hans-Ulrich Derlien entwickeltes Schema lassen sich die Mitglieder des (Erweiterten) Landesausschusses in zehn Geburtskohorten einteilen ${ }^{338}$ : Vor 1875 geboren: Ära Bismarck, 1875-1880 und 1881-1886: wilhelminische Ära, 1887-1892: Vorgeschichte des Ersten Weltkriegs, 1893-1898: Erster Weltkrieg, 1899-1904: Revolution und Nachkriegswirren, 1905-1910: Jahre der scheinbaren Normalität, 1911-1916: Krise und Zerfall der Weimarer Republik, 1917-1922: NS-Machtergreifung und Machtsicherung, 1923-1928: Zweiter Weltkrieg.

Danach ergibt sich folgendes Bild: Die Mitglieder des (Erweiterten) Landesausschusses wurden zwischen 1868 und 1925 geboren. Die ältesten Delegierten hatten zu einer Zeit das Licht der Welt erblickt, als die Gründung des deutschen Kaiserreiches noch bevorstand, während die jüngsten in den wenigen scheinbar stabilen Jahren der Weimarer Republik zur Welt gekommen waren. Nicht wenige Delegierte hatten Monarchie, Revolution, Demokratie und Diktatur, einschließlich zweier Weltkriege, bewußt erlebt. Der älteste Delegierte war der 77 jährige Ernst-Arthur Voretzsch; der Protestant aus Sachsen-Altenburg hatte 1893 seine Studien mit der Promotion zum Dr. jur. beendet und trat anschließend in den Staatsdienst ein. Seit 1899 im diplomatischen Dienst, führte ihn seine Karriere über Indien, Norwegen und Südafrika in den Fernen Osten, von wo er in den Wirren des Ersten Weltkriegs zurückkehrte, um 1917 zum Generalkonsul in Kristiania ernannt zu werden. Das Ende des Krieges und die Novemberrevolution hatten auf Voretzsch' weitere Laufbahn keinen Einfluß; 1920 trat er sein Amt als deutscher Gesandter in Lissabon an und beendete seine Karriere 1933 als Botschafter in Tokio, da er die Altersgrenze erreicht hatte. Zu diesem Zeitpunkt war Franz Heubl, der zu den jüngsten Delegierten im (Erweiterten) Landesausschuß zählte, gerade neun Jahre alt. Während sich Voretzsch nach Mittelfranken zurückgezogen hatte, absolvierte Heubl im Schatten der nationalsozialistischen Diktatur das Gymnasium und wurde mit 19 Jahren zur Wehrmacht eingezogen. Beide zählten sie zu den Mitbegründern der CSU, Voretzsch in Mittelfranken, Heubl in München, beide bezogen sie in den Führungs- und Flügelkämpfen klar Stellung: Heubl für die katholisch-konservative Opposition um Schäffer und Hundhammer, Voretzsch für den Parteivorsitzenden Josef Müller. Der Botschafter a. D. zog sich bald aus der Politik zurück, und als er 1965 im Alter von fast 97 Jahren starb, war Heubl bereits drei Jahre lang Bayerischer Staatsminister für Bundesangelegenheiten und Bayerischer Bevollmächtigter beim Bund.

Die Graphik zeigt, daß die zwischen 1887 und 1904 Geborenen zu den wichtigsten Trägern der Parteiarbeit zählten. Diesen drei Alterskohorten gehörten insgesamt 89 Personen an, etwas mehr als die Hälfte des hier untersuchten Personenkreises. In den krisenhaften Jahren vor dem Ersten Weltkrieg, im Ersten Weltkrieg selbst oder in den schwierigen Anfangsjahren der Weimarer Republik politisch sozialisiert, hatten sie nicht nur die Novemberrevolution und die tiefgreifenden sozialen Umwälzungen, die Krieg und Zusammenbruch mit sich gebracht hatten, bewußt erlebt, sondern auch den Verlust herrschender Orientierungsmuster und Leitvorstellungen ${ }^{339}$. Diese Erleb-

$338 \mathrm{Vgl}$. Hans-Ulrich Derlien, Continuity and change in the West German federal elite 1949-1984, in: EJPR 18 (1990), S. 349-372. Für den hier untersuchten Personenkreis war es notwendig, Derliens Modell für die Geburtskohorten aus den Jahren vor 1893 zu differenzieren.

339 Vgl. dazu Detlef Peukert, Die Weimarer Republik. Krisenjahre der Klassischen Moderne, Frankfurt am Main 1987, S. 13-31. 
nisse führten bei vielen späteren Mitbegründern der CSU, die 1918/1919 zur jungen Generation gezählt hatten, zu einer tiefgreifenden Verunsicherung, zu einer Verstärkung konservativer Prädispositionen und zu einer ausgeprägten Sehnsucht nach Ruhe und Ordnung. Als die erste deutsche Demokratie nach der Berufung Hitlers zum Reichskanzler endgültig gescheitert war, hatten die 1887 bis circa 1895 Geborenen zum Teil bereits steile Karrieren hinter sich und bekleideten wie Fritz Schäffer oder Anton Pfeiffer politische Spitzenämter; die jüngeren Vertreter dieser drei Alterskohorten dagegen waren bis 1933 entweder politisch kaum hervorgetreten oder hatten als hoffnungsvolle Nachwuchspolitiker wie Alois Hundhammer gerade die ersten Stufen der Karriereleiter erklommen, als die nationalsozialistische Diktatur ihren Aktivitäten ein jähes Ende setzte. Bei Kriegsende zwischen 41 und 58 Jahre alt, drückten die zwischen 1887 und 1904 Geborenen der bayerischen Unionspartei ihren Stempel auf. Mit Joseph Baumgartner (1904), Hans Ehard (1887), Michael Horlacher (1888), Alois Hundhammer (1900), Josef Müller (1898), Anton Pfeiffer (1888), Fritz Schäffer (1888) und Alois Schlögl (1893) gehörten die vielleicht prominentesten Mitbegründer der CSU diesen Alterskohorten an. Ein Blick auf den im Dezember 1946 konstituierten Landesvorstand ergibt ein ähnliches Bild: 26 von 43 Vorstandsmitgliedern (60,47 Prozent) hatten zwischen 1887 und 1904 das Licht der Welt erblickt.

$\mathrm{Zu}$ den politisch erfahrensten Mitbegründern der CSU zählten zweifellos die bis 1886 Geborenen. Der Einfluß dieser Alterskohorten, die im (Erweiterten) Landesausschuß mit mindestens 30 Personen (16,95 Prozent) vertreten waren, ist gerade in der Formierungsphase der bayerischen Unionspartei deutlich erkennbar, nahm jedoch in der Folgezeit mehr und mehr ab. Auf der anderen Seite der Alterspyramide standen die zwischen 1905 und 1928 zur Welt Gekommenen, unter denen die zwischen 1905 und 1916 Geborenen mit 47 Delegierten (26,55 Prozent) die größte Gruppe stellten. Diese Delegierten, deren politische Sozialisation sich teils in der krisengeschüttelten Weimarer Republik, teils unter den Bedingungen totalitärer Herrschaft vollzogen hatte, waren nach dem Ende des Zweiten Weltkriegs, an dem sie zumeist teilgenommen hatten, überwiegend politische "Greenhorns“. Nur wenige waren vor 1933 in der Lage gewesen, parteipolitische Erfahrungen zu sammeln, schließlich waren selbst die Ältesten erst 28 Jahre alt gewesen, als Hitler zum Reichskanzler ernannt wurde, während die Jüngsten noch ihre Grundschulausbildung absolvierten. Um so prägender waren für viele junge Mitbegründer der bayerischen Unionspartei die erbitterten Auseinandersetzungen der Jahre 1945 bis 1949, die für sie am Beginn ihrer politischen Laufbahn standen. Während der Einfluß der älteren Generation nach 1954 mehr und mehr schwand, zählte eine Reihe von Mitbegründern der CSU, die 1946 noch zum hoffnungsvollen Nachwuchs gehört hatten, zu den Trägern einer tiefgreifenden inneren Reform der Partei, ohne die ihre großen Erfolge kaum möglich gewesen wären. $\mathrm{Zu}$ nennen wären dabei neben Franz Josef Strauß, der 1915 zur Welt kam, vor allem Franz Heubl (1923), Richard Jaeger (1913), Otto Schedl (1912), Richard Stücklen (1916) oder Hans Weiß (1919). Das Verhältnis der Generationen gestaltete sich dabei keinesfalls immer harmonisch. So betrachteten etablierte Entscheidungsträger den Gestaltungsund Veränderungswillen jüngerer Parteifreunde mit Unbehagen ${ }^{340}$, während diese der

${ }^{3+0}$ BayHStA, NL Pfeiffer 42, Rundschreiben Anton Hergenröders "Was ist Parteijugend und was ist Junge Union'?" vom 21.1.1947. 
politischen Vergangenheit mancher älterer Kollegen skeptisch gegenüberstanden. Richard Jaeger bemerkte beispielsweise im November 1946:

„Es wäre für uns alle das Beste, wenn diese ,alten` Männer von 1933, die mit dem Ermächtigungsgesetz belastet sind, endlich einmal in der Union verschwinden würden, zumindest von den führenden Posten. Daran ist kein Zweifel, daß diese alten Abgeordneten und Politiker von 1933 schmählich versagt haben, ob aus Feigheit oder Dummheit, sei dahingestellt. Tatsache sei, daß diese Männer gegen den Nationalsozialismus gewählt worden seien und dann für den Nationalsozialismus gestimmt hätten! Diese Schuld könne ihnen niemand abnchmen!“341

\section{e) Berufsgruppenschichtung}

Fragt man nach der Sozialstruktur der Gründergeneration der CSU, wie sie sich im (Erweiterten) Landesausschuß widerspiegelt, dann ist eine Analyse der Berufsgruppenschichtung unerläßlich, die nicht nur Aufschluß über soziale Herkunft und Rekrutierung von Funktionsträgern gibt, sondern auch darüber, welche Bevölkerungsgruppen in welchem Ausmaß am Aufbau der bayerischen Unionspartei beteiligt waren. Um erste Antworten auf diese Fragen zu erhalten, erwies sich ein von Heino Kaack entwickeltes und für die vorliegende Studie modifiziertes Berufsgruppenschema als hilfreich ${ }^{342}$. Entscheidendes Kriterium war hierbei nicht der erlernte, sondern der unmittelbar vor den Wahlen zur Verfassunggebenden Landesversammlung im Juni 1946 ausgeübte Beruf. Dieser Stichtag läßt sich einfach begründen: Mit der Wahl in die Verfassunggebende Landesversammlung begann für eine Reihe von Delegierten des (Erweiterten) Landesausschusses eine Karriere als Berufspolitiker; der Blick auf die Zeit vor dem 30. Juni 1946 ergibt ein differenzierteres Bild von der Gründergeneration der bayerischen Unionspartei. Ohne die folgende Tabelle erschöpfend interpretieren zu wollen, zeigt die Berufsgruppenschichtung einige markante Auffälligkeiten.

\section{Berufsgruppenschichtung der Mitglieder des (Erweiterten) Landesausschusses}

Berufspolitiker

sonstiger öffentlicher Dienst

Dozenten, Wissenschaftler, Lehrer

Journalisten, Medienbereich

Rechtsanwälte

sonstige freie Berufe

Angestellte

Unternehmer
23 selbständiger Mittelstand

24 Landwirte

12 Arbeiter

5 Parteiangestellte

$4 \quad$ Verbandsangestellte

6 Pfarrer

18 Sonstige (Hausfrauen, Rentner, Studenten)

2 unbekannt

${ }^{341}$ Sitzung des Dienstag-Clubs am 12. 11. 1946, in: Lehrjahre, S. 110; ähnlich auch Sitzung des Dienstag-Clubs am 24. 9. 1946, in: ebenda, S. 98; Protokoll der Sitzung des Erweiterten Vorläufigen Landesausschusses der CSU am 30./31.3. 1946 in Bamberg, in: Protokolle und Materialien, S. $93 \mathrm{ff}$. (Franz Josef Strauß, Anton Ott), und ACSP, CSU-LTF I, 15-12/4 und 5, Alois Hundhammer an Anton Pfeiffer vom 25. 7. 1947, sowie CSU-LTF I, 15-20/0, Bericht über die Tagung des Bundesrats der Jungen Union Deutschlands in Holzkirchen am 14./15. 9. 1947.

342 Vgl. Heino Kaack, Die soziale Zusammensetzung des Deutschen Bundestages, in: Uwe Thaysen, Roger H. Davidson, Robert G. Livingston (Hrsg.), US-Kongreß und Deutscher Bundestag. Bestandsaufnahmen im Vergleich, Opladen 1988, S. 128-151. Im Unterschied zu Kaack, der zwölf Berufsgruppen unterscheidet, hat sich für die vorliegende Untersuchung ein etwas differenzierteres Modell mit 16 Kategorien als nützlich erwiesen. 
Da ist zum einen der hohe Anteil von Berufspolitikern, das heißt von Personen, die „hauptsächlich ein Amt ausgeübt haben, für das Parteiaktivitäten eine unerläßliche Voraussetzung sind ${ }^{\star 343}$. Dieses Kriterium trifft vor allem auf die Mitglieder der Staatsregierung zu sowie auf sonstige Inhaber von Spitzenämtern im Bereich der Exekutive und auf kommunale Wahlbeamte. Soweit die Minister und Staatssekretäre der CSU angehörten, waren sie seit März 1946 qua Amt mit Sitz und Stimme im (Erweiterten) Landesausschuß vertreten. Neben diesen fünf Kabinettsmitgliedern (Joseph Baumgartner, Hans Ehard, Michael Helmerich, Heinrich Krehle und Anton Pfeiffer) finden sich in der Sparte Berufspolitiker vor allem Landräte und hauptamtliche Bürgermeister größerer bayerischer Städte. Diese Kommunalpolitiker verdankten ihre Ämter zwar auch ihrer aktiven Mitarbeit in der CSU, in vielen Fällen war es aber so, daß die bewährten Amts- und Mandatsträger auf lokaler und regionaler Ebene in klassischer Honoratiorenmanier einen funktionsfähigen Parteiapparat ersetzten und dafür mit Parteiämtern belohnt wurden.

Auffallend hoch ist der Anteil an Lehrern, Dozenten und sonstigen Angehörigen des öffentlichen Dienstes. Diese Mitbegründer der CSU verfügten zumeist über eine fundierte Ausbildung, die ihren Einstieg in die Parteiarbeit erleichterte. Sie waren oftmals in politiknahen Bereichen tätig und hatten genügend Zeit für ihre parteipolitischen Aktivitäten. Der hohe Anteil an Beamten und Angestellten im öffentlichen Dienst ist aber auch ein Reflex auf den Erfolg der CSU 1946; damit bestand die Möglichkeit, Mitglieder der eigenen Partei in bestimmte Positionen zu bringen, sofern sie politisch nicht belastet waren. Die Zusammensetzung des (Erweiterten) Landesausschusses erinnert an die Zusammensetzung der Führungselite der BVP, die sich zu einem großen Teil aus der höheren Beamtenschaft und sonstigen Angehörigen des öffentlichen Dienstes rekrutiert hatte ${ }^{344}$.

Eklatant unterrepräsentiert war die Arbeiterschaft. Mit dem Holzarbeiter Fritz Kaiser aus dem oberfränkischen Forchheim war lediglich ein Arbeiter Mitglied des (Erweiterten) Landesausschusses. Allein darin zeigt sich, wie schwer es für die als Sammlungsbewegung „aller Berufsstände aus einst getrennten politischen Lagern“ angetretene CSU war ${ }^{345}$, in den Reihen der Arbeiterschaft Fuß zu fassen. In Anlehnung an die Tradition der katholischen Arbeiterbewegung und der Christlichen Gewerkschaften ${ }^{346}$ dürfte es der bayerischen Unionspartei - wie beispielsweise in Augsburg - zwar gelungen sein, einen Teil der bewußt christlichen Arbeiter für sich zu gewinnen, aber ebenso wie in der Weimarer Republik war auch in der Nachkriegszeit die SPD die politische Heimat für die große Mehrheit der bayerischen Arbeiter ${ }^{347}$. Daran änderte auch die

${ }^{343}$ Ebenda, S. $131 \mathrm{f}$. Kaack bezicht auch Parteiangestellte in diese Berufsgruppe mit ein. Für die vorliegende Analyse erwies es sich jedoch als sinnvoll, die Mitarbeiter der Parteiverwaltung und die Redakteure der Parteipresse gesondert auszuweisen, wobei vor allem zwei Gründe ausschlaggebend waren: Zum einen läßt sich das Personal des im Aufbau befindlichen Parteiapparats auf diese Weise besser untersuchen, zum anderen wurden die Mitarbeiter der Parteiverwaltung von den meisten Mitbegründern der CSU nicht als politische Funktionsträger, sondern als technisch-administrative Exekutivkräfte verstanden.

344 Zur Begünstigung von Landwirten und Beamten in der BVP vgl. Schönhoven, BVP, S. 81 f., und Unger, Bayerische Bewegung, S. 50.

345 "Zehn Punkte der Union" vom 31. 12. 1945, abgedruckt in: Protokolle und Materialien, S. $1713 \mathrm{f}$.

${ }^{3+6}$ Vgl. dazu ausführlich Dorit-Maria Krenn, Die christliche Arbeiterbewegung in Bayern vom Ersten Weltkrieg bis 1933, Mainz 1991, und Noel D. Cary, Political Catholicism and the reform of the German party system 1900-1957, Diss., Ann Arbor/Mich. 1988, insbesondere S. 310-409.

347 Vgl. Mintzel, Anatomie, S. 185 f., und Behr, Sozialdemokratie und Konservatismus, S. 145. 
Tatsache nichts, daß dem (Erweiterten) Landesausschuß der CSU mindestens 17 Mitglieder der 1933 zerschlagenen Christlichen Gewerkschaften angehörten, die als Träger des interkonfessionellen und sozialen Gedankens in der Formierungsphase der bayerischen Unionspartei eine wichtige Rolle spielten. Zwölf davon waren sogar aktive Gewerkschaftsfunktionäre gewesen, darunter Adolf Konrad, der Landesvorsitzende des christlich-nationalen Deutschen Gewerkschaftsbundes in Bayern, Heinrich Krehle, der Landessekretär der bayerischen Christlichen Gewerkschaften, oder Michael Helmerich, der Vorsitzende des christlichen Bayerischen Eisenbahnerverbands. Mit der Gründung von offiziell parteipolitisch neutralen, de facto aber vor allem der Sozialdemokratie nahestehenden Einheitsgewerkschaften hatte sich nach dem Ende des Zweiten Weltkriegs die Szenerie grundlegend verändert, und die im (Erweiterten) Landesausschuß der CSU vertretenen ehemaligen christlichen Gewerkschafter knüpften meist nicht mehr an ihre 1933 zwangsweise beendeten Aktivitäten an.

Soweit sich feststellen läßt, waren mit Hugo Karpf, Lorenz Sedlmayr und Paul Strenkert aus Kempten nur drei Delegierte des (Erweiterten) Landesausschusses aktiv am Aufbau des Bayerischen Gewerkschaftsbundes beteiligt. Josef Donsberger, vor 1933 Bezirksleiter beim christlichen Bayerischen Eisenbahnerverband, engagierte sich beim Bayerischen Beamtenbund. Heinrich Krehle, der auch in der Führungsetage des Bayerischen Gewerkschaftsbundes (BGB) in hohem Ansehen stand ${ }^{348}$, wurde 1946 zwar als prominenter Vertreter der ehemaligen Christlichen Gewerkschaften zum Staatssekretär im Arbeitsministerium berufen, ansonsten gestaltete sich das Verhältnis zwischen CSU und BGB aber mehr schlecht als recht ${ }^{349}$. Johann Amberger und Heinrich Schilling, die beiden Vertreter der CSU im Vorstand des BGB, spielten in der Partei auch keine große Rolle und gehörten weder dem Landesvorstand noch dem Landesausschuß noch der Landtagsfraktion $\mathrm{an}^{350}$.

Mit Blick auf die Mitgliederstruktur hat Alf Mintzel von der CSU als einer Partei des „Besitzmittelstandes bäuerlicher, handwerklicher und kleinunternehmerischer Provenienz" gesprochen ${ }^{351}$. Für den (Erweiterten) Landesausschuß gilt dieser Befund jedoch nur teilweise. Diesem Gremium gehörten zwar wenigstens 13 Vertreter des selbständigen Mittelstandes an, Einzelhändler wie der Münchner Delegierte Ludwig Blum, Handwerksmeister wie der Konditor Heinrich Elhardt oder mittelständische Unternehmer wie der Feinmechanikermeister Hans Hagn. Drei Landesausschußmitglieder der schon erwähnte Elhardt als Obermeister der Münchner Bäcker- und Konditorinnung, Franz Schäfer als Kreishandwerkermeister und Vorstandsmitglied der oberbayerischen Handwerkskammer sowie Georg Weinzierl als Obermeister der Schlosserinnung und Vorstandsmitglied der Handwerkskammer für Mittelfranken - zählten nachweisbar zu den verbands- und standespolitisch aktiven Vertretern ihrer Zunft, bei anderen ist dies anzunehmen. Dagegen nahmen nur sieben nicht zugleich als Landräte oder

348 Vgl. Claudia Lanig-Heese, Gewerkschaften in Bayern 1945 bis 1949, Marburg 1991, S. 201.

${ }^{349}$ Vgl. z. B. die Diskussion über den Generalstreik in Bayern während der Landesversammlung der CSU am 24./25. 1. 1948 in Marktredwitz, in: Protokolle und Materialien, S. 1464f., S. 1473, S. 1486 f. und S. 1515.

$350 \mathrm{Vgl}$. Handbuch politischer Institutionen und Organisationen 1945-1949, bearb. von Heinrich Potthoff in Zusammenarbeit mit Rüdiger Wenzel, Düsseldorf 1983, S. 409; vgl. auch Günther Gerstenberg, Der Wiederaufbau der Münchner Gewerkschaftsbewegung und der Bayerische Gewerkschaftsbund 1945 bis 1949, unveröffentlichte Magisterarbeit, München 1984, S. 25 ff. und S. 84.

351 Mintzel, Anatomie, S. 183. 
hauptamtliche Bürgermeister engagierte Landwirte an den Sitzungen des (Erweiterten) Landesausschusses teil ${ }^{352}$. Damit war dieser Berufsstand nicht nur im Vergleich zum Anteil der in Land- und Forstwirtschaft Beschäftigten, der 1946 in Bayern 25,8 Prozent der berufszugehörigen Bevölkerung betrug ${ }^{353}$, stark unterrepräsentiert, sondern auch im Vergleich zum Anteil der bäuerlichen Bevölkerung an den Wählern und Mitgliedern der $\mathrm{CSU}^{354}$. Auch wenn man neben dem ausgeübten den erlernten Beruf als Kriterium heranzieht, gestaltet sich das Verhältnis nicht wesentlich günstiger, und es lassen sich lediglich sechs weitere Mitglieder des (Erweiterten) Landesausschusses ermitteln, die dem Agrarsektor entstammten; berücksichtigt man zusätzlich noch die „Bauerndoktoren“ Joseph Baumgartner, Michael Horlacher, Alois Schlögl und - mit Abstrichen - Alois Hundhammer, so kommt man insgesamt auf 17 Personen, die den Bereich Landwirtschaft im (Erweiterten) Landesausschuß der CSU vertraten.

So gesehen waren die ständigen Klagen der führenden Repräsentanten des Bauernstandes nach stärkerer Berücksichtigung der von ihnen vertretenen Klientel in den Führungsgremien der CSU nicht ohne Berechtigung ${ }^{355}$. Allerdings waren die bäuerlichen Interessen bei den sieben Mitgliedern des Bayerischen Bauernverbands, die dem (Erweiterten) Landesausschuß nachweisbar angehörten, in den besten Händen. Fridolin Rothermel wurde im Dezember 1946 zum 1. Präsidenten des Bayerischen Bauernverbands gewählt, Michael Horlacher fungierte als einer der stellvertretenden Präsidenten und Alois Schlögl gehörte dem Präsidium des BBV als hauptamtlicher Generalsekretär an; Adam Sühler war Präsident des BBV in Oberfranken, Josef Piechl und Andreas Schweiger gehörten als stellvertretende Präsidenten in den Bezirken Niederbayern und Oberbayern ebenfalls zu den führenden Männern des Bauernverbands; der siebte im Bunde, Franz Ludwig Sauer, führte einen Kreisverband des BBV in Unterfranken. Keine andere Organisation war so eng mit der CSU verbunden wie der Bayerische Bauernverband. So gehörten im Dezember 1946 von sieben Präsidiumsmitgliedern des BBV mindestens vier der CSU an und nur je einer der SPD und der FDP; von den sieben Bezirksverbänden des BBV wurden ebenfalls mindestens vier von CSU-Mitgliedern geführt ${ }^{356}$. Waren sich die Vertreter agrarischer Interessen in den Führungsgremien der CSU einig, so konnten sie sicher sein, daß ihre Wünsche und Forderungen nicht ohne Wirkung blieben. Dieses Faktum kompensierte die mangelhafte zahlenmäßige Repräsentation im (Erweiterten) Landesausschuß der bayerischen Unionspartei reichlich.

Auffällig ist auch, wie viele Angestellte der Partei an den Sitzungen des (Erweiterten) Landesausschusses der CSU teilnahmen ${ }^{357}$. Dies zeigt einmal mehr die wichtige

352 Von diesen sieben Landwirten betrieben fünf nebenher einen Handwerksbetrieb, ein Einzelhandelsgeschäft, ein landwirtschaftliches Lagerhaus, eine Gastwirtschaft oder eine Brauerei.

353 Statistisches Jahrbuch für Bayern 1947, S. 164.

${ }^{35+} \mathrm{Vgl}$. Berberich, Historische Entwicklung, S. 153 f., und Mintzel, Anatomie, S. 173.

355 Protokoll der Sitzung des Erweiterten Vorläufigen Landesausschusses der CSU am 30./31. 3. 1946 in Bamberg, Protokoll der Sitzung des Landesarbeitsausschusses der CSU am 1. 5. 1946 in München, Protokoll der Sitzung des Landesausschusses der CSU am 31.10.1946 in München, Protokoll der Sitzung des Landesausschusses der CSU am 3.1. 1947 in Augsburg, in: Protokolle und Materialien, S. 179, S. 205, S. 687-693, S. 765 und S. 987.

$356 \mathrm{Vgl}$. Handbuch der politischen Institutionen und Organisationen, S. 377 f.; Zehn Jahre Bayerischer Bauernverband, München 1955; Heinz Haushofer, Der Bayerische Bauer und sein Verband 1945-1970, München u. a. 1970.

357 Aufgrund der schlechten Quellenlage war es nicht möglich, zwischen haupt-, neben- und ehren- 
Rolle, die Mitarbeitern der Landesgeschäftsstelle wie August Wilhelm Schmidt, Franz Liedig, Karl Gronwald, Fritz Gerathewohl oder Hanswolf Haunhorst beim Aufbau der Partei zufiel. Dies entsprach zwar der Konzeption Josef Müllers, dem eine mitgliederstarke Volkspartei mit einer schlagkräftigen Parteiverwaltung vor Augen stand, war aber in der CSU nicht unumstritten. Vor allem BVP-Traditionalisten liefen Sturm gegen diese seelenlose „Parteimaschine“ ${ }^{358}$, wie sie überhaupt wiederholt die Versuche Müllers torpedierten, einen zentral gesteuerten Parteiapparat mit von der Landesleitung hauptamtlich angestellten Mitarbeitern aufzubauen, in dem sie zu Recht eine Stütze des verhaßten Parteivorsitzenden sahen ${ }^{359}$.

Richtet man abschließend noch das Augenmerk auf die für eine christlich-interkonfessionelle Partei besonders wichtige Frage der Vertretung von Geistlichen und Theologen beider Konfessionen in den Führungsgremien, so ergibt sich ein ganz eindeutiges Bild: Während der Klerus - insbesondere die katholischen Pfarrer auf dem Land, in einigen Fällen aber auch evangelische Geistliche - beim Aufbau der CSU eine wichtige Rolle spielte, war er im (Erweiterten) Landesausschuß kaum vertreten. Für die katholische Seite gehörte der Münchner Stadtpfarrer und Müller-Intimus Emil Muhler dem (Erweiterten) Landesausschuß $a^{360}{ }^{36 u r}$ die evangelische der Jugendseelsorger und Religionslehrer Kurt Blaser aus Hof; dazu kamen noch der ehemalige BVP-Politiker und amtierende Landrat von Rottenburg, Pfarrer Wolfgang Prechtl, für den Bezirksverband Niederbayern und Hermann Strathmann, Professor für evangelische Theologie an der Universität Erlangen, für den Bezirksverband Mittelfranken. Auch die zahlenmäßig schwache Repräsentanz katholischer und evangelischer Geistlicher im (Erweiterten) Landesausschuß paßte in das Konzept Josef Müllers, der den Einfluß der Kirchen auf die neugegründete CSU gering zu halten gedachte, um so größere politische Handlungsfreiheit zu gewinnen, als sie die BVP besessen hatte, aber auch um das Risiko konfessioneller Konflikte so weit wie möglich zu verringern. Davon war man freilich bei den katholisch-konservativen Unionspolitikern nicht sonderlich begeistert, und insbesondere die katholischen Geistlichen, die sich vor 1933 in der BVP engagiert hatten und nun die Fortsetzung ihrer politischen Aktivitäten bedroht sahen, protestierten dagegen vehement ${ }^{361}$. Um die Vertretung spezifischer konfessioneller Interessen mußte es jedoch vor allem den Katholiken nicht bange sein. Immerhin 25 Mitglieder des (Erweiterten) Landesausschusses waren nachweislich im katholischen Vereinswesen aktiv - vermutlich waren es weit mehr - und brachten ihre dort erworbenen Erfahrungen und Zielvorstellungen in den Formierungsprozeß der bayerischen Unionspartei ein.

amtlichen Mitarbeitern zu differenzieren; es ist auch möglich, daß einzelne Mitarbeiter nicht von der Partei, sondern direkt von Josef Müller oder anderen führenden CSU-Politikern besoldet wurden.

358 BAK, NL Schäffer 25, Bl. 146, Fritz Schäffer an Karl Warmuth vom 13.6. 1948.

359 BAK, NL Schäffer 25, Bl. 242, Ludwig Dötsch an Fritz Schäffer vom 15. 3. 1948.

$360 \mathrm{Zu}$ Emil Muhler vgl. Johann Pörnbacher, Ein Pfarrer im Widerstand in München. Vor 100 Jahren wurde Emil Muhler in München geboren, in: Unser Bayern vom Oktober 1992, S. $78 \mathrm{ff}$.

361 Protokoll der Landesversammlung der CSU am 17. 5. 1946 in München, in: Protokolle und Materialien, S. $342 \mathrm{f}$. (Wolfgang Prechtl). 


\section{f) Kommunalpolitische Ämter und Mandate}

Die großen Erfolge bei den Kommunalwahlen von 1946 brachten es mit sich, daß viele Mitbegründer der CSU schnell und unerwartet Ämter und Mandate erhielten, auch wenn sie politisch noch unbeschriebene Blätter waren. Für diejenigen, die sich in den Führungs- und Flügelkämpfen zu behaupten wußten und nicht schon nach kurzer Zeit wieder aufgaben, stand die kommunalpolitische Tätigkeit oft am Beginn einer hoffnungsvollen Karriere. Die Institutionen der kommunalen Selbstverwaltung entwickelten sich gleichsam zu einer Schule und zu einem Rekrutierungsfeld für den politischen Nachwuchs der bayerischen Unionspartei. Erfahrungen als Landrat oder Bürgermeister galten bis in die sechziger Jahre hinein als Schlüsselqualifikation für die Berufung zum Minister oder Staatssekretä ${ }^{362}$, wie beispielsweise die Karriereverläufe der späteren Staatsminister Josef Schwalber, Otto Schedl, Rudolf Eberhard, Philipp Held oder Alfons Goppel zeigen. In der Gründungsphase der CSU war jedoch ein anderer Faktor von noch größerer Bedeutung. In diesen schwierigen Monaten wirkten viele Bürgermeister, Landräte, Gemeinde-, Stadt- und Kreisräte als Multiplikatoren des Unionsgedankens in den kleinräumig-fragmentierten ländlichen Regionen, wo sie als Teil des Honoratiorensystems, auf dem die CSU unter anderem basierte, die fehlenden Parteigeschäftsstellen ersetzten. Mit Blick auf die Region Ansbach und Fürth hat Hans Woller zu Recht darauf hingewiesen, daß es vielfach die Bürgermeister kleiner Dörfer waren, die "der neuen Partei die Chance“ eröffneten, "unter den protestantisch-kirchentreuen Bauern" Fuß zu fassen ${ }^{363}$. Auch im (Erweiterten) Landesausschuß wird dieser hohe Stellenwert der Kommunalpolitik sichtbar. Von den 178 erfaßten Delegierten waren mindestens 71 aktive Kommunalpolitiker; davon bekleideten 37 das Amt eines Gemeinde- oder Stadtrats, 17 auch/oder das eines Kreisrats, 18 fungierten als Bürgermeister oder stellvertretende Bürgermeister, 14 waren Landräte oder stellvertretende Landräte. 14 Mitglieder des (Erweiterten) Landesausschusses hatten nicht nur ein, sondern mehrere Ämter oder Mandate auf kommunaler Ebene inne. Georg Mack beispielsweise, ein protestantischer Landwirt aus dem Raum Ansbach, wurde 1945 von den amerikanischen Militärbehörden zum Bürgermeister seiner Heimatgemeinde ernannt und 1946 durch Wahl bestätigt; zugleich gehörte er dem Kreistag von Ansbach an, von dem er zum stellvertretenden Landrat gewählt wurde. Als prominenter Mitbegründer der CSU in Mittelfranken vertrat er seinen Stimmkreis zunächst auch in der Verfassunggebenden Landesversammlung und später im Landtag, dem er bis 1970 angehörte. Als zweites Beispiel mag Wilhelm Klenk aus Uffenheim dienen, der nicht nur als Stadtrat, Kreisrat und zeitweise als kommissarischer Landrat fungierte, sondern auch den CSU-Kreisverband Uffenheim führte und zeitweise auch dessen Geschäftsstelle leitete.

362 Vgl. Hansjörg Dürr, Soziale Strukturen des Bayerischen Landtags. Aspekte der Soziologie parlamentarischer Mandatsträger, in: Reinhold Bocklet (Hrsg.), Das Regierungssystem des Freistaates Bayern, Bd. 1: Beiträge, München 1977, S. 211-393, hier S. $263 \mathrm{ff}$.

363 Woller, Gesellschaft und Politik, S. 193. 


\section{g) Parteipolitische Aktivitäten}

Geht man der Frage nach, welche parteipolitischen Aktivitäten die Mitglieder des (Erweiterten) Landesausschusses sonst noch entfalteten, so zeigt sich, daß 143 Personen neben ihrer Mitgliedschaft im (Erweiterten) Landesausschuß weitere Ämter in der bayerischen Unionspartei, zumeist auf Kreis- und Bezirksebene, bekleideten. Dieser Befund weist den (Erweiterten) Landesausschuß als einen mehr oder weniger repräsentativen Querschnitt der Führungsschicht der neu gegründeten CSU aus und unterstreicht, wie ernst es der großen Mehrheit der Delegierten mit ihrem Engagement war. So nahmen zwischen Juli und Oktober 194654 Abgeordnete der Verfassunggebenden Landesversammlung an den Tagungen des (Erweiterten) Landesausschusses teil, wobei die starke Präsenz der CSU-Fraktion freilich weniger zu einer besseren Abstimmung der Unionspolitik als zu anhaltenden Konflikten führte, von denen noch ausführlich die Rede sein wird. Die Vorsitzenden der Bezirksverbände waren ebenfalls im (Erweiterten) Landesausschuß vertreten; sie wurden verstärkt durch mindestens 22 weitere Mitglieder von Bezirksvorständen, die die mittlere Führungsebene repräsentierten. 26 Delegierte leiteten gleichzeitig einen Kreisverband der CSU, 22 waren z. T. führend in den verschiedenen Arbeits- und Parteiausschüssen aktiv, weitere 25 zählten zu den Mitbegründern der Jugend- und der Frauenorganisation der CSU. Interessant ist, daß sich bereits in dieser frühen Phase eine erstaunliche Ämterhäufung bei vielen Mitgliedern des Landesausschusses feststellen läßt: mindestens 50 Personen nahmen mehrere Ämter und Funktionen in der bayerischen Unionspartei wahr.

Angesichts der heftigen innerparteilichen Auseinandersetzungen ist es zu erwarten, daß viele Mitbegründer die CSU bald wieder verließen. War das tatsächlich so? Die diesbezüglichen Angaben sind zwar nicht immer zuverlässig ${ }^{364}$, sie geben aber doch Aufschluß über politisch konnotierte Veränderungen in der Führungselite der bayerischen Unionspartei. Von den 178 erfaßten Mitgliedern des (Erweiterten) Landesausschusses zogen sich bis einschließlich 1949 mindestens 54 aus dem aktiven Parteileben zurück. Daß dafür vor allem die erbitterten Führungs- und Flügelkämpfe verantwortlich waren, die zu Resignation, Frustration, aber auch zu einer gewissen Radikalisierung führen konnten, liegt auf der Hand, obwohl man in Rechnung stellen muß, daß die personelle Fluktuation unter den Sonderbedingungen der Nachkriegszeit höher als normal gewesen ist.

1947 kehrten bereits zehn Mitbegründer der CSU, die ein Jahr zuvor noch dem (Erweiterten) Landesausschuß angehört hatten, ihrer Partei den Rücken. Die einen wandten sich aus Protest gegen die Ergebnisse der Regierungsbildung im Dezember 1946 von der bayerischen Unionspartei ab, andere - beispielsweise Anton Donhauser, Alfons Gaßner und Anfang 1948 auch Joseph Baumgartner und Ernst Falkner - traten aus der CSU aus, nachdem wiederholte „Putschversuche“ gegen den Ochsensepp und seine Führungsmannschaft gescheitert waren, und schlossen sich der aufstrebenden

364 Als Indikator für aktive Mitarbeit in der CSU galten nachweisbare Ämter oder Mandate; gerade das Engagement auf Orts- und Kreisebene war jedoch nur schwer zu fassen. Über die weitere politische Laufbahn von 22 Mitgliedern des (Erweiterten) Landesausschusses war nichts zu ermitteln. Die folgenden Zahlen umfassen auch die verstorbenen Delegierten des (Erweiterten) Landesausschusses. 
Zur weiteren Laufbabn der Mitglieder des (Erweiterten) Landesausschusses in der CSU

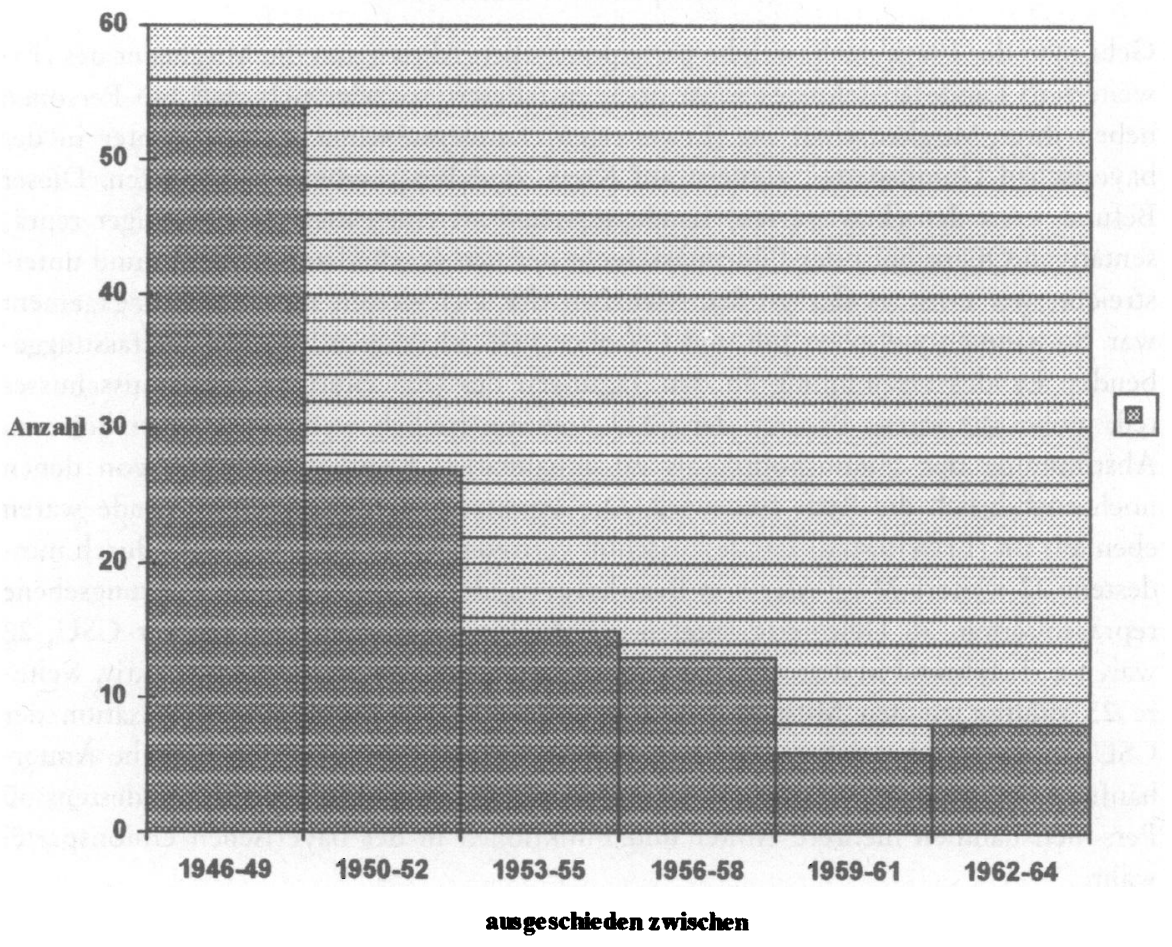

Bayernpartei $\mathrm{an}^{365}$. Dies waren jedoch nur Vorboten einer wahren Austritts- und Rückzugswelle, die zwischen 1948 und 1950 über die CSU hereinbrach. 1948 und 1949 kündigten insgesamt 36 Delegierte, die 1946 noch im (Erweiterten) Landesausschuß am Aufbau der bayerischen Unionspartei mitgewirkt hatten, ihrer Partei die Gefolgschaft auf, 1950 waren es noch einmal 19. Bis 1952 hatte nahezu die Hälfte der hier untersuchten Mitbegründer der CSU ihre Aktivitäten eingestellt. Diese dürren Zahlen verweisen auf eine fundamentale politische und organisatorische Krise, die mit der Rebellion des Bezirksverbands Oberbayern gegen die Parteiführung um Josef Müller im Februar 1948 eingesetzt hatte und durch die ersten Wahlerfolge der Bayernpartei wenige Wochen später noch verstärkt worden war; die Währungsreform im Juni wirkte auf den labil-krisenhaften Zustand der CSU geradezu katalytisch: Der Parteiapparat erwies sich als nicht mehr finanzierbar, Mitgliederbeiträge blieben aus, ganze Kreisverbände brachen zusammen, und die CSU begann in einigen Teilen Bayerns, wo sie gerade erst Fuß gefaßt hatte, für längere Zeit von der Bildfläche zu verschwinden. Mit dem Sturz Müllers im Mai 1949 war ein weiterer Höhepunkt der Dauerkrise erreicht, die nicht nur ehemalige Mitglieder des (Erweiterten) Landesausschusses aus der CSU trieb. Vor allem die Mitstreiter und Anhänger des Ochsensepp zogen sich enttäuscht

365 Vgl. dazu Regina Vossen, „Föderalistisch leben oder asiatisch sterben“. Joseph Baumgartner und die bayerische Politik 1945-1953, unveröffentlichte Zulassungsarbeit, München 1993, S. 69 f. 
und verbittert zurück, sei es, um sich anderen Parteien anzuschließen, oder um sich gänzlich von der politischen Bühne zu verabschieden. Dieser Verdrängungsprozeß ließ die CSU zu einer anderen Partei werden, als sie dies in ihren Gründungstagen gewesen war.

Ähnliche Schlußfolgerungen legt auch eine Untersuchung der Bezirksvertreter im (Erweiterten) Landesausschuß nahe. Die Gründergeneration der CSU, so scheint es, unterschied sich in den protestantischen Teilen Frankens zum Teil erheblich von der in Altbayern, Schwaben und im katholischen Mainfranken. So war in den ober- und niederbayerischen, aber auch in den oberpfälzischen und schwäbischen Kreisverbänden auf der Ebene der Funktionäre nur wenig vom Unionsgedanken zu spüren, wenigstens suggeriert dies die konfessionelle Zusammensetzung der Delegierten, die sie in den (Erweiterten) Landesausschuß entsandten. Während - soweit feststellbar - Oberbayern, Augsburg und Schwaben keinen einzigen protestantischen Vertreter benannten, saß für die Oberpfalz und für Niederbayern wenigstens je ein Protestant im (Erweiterten) Landesausschuß, für Niederbayern mit dem ehemaligen BBB-Spitzenpolitiker Konrad Kübler immerhin der Bezirksvorsitzende. Sogar in Mittelfranken, dem Bezirksverband mit dem höchsten protestantischen Bevölkerungsanteil, waren die protestantischen Delegierten im Verhältnis 4:3 in der Unterzahl. Lediglich in Oberfranken stellten die Protestanten die Mehrheit der Bezirksvertreter für den (Erweiterten) Landesausschuß, nämlich sieben bei nur vier katholischen Delegierten. Doch die Repräsentanten des Bezirksverbands Oberfranken wiesen noch eine weitere Besonderheit auf: Soweit sich feststellen läßt, befand sich unter ihnen nur ein ehemaliges BVP-Mitglied, dafür aber fünf Politiker, die vor 1933 Parteien angehört hatten, deren Anhänger nun für die CSU gewonnen werden sollten. Daß damit die katholische Bevölkerung der alten BVP-Hochburg Bamberg nur schwach im (Erweiterten) Landesausschuß vertreten war, dürften Josef Müller und seine Mitstreiter gerne in Kauf genommen haben. Denn die oberfränkischen Delegierten waren so am ehesten in der Lage, den Unionsgedanken glaubhaft zu vertreten. Außerdem schien es zumindest vorübergehend gelungen zu sein, die politisch wieder aktive Prominenz der ehemaligen BVP ins zweite Glied zu verdrängen und damit dem oft gehörten Vorwurf, die CSU sei nichts anderes als die getarnte Neuauflage der BVP, die Spitze abzubrechen. Tatsächlich zählte der Bezirksverband Oberfranken bis 1948 zu den stärksten Stützen Josef Müllers; gerade dieser Bezirksverband war jedoch von der Zerfallskrise, die die CSU 1948 erfaßt hatte, besonders stark betroffen ${ }^{366}$.Von den elf Delegierten, die Oberfranken 1946 im (Erweiterten) Landesausschuß vertreten hatten, zogen sich bis 1950 sechs weitgehend aus der CSU zurück oder traten gar aus der Partei aus. Von den 16 oberbayerischen Delegierten, die mehrheitlich zur innerparteilichen Opposition gegen Josef Müller zählten, schieden dagegen bis 1952 nur vier aus der aktiven Parteiarbeit aus. Diese Angaben verweisen wiederum auf den bereits angesprochenen Verdrängungsprozeß, dem überwiegend Anhänger des Ochsensepp zum Opfer fielen. Die Folge davon war eine innere Homogenisierung der CSU, die zwar eine wichtige Voraussetzung für ein Abflauen der inneren Konflikte bildete, die bayerische Unionspartei aber zugleich wesentlich ärmer werden ließ.

${ }^{366}$ Zur Entwicklung des Bezirksverbands Oberfranken vgl. die Aktenüberlieferung im ACSP, NL Müller 133. 


\section{Die parteiinternen Führungs- und Flügelkämpfe}

\section{a) Konstellationen}

Die Führungs- und Flügelkämpfe in der Ära Müller gehören zweifellos zu den signifikantesten Erscheinungen in der Geschichte der $\mathrm{CSU}^{367}$. Nicht nur, daß sie die Arbeit in den Gremien der Partei teilweise vollständig lähmten, die andauernden Auseinandersetzungen und die Unfähigkeit, zu tragfähigen Kompromissen zu kommen, brachten die CSU bereits im ersten Jahr ihres Bestehens wiederholt an den Rand der Spaltung $^{368}$. Für die politisch interessierte Öffentlichkeit, die das Spektakel der mit äußerster Härte ausgetragenen Konflikte in der Presse verfolgen konnte ${ }^{369}$, war es im Laufe der Zeit immer weniger möglich, in dem Verwirrspiel der Führungs- und Flügelkämpfe die eigentlichen Ursachen für den Dauerkonflikt zu erkennen, ja es war in einigen Fällen schon schwierig genug herauszufinden, wer auf welcher Seite stand.

Vereinfacht gesagt verliefen die Frontlinien innerhalb der CSU seit den letzten Monaten des Jahres 1945 folgendermaßen ${ }^{370}$ : Auf der einen Seite standen der Parteivorsitzende Josef Müller und seine politischen Freunde, die sich mit den Worten August Haußleiters selbst als den „fortschrittlichen Flügel“ bezeichneten ${ }^{371}$ und die für eine liberal-konservative, christlich-interkonfessionelle und gemäßigt föderalistische Politik eintraten. Neben Müller und seinem späteren Stellvertreter zählten die Landtagsabgeordneten Gerhard Kroll und Eugen Rindt, die Regierungsmitglieder Willi Ankermüller und Hanns Seidel, der Schongauer Landrat Franz Josef Strauß sowie führende CSU-Politiker auf regionaler Ebene wie der Mittelfranke Karl Sigmund Mayr oder die beiden Oberpfälzer Otto Schedl und Georg Gamperl zu den Mitgliedern dieser mehr oder weniger lockeren Gruppierung. Den Gegenpol zum sogenannten MüllerFlügel bildeten katholisch-konfessionelle, konservative und radikal föderalistische

367 Becker, Gründung und Wurzeln, in: Geschichte einer Volkspartei, S. 102, hat versucht, die Bedeutung der Führungs- und Flügelkämpfe zu relativieren. Genauer besehen, so Becker, ging die „These [von der überragenden Bedeutung der innerparteilichen Konflikte] auf teils überspitzt formulierte Auffassungen von Vertretern des Müller-Flügels selbst zurück“. Eine wissenschaftliche Betrachtung sollte sich jedoch „über den Horizont der beteiligten Zeitgenossen erheben“. Meines Erachtens führt aber kein Weg an der - von den Quellen gestützten - Erkenntnis vorbei, daß die innerparteilichen Auseinandersetzungen für die Geschichte der CSU zwischen 1945 und 1949 von zentraler Bedeutung waren. Daran ändert auch die Tatsache nichts, daß einige der damaligen Kontrahenten in der Rückschau die Kämpfe der Vergangenheit milder beurteilten - übrigens nicht ohne politisches Kalkül.

${ }^{368}$ Solche wiederkehrenden Spaltungsgerüchte finden sich beispielsweise in einer Aktennotiz Hanswolf Haunhorsts für Josef Müller vom 23. 10. 1946; ACSP, NL Müller 52.

${ }^{369}$ Henzler, Fritz Schäffer, S. 253, ist der Meinung, daß die scharfen Auseinandersetzungen in der bayerischen Unionspartei erst im Sommer 1948 einer breiteren Bevölkerungsschicht genauer bekannt geworden seien. Ein Blick in die wichtigsten Zeitungen Bayerns, in denen seit 1946 praktisch über alle wichtigen Sitzungen der Parteigremien ausführlich berichtet wurde, legt jedoch die gegenteilige Vermutung nahe.

370 Vgl. dazu Mintzel, CSU, in: ders./Oberreuter (Hrsg.), Parteien in der BRD, S. 201 f., und Mintzel, Geschichte der CSU, S. $59 \mathrm{f}$. In diesem Zusammenhang soll insbesondere auf den sogenannten Bauernflügel der CSU näher eingegangen werden, über dessen innerparteiliche Aktivitäten in der Literatur nur wenig bekannt ist. Vgl. dazu vor allem Walter Stelzle, Föderalismus und Eigenstaatlichkeit. Aspekte der bayerischen Innen- und Außenpolitik 1945-1947. Ein Beitrag zur Staatsideologie, Diss., München 1980, S. 39-42.

371 BayHStA, NL Ehard 1471, August Haußleiter, Die Politische Gesamtplanung des fortschrittlichen Flügels der CSU, undatiert. 
Kreise um die ehemaligen BVP-Politiker Fritz Schäffer, Alois Hundhammer und Anton Pfeiffer ${ }^{372}$.

Zwischen diesen beiden "Hauptkerngruppen “ ${ }^{373}$ standen die Vertreter agrarischer Interessen, meist nur der „Bauernflügel“ ${ }^{374}$ genannt. Unter der Führung Joseph Baumgartners, Michael Horlachers und Alois Schlögls bildeten die bäuerlichen Delegierten in den Führungsgremien der Parteiorganisation und später vor allem die bäuerlichen Abgeordneten in der CSU-Fraktion eine einflußreiche Pressure Group ${ }^{375}$. Baumgartner, seit Oktober 1945 Landwirtschaftsminister ${ }^{376}$, Horlacher, ein Multifunktionär im landwirtschaftlichen Verbands- und Genossenschaftswesen, und Alois Schlögl, der Generalsekretär des Bayerischen Bauernverbands, kontrollierten Schlüsselpositionen der Agrarpolitik, was ihnen in der CSU ein entsprechendes Gewicht verlieh, die ihre Wähler zu einem großen Teil aus der bäuerlichen Bevölkerung rekrutierte ${ }^{377}$.

Einigermaßen geschlossen agierten die Vertreter agrarischer Interessen allerdings nur 1946 und bedingt 1947, als wiederholt versucht wurde, Sach- und Personalentscheidungen massiv zu beeinflussen ${ }^{378}$. In der Wahl der Mittel waren sie dabei nicht zimperlich; Michael Horlacher scheute sich beispielsweise nicht, die Parteiführung mit der Drohung, eine eigene Bauernpartei zu gründen, unter Druck zu setzen ${ }^{379}$. Persönliche Rivalitäten, insbesondere zwischen Baumgartner und Schlögl, aber auch Spannungen zwischen verschiedenen Gruppierungen, die in der CSU wie auch im neu gegründeten Bayerischen Bauernverband unterschiedliche Traditionsstränge landwirtschaftlicher Interessenvertretung repräsentierten, gestalteten das gemeinschaftliche Handeln

${ }^{372}$ Becker, Gründung und Wurzeln, in: Geschichte einer Volkspartei, S. 103-106, hat jüngst eine Lanze für die ehemaligen BVP-Politiker in der CSU gebrochen, deren Verdienste um die bayerische Unionspartei er bisher nicht angemessen gewürdigt sieht. Beckers Argumentation ist dabei jedoch nicht unproblematisch. Was soll man etwa von der Aussage halten, vor dem "spezifisch bayerischen zeitgeschichtlichen Hintergrund“ sei der Charakter der BVP "demokratisch“ zu nennen, weil sich die Partei im Kampf gegen den Nationalsozialismus bewährt habe? Schließlich stehen Widerstand und Demokratie nicht unbedingt in kausalem Zusammenhang. Überdies läßt Becker die Rolle der BVP beim Aufstieg Hitlers und der NSDAP in den frühen zwanziger Jahren unerwähnt.

${ }^{373}$ Mintzel, CSU, in: ders./Oberreuter (Hrsg.), Parteien in der BRD, S. 201.

${ }^{374}$ So beispielsweise Josef Müller vor dem Ochsen-Club am 24. 7. 1946, in: Lehrjahre, S. 84.

375 Mintzel, Geschichte der CSU, S. 59, und Gelberg, Hans Ehard, S. 38, zählen Alois Hundhammer ebenfalls zum „Bauernflügel“. Hundhammer stand zwar in der Tradition Georg Heims und bekleidete führende Positionen im Generalsekretariat der Bayerischen Christlichen Bauernvereine, stand den verbands- und parteipolitischen Konzeptionen Baumgartners, Horlachers und Schlögls nach dem Zweiten Weltkrieg jedoch fern. Der Generalsekretär des Bayerischen Bauernverbands schrieb Ende 1945: „Am meisten ärgern mich Hundhammer und Schäffer, die herumstänkern und bisher unserer Organisation [dem Bayerischen Bauernverband] ablehnend gegenüberstehen." IfZ-Archiv, ED 719 Smlg. Bayernpartei 156, Alois Schlögl an Jakob Fischbacher vom 29. 12. 1945. Zu Hundhammers Querelen mit Joseph Baumgartner und Alois Schlögl vgl. IfZ-Archiv, Fh 56, Aktennotiz Josef Müllers vom 25. 2. 1946.

${ }^{376}$ Zur Biographie des späteren Vorsitzenden der Bayernpartei vgl. die auf der Basis bislang unbekannter Quellen geschriebene Zulassungsarbeit von Vossen, Joseph Baumgartner.

377 Vgl. Mintzel, Geschichte der CSU, S. 432.

378 ACSP, NL Müller 224, Memorandum: "Politische Lage in Bayern“, ungezeichnet, undatiert (Oktober/November 1946); darin wird der Bayerische Bauerverband als "Partei in der Partei“ bezeichnet.

${ }^{379}$ Vgl. den Wortwechsel zwischen Müller und Horlacher während der Sitzung des Landesarbeitsausschusses der CSU am 1. 5. 1946 in München, in: Protokolle und Materialien, S. 205 f.; Müller sah sich fünf Wochen später veranlaßt festzustellen: „Was das Verhältnis zu Dr. Horlacher, Schlögl und dem Bauernverband angehe, so könne er für die Union die immerwährende Drohung eines Austrittes der Mitglieder des Bauernverbandes oder der Lawine einer Bauernpartei nicht vertragen." Protokoll der Sitzung des Erweiterten Landesausschusses der CSU am 6.7.1946 in München, in: ebenda, S. 495. 
schwierig ${ }^{380}$. Überdies waren die politischen Leitlinien über bestimmte Fixpunkte hinaus eher unklar. Böse Zungen behaupteten sogar, die Vertreter der Bauern und ihrer Organisationen hätten überhaupt „keine echte politische Konzeption“, sondern verfolgten „eine ganz primitive Interessenpolitik“ und überträfen „an bajuwarischem Partikularismus und an politischer Instinktlosigkeit" sowohl den konservativen Flügel der CSU als auch den politischen Hauptgegner, die von Wilhelm Hoegner verkörperte Variante der bayerischen Sozialdemokratie ${ }^{381}$.

Die Führungspersönlichkeiten der Agrarlobby standen im Formierungsprozeß der CSU auf der Seite Josef Müllers, wie Baumgartner, Horlacher und Schlögl später teils mit Stolz, teils mit Unbehagen betonten. Wie Müller lehnten auch sie eine Revitalisierung der BVP strikt $a b$ und unterstützten einen parteipolitischen Neuanfang ${ }^{382}$. Diese Grundhaltung kam nicht von ungefähr und resultierte nicht nur aus den negativen Erfahrungen von Krieg und Diktatur. Die Präferenz wichtiger „Bauernführer“383 für den Unionsgedanken hatte ihre tiefere Ursache vielmehr in einer Reihe von Problemen, die die Gründung der CSU und die Gründung des Bayerischen Bauernverbands gleichermaßen belasteten. Sowohl die CSU als auch der BBV hatten die Zusammenführung von Gruppierungen auf ihre Fahnen geschrieben, deren Einigung vor 1933 unmöglich gewesen war. Der BBV bildete gleichsam das verbands- und interessenpolitische Gegenstück zur bayerischen Unionspartei und war mit dieser - personell und weltanschaulich $^{384}$ - vielfach verflochten. Ein Auseinanderbrechen der CSU und eine Wiederbelebung der BVP, wie sie in den Sommer- und Herbstmonaten des Jahres 1945 verschiedentlich erwogen worden war, ließ auch eine Wiederbelebung der Bayerischen Christlichen Bauernvereine in den Bereich des Möglichen rücken und hätte die Einheit des Bayerischen Bauernverbands akut gefährdet. Bei einer allzu starken Dominanz ehemaliger BVP-Spitzenpolitiker in der CSU drohte ebenfalls eine Abspaltung der Kreise, die vor 1933 im Bayerischen Bauernbund oder im protestantischen Bayerischen Landbund organisiert gewesen waren ${ }^{385}$. Den Zusammenhalt ihres Verbands zu wah-

380 Zur Rivalität zwischen den verschiedenen Organisationen landwirtschaftlicher Interessenvertretung in Bayern in der Weimarer Republik vgl. Bergmann, BBB und BCBV.

${ }^{381}$ BayHStA, NL Ehard 1471, August Haußleiter, Die Politische Gesamtplanung des fortschrittlichen Flügels der CSU, undatiert. Auf Unverständnis stieß auch die enge Zusammenarbeit zwischen dem offiziell zwar neutralen, aber der CSU nahestehenden BBV und dem offiziell ebenfalls neutralen, aber der SPD nahestehenden Bayerischen Gewerkschaftsbund. Vgl. Stelzle, Föderalismus und Eigenstaatlichkeit, S. 40. ACSP, NL Müller 109, „Politischer Stimmungsbericht über Oberbayern“, verfaßt von Sepp Hort für Josef Müller und Otto Schedl, vom 10. 9. 1947.

382 Protokoll der Sitzung des Erweiterten Landesausschusses der CSU am 6. 7. 1946 in München, in: Protokolle und Materialien, S. 488-495 (Alois Schlögl), Protokoll der Sitzung des Landesausschusses der CSU am 3. 1. 1947 in Augsburg, in: ebenda, S. 974 ff. (Michael Horlacher), und ACSP, CSU-LTF I, 15-14, Protokoll der Fraktionssitzung am 10. 1. 1947 (Joseph Baumgartner); IfZ-Archiv, RG 260, 13/142-2/3, Military Government Weekly Summary No. 35, 3.1.-10.1. 1946.

${ }^{383}$ Protokoll der Sitzung des Landesausschusses der CSU am 3. 1. 1947 in Augsburg, in: Protokolle und Materialien, S. 977.

${ }^{38+} \mathrm{Zu}$ den personellen Verflechtungen vgl. S. 83 f.; ebenso wie die CSU bekannte sich der BBV zum Prinzip der Interkonfessionalität und zum christlichen Sittengesetz als Grundlage der Politik. Wie Josef Müller und viele seiner Mitstreiter traten auch führende Vertreter der Agrarlobby in der CSU für eine fortschrittliche Sozialpolitik ein. Vgl. Stelzle, Föderalismus und Eigenstaatlichkeit, S. $41 \mathrm{f}$.

${ }^{385}$ In einem Schreiben des ehemaligen BBB-Politikers August Schwingenstein an Josef Müller vom 11.2. 1946 (IfZ-Archiv, Fh 56) heißt es beispielsweise: „Herr Dr. Hundhammer hätte allen Anlaß, Lobreden auf die Bayerische Volkspartei endlich zu unterlassen. Er täuscht sich, wenn er glaubt, daß die Bauernbündler lammfromm der Union folgen. Es war für mich nicht so einfach, diese mißtrauische Schar fast geschlossen in die Union einzuführen. Wenn nicht bald diese Lobgesänge auf 
ren und den $\mathrm{BBV}$ als möglichst einzige Interessenvertretung der bayerischen Bauern dauerhaft zu etablieren, war jedoch das primäre Ziel von Horlacher, Schlögl und Co., denen daher daran gelegen sein mußte, den Einfluß der BVP-Traditionalisten in der CSU zu begrenzen und die Unionsidee glaubwürdig umzusetzen ${ }^{386}$.

Nachdem sich der BBV im Frühjahr 1946 einigermaßen konsolidiert hatte und auch eine Revitalisierung der BVP nicht mehr zu befürchten war, begann sich die Szenerie zu verändern. Die Mehrheit der Bauernvertreter trat nun ebenso wie der katholischkonservative Flügel der CSU für die möglichst weitgehende Selbständigkeit Bayerns in einem künftigen deutschen Staat ein und stellte sich im Laufe des Jahres 1946 mehr und mehr gegen den als Zentralisten diffamierten Josef Müller ${ }^{387}$. In toto war der sogenannte Bauernflügel weder der einen noch der anderen Seite zuzurechnen; man ging Koalitionen in Sach- und Personalfragen ein oder wechselte die Fronten, wenn es nötig schien. Im Herbst 1947 bahnte sich jedoch ein Zerfall der Führungstroika an, der den Einfluß der Agrarlobby in der bayerischen Unionspartei erheblich schwächte: Michael Horlacher und Josef Müller konnten ihre Meinungsverschiedenheiten beilegen, der enttäuschte Joseph Baumgartner hingegen wechselte zur Bayernpartei ${ }^{388}$.

Die skizzierten Gruppierungen waren alles andere als homogen, sondern stellten sich dem Betrachter vielfach fragmentiert dar ${ }^{389}$. Ehrgeiz und persönliche Ambitionen, das Streben nach Ämtern und Mandaten, alte Animositäten, Freundschaften oder Loyalitätsverpflichtungen überlagerten vielfach politische Überzeugungen und ließen die Akteure in den Führungs- und Flügelkämpfen immer wieder anders handeln, als man dies von ihnen erwartet hätte. Die Hochburgen des Müller-Flügels lagen vor allem in den vier fränkischen Bezirksverbänden, aber auch in Schwaben und der Oberpfalz; selbst im Bezirksverband Niederbayern gab es eine vergleichsweise starke Fraktion, die den Kurs des Parteivorsitzenden unterstützte. München und Oberbayern waren dagegen die stärksten Bastionen der innerparteilichen Opposition; vor allem im Bezirksverband Oberbayern, der von Alois Hundhammer geführt wurde, blieben die Anhänger des Ochsensepp ein verlorenes Häuflein ${ }^{390}$.

Die erbitterten Auseinandersetzungen, die die CSU zwischen 1945 und 1949 erschütterten, drohten die bayerische Unionspartei nicht nur auf Landesebene zu paralysieren. Sie reproduzierten sich auf allen Ebenen und machten eine effektive politische Arbeit in vielen Kreisverbänden, Kreistags- und Stadtratsfraktionen oder in den Arbeitgemeinschaften der CSU nahezu unmöglich. In fast allen Gremien waren Zirkel der einen wie

die Bayerische Volkspartei verstummen, dann sind auch die Bündler nicht mehr zu halten und brechen aus.“ Die Bedeutung der „bayerischen Frage“ für die Beziehungen zwischen Josef Müller und den führenden Vertretern der Agrarlobby in der CSU unterstreicht ein Schreiben August Schwingensteins an Fritz Schäffer vom 18.5. 1948; BAK, NL Schäffer 25, Bl. $162 \mathrm{f}$. Zum Verhältnis von CSU und BBV in statu nascendi vgl. auch ein Schreiben Sebastian Hubers vom 18. 9. 1945 (IfZ-Archiv, Fh 56).

386 IfZ-Archiv, Fh 56, Joseph Baumgartner an Josef Müller vom 25. 10. 1945, Fritz Schäffer an Josef Müller vom 13. 1. 1946, Joseph Baumgartner an Josef Müller vom 30. 1. 1946, Michael Horlacher an Josef Müller vom 23. 2. 1946.

387 IfZ-Archiv, RG 260, 10/90-3/8, „Subject: CSU-Funktionär zu Ehards Stellung zu Bonn“ vom 24. 3. 1949.

388 Vgl. dazu Vossen, Joseph Baumgartner, S. $69 \mathrm{f}$.

389 Neue Zürcher Zeitung vom 22.6. 1947: „Die politischen Strömungen in Bayern. Die Stellung des Kabinetts Ehard“; Sopade-Informationsdienst vom 18. 8. 1947: „Konflikt in der CSU“; Der Spiegel vom 30. 8. 1947: „Die vier Flügel. Und eine Weltregierung“.

390 Vgl. die differenzierungsbedürftigen Ausführungen bei Mintzel, Anatomie, S. 83-88. 
auch der anderen Seite vertreten, lediglich die Kräfteverhältnisse wechselten. Im Bezirksverband Oberfranken, der bis Ende 1948 zu den stärksten Stützen Müllers zählte, bemühten sich Vertreter der Kreisverbände Bamberg-Stadt und -Land vorsichtig, die Interessen des BVP-nahen, katholisch-konservativen Flügels der CSU zu vertreten ${ }^{391}$. In Oberbayern waren es Mitglieder der Kreisverbände Schongau, Bad Aibling und Garmisch-Partenkirchen sowie Teile der Jungen Union und der organisierten katholischen Arbeiterschaft, die Josef Müller über Interna aus dem gegnerischen Lager auf dem laufenden hielten und gleichzeitig als Ansprechpartner für eigene Aktionen dienten ${ }^{392}$.

„Die planmäßige Neugestaltung der Union" im Bereich des Bezirksverbands Oberbayern, so konnte man Ende 1946 in einem für Josef Müller bestimmten Strategiepapier lesen, „setzt eine Kleinarbeit voraus, die eine gewisse Zeit erfordert ${ }^{\text {“393 }}$. Doch derartige Absichten erwiesen sich bald als illusorisch. Die Ressourcen des Parteivorsitzenden erwiesen sich letztlich als zu schwach, um die historischen Hypotheken und politischen Gegensätze überwinden zu können. Im Gegenteil: Seit den Sommermonaten des Jahres 1948 begann der Parteiflügel um Josef Müller akute Auflösungserscheinungen zu zeigen ${ }^{394}$.

Die Forschung hat vor allem die strukturellen Ursachen für die innerparteilichen Auseinandersetzungen herausgehoben, und insbesondere Alf Mintzel versuchte, die krisenhaften Entwicklungen in der CSU als landeshistorisch bedingte Konsequenz innerbayerischer Regionalismen und Spannungslinien zu erklären ${ }^{395}$. Daran ist sicherlich vieles richtig. Eine Überbetonung der strukturellen Faktoren führt jedoch zu verzerrten Interpretationen und zu einem gewissen Determinismus, der den historischen Entwicklungsmöglichkeiten nicht gerecht wird ${ }^{396}$. Was die Führungs- und Flügelkämpfe in der CSU betrifft, so muß festgestellt werden, daß gerade persönliche Gegensätze und Aversionen oder die Ambitionen einzelner Persönlichkeiten im Laufe der Auseinandersetzungen zunehmend an Eigengewicht gewannen und abgelöst von den ursprünglichen Ursachen der Kontroverse zur Fortdauer der Streitigkeiten beitrugen. Auf dem vorläufigen Höhepunkt der Parteikrise - ausgelöst durch die Rebellion des Bezirksverbands Oberbayern gegen die Parteileitung im Februar 1948 - waren zumindest Teile der Parteibasis nicht mehr in der Lage, die eigentlichen Konfliktursachen zu erkennen. Für sie waren die Führungs- und Flügelkämpfe in der CSU mehr oder weniger Ausdruck persönlicher Auseinandersetzungen, die den Bestand der Partei gefährdeten ${ }^{397}$. Schon im Vorfeld der außerordentlichen Landesversammlung der bayerischen

391 BayHStA, NL Ehard 887, Anton Hergenröder an Josef Müller vom 18. 1. 1947.

392 ACSP, NL Müller 410/5, Berichte Josef Plonners über seine Informationsreise durch oberbayerische Kreisverbände vom 10.-13. 10. 1946, und Josef Plonner an Josef Müller vom 15. 11. 1946, sowie NL Müller 109, Bericht über eine Arbeitstagung der Flüchtlingsvertrauensleute aus dem Bezirksverband Oberbayern am 17. 4. 1947, und NL Müller 118, Bericht über die Bezirksversammlung Oberbayern am 25. 8. 1947, und Kreisverband Garmisch-Partenkirchen an Josef Müller vom 18. 2. 1948.

393 ACSP, NL Müller 224, Memorandum: „Politische Lage in Bayern“, ungezeichnet, undatiert (Oktober/November 1946).

394 Vgl. S. 280-292.

$395 \mathrm{Vgl}$. Alf Mintzel, Die Christlich-Soziale Union in Bayern e. V., in: Stöss (Hrsg.), Parteien-Handbuch, Bd. 2, S. 661-718, hier S. 662-670, und Karl Möckl, Die Struktur der Christlich-Sozialen Union in Bayern in den ersten Jahren ihrer Gründung, in: ZfBLG 36 (1973), S. 719-753, hier S. 751.

396 Vgl. Mintzel, Anatomie, S. $229 \mathrm{ff}$.

397 BAK, NL Schäffer 23, Bl. 58, Fritz Schäffer an Michael Grassl vom 31. 3. 1948: „Heute erhielt ich die Entschliessung des Kreisverbandes Berchtesgaden - Bad Reichenhall vom 23. 3. 1948. Offen gestanden, bin ich mir nicht über den Sinn der Entschliessung im klaren. Wenn ich Sie richtig verstehe, 
Unionspartei im August 1947 bemerkte Andreas Maderer, immerhin ein Mitglied der Landtagsfraktion:

„Uns trennt nichts Grundsätzliches; man soll mich zählen zum Flügel der Vernünftigen. Wie hat sich der Zwist entwickelt? Als die Union aufgestellt wurde, war alles einig, dann kam die persönliche Eitelkeit der Herren da droben, jeder wollte der Schöpfer gewesen sein. Man kann durch falsche Erziehung einen Menschen zum R[owdy] machen. Müller hat man angegriffen, man hat ihn nicht in Schutz genommen. Durch das Hin- und Wider hat man sich entzweit, die Gegensätze haben sich vergößert und vertieft, und so war der Müller-Flügel und alle die anderen Flügel da. “"

Die Führungs- und Flügelkämpfe waren aber auch nicht nur Ausdruck von zwangsläufig auftretenden Konflikten in einer neu gegründeten Sammlungspartei, wie dies Josef Müller immer wieder betonte ${ }^{399}$. Zumindest in der Parteispitze war man sich darüber klar, daß die Auseinandersetzungen auch grundsätzlicher Natur waren und über persönliche Konflikte hinausgingen ${ }^{400}$.

\section{b) Protagonisten: Josef Müller, Fritz Schäffer, Alois Hundhammer, Michael Horlacher}

Im Zentrum der Auseinandersetzungen stand der Münchner Rechtsanwalt Dr. Josef Müller ${ }^{401}$, der am 17. Mai 1946 zum Parteivorsitzenden gewählt worden war. Der gebürtige Oberfranke hatte seit 1920 der BVP angehört ${ }^{402}$, ohne allerdings ein Parteiamt oder ein landespolitisch bedeutsames Mandat zu bekleiden. Zum Eintrittsbillet für eine politische Karriere nach Kriegsende wurde für Müller seine Tätigkeit im Geheimdienst der Wehrmacht, wo sich unter Admiral Wilhelm Canaris und General Hans Oster eine Widerstandsgruppe formiert hatte. Seit 1939 selbst Abwehroffizier, führte Müller im Auftrag der Militäropposition mit der Regierung Großbritanniens Verhandlungen unter Vermittlung des Vatikans; zur römischen Kurie unterhielt der Katholik Müller beste Beziehungen ${ }^{403}$. Durch seine Mitarbeit bei der Abwehr wußte Müller

dann wird die Sache so aufgefasst, als ob nur ein aus persönlichem Ehrgeiz geborener Streit unter den führenden Männern der CSU ausgebrochen wäre, hinter dem sachlich nichts steht und der sich bei gutem Willen sofort bereinigen liesse."

398 ACSP, CSU-LTF I, 15-14, Protokoll der Fraktionssitzung am 21. 8. 1947.

399 Müller versuchte, dem Dauerkonflikt in der bayerischen Unionspartei etwas Positives abzugewinnen: „Die Union ist eine Mehrheitspartei, und infolgedessen wäre es sogar ungesund, wenn sich die Krisis, die unsere Demokratie bedroht, nicht auch in unserer Partei widerspiegeln würde. Wir sind kein kollektiver Haufen, der in einer Marschkolonne marschiert. Wir haben Persönlichkeiten und wir haben Gruppen, die verschiedene Meinungen haben. Und es ist gut so, denn dadurch zeigt sich, daß die Union eine lebende Partei ist. Nur greisenhafte Parteien würden heute eventuell eine besondere Geschlossenheit zur Schau tragen, denn nur sie könnten sagen, daß sie mit den Problemen des Alltags fertig werden." Protokoll der außerordentlichen Landesversammlung der CSU am 30./ 31. 8. 1947 in Eichstätt, in: Protokolle und Materialien, S. 1062.

400 So meinte beispielsweise Wilhelm Eichhorn treffend: „Es war nie ein reiner Personenstreit.“ Protokoll der Sitzung des Landesausschusses der CSU am 28./29. 2. 1948 in Regensburg, in: Protokolle und Materialien, S. 1651.

401 Personalangaben nach IfZ-Archiv, RG 260, 10/125-2/12, OMGUS-Fragebogen Josef Müllers vom 16.8. 1945; der neueste Überblick - mit kritischen Untertönen - über die Biographie des Ochsensepp von Karl-Ulrich Gelberg, Josef Müller (1898-1979), in: Aretz/Morsey/Rauscher (Hrsg.), Zeitgeschichte in Lebensbildern, Bd. 8, S. 155-172.

$402 \mathrm{Zu} \mathrm{Müllers} \mathrm{Stellung} \mathrm{in} \mathrm{der} \mathrm{BVP} \mathrm{und} \mathrm{zu} \mathrm{seiner} \mathrm{Rolle} \mathrm{im} \mathrm{Freundeskreis} \mathrm{um} \mathrm{Heinrich} \mathrm{Held} \mathrm{vgl.}$ BayHStA, NL Ehard 887, Josef Held an Willibrord Braunmiller vom 12. 11. 1946.

403 Die ausführlichste, wenn auch nicht immer befriedigende Darstellung von Müllers Widerstandstätigkeit und Haftzeit bei Hettler, Josef Müller, S. 56-193. Müller selbst hat sich immer wieder ausführlich dazu geäußert: IfZ-Archiv, ZS 659/1-4, Transkripte von Interviews mit Josef Müller. 
von den Plänen und Konzeptionen des nationalkonservativen Widerstandes gegen den Nationalsozialismus, und so konnte er auch an andere Traditionsstränge anknüpfen als die Mitbegründer der CSU, die die Schreckensherrschaft des NS-Regimes in weitgehend unpolitischer Haltung überlebt hatten oder in staatsbayerisch-monarchistischen Widerstandszirkeln aktiv gewesen waren ${ }^{404} .1943$ verhaftet und vor dem Reichskriegsgericht wegen Wehrkraftzersetzung, militärischem Ungehorsam und Vergehen gegen das Heimtückegesetz angeklagt ${ }^{405}$, wurde Müller zwar freigesprochen, blieb aber weiterhin in Haft, aus der er erst Anfang Mai 1945 von amerikanischen Truppen befreit wurde. Die zweijährige Odyssee durch die Gefängnisse und Konzentrationslager des Dritten Reiches hatte tiefe Spuren in der Psyche und im politischen Denken des späteren CSU-Vorsitzenden hinterlassen; noch Jahre später kam Müller immer wieder auf seine Erlebnisse in der Haft zurück ${ }^{406}$. Dies zeigte sich im vertrauten, fast freundschaftlichen Umgang, den Müller mit ehemals politisch Verfolgten auch dann pflegte, wenn sie sozialdemokratischen oder sozialistischen Parteien angehörten ${ }^{407}$, und dies zeigte sich, als Müller in den fünfziger und frühen sechziger Jahren gegen die Mitarbeit von aus der NS-Zeit belasteten Personen in der CSU opponierte ${ }^{408}$. Müller selbst hat auch nie einen Zweifel daran gelassen, wie sehr die Erfahrungen und Erlebnisse aus den Jahren der nationalsozialistischen Diktatur seine Konzeptionen geprägt haben ${ }^{409}$.

Als Müller im Herbst 1945 zum vielleicht wichtigsten Initiator der Unionsgründung in Bayern avancierte, war er ein homo novus in der Politik. Er konnte nicht wie seine wichtigsten Konkurrenten auf eine politische Karriere in der Weimarer Republik zurückblicken, und ihm fehlte der typische Stallgeruch der bayerischen Ministerialbürokratie, der Politiker wie Ehard und Hoegner auch dann verband, wenn sie unterschiedlichen Parteien angehörten ${ }^{410}$. Müller verfügte überdies nur über geringe politisch-parlamentarische und organisatorisch-administrative Erfahrungen, was sich in entscheidenden Situationen immer wieder als gravierender Nachteil erwies. Der erste Vorsitzende der CSU, der seinen Beinamen Ochsensepp beinahe wie einen nom de guerre trug, hatte aber auch Vorzüge. Einer davon war, daß er einmal ins Auge gefaßte Ziele mit an Sturheit grenzender Hartnäckigkeit verfolgte. Müller war dabei bei der Wahl seiner taktischen Mittel so flexibel, daß er bald in dem Ruf stand, ein Meister der Regie und Intrige, wenn nicht sogar gänzlich prinzipienlos zu sein. Außerdem hatte er nach-

404 Vgl. Niethammer, Mitläuferfabrik, S. 80.

${ }^{405}$ Militärhistorisches Archiv Prag, Reichskriegsgericht - Anklageschriften und Urteile, Anklageverfügung gegen Josef Müller und Randolf Freiherr von Breidbach vom 16. 9. 1943. Ich danke meinem Kollegen Jürgen Zarusky für die Kopie dieses Dokuments.

406 ACSP, NL Müller 416, Rede Josef Müllers „Der neue Weg“ am 30. 4. 1946 in München, NL Müller 198, Rede Josef Müllers am 28. 5. 1948 in Würzburg, NL Müller 412, Manuskript einer Rundfunksendung „Das taten sie für Deutschland“ am 18. 5. 1951, NL Müller 416, Rede Josef Müllers anläßlich der Feierlichkeiten am 20.7. 1959 in Berlin.

407 Vgl. Müller, Konsequenz, S. 329 f. (über ein Gespräch mit Kurt Schumacher), und Stiftung Archiv der Parteien und Massenorganisationen der DDR im Bundesarchiv, NL Nieckisch 517, Bericht Ernst Nieckischs über ein Gespräch mit Josef Müller im März 1950.

408 BAK, NL Guttenberg 248, B1. 219-230, Protokoll der außerordentlichen Sitzung des Vorstands des CSU-Bezirksverbands München am 8. 9. 1958; ACSP, CSU-LL, Protokoll der Sitzung des geschäftsführenden Landesvorstands am 30. 11. 1963.

409 Vgl. Müller, Konsequenz, S. 281-322.

410 Zur bayerischen "Staatsbürokratie“ als „einem maßgeblichen Traditionsfaktor“ bayerischer Politik vgl. Mintzel, Regionale politische Traditionen, in: Oberndörfer/Schmitt (Hrsg.), Parteien und regionale Traditionen, S. $139 \mathrm{f}$. 
gerade einen Hang dazu, seine Karten nie vollständig aufzudecken oder mit versteckten Drohungen zu arbeiten ${ }^{411}$. Daß man ihm nachsagte, "Tod und Teufel“ zu kennen ${ }^{412}$, konnte dem Ochsensepp dabei nur recht sein, auch wenn er seine Beziehungen zur amerikanischen Militärregierung ${ }^{413}$ oder auch zur Sowjetischen Militäradministration $^{414}$ erheblich überbewertete und diesen Kontakten weit größeres Gewicht zumaß, als ihnen tatsächlich zukam. In den Führungs- und Flügelkämpfen der ersten Nachkriegsjahre war dieser Faktor jedenfalls nicht zu unterschätzen; durch seine Berichte von Zusammenkünften mit hochrangigen Vertretern der Alliierten, die er wiederholt in die Form geheimnisvoller Andeutungen kleidete, verstand er es, seine Gefolgsleute $\mathrm{zu}$ beeindrucken und seine Gegenspieler zu verunsichern.

Müllers gesamtdeutsche Orientierung, sein Eintreten für ein flexibles Vorgehen gegenüber der sowjetischen Besatzungsmacht ${ }^{415}$, seine Verbindungen zu Vertretern der SMAD in Karlshorst und seine Gespräche mit Vertretern von KPD und SED ${ }^{416}$ lösten vielfach Unbehagen und Mißtrauen aus. So bot es sich für die Widersacher des Ochsensepp in den Monaten des heraufziehenden Kalten Krieges geradezu an, den CSUVorsitzenden als Befehlsempfänger der Sowjets und als Kryptomarxisten zu brandmar$\operatorname{ken}^{417}$. Dagegen hielt Jakob Kaiser, der Vorsitzende der CDU in der SBZ, große Stücke auf seinen bayerischen Kollegen ${ }^{418}$. Dieser hob zwar offiziell immer wieder hervor, seine eigene Konzeption liege „in der Mitte zwischen Adenauer und Kaiser“419, tatsächlich aber standen sich Müller und Kaiser weitaus näher als Müller und Adenauer, bei

${ }^{411}$ Vgl. die treffende Charakterisierung Müllers von Henke und Woller, in: Lehrjahre, S. 12 f. Im November 1946 seufzte "von allgemeinem Kopfnicken“ begleitet ein Mitglied des Dienstag-Clubs: "Wenn man doch nur wüßte, wann Dr. Müller einmal die Wahrheit sagt!" Ebenda, S. 111.

412 Franz Josef Strauß, Die Erinnerungen, Berlin 1989, S. 69.

+13 Die Skepsis, mit der Teile von OMBGY dem Ochsensepp gegenüberstanden, wird deutlich aus IfZArchiv, RG 84, 459/2, Pierre M. Purves an Donald R. Heath vom 13. 5. 1946, und IfZ-Archiv, RG 260, 10/91-1/1, „Subject: Confidental talk with Pater Johannes, Kloster Ettal“" vom 5. 1. 1947. Vgl. auch Hettler, Josef Müller, S. $264 \mathrm{ff}$. Auch in der amerikanischen und jüdischen Presse stand man dem Ochsensepp mit gemischten Gefühlen gegenüber: Vgl. Sefton Delmer, Dr. Müller bedarf der Beobachtung! Untergrundbewegung in Deutschland!, in: Daily Express vom 13. 9. 1946 (Übersetzung im BayHStA, NL Ehard 1058), und Joseph Dunner, Der neue „Führer“ Bayerns, in: Aufbau vom 7.6. 1946 (Abschrift im BayHStA, NL Ehard 1058).

${ }^{114}$ Über Müllers Gespräche mit Vertretern der SMAD, insbesondere mit Leonid Georgiew und Sergej Tjulpanow, ist bisher kaum mehr als das bekannt, was der Ochsensepp selbst darüber berichtet hat. Vgl. Müller, Konsequenz, S. 324-332; Hettler, Josef Müller, S. 269-272; ACSP, CSU-LSG, Ordner Müller - Hundhammer 1952, „Niederschrift über den Beleidigungsprozeß Staatsminister Dr. Müller - Gaßner in Landshut" am 23. und 25. 8. 1948.

415 ACSP, NL Müller 410/6, Josef Müller an Maria Sevenich vom 14. 8. 1946, und NL Müller 128, Josef Müller an Karl Köhler vom 9. 5. 1947.

416 ACSP, NL Müller 406, Protokoll einer Besprechung zwischen Vertretern von CSU, KPD und SED am 27. 7. 1947 in München.

417 Vgl. beispielsweise das Flugblatt Josef E. Messmers, das während der Tagung des Erweiterten Vorläufigen Landesausschusses der CSU am 30./31.3. 1946 in Bamberg verteilt wurde, und die im Ton moderatere Rede Schäffers vor diesem Gremium; Protokolle und Materialien, S. 87-91 bzw. S. $110 \mathrm{ff}$. In diesem Zusammenhang auch interessant und wichtig BAK, NL Schäffer 24, BI. 30-34, Zeugenaussagen Alois Hundhammers und Joseph Baumgartners in der Strafsache gegen Anton Donhauser wegen Beleidigung am 26. 8. 1948, und BayHStA, NL Ehard 1006, Zeugenaussage Fritz Schäffers in der Strafsache gegen Anton Donhauser wegen Beleidigung am 21.7.1948, sowie ACSP, CSU-LSG, Ordner Müller - Hundhammer 1952, „Niederschrift über den Beleidigungsprozeß Staatsminister Dr. Müller - Gaßner in Landshut ${ }^{\alpha}$ am 23. und 25. 8. 1948. Beide Verfahren hatte der CSU-Vorsitzende angestrengt, um sich gegen den Vorwurf zur Wehr zu setzen, er sei wiederholt zum Befehlsempfang nach Karlshorst, dem Sitz der SMAD, gefahren.

${ }^{418}$ IfZ-Archiv, RG 84, 459/2, Pierre M. Purves an Donald R. Heath vom 13. 5. 1946.

${ }^{419}$ ACSP, NL Müller 410/6, Josef Müller an Konrad Adenauer vom 8. 8. 1946. 
dem August Haußleiter Gemeinsamkeiten mit dem katholisch-konservativen Flügel der CSU zu entdecken glaubte ${ }^{420}$. Kein Wunder, daß das Verhältnis der beiden einflußreichen Unionspolitiker von gegenseitigem Mißtrauen geprägt war. So fiel in einem Gespräch zwischen dem CSU-Vorsitzenden und Vertretern der britischen Besatzungsmacht die Bemerkung, Konrad Adenauer sei „der Schäffer der britischen Zone“ und spiele dort die gleiche unglückliche Rolle wie der ehemalige Ministerpräsident in Bay$\mathrm{ern}^{421}$. Adenauer machte andererseits keinen Hehl aus der Abneigung, die er für Josef Müller empfand, und bezeichnete ihn gegenüber Robert Murphy, dem politischen Berater des amerikanischen Militärgouverneurs, als "Abenteurer“, der keine Zukunft habe ${ }^{422}$.

Mit seinem unnachgiebigen, bisweilen selbstherrlichen Auftreten und seinen geheimnisumwitterten Touren schuf sich Müller eine Vielzahl unversöhnlicher Feinde. Selbst bei engen Mitarbeitern oder politischen und persönlichen Freunden löste sein Hang zur Geheimniskrämerei, seine Art, Versammlungen zu leiten und seine Gegenspieler durch überlegene Regie auszumanövrieren, immer wieder Irritationen aus und führte zu vermeidbaren Zerwürfnissen, die nur seine eigene Position schwächten ${ }^{423}$. $\mathrm{Da}$ er des öfteren Parteiarbeit mit seiner früheren Tätigkeit als Abwehroffizier zu verwechseln schien, fiel es seinen Widersachern nicht schwer, ihm und seinen Mitarbeitern „Canaris-Methoden“ vorzuwerfen ${ }^{424}$. Überhaupt hielt man es für ein probates Mittel, Müllers Engagement für den Widerstand ins Zwielicht zu rücken ${ }^{425}$; noch 1952 bezeichnete Fritz Schäffer die Aktivitäten seines Kontrahenten während des Zweiten Weltkriegs offen als „Landesverrat ${ }^{\text {“426. }}$.

${ }^{420}$ BayHStA, NL Ehard 1471, August Haußleiter, Die Politische Gesamtplanung des fortschrittlichen Flügels der CSU, undatiert. Adenauer versuchte tatsächlich, Kontakt mit den Gegnern Müllers in der CSU aufzunehmen. BayHStA, NL Pfeiffer 533, Konrad Adenauer an Gebhard Seelos vom 9. 2. 1947.

${ }^{421}$ ACSP, NL Müller 410/6, Aktennotiz Maria Sevenichs über eine Besprechung mit Anton Schwan, Bruno Dörpinghaus, Josef Müller und zwei weiteren Vertretern der CSU am 30.7. 1946 in München, und Maria Sevenich an Josef Müller vom 21. 8. 1946. Ob diese Aussage tatsächlich von Müller stammte, wie Maria Sevenich behauptete, oder von einem seiner britischen Gesprächspartner, wie Josef Müller berichtete (ACSP, NL Müller 410/6, Entwurf eines Schreibens Josef Müllers an Konrad Adenauer, undatiert), läßt sich nicht klären. Vgl. auch Köhler, Adenauer, S. 422.

${ }^{422}$ IfZ-Archiv, RG 84, 461/16, Memorandum Robert Murphys vom 24. 11. 1948. Vgl. auch Hans-Peter Schwarz, Adenauer. Der Aufstieg: 1876-1952, Stuttgart ${ }^{21986, ~ S . ~} 610$.

${ }^{423}$ IfZ-Archiv, Fh 56, Karl Theodor Freiherr von und zu Guttenberg an Josef Müller vom 8. 4. 1946; ACSP, NL Müller 144, Heinz Fischer an Josef Müller vom 4. 5. 1949, NL Müller 168, Eugen Rindt an Josef Müller vom 17. 7. 1948, und NL Müller 410/6, Josef Müller an Franz Steber vom 22. 11. 1946; BAK, NL Schäffer 25, Bl. 162f., August Schwingenstein an Fritz Schäffer vom 18. 5. 1948.

424 IfZ-Archiv, ED 132 NL Baumgartner 3, Joseph Baumgartner an Alois Hundhammer vom 8. 4. 1947, und das Protestschreiben Franz Liedigs an Joseph Baumgartner vom 14. 4. 1947. Auch Hundhammer warf seinem Parteivorsitzenden "Canaris-Methoden“"vor; BAK, NL Schäffer 22, Bl. 1-48 (hier B1. 23), Protokoll der Bezirksversammlung der CSU Oberbayern am 14. 2. 1948 in München. Das Nachrichtenmagazin Der Spiegel schlug in dieselbe Kerbe und schrieb, Müller sei.der „begabteste Schüler des Spionagechefs Canaris" und "mit allen Wassern der Menschenbeeinflussung gewaschen"; Der Spiegel vom 10.1. 1948: „Pfeiffer in den Rücken“. Eine Stellungnahme Müllers findet sich im IfZ-Archiv, RG 260, AG 1947/1/2, "The Secret round Canaris", undatiert.

${ }^{425}$ IfZ-Archiv, RG 260, 10/90-1/16, „Subject: Utterances about the affair Dr. J. Müller/Loritz“ vom 22. 10. 1946.

${ }^{426}$ Im Zentrum der Macht. Das Tagebuch von Staatssekretär Lenz 1951-1953, bearb. von Klaus Gotto, Hans-Otto Kleinmann, Reinhard Schreiber, Düsseldorf 1989, Eintrag vom 12. 5. 1952, S. 327. Während der Bezirksversammlung der CSU Oberbayern am 14.2. 1948 in München bezeichnete ein Teilnehmer Müller als „Spitzel“; BAK, NL Schäffer 22, Bl. 1-48 (hier Bl. 23). 
Müllers Herkunft, sein Temperament und sein nicht immer durchsichtiges Geschäftsgebaren als Wirtschaftsjurist ${ }^{427}$ lieferten seinen Gegnern innerhalb und außerhalb der CSU genügend Munition, um ihn als „Frankenführer “428, „Parteidiktator“429 oder "typische Schieberfigur “430 diffamieren zu können. Besonders verhaßt war der Landesvorsitzende bei seinen Parteifreunden in München und Oberbayern. Man wisse $\mathrm{ja}$, „was der Ochsensepp für eine zwielichtige Type“ sei, „sowohl in politischer wie in moralischer Hinsicht“, erklärte Toni Böck, Mitglied der Jungen Union in München und Landessekretär der Katholischen Jungen Mannschaft Bayerns, einem Vertrauensmann der Militärregierung. „Ich kenne keine Persönlichkeit in der bayerischen Union", so Böck weiter, die „ein derart doppelzüngiges, undurchsichtiges Wesen hat wie der Ochsensepp“. Müller sei dafür verantwortlich, „daß immer mehr Anständige aus der Union vertrieben“ würden ${ }^{431}$. Auch Adolf Miller, Geschäftsführer des CSU-Bezirksverbands München, sprach aus, was viele dachten: „Dr. Müller ist der böse Geist der Partei.“432

Gemäß der Parole: „Wir werden in Zukunft so wie die Ratten den alten Unrat aus den Kanalröhren holen, um ihn gegen Dr. Müller zu werfen “433, sah sich der Ochsensepp einer dauerhaften Kampagne gegen seine eigene Person, seine Familie und seine Freunde ausgesetzt. Halbwahrheiten, gezielte Diffamierungen und Flüsterpropaganda sollten den CSU-Vorsitzenden in der Öffentlichkeit unmöglich machen und seine Stellung in der Partei untergraben ${ }^{434}$. Doch Müller, obwohl zunehmend dünnhäutiger, erwies sich als harter Brocken; „ich habe noch niemand gekannt, der ein so zähes Leben hat wie der Ochsensepp“, stöhnte einer seiner Widersacher Ende $1948^{435}$.

$\mathrm{Zu}$ diesen persönlichen Vorbehalten kam hinzu, daß Müllers politische Ziele von Anfang an umstritten waren und insbesondere seine altbayerischen Kontrahenten reizten. Der Parteivorsitzende war zwar weit davon entfernt, ein großer Programmatiker oder gar ein Visionär zu sein - noch 1963 wehrte er sich gegen eine Neufassung des Grundsatzprogramms der CSU mit den Worten, man solle „nicht gleich wieder mit den Programmen“ anfangen, die "besten Wahlen habe man gewonnen, als man kein

${ }^{427}$ Vgl. zu den verschiedenen Fällen Hettler, Josef Müller, S. 36-44, S. 47-51 und S. 386-390; zu den Arisierungsvorwürfen gegen Müller vgl. Johannes Ludwig, Boykott, Enteignung, Mord. Die „Entjudung" der deutschen Wirtschaft, Hamburg, München 1989, S. 87-103.

${ }^{428}$ BayHStA, NL Ehard 887, CSU-Kreisverband Mindelheim an Hans Ehard, Alois Hundhammer und August Schwingenstein vom 31.5. 1948.

${ }^{429}$ IfZ-Archiv, ED 132 NL Baumgartner 3, Joseph Baumgartner an Alois Hundhammer vom 29.7. 1947.

${ }^{430}$ So Franz Heubl im Dienstag-Club am 2. 4. 1946, in: Lehrjahre, S. 41.

431 IfZ-Archiv, RG 260, 10/90-3/4, „Subject: Mitglied der Jungen Union über Dr. Josef Müller“ vom 3. 8.1948.

${ }^{432}$ IfZ-Archiv, RG 260, 10/90-3/5, „Subject: Über Dr. Joseph Müller“ vom 9. 12. 1948.

433 ACSP, CSU-LSG, Ordner Müller - Hundhammer 1952, „Niederschrift über den Beleidigungsprozeß Staatsminister Dr. Müller - Gaßner in Landshut“ am 23. und 25. 8. 1948.

434 Ein 21-seitiges Dossier über Josef Müller, das wohl Ende 1948 entstanden ist und eine Vielzahl solcher diffamierenden Gerüchte enthält ("It is a very strange fact that there is a certain ,trend“ among Müller's followers regrading the high percentages of homosexes and morphinists."), findet sich im IfZ-Archiv, RG 260, 10/90-3/1; ähnlich auch IfZ-Archiv, RG 260, 10/90-3/4, „Subject: Der Müller-Ring“ vom 25. 6. 1948. Der spätere Bayernpartei-Vorsitzende Josef Panholzer schrieb am 14.8. 1947 an einen Freund (BayHStA, NL Panholzer 55), Müller sei "das wahre Verhängnis“ Bayerns, ein russophiler Zentralist „von schrankenlosem E[hr]geiz und Geltungsbewusstsein“. Durch seine Tätigkeit als Offizier der Abwehr sei der Ochsensepp überdies „reichlich kompromittiert" und bringe keinerlei Interesse für geistige Dinge auf, „solange man den Alkohol nicht zum Geist“ rechne.

435 IfZ-Archiv, RG 260, 10/90-3/5, „Subject: Über Dr. Joseph Müller“ vom 9. 12. 1948. 
Programm gehabt habe ${ }^{\text {“436 }}$-, doch viele seiner Ideen und Überzeugungen wiesen den Weg in die Zukunft, während seine katholisch-konservativen Gegenspieler zumeist der Vergangenheit verhaftet blieben ${ }^{437}$. Dabei gehörte die Ausarbeitung eines Programms nicht zu den Aufgaben, denen Josef Müller in den Gründungsmonaten der CSU Priorität einräumte, für ihn waren der Aufbau und die organisatorische Konsolidierung der Partei wichtiger. Frühzeitige programmatische Festlegungen, wie sie von führenden Vertretern der innerparteilichen Opposition immer wieder gefordert wur$\operatorname{den}^{438}$, hätten auch dem umfassenden Sammlungskonzept Müllers widersprochen, der hoffte, möglichst viele nichtsozialistische Gruppierungen in der Union zusammenführen zu können ${ }^{439}$. In diesem Sinne betonte der Landesvorsitzende, daß der Begriff christlich im Parteinamen der CSU für ihn lediglich bedeute, „daß jeder, der die christliche Kultur anerkenne, in die Partei aufgenommen werden könne“440. Diese Einstellung war nicht nur Männern wie dem entschiedenen Katholiken Hundhammer zu liberal, sondern auch in gemäßigteren Kreisen nicht leicht zu vermitteln. Doch Müllers Versuche, das Parteiprogramm auf die lange Bank zu schieben, hatten auch einen anderen Grund als den, vorhersehbare Konflikte zwischen den Repräsentanten verschiedener Traditionsstränge in der fragilen Sammlungspartei zu vermeiden ${ }^{441}$; der Ochsensepp wollte auch Zeit gewinnen, die notwendig war, wollte man der neuen Partei auch ein wirklich neues programmatisches Fundament zugrunde legen ${ }^{442}$.

Wie indifferent die Konzeption Josef Müllers aber zunächst auch gewesen sein mag, eine Honoratiorenpartei nach dem Muster der BVP kam für ihn nicht in Frage. Seine Planungen liefen vielmehr darauf hinaus, die CSU mittels einer „zentral gesteuerten Organisationspolitik" in möglichst allen politischen Gemeinden des Freistaates zu verankern ${ }^{443}$. Am Ende der Entwicklung sollte eine liberal-konservative, christlich-interkonfessionelle Sammlungspartei gemäßigt föderalistischen Charakters stehen, die als große Mitgliederpartei mit schlagkräftigem Parteiapparat die Alternative zur Sozialdemokratie bilden sollte.

Der Parteichef versuchte vor allem, die junge Generation für seine Vorstellungen zu gewinnen. Unter den Nachwuchspolitikern, die in vielen Fällen seine Kritik an den Parteien der Weimarer Republik teilten ${ }^{444}$, sollte ein "Stamm an Organisatoren und Funktionären“ für die CSU geworben werden; von ihnen erwartete Josef Müller „die

436 ACSP, CSU-LL, Protokoll der Sitzung des geschäftsführenden Landesvorstands am 19. 10. 1963.

437 Auch Franz Heubl, einer der erbittertsten Gegner des Ochsensepp, räumte in der Rückschau ein, daß sich die Konzeption Josef Müllers als die tragfähigere und erfolgreichere erwiesen habe; vgl. Heubl, Jugend und Demokratie, in: Böhr (Hrsg.), Jugend bewegt Politik, S. 72-77.

438 So bemerkte ein Mitglied des Dienstag-Clubs, „die Programmlosigkeit der Union sei nachgerade ein Skandal“. Sitzung des Dienstag-Clubs am 4. 6. 1946, in: Lehrjahre, S. 56. Ähnlich auch IfZ-Archiv, RG 260, 10/80-1/26, „Subject: CSU round-up, week April 14th to 21st“ vom 25. 4. 1946.

439 ACSP, NL Müller 410/2, Fritz Gerathewohl, Meine Stellung zur Christlich-Sozialen Union, undatiert, und NL Müller 401, Thomas Dehler an Josef Müller vom 12. 3. 1946.

440 Sitzung des Dienstag-Clubs am 14. 5. 1946, in: Lehrjahre, S. 52 ; zum folgenden vgl. ebenda, S. $52 \mathrm{f}$.

$441 \mathrm{Vgl}$. die in dem OSS-Bericht: Die politischen Parteien in Bayern - Tendenzen im Landesmaßstab vom 8. 11. 1945, in: Zwischen Befreiung und Besatzung, S. 235, zitierten Ausführungen Josef Müllers.

442 IfZ-Archiv, RG 260, 13/147-3/3, Military Government Weekly Summary No. 28, 15.11.-12. 12. 1945.

${ }^{443}$ Vgl. hierzu und zum folgenden Mintzel, Anatomie, S. 83-86, Zitat S. 83.

444 So beispielsweise ein u. a. von Toni Böck und Richard Jaeger gezeichnetes Schreiben an Josef Müller vom 21. 12. 1945; IfZ-Archiv, Fh 56. 


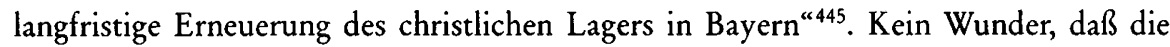
Junge Union zu den Stützen des umstrittenen Landesvorsitzenden zählte, kein Wunder auch, daß sich unter den Funktionären des im Aufbau befindlichen Parteiapparats eine ganze Reihe von CSU-Mitgliedern fanden, die der jüngeren Generation angehörten. Der Ochsensepp scheint es verstanden zu haben, gerade diesen Personenkreis besonders anzusprechen. So schrieb der 26 jährige Josef Plonner, der später auch zu den Mitarbeitern der Landesgeschäftsstelle stieß, nach einer Rede Müllers in Rosenheim an den Parteivorsitzenden:

„Die jungen Menschen, die viel Leid hinter sich haben, die um die Wahrheit u. Sauberkeit ringen und an das Gute glauben wollen, sind Ihnen jedenfalls von innerstem Herzen her dankbar. Ich habe das gespürt, als ich mit einigen noch nach der Versammlung sprach und deren Augen leuchteten, wie von einem heimlichen Feuer, das Sie angezündet u. entfacht haben." ${ }^{446}$

Die vielleicht erbittertsten Widersacher Müllers waren Fritz Schäffer, Alois Hundhammer und zeitweise auch Michael Horlacher. Ein ständiger Konfliktherd war - abgesehen von allen anderen Gegensätzen - Schäffers Anspruch auf die Führung der CSU. Auch wenn er öffentlich alle Ambitionen leugnete ${ }^{447}$, schien er, der bayerische Staatsrat und langjährige BVP-Vorsitzende, nicht gewillt zu sein, den Newcomer Josef Müller für längere Zeit an der Spitze der CSU zu dulden ${ }^{448}$. So verwundert es nicht, daß Schäffer in den parteiinternen Führungs- und Flügelkämpfen ständig bemüht war, seine bisherige politische Karriere und seine daraus resultierende Prominenz in die Waagschale zu werfen ${ }^{449}$. Was seine Aktionen gegen den Parteichef vor allem auszeichnete, war neben kompromißloser Härte und rücksichtsloser Wahl der Mittel ein geradezu „religiöses Sendungsbewußtsein “450. Auch vor einer bewußten Verschärfung des Konflikts schreckte das „Eisenhaupt ${ }^{4451}$ der bayerischen Unionspartei nicht zurück, die Einheit der CSU schien für ihn kein Wert an sich zu sein. „Mit dem bloßen Ruf nach Einigkeit", so der Staatsrat, „werden sie die CSU nicht erhalten. ,Einig“ sind auch die Schafe, die sich von dem hirnkranken Leithamm[el] in den Abgrund führen lassen." Widerstand zu leisten sei dann geradezu eine „Frage des sittlichen Rechts", wenn „ein Mann, der das Unglück und das Verderben einer Partei ist, die Führung an sich gerissen und eine dem Wesen der Partei feindliche Parteimaschine in die Hand genom-

4+5 OSS-Bericht: Die politischen Parteien in Bayern - Tendenzen im Landesmaßstab vom 8. 11. 1945, in: Zwischen Befreiung und Besatzung, S. 235.

446 ACSP, NL Müller 410/5, Josef Plonner an Josef Müller vom 13. 5. 1946.

${ }^{447}$ Protokoll der Sitzung des Erweiterten Vorläufigen Landesausschusses der CSU am 30./31. 3. 1946 in Bamberg, in: Protokolle und Materialien, S. $122 \mathrm{f}$.

${ }^{448}$ BAK, NL Schäffer 17, Bl. 372, Richard Pflaum an Fritz Schäffer vom 1. 2. 1946. Nach einer Aktennotiz Josef Müllers vom 25. 2. 1946 (IfZ-Archiv, Fh 56) rechnete man in Schäffers Umfeld zu dieser Zeit noch mit dessen Wahl zum Landesvorsitzenden der CSU.

${ }^{4+9} \mathrm{Vgl}$. z. B. Schäffers Rede vor dem Erweiterten Vorläufigen Landesausschuß der CSU am 30./31. 3. 1946 in Bamberg: „Nun sage ich Ihnen ehrlich: Ich bin eitel genug anzunehmen, daß weite Bevölkerungskreise in Bayern mich schätzen, (Bravo!) infolgedessen [ist] anzunehmen, daß, wenn Fritz. Schäffer aus der Union ausscheidet, es für die Union ein Schlag sein wird." Protokolle und Materialien, S. 109. Vgl. auch BAK, NL Schäffer 17, Bl. 473 f., Johannes Semler an Fritz Schäffer vom 1.3. 1946.

${ }^{450}$ Mintzel, Anatomie, S. 225. Zu den erfolglosen Versuchen, eine „Entgiftung des politischen Kampfes" zwischen dem Staatsrat und den Exponenten des Müller-Flügels zu erreichen: BAK, NL Schäffer 17, Bl. 476-479, Johannes Semler an Fritz Schäffer vom 12. 2. 1946.

451 Franz Josef Strauß über Schäffer; zit. nach Wolfgang Zorn, Bayerns Geschichte im 20. Jahrhundert. Von der Monarchie zum Bundesland, München 1986, S. 550. 
men hat". Für Schäffer bestand die "Treue gegenüber der Partei“ in einem solchen Fall darin, daß „man diese Führung ablehnt“, ja er verstieg sich sogar zu einem Vergleich zwischen der Parteiführung der CSU und dem NS-Regime: „Der Führer, der an der Macht ist, wird immer sagen, das bedrohe die Einigkeit; er selbst wird nämlich der Einigkeit nie ein Opfer bringen. Als die Nazi an der Macht waren, war auch jeder Widerstand gegen sie eine Verletzung der deutschen ,Einigkeit'! "452

Der Staatsrat warf dem Ochsensepp immer wieder vor, ihn bei der amerikanischen Militärregierung verleumdet zu haben und für seine Entlassung als Ministerpräsident verantwortlich zu sein ${ }^{453}$. Vom Gegenteil ließ er sich weder durch Erklärungen Müllers noch durch Stellungnahmen von Parteifreunden oder von amerikanischer Seite überzeugen ${ }^{454}$. Auch wenn Schäffer seine Vorwürfe nicht beweisen konnte, waren derartige Verdächtigungen eine scharfe Waffe in den Auseinandersetzungen um die Führung der bayerischen Unionspartei.

Sowohl für seine Anhänger als auch für seine Gegner galt Schäffer als der Inbegriff der BVP-Tradition ${ }^{455}$. Er selbst bekannte sich freimütig zu seiner alten Partei und ließ kaum eine Gelegenheit ungenutzt, um sie mit durchaus apologetischen Argumenten gegen alle Angriffe in Schutz zu nehmen ${ }^{456}$. Georg Pix, ein Intimfeind Schäffers, der Ende 1945 kurzzeitig als Generalsekretär der CSU fungiert hatte ${ }^{457}$, erklärte in diesem Zusammenhang:

„Meine politischen Freunde und ich stehen auf dem Standpunkt, dass Sie auf Grund Ihrer politischen Vergangenheit belastet sind. Warum? Sie selber haben mit der Methode begonnen, die alte Bayerische Volkspartei zu verteidigen und es so hinzustellen, als ob die BVP vor 1933 politisch sich richtig verhalten habe. Können Sie sich da wundern, wenn [a]ndere kommen (und zwar nicht nur Sozialdemokraten!), die etwas anderer Meinung sind? Haben nicht gerade Sie mit dieser Taktik unerquickliche Auseinandersetzungen provoziert? Ich verstehe es durchaus, dass Sie als früherer Parteivorsitzender der BVP das Bestreben haben, die BVP zu rehabilitieren. Aber ich frage Sie: kann es die Aufgabe der Union sein, in Unions-Versammlungen die BVP zu rehabilitieren? Die Union soll und darf mit früberen Sünden der BVP nicht belastet werden. [.. .] Sie selber, Herr Staatsrat, waren Parteivorsitzender der BVP. Wenn Sie jetzt, nach dem Zusammenbruch, sich we-

452 BAK, NL Schäffer 25, Bl. 146, Fritz Schäffer an Karl Warmuth vom 13.6. 1948.

453 Protokoll der Sitzung des Erweiterten Vorläufigen Landesausschusses der CSU am 30./31. 3. 1946 in Bamberg, in: Protokolle und Materialien, S. 109-120 und S. 158-161; BAK, NL Schäffer 22, Bl. 1-48 (hier Bl. $15 \mathrm{ff}$.), Protokoll der Bezirksversammlung der CSU Oberbayern am 14.2.1948 in München; Protokoll der Sitzung des Landesausschusses der CSU am 28./29. 2. 1948 in Regensburg, in: Protokolle und Materialien, S. 1541-1546. Schäffer verdächtigte auch andere Mitglieder der CSU, z. B. Georg Pix, den Mitbegründer der CSU in Landshut und Chefredakteur der Isar Post, oder Michael Horlacher.

454 Protokoll der Sitzung des Erweiterten Vorläufigen Landesausschusses der CSU am 30./31. 3. 1946 in Bamberg, in: Protokolle und Materialien, S. $137 \mathrm{f}$. und S. 160. Eine für Müller hochwillkommene Stellungnahme lieferte Robert G. Neumann, Professor der Staatswissenschaften an der University of California und 1945/1946 amerikanischer Nachrichtenoffizier in München, der Müller von allen diesbezüglichen Vorwürfen freisprach. BayHStA, NL Ehard 1006, Robert G. Neumann an Josef Müller vom 16.11. 1948, und das Protestschreiben von Fritz Schäffer an Josef Müller vom 15. 12. 1948. ACSP, CSU-LSG, Ordner Müller - Hundhammer 1952, „Niederschrift über den Beleidigungsprozeß Staatsminister Dr. Müller - Gaßner in Landshut“ am 23. und 25. 8. 1948.

455 BayHStA, NL Pfeiffer 368, Franz August Schmitt an Fritz Schäffer vom 14. 9. 1945.

456 IfZ-Archiv, Fh 56, Fritz Schäffer an Georg Pix vom 14. 12. 1945 und Fritz Schäffer an Josef Müller vom 21. 12. 1945; vgl. auch die Ausführungen Schäffers vor dem Erweiterten Vorläufigen Landesausschuß der CSU am 30./31. 3. 1946 in Bamberg, in: Protokolle und Materialien, S. $113 \mathrm{f}$.

457 IfZ-Archiv, Fh 56, Fritz Schäffer an Georg Pix vom 14. 12. 1945 und ein von Georg Pix als verantwortlicher Generalsekretär der CSU unterzeichneter Aufruf von November oder Dezember 1945; die Angabe in: Lehrjahre, S. 39 Anm. 7, ist nicht korrekt. 
nigstens von diesen Sünden der BVP losgesagt hätten und ehrlich und offen frübere politische Febler zugegeben hätten, - dann hätte es vielleicht noch eine Plattform gegeben. Aber so stehen wir vor der Tatsache, dass sie diese Fehler heute noch decken wollen in einem Augenblick, da die Geschichte schon gesprochen und ihr Urteil gefällt hat. Begreifen Sie es nicht Herr Staatsrat, dass wir mit dem früheren Parteiplunder nichts mehr zu tun haben wollen, dass wir aus dem früheren Parteigestrüpp, aus all den Irrungen und Wirrungen heraus wollen? Dass wir nichts mehr wissen wollen von dem früheren Parteigezänk und all den parlamentarischen Kniffen, mit denen man ein gutmütiges Volk hinter den Mond geführt hat? Spüren Sie denn nicht, dass es uns darum geht, heute ins Volk hineinzukommen, und dass wir das Volk nicht mehr mit früheren Gemeinplätzen füttern dürfen? “458

Schäffer lehnte es ab, sich mit der Rolle der BVP in der Weimarer Republik wirklich auseinanderzusetzen. Seinem hitzigen Temperament entsprechend ${ }^{459}$ kannte er meist nur eine Reaktion: den Gang vor das Schiedsgericht der bayerischen Unionspartei ${ }^{460}$.

Während Schäffer in Altbayern hoch geachtet und verehrt wurde ${ }^{461}$, sahen die Anhänger Josef Müllers in ihm und seinen „Hammer“-Methoden einen "Amokläufer“ und den „Zerstörer“ der Union in Bayern ${ }^{462}$. Vor allem evangelische Christen standen dem Führungsanspruch Schäffers mit großem Mißtrauen gegenüber. Wilhelm Eichhorn, prominentes Mitglied der Synode der Evangelisch-Lutherischen Kirche Bayerns und einer der autorisierten Sprecher der evangelischen Christen in der CSU, sprach sogar offen davon, daß Schäffer als Repräsentant einer prononciert katholischen Partei "für den protestantischen Bevölkerungsteil eine Belastung“ sei ${ }^{463}$.

Die Zurückhaltung der evangelischen Christen war ein wesentlicher Grund dafür, daß die BVP-Traditionalisten spätestens seit Ende 1945 eine bloße Revitalisierung ihrer 1933 untergegangenen Partei nicht mehr ernsthaft in Erwägung zogen. Sie wollten die Entscheidung innerhalb der CSU suchen, aber ihre Bekenntnisse zum Zusammenwirken der christlichen Konfessionen und zu konfessioneller Toleranz klangen eher taktisch bestimmt ${ }^{464}$. Die neu gegründete Partei sollte zwar für evangelische Wähler und Mitglieder möglichst weit offen sein - dies war schon notwendig, um Mehrheiten zu gewinnen -, wenn es jedoch um Zugeständnisse an die Protestanten im kultur-, personal- oder staatspolitischen Bereich ging, zeigte sich, daß die Kompromißbereitschaft des katholisch-konservativen Flügels schnell erschöpft war ${ }^{465}$. Als sich Schäffer im September und Oktober 1945 an der Gründung der CSU zu beteiligen begann, schwebte auch ihm keine bloße Neuauflage der BVP vor, sondern ein "Zusammen-

${ }^{458}$ IfZ-Archiv, Fh 56, Georg Pix an Fritz Schäffer vom 11. 2. 1946; Hervorhebungen im Original.

459 Vgl. Zorn, Bayerns Geschichte, S. 550.

460 IfZ-Archiv, Fh 56, Fritz Schäffer an Josef Müller vom 13. 1. 1946 und Fritz Schäffer an Josef Müller vom 28. 1. 1946.

+61 BAK, NL Schäffer 22, Bl. 1-48 (hier Bl. 36 ff.), Protokoll der Bezirksversammlung der CSU Oberbayern am 14. 2. 1948 in München.

462 Protokoll der Sitzung des Landesausschusses der CSU am 28./29. 2. 1948 in Regensburg, in: Protokolle und Materialien, S. 1628 (Gerhard Kroll), S. 1608 (August Haußleiter) und S. 1638 (Franz Josef Strauß).

463 BAK, NL Schäffer 17, Bl. 71, Fritz Schäffer an Wilhelm Eichhorn vom 1. 12. 1945.

464 BAK, NL Schäffer 23, Bl. 32 f., Fritz Schäffer an Amia von Montgelas vom 12. 4. 1948, und NL Schäffer 25, Bl. 267, Pfarrer Joseph Eberl an Fritz Schäffer vom 26. 2. 1948: „Ausgerechnet die kath. Männer mit kath. Grundsätzen sollten weg! Wir wollen von einem Mann wie Hau[ß]leit[er] nichts wissen: Er hat bereits früher Reden geführt - gegen Dr. Hundhammer -, die zu einem Freimaurer passen würden, aber einem CSU-Mann schlecht anstehen. Wir verlangen eine christliche Weltanschauungspartei, die wirklich kath. Grundsätze vertritt, mag die Partei nun heissen, wie sie will." Hervorhebung im Original.

465 Vgl. z. B. die Kritik August Haußleiters in der Sitzung des Erweiterten Landesausschusses der CSU am 6. 7. 1946 in München, in: Protokolle und Materialien, S. 426-429. 
schluss aller Nicht-Sozialisten und aller Nicht-Kommunisten“ zu einem "geschlossenen Einheitsblock “466. Insofern traf sich Schäffer mit denjenigen, die die Gründung einer interkonfessionellen Sammlungspartei im Auge hatten. Die Union zwischen katholischen und evangelischen Christen stand dabei aber nicht im Zentrum der Überlegungen des Staatsrats. Er zielte vielmehr auf eine Fusion von BVP und Bayerischem Bauernbund ${ }^{467}$, die in der Weimarer Republik getrennte Wege gegangen waren ${ }^{468}$, oder um mit Mintzel zu sprechen - auf eine „katholische Blockbildung mit altbayerischem Schwergewicht und Zentrum“ 469 .

Es gelang dem Staatsrat freilich nicht, seinen Führungsanspruch in der bayerischen Unionspartei durchzusetzen. Zwar wählte ihn die Bezirksversammlung der Münchner CSU am 21. März 1946 zum Vorsitzenden des Bezirksverbands ${ }^{470}$, nur zehn Tage später mußte er jedoch auf der von Josef Müller geschickt inszenierten Tagung des Erweiterten Vorläufigen Landesausschusses in Bamberg eine entscheidende Niederlage hinnehmen ${ }^{471}$. Bevor Schäffer weitere Schritte unternehmen konnte ${ }^{472}$, setzte die amerikanische Militärregierung am 24. April 1946 seinen Aktivitäten durch das Verbot jeder politischen Betätigung ein Ende. Begründet wurde dies mit Untersuchungsergebnissen der Special Branch, die ergeben hätten, daß Schäffer in seiner "ganzen politischen Laufbahn ein Exponent ultranationalistischer und militaristischer Ideologie gewesen" sei und während seiner Amtszeit als Ministerpräsident die amerikanische Entnazifizierungs- und Entmilitarisierungspolitik obstruiert habe ${ }^{473}$. Damit hatte Schäffer seine innerparteiliche Machtbasis und der katholisch-konservative Flügel der CSU eine Führungsfigur verloren, während die Parteiführung um Josef Müller eine Atempause in den parteiinternen Führungs- und Flügelkämpfen gewann. Allerdings verstärkte die neuerliche Intervention der Militärregierung die Vorbehalte der parteiinternen Opposition gegen Josef Müller, dem man wiederum unterstellte, er habe dabei seine Hände im Spiel gehabt ${ }^{474}$. Schlüssige Indizien für ein regelrechtes Komplott führender CSU-

${ }^{466}$ IfZ-Archiv, Fh 56, Fritz Schäffer an Zeitungsverleger Bichlmeier (Moosburg), undatiert.

${ }^{467}$ IfZ-Archiv, Fh 56, Aktennotiz Josef Helds vom 6. 2. 1946.

${ }^{468}$ Vgl. dazu den instruktiven Überblick bei Vossen, Joseph Baumgartner, S. 2-11.

${ }^{469}$ Mintzel, Anatomie, S. 227; Stadtarchiv Bamberg, NL Etzel 18, Fritz Schäffer an Hermann Etzel vom 11.11. 1948.

470 ACSP, NL Müller 68, Protokoll der Bezirksversammlung der CSU München am 21. 3. 1946. Schäffer hatte seit Mai 1924 den Kreisverband München der BVP geführt; vgl. Otto Altendorfer, Fritz Schäffer als Politiker der Bayerischen Volkspartei (1888-1945), München 1993, S. 284-308.

${ }^{+71}$ Vgl. dazu Fait, Einleitung zu: Protokolle und Materialien, S. XXXV-XLVI. Zur Bedeutung der Bamberger Tagung, auf der die Delegierten Müller in seinem Amt als vorläufiger Landesvorsitzender bestätigten, vgl. auch ACSP, CSU-LSG, Ordner Müller - Hundhammer 1952, „Niederschrift über den Beleidigungsprozeß Staatsminister Dr. Müller - Gaßner in Landshut " am 23. und 25. 8. 1948.

472 Nach Aktennotizen Josef Müllers vom 2.4. und 5. 4.1946 plante Schäffer, gegen die Entscheidungen der Bamberger Tagung bei der Militärregierung zu protestieren; IfZ-Archiv, Fh 56.

${ }^{473}$ BAK, NL Schäffer 9, Bl. 119, OMGBY (Major Peter Vacca) an Fritz Schäffer vom 24. 4. 1946. Zur Haltung der Militärregierung IfZ-Archiv, RG 260, AG 1948/27/2, Memorandum von Walter J. Muller an OMGUS bezüglich Fritz Schäffer vom 28. 3. 1946, und IfZ-Archiv, RG 260, AG 1948/27/2, G. H. Garde an Lucius D. Clay vom 4. 4. 1946. Zur offiziellen Reaktion Josef Müllers: BAK, NL Schäffer 9, Bl. 115, Josef Müller an Fritz Schäffer vom 24. 4. 1946, und Bl. 116, Josef Müller an Fritz Schäffer vom 24.4. 1946. Die beste Darstellung der Ausschaltung Schäffers bei Henzler, Fritz Schäffer, S. 186-199. Vgl. auch Isar Post vom 30. 4. 1946: „Der Fall Schäffer“ und „Schäffer aus der Politik ausgeschlossen“, sowie SZ vom 3. 5. 1946: „Die CSU und der Fall Schäffer. Eine Stellungnahme des Landesvorsitzenden Dr. Müller".

${ }^{474}$ Vgl. den Bericht über die Sitzung des Dienstag-Clubs am 30. 4. 1946, in: Lehrjahre, S. 49. 
Politiker gegen Schäffer finden sich in den Quellen jedoch nicht ${ }^{475}$. Dagegen gibt es durchaus Hinweise darauf, daß die Pressekampagne gegen Schäffer im Vorfeld der Bamberger Tagung mit Wissen Horlachers, Müllers und Baumgartners ${ }^{476}$ inszeniert wurde. So mußte der Ochsensepp im August 1948 während eines Beleidigungsprozesses, den er gegen Alfons Gaßner von der Bayernpartei angestrengt hatte, einräumen, von den gegen Schäffer gerichteten Artikeln in der von Georg Pix herausgegebenen Isar Post ${ }^{477}$ vor ihrer Veröffentlichung Kenntnis genommen zu haben ${ }^{478}$.

Nach der Ausschaltung des ehemaligen BVP-Vorsitzenden - und dies zeigt, wie gespalten die CSU im Frühjahr 1946 noch vor ihrer ersten ordentlichen Landesversammlung war - gab es in der Partei Stimmen, die mit den Worten, nach dem Schäffer kämen nun die Schäffer an die Reihe, eine Säuberung der bayerischen Unionspartei forder$\operatorname{ten}^{479}$.

Zur neuen Führungsfigur des katholisch-konservativen Flügels der CSU avancierte nach der Kaltstellung Schäffers der promovierte Historiker und Volkswirt Alois Hundhammer, der - im September 1945 aus der Kriegsgefangenschaft zurückgekehrt - schon im schwierigen Prozeß der Parteigründung für Fritz Schäffer eingetreten war. Der streng katholische Hundhammer, nach eigener Aussage überzeugter Monarchist $^{480}$, dessen schwarzer Vollbart zu einem Symbol „von finsterer Entschlossenheit, religiöser Intoleranz und zivilisatorischer Rückständigkeit" werden sollte ${ }^{481}$, hatte mit 18 Jahren noch an den letzten Monaten des Ersten Weltkriegs teilgenommen und war 1919 als Mitglied eines Freikorps gegen die Münchner Räterepublik zu Felde gezogen $^{482}$. Nach Abschluß seiner Studien machte Hundhammer schnell Karriere bei den Bayerischen Christlichen Bauernvereinen, deren stellvertretender Generalsekretär er 1927 wurde, und in der BVP, für die er 1932 in den bayerischen Landtag einzog. Auch in der CSU gehörte er bald zu den führenden Persönlichkeiten. Seit Januar 1946 führte Hundhammer den Bezirksverband Oberbayern, den er nicht nur zu seiner persönlichen Hausmacht, sondern auch zu einer Speerspitze der innerparteilichen Opposition im Kampf gegen die Parteiführung ausbaute. Nach der Ausschaltung Schäf-

${ }^{475}$ Vgl. dazu Fait, Einleitung zu: Protokolle und Materialien, S. XLIV-XLVIII.

${ }^{476}$ IfZ-Archiv, RG 260, 10/80-1/26, „Subject: CSU round-up, week April 14th to 21st“ vom 25.4. 1946. In diesem Bericht wird Baumgartner mit den Worten zitiert, Schäffer sei zu sehr auf der Linie der ehemaligen BVP, seine Ideen seien zu gefährlich und es sei zu riskant, den „old Nazi“ Schäffer die Führung der CSU übernehmen zu lassen. Überdies notierte der Vertrauensmann der Militärregierung, Baumgartner habe ihm Material gezeigt, das Schäffer belaste.

477 Isar Post vom 12. 3. 1946: „Der Weg der Union“, vom 22. 3. 1946 unter derselben Schlagzeile, und vom 29. 3. 1946: „Ein Schritt zurück?" Die Artikel stammen sämtlich aus der Feder von Georg Pix.

${ }^{478}$ ACSP, CSU-LSG, Ordner Müller - Hundhammer 1952, „Niederschrift über den Beleidigungsprozeß Staatsminister Dr. Müller - Gaßner in Landshut" am 23. und 25. 8. 1948.

${ }^{+79}$ So erklärte Hans Hermann von Eicken vor dem Landesarbeitsausschuß der CSU am 1. 5. 1946 in München: „Ich habe an den zweiten Vorsitzenden einen Brief schreiben müssen und muß auch im Lande feststellen, daß Schäffer zwar kaltgestellt ist, und die kleinen Schäffer dort weiterarbeiten. Wenn das so weiter geht, wird ein neuer Reinigungsprozeß nötig sein [. . .]" Protokolle und Materialien, S. 195. Ähnliches auch im Protokoll der Sitzung des Landesausschusses der CSU am 9. 5. 1946 in München, in: ebenda, S. 213.

${ }^{480}$ Protokoll der Sitzung des Landesarbeitsausschusses der CSU am 1.5. 1946 in München, in: Protokolle und Materialien, S. 208.

481 SZ vom 25. 2. 1965: „Der schwarze Mann schreckt nicht mehr. Alois Hundhammer, Mitbegründer der CSU und einstmals bayerischer Sittenwächter, wird 65 Jahre alt".

${ }^{482}$ Biographisches zu Hundhammer findet sich in einem interessanten Dossier der amerikanischen Militärregierung; IfZ-Archiv, RG 260, 10/90-1/33, „Subject: Dr. Alois Hundhammer, CSU“, vom 27. 12. 1946. 
fers konnte Müller es nur mit Mühe verhindern, daß Hundhammer auch noch zum Vorsitzenden des Bezirksverbands München aufstieg ${ }^{483}$. Im Juli 1946 gelang es dem Ochsensepp und seinen Mitstreitern jedoch nicht, Hundhammers Wahl zum Chef der CSU-Fraktion in der Verfassunggebenden Landesversammlung zu blockieren, und vier Monate später stand er auch an der Spitze der CSU-Landtagsfraktion. Im Dezember 1946 trat Hundhammer als Kultusminister in das Koalitionskabinett des neuen Ministerpräsidenten Hans Ehard ein, an dessen Wahl er großen Anteil hatte. Damit hatte der „schwarze Alois“, wie man ihn spöttisch, aber auch respektvoll nannte ${ }^{484}$, drei Schlüsselpositionen inne, die ihm weitreichende Möglichkeiten in den innerparteilichen Auseinandersetzungen eröffneten, die ihn aber auch zu gewissen Rücksichten im politischen Kampf zwangen.

Die Konzeptionen und Zielvorstellungen Hundhammers deckten sich in vieler Hinsicht mit denen Schäffers. Während der ehemalige BVP-Vorsitzende aber von Anfang an jede wirkliche Einigung mit Josef Müller ablehnte, scheint Hundhammer nicht ganz so stur gewesen zu sein und das „zweifellos auch durch seinen Ehrgeiz“ bestimmte Vorgehen des Staatsrats nicht immer gebilligt zu haben ${ }^{485}$. Für Hundhammer gab es angesichts der Konstellation in den Führungszirkeln der neu gegründeten CSU dennoch kaum eine andere Möglichkeit als einen möglichst engen Schulterschluß mit Schäffer. Josef Müller war darum bemüht, den Einfluß von Spitzenpolitikern der untergegangenen BVP auf die CSU zu begrenzen, und erhob in diesem Sinne auch Einspruch gegen die Wahl Hundhammers zum Vorsitzenden des CSU-Bezirksverbands Oberbayern. Der Weg in eine Position an der Spitze des Bayerischen Bauernverbands, die Hundhammer noch in den ersten Monaten des Jahres 1946 gereizt hätte, war verbaut, da einflußreiche Agrarlobbyisten wie Baumgartner, Horlacher oder Schlögl den programmatischen und verbandspolitischen Überzeugungen des früheren BVP-Landtagsabgeordneten und stellvertretenden Generalsekretärs der Bayerischen Christlichen Bauernvereine skeptisch gegenüberstanden und im Oktober 1945 bereits seine Berufung zum Landwirtschaftsminister erfolgreich hintertrieben hat$\operatorname{ten}^{486}$.

Der „mit fast alttestamentarischem $\mathrm{Haß}^{\text {“487 }}$ ausgetragene Konflikt zwischen Hundhammer und Müller hatte jedoch tiefere Ursachen: Müller plädierte für einen Dialog mit der Sowjetunion und für eine flexible Haltung gegenüber sozialistischen $\operatorname{Ideen}^{488}$,

${ }^{483}$ ACSP, NL Müller 67, Protokoll der Sitzung des Bezirksausschusses der CSU München am 6. 5. 1946.

484 Der Spiegel vom 5. 8. 1974: „Alois Hundhammer †“.

${ }^{485}$ Aufschlüsse hierzu und zum folgenden gibt eine Aktennotiz Josef Müllers über sein Verhältnis zu Alois Hundhammer vom 25. 2. 1946; IfZ-Archiv, Fh 56.

${ }^{486}$ Zur Regierungsbildung Ende September/Anfang Oktober 1945 und zur Rolle Alois Hundhammers ACSP, CSU-LSG, Ordner Müller - Hundhammer 1952, „Niederschrift über den Beleidigungsprozeß Staatsminister Dr. Müller - Gaßner in Landshut" am 23. und 25. 8. 1948; IfZ-Archiv, RG 260, 10/90-3/5, „Subject: CSU - Versammlung - Dr. Hundhammer" vom 10. 11. 1948; BayHStA, NL Pfeiffer 53, Aufzeichnungen Anton Pfeiffers über die Bildung des Kabinetts Hoegner 1, undatiert; Echo der Woche vom 18. 7. 1947: „Parteipolitik gegen Personalpolitik. Die CSU und die Politik Dr. Hundhammers". Vgl. auch die Einleitung zu: Die Protokolle des Bayerischen Ministerrats 1945-1954: Das Kabinett Hoegner I - 28. September 1945 bis 21. Dezember 1946, bearb. von KarlUlrich Gelberg, München 1996, S. XXXI-LII.

487 Münchner Merkur vom 25. 2. 1970: „Ein Wahrzeichen Bayerns. Alois Hundhammer siebzig Jahre alt - Noch immer Einfluß und Gewicht in der weiß-blauen Politik".

${ }^{488}$ ACSP, NL Müller 128, Josef Müller an Karl Köhler vom 9. 5. 1947. 
Hundhammer war dagegen zeitlebens ein brennender Antikommunist, ja gleichsam ein „Erbfeind des Bolschewismus “489, der jeden Dialog mit kommunistischen Parteien strikt ablehnte und die Haltung seines Parteivorsitzenden in dieser Frage auf das schärfste mißbilligte ${ }^{490}$. Selbst das im Dezember 1946 geschlossene Regierungsbündnis zwischen CSU und SPD betrachtete Hundhammer mit gemischten Gefühlen; die Koalition sah er zwar als notwendig an, um die Wahl Josef Müllers zum Ministerpräsidenten zu verhindern, die Sozialdemokratie war für ihn jedoch stets mehr politischer Gegner als wirklicher Partner ${ }^{491}$. Hinzu kam, daß Hundhammer und Müller so unterschiedliche Charaktere hatten, daß eine enge Zusammenarbeit schon von daher kaum möglich war.

Die tiefe Gläubigkeit Hundhammers - für den Ritter des Ordens vom Heiligen Grab und Träger des Großkreuzes des Ordens vom Heiligen Papst Sylvester war es auch im fortgeschrittenen Alter eine Selbstverständlichkeit, in der Kirche zu ministrieren $^{492}$ - verband sich mit einem moralischen Rigorismus von seltener Schärfe, der ihm den zweifelhaften Ruf eines bayerischen „Großinquisitors“ eintrug ${ }^{493}$. Als schwarzer Mann mit weißer Weste war er bei Freund und Feind gefürchtet ${ }^{494}$; insbesondere der Bohemien Josef Müller, den Hundhammer für einen „zweiten Hitler“ hielt ${ }^{495}$, und später auch Franz Josef Strauß wußten ein Lied von den Attacken Hundhammers gegen ihren Lebenswandel oder ihr Finanz- und Geschäftsgebaren zu singen $^{496}$.

Wie die meisten katholisch-konservativen CSU-Politiker hatte auch der „Homo Bavaricus "497 Hundhammer die Festigung und Verteidigung der bayerischen Eigenstaatlichkeit auf seine Fahnen geschrieben. Seine radikal föderalistischen Positionen, die von antipreußischen Affekten und Überfremdungsängsten begleitet wurden, leitete er aus einer 1500 jährigen bayerischen Staats- und Kulturgeschichte $\mathrm{ab}^{498}$. Orientiert an den „Leitbildern einer traditionalistischen Gesellschaft auf bäuerlicher Basis“, lehnte Hundhammer jeden Versuch einer zentral gesteuerten Organisationspolitik ab und setzte dagegen das Modell einer mehr oder weniger locker organisierten Honoratiorenpartei ${ }^{499}$.

Auch dem Versuch Josef Müllers, die CSU für Wähler außerhalb des prononciert christlichen Lagers attraktiv zu machen, stand er mehr als skeptisch gegenüber. Hundhammer meinte dazu in seiner kompromißlos-prinzipientreuen Art:

489 Der Spiegel vom 5. 3. 1949: „Wo der Staat das Geld gibt“.

490 IfZ-Archiv, Fh 56, Schreiben Hundhammers an eine unbekannte Freundin vom 25. 12. 1946.

491 ACSP, CSU-LTF I, 15-12/4 und 5, Rede Alois Hundhammers am 25. 9. 1947 in München.

492 Münchner Merkur vom 25. 2. 1970: „Ein Wahrzeichen Bayerns. Alois Hundhammer siebzig Jahre alt - Noch immer Einfluß und Gewicht in der weiß-blauen Politik“; Der Spiegel vom 5. 8. 1974: "Alois Hundhammer †“.

493 Stuttgarter Zeitung vom 21. 4. 1954: „Sturm um Dr. Hundhammer“.

${ }^{494}$ SZ vom 25. 2. 1965: „Der schwarze Mann schreckt nicht mehr. Alois Hundhammer, Mitbegründer der CSU und einstmals bayerischer Sittenwächter, wird 65 Jahre alt“.

495 IfZ-Archiv, Fh 56, Schreiben Hundhammers an eine unbekannte Freundin vom 25. 12. 1946.

496 Zur Affäre Auerbach vgl. S. 408 ff., zu den Auseinandersetzungen zwischen Strauß und Hundhammer vgl. Hans Ferdinand Groß, Hanns Seidel 1901-1961. Eine politische Biographie, München 1992, S. $134 \mathrm{ff}$.

497 Die Zeit vom 9. 8. 1974: „Patriot und Poltergeist“; den zitierten Begriff prägte Franz Josef Strauß.

498 IfZ-Archiv, Fh 56, Aufzeichnung einer Rede Alois Hundhammers „über die Grundsätze seiner Politik“ am 10.8. 1947 in Waldsassen.

499 Vgl. Mintzel, Anatomie, S. 87 f., dort auch das Zitat. 
„Die Werbekraft der Partei liegt nicht in der Verwaschenheit, dadurch dass man glaubt, mit Freimaurern u[nd] Liberalen u[nd] Nationalsoz[ialisten], die man in die Partei hincin nimmt, die Partei zu stärken. Die CSU hat ihre Wähler bekommen, weil die grosse Mehrheit geglaubt hat, dass diese Partei bayerisch, christlich $\mathrm{u}$ [nd] sozial ist. Nur wenn man diese Prinzipien grundsätzlich vertritt $u[n d]$ wenn man bereit ist, die Konsequenzen zu ziehen, dann wird man die Wähler hinter sich behalten. " 500

Daß Hundhammer im Dezember 1946 das Kultusministerium übernahm, war kein Zufall. Der Ausbau Bayerns zu einem christlichen Bollwerk gegen den Kommunismus und die Stärkung des bayerischen Staatsbewußtseins schienen ihm aus dieser Position heraus am ehesten möglich zu sein ${ }^{501}$. In diesem Sinne verstand sich Hundhammer gleichsam als Wächter und Gralshüter der bayerischen Politik ${ }^{502}$, und obwohl er nur eine Legislaturperiode als Kultusminister amtierte, überschatteten diese vier Jahre dic weitere Karriere Hundhammers, der die Öffentlichkeit polarisierte wie kaum ein anderer bayerischer Politiker ${ }^{503}$.

August Haußleiter, einer der engsten Mitarbeiter Müllers, brandmarkte Vertreter von politischen Positionen, wie auch Hundhammer sie verfocht, als „Exponenten einer ultramontanen und klerikalen Politik“, die mit der Monarchie liebäugelten, „bayerische Separatisten oder zumindest Partikularisten“ seien und - soweit sie außenpolitische Pläne hegten - „an Paris oder Wien“ dächten, „wie es ihre Vorfahren schon vor 200 Jahren taten“. Gesellschaftspolitisch hielt Haußleiter die führenden Persönlichkeiten des katholisch-konservativen Flügels der eigenen Partei für Vertreter eines „besitzreaktionären“ Standpunkts, staatspolitisch für „Anhänger einer schwach geführten Demokratie“, die bei Regierungsbildungen „wirkliche Verantwortung vermeiden“ und deshalb „Koalitionen um jeden Preis“ bilden wollten. Daraus zog Haußleiter den Schluß: „Sie [die Vertreter des Schäffer/Hundhammer-Flügels] stehen in ihrer Politik dem weissblau-reaktionären $\mathrm{H}$ [oe]gnerflügel der SPD wesentlich näher als dem fortschrittlichen Flügel der eigenen Partei, dessen grundsätzlich revolutionäre Einstellung sie nicht begreifen, aber ahnen. “504

Von den Personen, die die innerparteilichen Auseinandersetzungen bestimmten, gehörte Michael Horlacher sicher zu den undurchsichtigsten. Der selbsternannte „Führer des Landvolkes“ ${ }^{505}$, der wenig auf seine äußere Erscheinung achtete ${ }^{506}$ und selten ohne sein Markenzeichen, eine brennende Virginia-Zigarre, zu sehen war ${ }^{507}$, hatte vor 1933 die BVP im Landtag und im Reichstag vertreten. Nach 1945 stieg er als einer der Prä-

500 IfZ-Archiv, Fh 56, Aufzeichnung einer Rede Alois Hundhammers „über die Grundsätze seiner Politik“ am 10.8. 1947 in Waldsassen.

501 Zur Konzeption „christliches Bollwerk Bayern“ vgl. Mintzel, Geschichte der CSU, S. 272 ff. IfZ-Archiv, RG 260, 10/90-3/5, „Subject: CSU - Versammlung - Dr. Hundhammer“ vom 10.11. 1948. Noch 1950 rief Hundhammer den CSU-Landtagsabgeordneten zu, die Kulturpolitik sei und bleibe „das Schlüsselproblem der Staatspolitik“. ACSP, CSU-LTF I, 15-14, Protokoll der Fraktionssitzung am 31. 5. 1950.

502 IfZ-Archiv, Fh 56, Schreiben Hundhammers an eine unbekannte Freundin vom 25. 12. 1946.

503 Stuttgarter Zeitung vom 21.4. 1954: „Sturm um Dr. Hundhammer“, oder Münchner Merkur vom 3./4.8. 1974: „Die karge Jugend in hohen Ämtern nicht vergessen. Von den Freunden verehrt, von den Feinden respektiert".

504 BayHStA, NL Ehard 1471, August Haußleiter, Die Politische Gesamtplanung des fortschrittlichen Flügels der CSU, undatiert.

505 Protokoll der Sitzung des Landesausschusses der CSU am 3. 1. 1947 in Augsburg, in: Protokolle und Materialien, S. 973.

${ }^{506}$ Bericht über die Sitzung des Dienstag-Clubs am 24. 9. 1946, in: Lehrjahre, S. 98.

507 BayHStA, NL Pfeiffer 46, Verse für die Weihnachtsfeier der CSU-Landtagsfraktion am 10. 1. 1947. 
sidenten des Bayerischen Bauernverbands und Staatskommissar für das landwirtschaftliche Genossenschaftswesen zu einem der einflußreichsten Vertreter agrarischer Interessen in der CSU auf ${ }^{508}$. Impulsiv bis zur Unberechenbarkeit - auch Parteifreunde warfen ihm vor, „zu viel Schaukelpolitik“ zu betreiben ${ }^{509}$ - und schnell bereit, sich vom Feuer der eigenen Rede zu drastischen Ausfällen verführen zu lassen ${ }^{510}$, dabei aber überaus empfindlich und leicht beleidigt ${ }^{511}$, zählte Horlacher zunächst zu den verläßlichsten Stützen Josef Müllers.

Warum es im Laufe der ersten Monate des Jahres 1946 zum Bruch zwischen Horlacher und Müller kam, läßt sich nicht mehr zweifelsfrei feststellen. Erste offene Zusammenstöße gab es im Vorfeld der ersten ordentlichen Landesversammlung der CSU im Mai $1946^{512}$. Nachdem eine Pressemeldung, die Josef Müller mit den Worten zitierte, der „Zusammenschluß der Christlichen Unionen aller Zonen [stehe] kurz vor seinem Abschluß" und das weitere Ziel einer "deutschen Union“ sei eine "Christliche Union Europas“, für erhebliche Aufregung in den Reihen der CSU gesorgt hatte ${ }^{513}$, legte Horlacher dem Landesarbeitsausschuß eine fünf Punkte umfassende EntschlieBung ${ }^{514}$ vor und verlangte ultimativ im Namen von ca. 20 Unterzeichneten, darunter die führenden Bauernvertreter, daß die Landesversammlung darüber abstimmen sollte, am besten noch vor der Wahl des Parteivorsitzenden ${ }^{515}$. Die Mehrheit der Mitglieder des Landesarbeitsausschusses fühlte sich durch diesen Versuch, eine Art Wahlkapitulation in der Form kurzer programmatischer Erklärungen zu erzwingen, erpreßt, und Hans Hermann von Eicken befürchtete sogar, dies sei ein verstecktes Mißtrauensvotum gegen den Ochsensepp. Im Mittelpunkt der Auseinandersetzung stand der erste Abschnitt der Entschließung, in dem ein „klares Bekenntnis zum bayerischen Volk und Staat" gefordert wurde und dessen Bedeutung Horlacher nachdrücklich herausstellte $^{516}$. Müller lehnte diesen Punkt „glatt ab“ und drohte für den Fall, daß „diese Re-

${ }^{508}$ Zur verbandspolitischen Tätigkeit Horlachers vgl. die Mitteilungen des Bayerischen Raiffeisenverbandes vom 15. 1. 1948: „Dr. Horlacher 60 Jahre“; Bayerisches Raiffeisenblatt vom 15. 1. 1953: „Präsident Dr. Horlacher 65 Jahre alt“, vom 15.10. 1957: „Dr. Horlacher ist nicht mehr“, vom 1. 11. 1957: „Auf dem Waldfriedhof in Bad Tölz fand Dr. Horlacher seine letzte Ruhestätte“.

509 ACSP, CSU-LTF I, 15-14, Protokoll der Fraktionssitzung am 17. 12. 1946 (Albert Kaifer).

510 So ein Mitglied des Dienstag-Clubs am 2. 4. 1946, in: Lehrjahre, S. 39. Franz Heubl bezeichnete Horlacher in derselben Sitzung (ebenda, S. 41) als "Klotz" und "Saubauer".

511 Protokoll der Sitzung des Landesausschusses der CSU am 31. 10. 1946 in München, in: Protokolle und Materialien, S. 765-769.

512 Vgl. auch die Auseinandersetzung zwischen Müller und Horlacher um den künftigen „Reichs-“Aufbau und den Aufbau der Union während der Sitzung des Landesarbeitsausschusses der CSU am 1. 5. 1946 in München; Protokolle und Materialien, S. 200-206.

513 Zit. nach dem Protokoll der Landesversammlung der CSU am 17. 5. 1946 in München, in: Protokollc und Materialien, S. 258. Zum Gesamtzusammenhang vgl. Mintzel, Anatomie, S. 262 ff.

514 Der vollständige Text der Entschließung, wie sie während der Sitzung des Landesarbeitsausschusses der CSU am 16.5. 1946 in München verlesen wurde, in: Protokolle und Materialien, S. 241-244; der Resolutionsentwurf ist - allerdings ohne die kontroversen Vor- und Nachbemerkungen - abgedruckt in: Berberich, Historische Entwicklung, S. 174.

515 Protokoll der Sitzung des Landesarbeitsausschusses der CSU am 16. 5. 1946 in München, in: Protokolle und Materialien, S. 249. Bei einer Ablehnung des Resolutionsentwurfes, der ausdrücklich als die "Mindestforderungen“ der Unterzeichneten gekennzeichnet war, drohte Horlacher, daß dann „die Schicksalsstunde der Union schlagen“ werde. Ebenda, S. 245.

516 "1. Klares Bekenntnis zum bayerischen Volk und Staat. Der politische Neuautbau muß den demokratischen Gedanken entsprechen und auf der Grundlage selbständiger Bundesstaaten erfolgen. Dem Reich ist an Aufgaben nur zu überlassen, was zur Erhaltung der politischen und wirtschaftlichen Reichseinheit unbedingt notwendig ist.“ Ebenda, S. 242. 
solution [...] morgen eingebracht und angenommen wird“, mit seinem sofortigen Rücktritt ${ }^{517}$.

Diese Episode, die hier nicht weiterverfolgt werden muß, zeigt, daß es auch hier die „bayerische Frage“ und damit verbunden die Frage der Stellung der CSU zu den anderen Unionsparteien in Deutschland war, die den Konflikt zwischen Horlacher und dem Ochsensepp wesentlich bestimmte, der in den Augen des Bauerndoktors ein Zentralist war ${ }^{518}$. Alf Mintzel ist freilich recht zu geben, wenn er Horlacher anders als Schäffer oder Hundhammer nicht zu den grundsätzlichen Gegnern Josef Müllers zählt $^{519}$, und Horlacher selbst meinte später, „in der grundsätzlichen Haltung, in den Grundlinien der Union“ sei man sich einig gewesen. „Das andere“, wie er seine Kämpfe mit dem Parteivorsitzenden umschrieb, seien lediglich „vorübergehende Erscheinungen" gewesen ${ }^{520}$. Diese Feststellung ändert jedoch nichts an der Tatsache, daß Horlacher länger als ein Jahr, bis Ende 1947, zu den führenden Köpfen der innerparteilichen Opposition gegen Josef Müller gehörte. Er war es, der als Präsident des bayerischen Landtags eine Ministerpräsidentschaft des eigenen Parteivorsitzenden verhindern half, und Horlacher war es auch, der auf der außerordentlichen Landesversammlung der CSU am 30. und 31. August 1947 der Parole folgte: „Heute wird der Ochsensepp geschlachtet. " 521

Nur wenige Monate später hatte sich die Szenerie grundlegend geändert. Angesichts der bevorstehenden Rückkehr Schäffers ins politische Leben vollführte Horlacher einen politischen „Purzelbaum“ und gesellte sich wieder dem Lager Josef Müllers $\mathrm{zu}^{522}$. Oberstleutnant Paul Burns, der Chef der Political Activities Branch von OMGBY, notierte am 17. Dezember 1947: „Horlacher then proposed that he and Mueller came to an agreement against the old BVP people (i.e. Pfeiffer, Hundhammer, Schaeffer etc.). " ${ }^{23}$ Dieser Grund für eine Wiederannäherung von Müller und Horlacher ist mehr als einleuchtend, wenn man berücksichtigt, daß Horlacher eine Anknüpfung an die BVP-Tradition von Anfang an abgelehnt hatte und sein persönliches Verhältnis zu Schäffer ausnehmend schlecht war ${ }^{524}$. Das Nachrichtenmagazin Der Spiegel vermutete darüber hinaus, Müller habe dem Landtagspräsidenten Versprechungen gemacht, etwa bezüglich des bayerischen Landwirtschaftsministeriums oder des stellvertretenden Parteivorsitzes, oder ihm mit „politischem Material“ gedroht, das er gegen ihn gesammelt

517 Ebenda, S. 250 f.

518 Horlacher vor dem Landesarbeitsausschuß (ebenda, S. 250): „Es ist eine Unmöglichkeit, daß wir eine Parteileitung ertragen können, die den reinen Unitarismus anstrebt.“ ̈̈hnlich auch ACSP, CSU-LTF I, 15-14, Protokoll der Fraktionssitzung am 19. 2. 1947.

519 Vgl. Mintzel, Anatomie, S. 104.

520 Protokoll der Sitzung des Landesausschusses der CSU am 28./29. 2. 1948 in Regensburg, in: Protokolle und Materialien, S. 1604.

521 Protokoll der Sitzung des Landesausschusses der CSU am 28./29. 2. 1948 in Regensburg, in: Protokolle und Materialien, S. 1619.

522 Der Spiegel vom 10.1. 1948: "Pfeiffer in den Rücken“.

523 IfZ-Archiv, RG 260, 15/102-2/1, Memorandum Lt.Col. Paul Burns“ zum Thema „Ministry of Food and Agriculture“ vom 17. 12. 1947.

524 Protokoll der Sitzung des Erweiterten Vorläufigen Landesausschusses der CSU am 30./31. 3. 1946 in Bamberg, in: Protokolle und Materialien, S. 79: „Dr. Horlacher: [...] Wir wollen, und soweit ich sehe, will die große Mehrheit der Wähler der Union, daß wir uns erst mit neuen Gedankengängen in der Bevölkerung weiter durchsetzen, und zwar so, daß sich Evangelische, Katholische und auch Andersgläubige in unseren Reihen wohl fühlen, (Bravo!) damit man sieht, daß wir nicht mehr der Wurmfortsatz der alten Bayerischen Volkspartei sind. “ Zu Horlachers Auseinandersetzungen mit Schäffer vgl. sein Schreiben an Josef Müller vom 23. 2. 1946; IfZ-Archiv, Fh 56. 
habe ${ }^{525}$. Ohne diese Spekulationen aus den Quellen bestätigen oder dementieren zu können, steht fest, daß Horlacher den Parteivorsitzenden im Streit um die Reform der Parteisatzung und bei der Abwehr der oberbayerischen Rebellion unterstützt hat. Seit der Wahl Horlachers zum stellvertretenden Landesvorsitzenden der CSU durch den Landesausschuß im Februar 1948 - übrigens auf Müllers Vorschlag - waren die Streitigkeiten zwischen dem Parteivorsitzenden und dem Präsidenten des bayerischen Landtags weitgehend beigelegt.

\section{c) Phasen und Themen}

Versucht man eine Periodisierung der Führungs- und Flügelkämpfe, so bietet sich ein Drei-Phasen-Modell an. Die ersten Monate zwischen den vorbereitenden Besprechungen im Sommer und Herbst 1945 bis zur Landesversammlung im Mai 1946 waren gekennzeichnet von erbitterten Auseinandersetzungen über die Politik der BVP in der Weimarer Republik, über ihre Haltung gegenüber dem aufkommenden Nationalsozialismus und über die Rolle, die das Führungspersonal der BVP in der CSU spielen sollte. Josef Müller und seine Mitstreiter nahmen als Anhänger der Unionsidee und des interkonfessionellen Gedankens die organisatorischen Unzulänglichkeiten und politischen Fehler der BVP zum Anlaß, um scharf gegen deren Revitalisierung Stellung zu beziehen. Die Liste der Vorwürfe war lang ${ }^{526}$. Die BVP habe die von der NS-Bewegung ausgehende Gefahr zu spät erkannt und sei ihr nicht entschieden genug entgegengetreten; in diesem Sinne wurde auch die 1925 von der BVP-Führung ausgesprochene Empfehlung kritisiert, nicht den Zentrumspolitiker Wilhelm Marx, sondern den preußischen Feldmarschall Hindenburg zum Reichspräsidenten zu wählen. Am stärksten geriet jedoch das Verhalten der BVP in der Endphase der Weimarer Republik unter Beschuß. So mußten sich ehemalige BVP-Politiker die unangenehme Frage gefallen lassen, wie sie 1933 den Ermächtigungsgesetzen im Land- und Reichstag hatten zustimmen können ${ }^{527}$ oder - noch schlimmer! - nach der Selbstauflösung ihrer Partei um Aufnahme in die NSDAP-Fraktionen als Hospitanten hatten nachsuchen können ${ }^{528}$. Diese mit zunehmender Härte geführte Auseinandersetzung barg für Josef Müller Chancen und Risiken; Chancen, weil die Diskussion über die politische Verantwor-

525 Der Spiegel vom 10. 1. 1948: „Pfeiffer in den Rücken“.

526 Vgl. dazu Müller, Konsequenz, S. 310 f.; ACSP, NL Müller 416, Rede Josef Müllers „Der neue Weg“ am 30. 4. 1946 in München, und NL Müller 201, Rundschreiben des Generalsekretariats der CSU vom 16. 1. 1946; IfZ-Archiv, Fh 56, Georg Pix an Fritz Schäffer vom 11.2. 1946 und Fritz Schäffer an Josef Müller vom 28. 1. 1946; Isar Post vom 12. 3. 1946: „Der Weg der Union“, vom 22. 3.1946 unter derselben Schlagzeile, und vom 29. 3. 1946: „Ein Schritt zurück?“.

527 Müller warf beispielsweise Horlacher während der Sitzung des Landesarbeitsausschusses am 16. 5. 1946 in München explizit vor, im Reichstag für das Ermächtigungsgesetz gestimmt zu haben; Protokolle und Materialien, S. 250; seitens der Betroffenen sah man sich genötigt, ein apologetisches Memorandum zu verfassen: ACSP, NL Müller 298, „Hitlers Ermächtigungsgesetz und die bürgerliche Mitte“, ungezeichnet, undatiert. Im ACSP, NL Müller, findet sich ein Ordner mit dem Titel „1933 Held, Presse, Ermächtigungsgesetz“, der eine umfangreiche Materialsammlung über das Zustandekommen der Ermächtigungsgesetze und zur Frage nach der politischen Belastung der BVP-Politiker, die diesen Gesetzesvorlagen zustimmten, enthält. Diese Sammlung diente wohl als Munition gegen die innerparteiliche Opposition und sollte - wie der Verteiler zeigt - auch der amerikanischen Militärregierung zur Verfügung gestellt werden.

${ }^{528}$ Einige Gesuche von Land- und Reichstagsabgeordneten der BVP aus dem Monat Juli 1933 mit der Bitte um Aufnahme in die jeweilige NSDAP-Fraktion als Hospitanten finden sich im BayHStA, NL Pfeiffer 14. 
tung der BVP für den Aufstieg des Nationalsozialismus geeignet war, Politikern wie Schäffer den Weg an die Spitze der CSU zu verbauen; Risiken, weil der Konflikt wiederholt zu eskalieren drohte und sogar zu einer Spaltung der Partei führen konnte, bevor diese noch ihre ersten Gehversuche unternommen hatte. Josef Müller befand sich daher in einem Dilemma. Einerseits mußte er darum bemüht sein, die Anhängerschaft der BVP möglichst vollständig in die CSU zu überführen, andererseits eröffnete sich durch die Attacken auf die BVP die Chance, maßgebliche BVP-Traditionalisten ins zweite Glied zu verdrängen und ungestört die neue Partei nach den eigenen Vorstellungen aufzubauen ${ }^{529}$, was auch dem protestantischen Flügel der CSU nur recht sein konnte ${ }^{530}$. Als es auf der Tagung des Erweiterten Vorläufigen Landesausschusses in Bamberg am 31. März 1946 zu einem harten Schlagabtausch zwischen den von Müller und Horlacher angeführten Verfechtern des Unionsgedankens und den BVP-Traditionalisten um Fritz Schäffer kam, erklärte der Ochsensepp:

„Weil die Union eine neue Gruppierung von Menschen ist, kann sie auch nicht an die alte Zeit anknüpfen, und der frühere Vorsitzende der Bayerischen Volkspartei kann nicht der Vorsitzende der Union sein, weil sonst sofort die Union nur zur weiterentwickelten, bestenfalls zur erweiterten Bayerischen Volkspartei würde. [...] Wäre das geschehen, dann hätte ich die Freunde verraten, die aus anderen Gruppierungen von Menschen, aus dem weltanschaulichen Bereich, aber auch aus früheren Parteien heraus zu uns gekommen waren. “531

Soweit sich die Spitzenpolitiker der untergegangenen BVP nicht wie Michael Horlacher oder Karl Scharnagl weitgehend von der Partei distanzierten ${ }^{532}$, für deren Ziele sie bis 1933 gekämpft hatten, blieb ihnen kaum etwas anderes übrig, als die Politik der Volkspartei und damit auch ihre eigenen Entscheidungen gegen alle Angriffe zu verteidigen, egal ob diese sachlich berechtigt waren oder nicht. Hätte man den immer wieder vorgetragenen Vorwürfen zugestimmt, so wäre dies einer Aufgabe aller Führungsansprüche und damit einer Selbstausschaltung gleichgekommen.

Das spektakuläre politische Betätigungsverbot, das die Militärregierung Ende April 1946 gegen Fritz Schäffer verhängte, bildete zugleich den Höhe- und den Endpunkt dieser ersten Phase der innerparteilichen Auseinandersetzungen. Damit war gleichsam der Stein des Anstoßes beseitigt, und zugleich hatten die Erfolge der CSU bei den ersten Wahlen viel dazu beigetragen, die Tragfähigkeit und Attraktivität des Unionsgedankens unter Beweis zu stellen. Zudem begann das politische Tagesgeschehen die Beschäftigung mit der Vergangenheit in den Hintergrund zu drängen. Als Schäffer diese Fragen nach seinem Comeback in den ersten Monaten des Jahres 1948 noch einmal aufrollte, zeigte sich schnell, daß die Zeit darüber hinweggegangen war.

529 ACSP, NL Müller 416, Rede Josef Müllers „Der neue Weg“ am 30. 4. 1946 in München, und Rede Müllers vor dem Erweiterten Vorläufigen Landesausschuß der CSU am 31. 3. 1946 in Bamberg, in: Protokolle und Materialien, S. 123-144.

530 ACSP, NL Müller 5, Memorandum Georg Barths „Ist die Bayerische Volkspartei tot?“ vom 17. 7. 1946.

\$31 Rede Müllers vor dem Erweiterten Vorläufigen Landesausschuß der CSU am 31. 3. 1946 in Bamberg, in: Protokolle und Materialien, S. 131.

$532 \mathrm{Zu}$ Horlacher vgl. dessen Redebeiträge vor den Delegierten des Erweiterten Vorläufigen Landesausschusses der CSU am 30./31. 3. 1946 in Bamberg und des Landesausschusses am 28. 2. 1948 in Regensburg, in: Protokolle und Materialien, S. 79, S. 167f. und S. 1557 f. Zu Scharnagl vgl. BayHStA, NL Pfeiffer 533, Anton Pfeiffer an Karl Scharnagl vom 13.9. 1945 und dessen Antwortschreiben vom 16.9. 1945. 
Die zweite, vom Frühjahr 1946 bis zum Februar 1948 reichende Phase der Konflikte stand ganz im Zeichen der „bayerischen Frage“. Seit Ende April/Anfang Mai 1946 beherrschten die Diskussionen über die Stellung Bayerns in einem künftigen deutschen Staat und über das Verhältnis der CSU zu den Unionsparteien in den anderen Teilen Deutschlands alle Auseinandersetzungen. Diese Kontroversen waren jedoch kein „Machtkampf zwischen Zentralisten und Föderalisten“533, selbst wenn immer wieder versucht wurde, die innerparteilichen Gegner unabhängig von ihrer tatsächlichen Position als Zentralisten oder als Separatisten zu brandmarken - eine scharfe Waffe im Kampf um die Führung und die Politik der CSU, die besonders Josef Müller immer wieder zu spüren bekam ${ }^{534}$. Diese These führt aber allein deshalb in die Irre, weil der CSU-Vorsitzende alles andere als zentralistisch eingestellt war und Berlin als Hauptstadt eines künftigen deutschen Staates ebenso ablehnte wie als Zentrale einer gesamtdeutschen Unionsparte ${ }^{535}$. Gleichzeitig warnte er jedoch davor, bayerische „Kirchturmpolitik“ zu betreiben ${ }^{536}$, und erklärte, der „Gedanke der Reichseinheit“ sei die „unantastbare Grundlage unserer politischen Überzeugung “537. Vor dem Landesarbeitsausschuß der CSU brachte der Ochsensepp seine Konzeption auf den kurzen Nenner, „er sei für die Reichseinheit, aber gegen das Einheitsreich“538. Es sei notwendig, der Zentrale soviel Macht einzuräumen, „daß sie mit der Not von innen und außen fertig werden“ könne. Dies werde jedoch nie der Fall sein, so Müller weiter, „wenn nicht die Länder ihrerseits wieder stark genug sind,

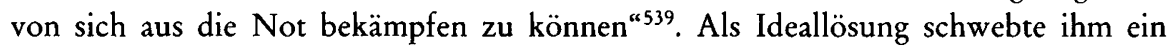
deutscher Bundesstaat vor, und zwar ein Bundesstaat als Mitglied einer europäischen Föderation ${ }^{540}$.

Bayern war für Müller Ausgangspunkt und Operationsbasis seiner Politik, und anders als viele seiner Kontrahenten dachte er in nationalen Kategorien ${ }^{541}$. Von entscheidender Wichtigkeit sei es, „die bayerischen politischen Probleme im Rahmen der Reichspolitik zu sehen“, weil Bayern „vor der Geschichte die Verantwortung“ dafür trage, daß nicht andere Teile Deutschlands „nach dem Osten“ abglitten, erklärte der

533 Müchler, CDU/CSU, S. 39.

534 BayHStA, NL Ehard 1471, August Haußleiter, Die Politische Gesamtplanung des fortschrittlichen Flügels der CSU, undatiert; Protokoll der Sitzung des Landesarbeitsausschusses der CSU am 16. 5. 1946 in München, in: Protokolle und Materialien, S. 241-253; BayHStA, NL Ehard 887, CSU-Kreisverband Mindelheim an Hans Ehard, Alois Hundhammer und August Schwingenstein vom 31. 5. 1948: „Sofortiges Handeln tut not, für Bayern eine ausgesprochen bayerische Politik zu treiben und für Deutschland eine föderalistische Politik und nicht den von Dr. Müller vertretenen Zentralismus zu fördern.“ Im selben Schreiben wird Müller für den „Ausverkauf“ der CSU verantwortlich gemacht.

535 Protokoll der Sitzung des Landesarbeitsausschusses der CSU am 1. 5. 1946 in München, in: Protokolle und Materialien, S. 198. Müllers föderalistische Grundhaltung bezeugt auch: BayHStA, NL Pfeiffer 533, Konrad Adenauer an Gebhard Seelos vom 9. 2. 1947.

536 Protokoll der Sitzung des Landesausschusses der CSU am 6. 9. 1946 in München, in: Protokolle und Materialien, S. 539.

537 Josef Müller, Der neue Weg, in: Bayerische Rundschau Nr. 1/2 (1946), S. 1 ff.

538 Protokoll der Sitzung des Landesarbeitsausschusses der CSU am 16. 5. 1946 in München, in: Protokolle und Materialien, S. 251.

539 Müller, Maximen der Unionspolitik, in: Unsere soziale Revolution, S. 6.

540 Vgl. ebenda, S. 3. August Haußleiter brachte diese Vorstellung auf dic einprägsame Formel: „Wir wollen nicht zurück zu einem Partikularismus des Jahres 1866, sondern wir wollen vorwärts zu einem europäischen Föderalismus des Jahres 2000.“ BayHStA, NL Ehard 1471, August Haußleiter, Die Politische Gesamtplanung des fortschrittlichen Flügels der CSU, undatiert.

541 Vgl. Josef Müller, Föderalismus als Ordnungsprinzip, in: FAZ vom 11. 5. 1948. 
Ochsensepp im Februar 1946 seinem Gegenspieler Alois Hundhammer ${ }^{542}$. Deshalb erschien ihm eine intensive Kooperation der Unionsparteien auf gesamtdeutscher Ebene noch 1948 dringend notwendig: „Komme was wolle, die Union in der Ostzone dürfen wir nicht aufgeben, vielmehr werden wir mit Intensität die Verbindung zu dieser Union pflegen. " ${ }^{543}$ Müller hielt auch den defensiven Verfassungsföderalismus, wie er von bayerisch-etatistischen CSU-Politikern wie Hans Ehard verfochten wurde, für nicht ausreichend, um die Rechte der Länder einerseits und die Stabilität des Gesamtstaates andererseits dauerhaft zu sichern. Er glaubte vielmehr, daß es notwendig sei, föderalistische Politik wirtschafts- und sozialpolitisch zu unterbauen ${ }^{544}$. Mit seiner gemäßigten Konzeption blieb der CSU-Vorsitzende allerdings weitgehend erfolglos, obwohl ihre Realisierungschancen wesentlich besser gewesen sein dürften als die der Maximalpositionen bayerischer Staatsföderalisten. Aber die politischen Entwicklungen zwischen 1946 und 1948 zwangen den Ochsensepp dazu, seine Pläne entweder schrittweise aufzugeben oder den Gegebenheiten anzupassen, die unter anderem vom Verlauf der Führungs- und Flügelkämpfe bestimmt wurden ${ }^{545}$.

Im Schatten der Auseinandersetzungen um die „bayerische Frage“ wurde 1946 in den Führungsgremien der CSU um die programmatische Linie der Partei gerungen. Dabei erschienen der innerparteilichen Opposition die von August Haußleiter und Eugen Rindt, zwei engen Mitarbeitern Müllers, erarbeiteten Entwürfe zu wenig bayerisch und zu reichsorientiert ${ }^{546}$. Ihr ging es primär um die Sicherung der bayerischen Eigenstaatlichkeit und um die Bewahrung bayerischer Kultur und Tradition. Aus diesem Grund waren die zahlreichen Gegner Josef Müllers bemüht, Probleme der Staatspolitik, die mit dem gleichzeitigen Prozeß der Verfassunggebung zusammenhingen, in den Mittelpunkt der Debatte zu rücken. Der Ochsensepp lehnte dies strikt ab. Die CSU sei „in erster Linie eine Zusammenfassung von gleichgerichteten Menschen auf kultureller Grundlage“, so der Parteivorsitzende; staatspolitische Überlegungen, die "von den Ideen der christlichen Kulturwelt bestimmt" sein müßten, hätten sich dem unterzuordnen ${ }^{547}$. In diesem Sinne hielten es Müller und seine politischen Freunde nach dem Zusammenbruch der staatlichen und gesellschaftlichen Ordnung in Deutschland für die Hauptaufgabe der CSU, der „Gefahr der Verelendung, aber auch der geistigen Verproletarisierung“ entgegenzuwirken ${ }^{548}$. Appelle an das Gewissen des einzelnen und an das Gebot der Nächstenliebe schienen in der gegebenen Situation ebensowenig auszureichen wie eine christliche Kulturpolitik, der alleine es Müller nicht zutraute, das "Ziel einer geistigen Erneuerung“ zu erreichen. Müller selbst, aber auch der Gewerkschafter Lorenz Sedlmayr, der spätere Ministerpräsident und Partei-

${ }^{5+2}$ IfZ-Archiv, Fh 56, Aktennotiz Josef Müllers über sein Verhältnis zu Alois Hundhammer vom 25.2. 1946.

${ }^{543}$ Müller, Maximen der Unionspolitik, in: Unsere soziale Revolution, S. $5 \mathrm{f}$.

${ }^{544} \mathrm{Vgl}$. Josef Müller, Föderalismus als Ordnungsprinzip, in: FAZ vom 11. 5. 1948, sowie seine Rede vor dem Erwciterten Vorläufigen Landesausschuß der CSU am 31. 3. 1946 in Bamberg, in: Protokolle und Materialien, S. 135.

${ }^{545}$ Vgl. dazu allgemein Mintzel, Geschichte der CSU, S. 78-93, und Hettler, Josef Müller, S. 318-328.

${ }^{546}$ Programmentwürfe Eugen Rindts und August Haußleiters, in: Protokolle und Materialien, S. 1717-1722 und S. 1729-1733. Zum Gesamtzusammenhang vgl. Mintzel, Geschichte der CSU, S. 209-215.

${ }^{547}$ Protokoll der Sitzung des Landesausschusses der CSU am 6. 9. 1946 in München, in: Protokolle und Materialien, S. $539 \mathrm{f}$.

${ }^{5+8}$ Müller, Maximen der Unionspolitik, in: Unsere soziale Revolution, S. 3; das folgende Zitat cbenda. 
vorsitzende Hanns Seidel oder der Wirtschaftsfachmann Johannes Semler betonten die Bedeutung der Wirtschafts- und Sozialpolitik und erhoben die Forderung nach einem umfassenden Ausgleich der Kriegsfolgelasten, um soziale Gerechtigkeit zu schaffen und die Not zu überwinden ${ }^{549}$. „Nur eine Revolution“, so lautete das Fazit, „kann den Wandel herbeiführen. Das ist unsere soziale Revolution. Es ist eine friedliche Revolution. Sie muß erfüllt sein vom tätigen Christentum. “550

Diese herausgehobene Stellung wirtschafts- und sozialpolitischer Grundsätze stieß bei Teilen der CSU auf Ablehnung und Unverständnis. Alois Hundhammer glaubte, sich "leidenschaftlich“ dagegen wehren zu müssen, daß „aus einer Weltanschauungspartei [...] eine Wirtschaftspartei gemacht" werde, da nicht die "Wirtschaftsfrage" das entscheidende Problem der Gegenwart sei, „sondern die Entscheidung zwischen dem christlichen Abendland und dem neuheidnisch russischen Osten "551. Prononciert christliche Kulturpolitik war für Hundhammer daher stets wichtiger als alle Fragen der Sozialoder Wirtschaftspolitik, und noch 1950 beschwor er die von ihm geführte Landtagsfraktion, „nie, auch nicht vorübergehend das Kultusministerium aus der Hand“" zu geben ${ }^{552}$.

Die Forderung nach einer christlichen Politik, verbunden mit einem spezifisch bayerischen Sendungsbewußtsein und oft genug mit einer antisozialistischen Spitze versehen, führte in letzter Konsequenz zu dem, was Alf Mintzel als Konzept eines „christlichen Bollwerks Bayern" bezeichnet hat ${ }^{553}$. Dabei war diese Zielvorstellung weniger umstritten als der Weg dorthin und die Konsequenzen, die sich daraus für die Politik der CSU ergaben. Als Repräsentant des katholisch-konservativen Flügels der Partei propagierte Hundhammer eine mehr defensive Strategie und trat dafür ein, „zunächst das bayerische Volk in sich selber [zu] festigen “, bevor man über die Grenzen des Freistaates hinausgreifen könne ${ }^{554}$. Gerhard Kroll, eine wichtige Stütze Josef Müllers,

${ }^{5+9}$ Vgl. Lorenz Sedlmayr, Die soziale Neuordnung, in: Unsere soziale Revolution, S. 8 ff.; IfZ-Archiv, RG 260, 13/149-2/1, Rundfunkrede Lorenz Seldmayrs „Die Wirtschafts- und Sozialpolitik der Christlich-Sozialen Union“ am 22. 10. 1946; ACSP, NL Müller 280, Denkschrift „Reale Wirtschaftspolitik. Gedanken über ein deutsches Mindestprogramm“, undatiert, und NL Müller 275, Denkschrift "Christliche Sozialordnung (nach Quadrigesimo anno Pius' XI.)“, undatiert. Zu den wirtschaftspolitischen Vorstellungen der CSU vgl. auch Johannes Semler, Wirtschaftslage und Wirtschaftsgestaltung, München 1946, und Mintzel, Geschichte der CSU, S. 235-247.

550 So das ungezeichnete Vorwort zu: Unsere soziale Revolution, S. 2. Diesen unbestimmten, vagen Revolutionsbegriff propagierten insbesondere August Haußleiter (BayHStA, NL Ehard 1471, Die Politische Gesamtplanung des fortschrittlichen Flügels der CSU, undatiert) und Eugen Rindt (Protokoll der Sitzung des Landesausschusses der CSU am 6. 9. 1946 in München, in: Protokolle und Materialien, S. 537). Die Überzeugung, revolutionäre Maßnahmen seien notwendig, um mit den ungeheuren politischen, sozialen und ökonomischen Problemen nach Kriegsende fertigzuwerden, war nicht nur unter den Mitbegründern der CSU verbreitet. So notierte Heinrich Krone, der an der Gründung der Union in Berlin beteiligt war, am 1.7.1945 in sein Tagebuch: „Die Zahl der Flüchtlinge aus dem Osten nimmt von Tag zu Tag zu. [...] Wie wollen wir diese vielen Menschen, diese Millionen aus unseren Ostgebieten unterbringen? Wir müssen den Großgrundbesitz aufteilen und ihnen Land geben. Die Not drängt, die Zeit verlangt es. Jetzt muß es geschehen, nicht später. Wir dürfen die Stunde nicht verpassen. Große Entscheidungen verlangen die richtige Stunde. Es gibt Zeiten, da der konservative Mensch fortschrittlich handeln muß. Der konservative Mensch muß zur gegebenen Stunde Revolutionär sein. Handelt er anders, wird er zum Totengräber dessen, was er erhalten will." Heinrich Krone. Tagebücher, Bd. 1: 1945-1961, bearb. von Hans-Otto Kleinmann, Düsseldorf 1995, S. 19; Hervorhebung von mir.

551 Alois Hundhammer vor dem Dienstag-Club am 30. 4. 1946, in: Lehrjahre, S. 45.

552 ACSP, CSU-LTF I, 15-14, Protokoll der Fraktionssitzung am 31. 5. 1950.

${ }^{553}$ Mintzel, Geschichte der CSU, S. 274. Zum Gesamtzusammenhang vgl. ebenda, S. $272 \mathrm{ff}$.

${ }^{554}$ Protokoll der außcrordentlichen Landesversammlung der CSU am 30./31. 8. 1947 in Eichstätt, in: Protokolle und Materialien, S. $1143 \mathrm{f}$.; die folgenden Zitate ebenda, S. $1137 \mathrm{f}$. 
sprach dagegen die Befürchtung aus, „daß bloße Defensive letztlich nicht hinreichend sein wird, um das Christentum zu erhalten" und daß die von Hundhammer vorgeschlagene Strategie letztlich auf „die Abkapselung eines noch christlichen Restgebietes in Europa " hinauslaufen könnte. Im Sinne der gemäßigt föderalistischen Orientierung der Parteiführung forderte Kroll eine aktiv gestaltende Rolle Bayerns in Deutschland und Europa und gab der Überzeugung Ausdruck, daß „wir eines Tages vom christlichen Süden her zur christlichen Offensive werden schreiten müssen, wenn wir das Abgleiten Europas in den Nihilismus verhindern wollen".

Im Zuge der Diskussion über die programmatische Linie der CSU kam es bald auch zu Auseinandersetzungen über das von Jakob Kaiser entwickelte Konzept eines christlichen Sozialismus ${ }^{55}$. Das maßgeblich von Adam Stegerwald beeinflußte Programm der Würzburger CSU hatte im Oktober 1945 noch keinen Zweifel daran gelassen, $\mathrm{da} ß$ die neu gegründete Union „einen wahren christlichen Sozialismus" vertrete ${ }^{556}$, und noch in der ersten Nummer der Fränkischen Volksstimme, einem der ersten Mitteilungsblätter der CSU, konnte man im Januar 1946 lesen, daß nur ein „christlicher Sozialismus, der einem christlich-geistigen Weltbild“ entspringe, in der Lage sei, die Probleme der Gegenwart zu bewältigen ${ }^{557}$. Selbst Politiker wie Alois Hundhammer konnten sich den kapitalismuskritischen Tendenzen der ersten Nachkriegsjahre nicht entziehen. Auf die Frage, inwieweit man von einem christlichen Sozialismus sprechen dürfe, antwortete er im April 1946:

„Wenn Sozialismus grundsätzlich die Vergesellschaftung aller Produktionsgüter bedeutet [...], dann wäre es ein Unding, von ,christlichem Sozialismus' zu sprechen. Dieser Sozialismus stünde im Widerspruch zur christlichen Lehre, die ausdrücklich besagt, daß in Übereinstimmung mit dem Naturrecht für den Christen das Privateigentum das Gottgewollte ist. Wenn wir aber Sozialismus heute so verstehen [...], nämlich als eine Vergesellschaftung von Produktionsgütern, deren Bedeutung so groß ist, daß sie die Privatinteressen in den Schatten stellen [...], dann ist ein ,christlicher Sozialismus' selbstverständlich. Die schwierige Frage ist nur, wo die Grenze liegen wird. Sie wird nicht mit dem Metermaß abzustecken sein, sondern immer eine Frage des Ermessens bleiben." ${ }^{~} 558$

${ }^{555}$ Vgl. dazu Werner Conze, Jakob Kaiser, Bd. 3: Politiker zwischen Ost und West 1945-1949, Stuttgart u. a. 1969, S. 29-41. Im BAK, NL Kaiser 88, findet sich eine instruktive Materialsammlung zum Problemkomplex christlicher Sozialismus. Zur Diskussion in der CSU vgl. auch Klaus Schreyer, Bayern - ein Industriestaat. Die importierte Industrialisierung. Das wirtschaftliche Wachstum nach 1945 als Ordnungs- und Strukturproblem, München, Wien 1969, S. 101-109. Die Unterschiede zwischen den Vorstellungen Jakob Kaisers und den programmatischen Überlegungen von Mitbegründern der Union in der britischen und amerikanischen Besatzungszone hat Hans-Otto Kleinmann präzise herausgearbeitet. Seine auf Köln und Frankfurt zugeschnittenen Ausführungen zur Bedeutung des Begriffs christlicher Sozialismus im Westen Deutschlands lassen sich cum grano salis auch auf die Kristallisationskerne der Unionsgründung in Bayern übertragen, sofern sie Adam Stegerwald und Josef Müller nahestanden: "Während im Westen die antikapitalistische und antiliberale Tradition katholischen Denkens sowie Grundvorstellungen der katholischen Soziallehre wie Genossenschaftsgedanke, Subsidiarität und Mitbestimmung die frühe Programmatik beeinflußten, entwickelte sich der Christliche Sozialismus Berliner Prägung unter Kaisers maßgeblichem Einfluß zu einem politischen Programm, das neben der prinzipiellen Abgrenzung gegen Marxismus und Kapitalismus vor allem [...] die Verknüpfung von sozialem Neuaufbau und nationaler Orientierung zur Verhinderung einer Teilung Deutschlands leisten sollte." Krone, Tagebücher, Bd. 1, S. 48 Anm. 20. Zu diesem Problem vgl. allgemein Franz Focke, Sozialismus aus christlicher Verantwortung. Die Idee eines christlichen Sozialismus in der katholisch-sozialen Bewegung und in der CDU, Wuppertal ${ }^{2} 1981$, und Rudolf Uertz, Christentum und Sozialismus in der frühen CDU. Grundlagen und Wirkungen der christlich-sozialen Ideen in der Union 1945-1949, Stuttgart 1981.

556 Abgedruckt in: Becker (Hrsg.), Kapitulation, S. 287-292, hier S. 290.

557 Fränkische Volksstimme vom 26. 1. 1946: „Der Weg ist frei!“

558 Alois Hundhammer vor dem Dienstag-Club am 30.4. 1946, in: Lehrjahre, S. 46. 
Wie die verbreitete Unsicherheit im Umgang mit dem Sozialismusbegriff zeigt, war es für die CSU in der Tat ein Problem, die eigenen Positionen von denen sozialdemokratischer und kommunistischer Parteien abzugrenzen ${ }^{559}$, und das damit verbundene Unbehagen wuchs, je tiefer der sich mehr und mehr verschärfende Gegensatz zwischen Ost und West in das Bewußtsein der Akteure drang ${ }^{560}$. Als der Landesausschuß der CSU im September 1946 über die programmatischen Grundsätze der bayerischen Unionspartei beriet, waren Begriff und Konzept des christlichen Sozialismus auch bei den Anhängern Josef Müllers umstritten. So sehr die Mitstreiter des Ochsensepp in ihrer Mehrheit auch darum bemüht waren, ein innovatives Parteiprogramm als Antwort auf die Herausforderungen des politischen und materiellen Wiederaufbaus zu entwickeln $^{561}$, so sehr fürchteten sie andererseits, daß der christliche Sozialismus ein erster Schritt zu einem "neuen Staatskollektivismus“ bolschewistischer Provenienz sein könnte. Der Parteivorsitzende selbst stand den Vorstellungen Jakob Kaisers durchaus positiv gegenüber und hatte sie sogar wiederholt verteidigt, aber auch er lehnte es ab, die Bezeichnung christlicher Sozialismus zu übernehmen. Allerdings empfahl er, die Konzeption Kaisers bei der Erarbeitung der eigenen Programme zu berücksichtigen, wobei es ihm weniger darauf ankam, „den christlichen Sozialismus als Forderung zu deklarieren, als vielmehr den Nachweis zu führen, dass der christliche Sozialismus vor dem marxistischen da war ${ }^{\star 562}$. Um den Sozialismusbegriff zu vermeiden, warf Müller die Termini „christliche Sozialreform" und „christlicher Solidarismus" in die Debatte ${ }^{563}$, während Karl Scharnagl, der „das Wort und den Begriff christlicher Sozialismus“ strikt ablehnte, für ein „soziales Christentum“ plädierte. Gerhard Kroll sprach sich jedoch vorsichtig dafür aus:

„Bei der Ablehnung des Begriffes christlicher Sozialismus durch Herrn Dr. von Eicken möchte ich meinerseits feststellen, daß ich mich mehr darum bemühen muß, den christlichen Kapitalismus abzulehnen, (Sehr gut!) den es einmal gegeben hat und immer noch gibt, als den christlichen Sozialismus zu verdammen. Wir ringen [...] um einen schlagkräftigen Begriff eines revolutionärchristlich gestalteten Parteiprogramms. Mit bloßen Versprechungen der alten Schulen und der alten Parteien, mit dem Hinhalten in dieser Not der Flüchtlinge, der Ausgebombten und Evakuierten werden wir - das haben wir erfahren - keinen Hund hinter dem Ofen hervorlocken. Hier geht es nicht um den Begriff als solchen. Aber dic Haltung, dic in ihm ausgedrückt ist, muß Wirklichkeit werden, wenn wir etwas anderes sein wollen als cine alte bourgeoise Partei.“

Aber auch wenn die Befürworter des christlichen Sozialismus in der CSU in der Minderheit blieben, zeigen die programmatischen Diskussionen der ersten Nachkriegsjahre neben einer antisozialistischen auch eine „antikapitalistische Grundströmung “564,

559 ACSP, NL Müller 275, Ausarbeitung Wilhelm Arnolds „Christentum und Sozialismus - eine Einheit?", undatiert; Fränkische Volksstimme vom 14.2. 1946: „Die Maske ist gefallen“; Bayerische Rundschau vom 23. 2. 1946: „Ist ,marxistisch" ein Schimpfwort?“

560 Archiv des Erzbistums Bamberg, Rep. 4/3-192, Wilhelm Arnold an Bischof Joseph Otto Kolb vom 7. 9.1946 und Stadtpfarrer J. Krauß (Nürnberg) an Bischof Joseph Otto Kolb vom 14. 9. 1946.

561 Protokoll der Sitzung des Landesausschusses der CSU am 6. 9. 1946 in München, in: Protokolle und Materialien, S. 537; das folgende Zitat ebenda, S. 547. IfZ-Archiv, RG 260, 13/149-2/1, Rundfunkrede August Haußleiters "Das Programm der Union“ am 12. 11. 1946.

562 ACSP, NL Müller 410/6, Entwurf eines Schreibens Josef Müllers an Konrad Adenauer, undatiert (August 1946).

563 Protokoll der Sitzung des Landesausschusses der CSU am 6. 9. 1946 in München, in: Protokolle und Materialien, S. 541; die folgenden Zitate ebenda, S. 546 und S. 545.

56+ Mintzel, Geschichte der CSU, S. 215. 
die sich teilweise noch pointierter in der politischen Programmatik anderer Unionsparteien findet und die erst in der zweiten Hälfte des Jahres 1947 zu verlöschen begann.

Angesichts der Mehrheitsverhältnisse in den Führungsgremien der bayerischen Unionspartei hatte die innerparteiliche Opposition nur geringe Chancen, ihre programmatischen Vorstellungen durchzusetzen. Das Grundsatzprogramm der CSU, das ebenfalls im Dezember 1946 von der Landesversammlung verabschiedete Aktionsprogramm und das im August 1947 beschlossene Wirtschafts- und Sozialprogramm waren damit mehr oder weniger Programme des Müller-Flügels ${ }^{565}$. Da die Gegner des Ochsensepp jedoch Schlüsselstellen in Parlament und Regierung kontrollierten, gestaltete sich die Umsetzung der Parteiprogramme für die Führung der bayerischen Unionspartei auBerordentlich schwierig, und obwohl das Grundsatzprogramm offiziell bis 1957 in Kraft blieb, war seine tatsächliche Relevanz gering.

Die dritte Phase der innerparteilichen Führungs- und Flügelkämpfe begann im Februar 1948 mit der Rebellion des von Fritz Schäffer geführten Bezirksverbands Oberbayern gegen die Parteiführung um Josef Müller und endete mit dem Sturz des Ochsensepp im Mai 1949. Der offene Kampf um die Macht, der Aufstieg der Bayernpartei und der Zusammenbruch des Parteiapparats im Zuge der Währungsreform brachten die CSU an den Rand des Abgrunds. Die Eskalation der Auseinandersetzungen drohte die Partei zu einem Zeitpunkt zu lähmen, als über die künftige Gestalt Westdeutschlands entschieden wurde, und der Landesvorsitzende Josef Müller, immerhin auch Justizminister und stellvertretender Ministerpräsident im Kabinett Hans Ehards, war mehr damit beschäftigt, seine erschütterte Position zu festigen als in den politischen Entscheidungsprozeß einzugreifen.

565 Abgedruckt in: Protokolle und Materialien, S. 1723-1728, S. 1734-1741 und S. 1742-1750; vgl. auch Mintzel, Geschichte der CSU, S. 213-216 und S. 218-222, und Schreyer, Industriestaat, S. 93-99. Wenig überzeugend die Darstellung bei Kirchmann, Bedeutung christlicher Werte, S. 98-106. 